DOI: 10.24275/uama.5813.7498

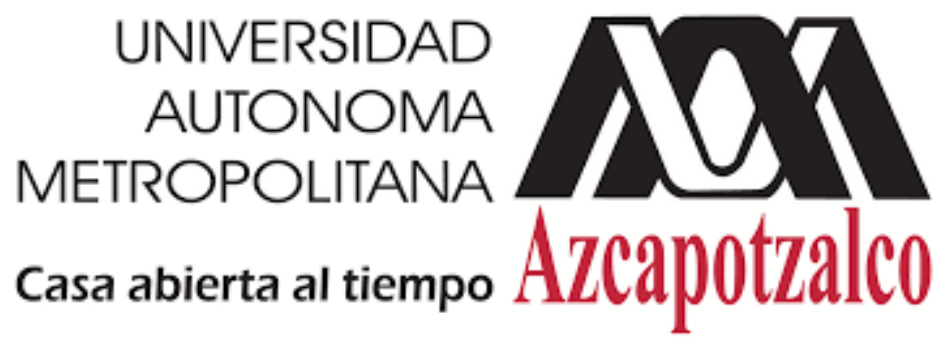

DIVISIÓN DE CIENCIAS Y ARTES PARA EL DISEÑO Doctorado en Diseño y Visualización de la información

\title{
COMPORTAMIENTO DE NIÑOS CON TRASTORNO DEL ESPECTRO AUTISTA (TEA) EN EL USO DE SUS FUNCIONES EJECUTIVAS SUSCITADAS A PARTIR DE INTERACCIONES COGNITIVAS CON UN ROBOT HUMANOIDE
}

\section{María de la Luz Palacios Villavicencio}

Tesis para optar por el grado de Doctora en Diseño Posgrado en Diseño y Visualización de la Información LGAC: Diseño de la Interacción Cognitiva Inteligente

Integrantes del Jurado Dra. Ana Lilia Concepción Laureano Cruces Dirección

Dr. José Aníbal Arias Aguilar Codirección

Dr. Gustavo Iván Garmendia Ramírez Dra. María Auxilio Medina Nieto Dra. Martha Mora Torres

Revisión

Ciudad de México Diciembre 2020 
A mi querida, amada y feliz compañera de viaje: María del Carmen Valenzuela Martínez, de quien he aprendido de la generosidad, del agradecimiento, de la magia, de los milagros, y de la virtud de dejarme guiar por las señales de la vida.

Gracias Carmenzuela por tu amoroso acompañamiento durante este proceso y por el impulso cuántico que le has dado a mi vida.

A Alex Lestrade Valenzuela por inspirarme a explorar las realidades desde las que otros niños, niñas y jóvenes con TEA perciben su entorno. Te agradezco hacerme partícipe de esa insistente búsqueda de respuestas ante lo evidente para los demás, pero que parece ininteligible desde una perspectiva sin filtros sociales como la tuya.

A Thessy y Esponjita, por las lecciones de etología y por su amoroso acompañamiento en muchas noches en las que todos los demás dormían. 
Agradecimientos

Sin duda alguna esta tesis es producto de la generosa aportación de las instituciones y personas que me acompañaron durante su desarrollo. Por ello, antes que nada, toda mi gratitud a la vida por este momento, y por la fortuna que tuve de conocer a extraordinarias personas que compartieron conmigo algo de sí mismas para bien de esta investigación y de los niños con TEA.

De manera especial a la Dra. Ana Lilia Concepción Laureano Cruces, catedrática de la Universidad Autónoma Metropolitana (UAM), por sus entrañables e interesantes seminarios y el impulso que me dio para que cerrara esta primera etapa de la investigación, gracias por la cálida compañía y el decidido impulso. Al Dr. José Aníbal Arias Aguilar, catedrático de la Universidad Tecnológica de la Mixteca (UTM), mi gratitud por su apoyo para la implementación de las tareas robóticas y por su solidario e incondicional acompañamiento durante todas las pruebas de interacción in situ y en su laboratorio de robótica. A ambos les agradezco su confianza para adherirse a este trabajo multidisciplinario que hicimos crecer juntos.

A las tres instituciones que me otorgaron el acceso a sus recursos sin los cuales la tesis no hubiera sido posible: en primer lugar, a la UAM unidad Azcapotzalco, Ciudad de México, por la beca otorgada durante mis estudios, por sus recursos digitales y por su valiosa Biblioteca Digital (BIDI-UAM); en segundo lugar, a la UTM ubicada en la Heroica ciudad de Huajuapan de León, Oaxaca, por permitirme usar sus recursos tecnológicos, su laboratorio de interacción para niños, su laboratorio de robótica y por facilitarme el uso de sus robots NAO con los que desarrollamos las pruebas de interacción; y en tercer lugar al Programa para el Desarrollo Profesional Docente, para el tipo superior (PRODEP) por la beca otorgada para la escritura de esta tesis.

A los lectores de mi tesis, Dr. Gustavo Iván Garmendia Ramírez en quien encontré siempre un apoyo e invaluable disposición a nivel administrativo, académico y ahora como lector de mi tesis. A la Dra. Martha Mora Torres, por sus sugerencias en los seminarios, por la lectura y observaciones a mi trabajo. A la Dra. María Auxilio Medina Nieto, por su dedicada y puntual revisión a este trabajo, los comentarios y sugerencias que realizó fueron sin duda un elemento importante para mejorar la escritura y presentación de la investigación. Al Dr. Armando Páez García, a quien agradezco escucharme constructivamente y ayudarme a dar orden a mis ideas; indudablemente, la lectura y comentarios que hizo a esta tesis, desde una posición externa a la misma, fueron el acuse de recibo de que, lo escrito en ella, sí cumplía con una perspectiva multi y transdisciplinaria. Y de manera especial, al Dr. Román Mora Gutiérrez, por su gran disposición 
para leer mi trabajo durante la última fase del proceso, por ayudarme a integrar el esquema metodológico, los pseudocódigos, y sobre todo por su apertura para ayudarme a identificar el mejor ángulo de mis resultados.

Extiendo un sincero y sentido reconocimiento a las directoras de las instituciones que me facilitaron el acceso y los permisos para trabajar con sus niños. Su actitud y apertura para compartir conmigo sus conocimientos fueron determinantes para reforzar los conceptos y aplicaciones de la propuesta que se aplican en la presente tesis. En primer lugar, a la Lic. Rocío Rojas Moran, directora de la Escuela Bernal Díaz del Castillo, ubicada en la Heroica ciudad de Huajuapan de León, Oaxaca, en donde realizamos las primeras pruebas de interacción con niños neurotípicos. En segundo lugar, a la L.T.O. María de los Ángeles Álvarez Romo de Vivar, coordinadora del Centro de Atención para Niñas y Niños con Autismo (CANNA) del DIF Oaxaca, con quien tuve la oportunidad de evaluar los materiales y ejercicios que se emplearon durante las interacciones. En tercer lugar, a la Lic. Ana Karemi López Cortés, directora de la Clínica de Autismo, ubicada en Santa María Huatulco, y con quien pude implementar por primera vez las pruebas humano-humano que posteriormente fueron adaptadas a las interacciones niño-robot. A las tres directoras, gracias por su apoyo y sabiduría compartida.

A las maestras de educación especial a quienes admiro profundamente por la noble labor que realizan con sus niños. $Y$ en quienes he encontrado un apoyo incondicional para generar sinergia en torno a la aplicación de la tecnología a favor de los niños desde la perspectiva del diseño universal e inclusivo. Maestras: Mari Carmen, Olivia, Maggie, Mimi, Monse, Laura, Gaby Cortés, y psicóloga Areli, gracias por confiar en mi trabajo, por compartir conmigo y mis alumnos sus valiosos conocimientos. Siempre es un placer trabajar con ustedes.

A mis tesistas y estudiantes de la UTM por su incansable afán por conocer, integrarse y poner al servicio del diseño universal e inclusivo sus valiosos conocimientos de licenciatura y maestría. Contar con su apoyo para la materialización de las ideas es una experiencia única que emprendemos juntos con cada nuevo proyecto. Su interés y sobre todo sus aportaciones desde la ingeniería en diseño, la computación, los medios interactivos, la robótica y la mecatrónica ha sido una verdadera bendición para andar este camino. Particularmente agradezco a los que han colaborado con el trabajo de niños con TEA o con NAO; Wendy, Cuauhtli, Anabel, Diana, Ramsés, David, Omar, Gaby y recientemente Claudio y Suri.

De manera especial, reconozco y agradezco la colaboración de Roberto Falcón Bretado Gallegos, por su extraordinaria disposición para la implementación de los escenarios de interacción con el robot y los niños. 
Por otro lado, pero con gran relevancia, destaco la participación de las familias, mamás, papás, abuelitas, abuelito o hermanas de los niños que participaron en este trabajo. Gracias a su interés de adherirse a esta investigación fue posible tener acceso a niños, niñas y jóvenes neurotípicos o con TEA en la Mixteca, la Costa y el centro de Oaxaca.

Un profundo agradecimiento a los protagonistas de esta tesis, a los niños, niñas y jóvenes con TEA. Quienes desde sus peculiares maneras de relacionarse me permitieron estar cerquita y entender un poco más la bendición de su condición.

También deseo aprovechar este espacio para reconocer el amoroso acompañamiento que tuve de mi familia (nuclear y política) con quienes muchas veces tuve que posponer encuentros o charlas divertidas y disfrutables por mantener activo el objetivo de terminar esta investigación lo antes posible. A mi mamá María de la Luz Villavicencio Herrera, a mis hermanas y hermanos, gracias, esto es algo que de alguna manera empezamos como familia, con una certera guía de amoroso cuidado. A mis sobrinas y sobrinos porque disfruto verlos crecer cada día.

Y finalmente, a ellos que están desde otras dimensiones. Por acompañarme con sus repentinas risas y por el optimismo con el que venían a visitarme mientras escribía o planeaba lo que seguía. Gracias, papá, gracias abuelita.

$¡$ ¡Que las bendiciones sean! 


\section{Resumen}

Los niños con Trastorno del Espectro Autista (TEA) presentan primordialmente tres tipos de problemas: 1) patrones de comportamiento como actividades e intereses repetitivos y restringidos; 2) deterioro de la comunicación e interacción social, y 3) deterioro en la flexibilidad de pensamiento (DSM-5). La exploración diagnóstica ha estado mediada por aspectos empíricos, teóricos, metodológicos o epistemológicos. Analizados desde distintas áreas del conocimiento, a través de las cuales se han propuesto diversos tipos de intervenciones.

Las explicaciones teóricas más importantes del comportamiento dentro del TEA han enfatizado la falta de interacción social de los niños con otras personas debido a: 1) un deficiente sistema de interpretación de las intenciones y del estado mental de otras personas; 2) la carencia de la optimización de sus funciones ejecutivas (FE) relacionadas con la capacidad para mantener una disposición adecuada durante la solución de problemas a largo plazo, y 3) deficiente adaptación social en relación con la falta de empatía, debido a una alta recurrencia de patrones detectados como las actividades e intereses restringidos y repetitivos.

El objetivo que se cumple en la investigación es: describir, visualizar y analizar el comportamiento de niños con TEA mientras interactúan con un robot humanoide empleado como vehículo de interacción asistida para generar un modelo de interacción cognitiva. También ha sido importante evaluar su flexibilidad adaptativa a partir del empleo de sus FE asociadas a un nivel de consciencia.

Se consideró la inclusión del robot humanoide debido a la alta aceptación que ha tenido entre los niños, incluyendo a los del espectro autista. A través del robot se desarrollaron tareas para ejercitar algunas de sus FE asociadas a los niveles de consciencia. Se empleó una metodología propia transdisciplinaria con el fin de: 1) explorar, 2) visualizar, y 3) analizar la conducta de los niños bajo condiciones experimentales, con el fin de establecer un modelo de interacción cognitivo. El modelo como resultado de la tesis se pone a prueba con niños con TEA y se sustenta en la alta capacidad de logro de las tareas e intereses que alcanzan los infantes durante las interacciones. 


\section{Contenido}

Índice de Figuras............................................................................................................... 10

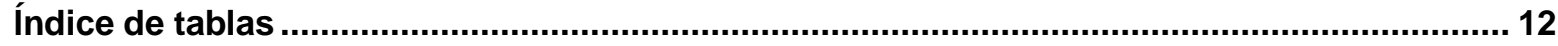

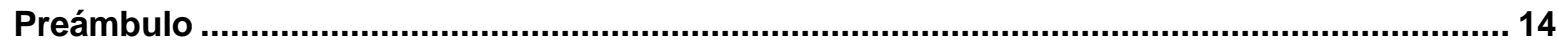

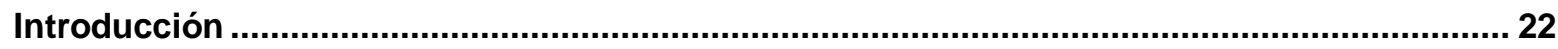

$1.1 \quad$ Delimitación referencial ..........................................................................................25

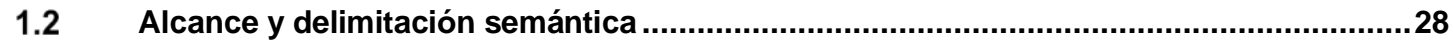

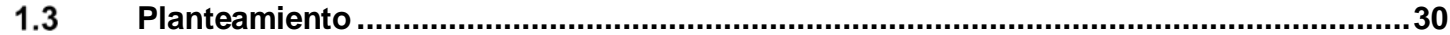

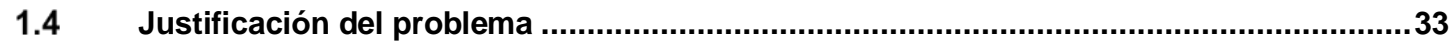

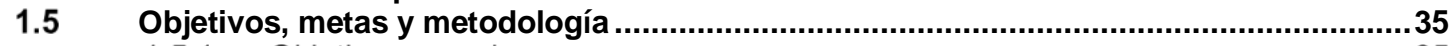

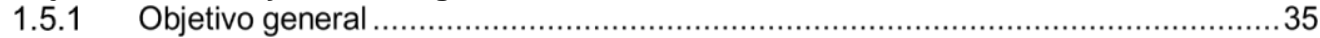

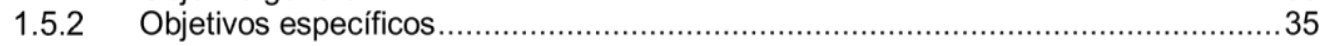

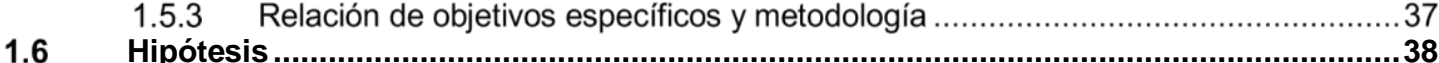

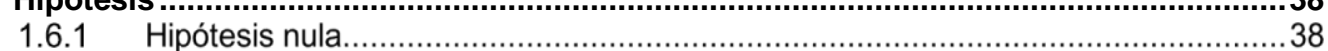

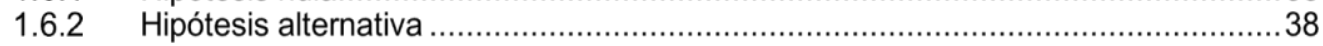

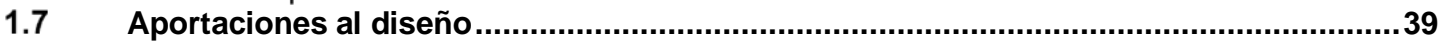

$1.8 \quad$ Estructura de la tesis ............................................................................................ 42

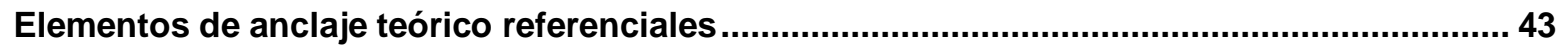

2.1 EATR 1. Caracterización diagnóstica. Apuntes para el diseño universal e incluyente, discapacidad y el trastorno del espectro autista ...........................................................45

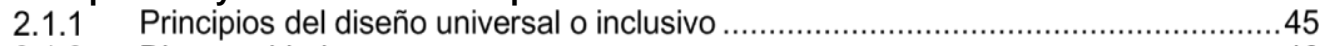

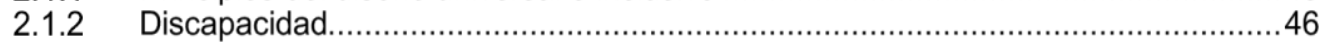

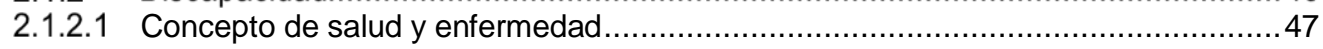

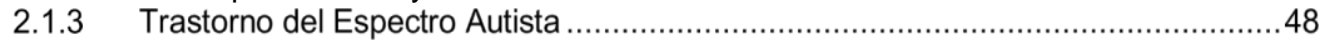

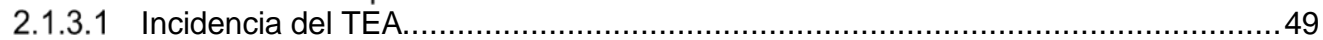

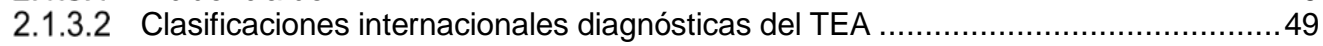

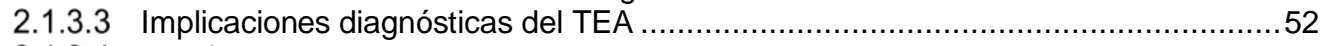

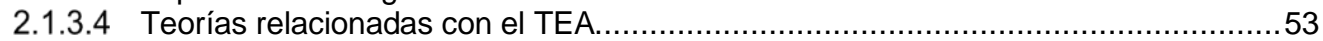

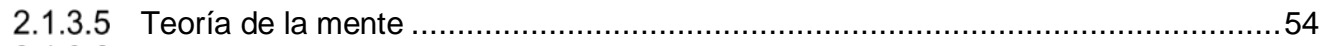

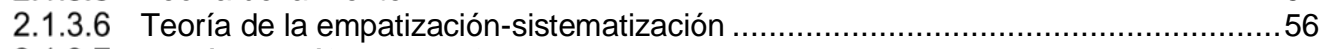

2.1.3.7 Teoría del déficit de las funciones ejecutivas ............................................59

2.1.3.8 Intervenciones naturalistas: etología cognitiva y regulación del comportamiento.....61

2.2 EATR 2. Proceso de significación y comunicación.......................................................63

2.2.1 La significación y el TEA .......................................................................... 63

2.2.2 Teorías posibles para explicar la significación en las personas con TEA ...............64

2.2.3 Dos teorías para una ciencia en común: la semiótica.....................................66

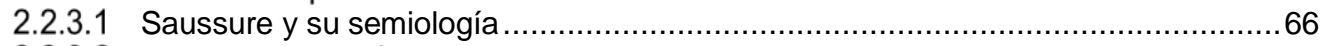

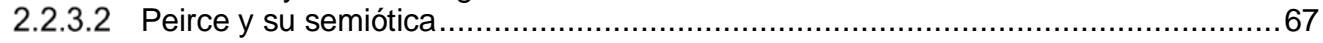

2.2.3.2.1 Elementos del signo: representamen, objeto e interpretante .........................71

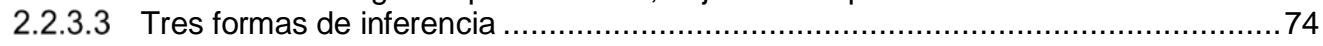

2.2.3.4 Proceso de significación y comunicación .................................................... 79

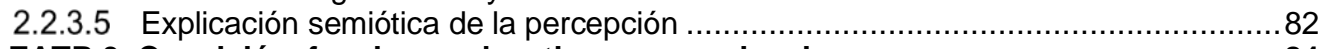

2.3 EATR 3. Cognición, funciones ejecutivas y consciencia ...............................................84

2.3.1 Bases del procesamiento sensorial perceptivo ........................................... 84

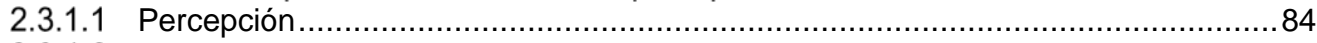

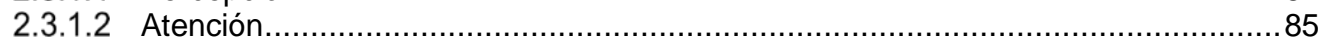

2.3.1.3 Elementos para la aplicación operativa de la percepción y la atención .....................85

2.3.2 Funciones ejecutivas, bases neurológicas .............................................. 87

2.3.2.1 Delimitación conceptual de las funciones ejecutivas .................................... 88 


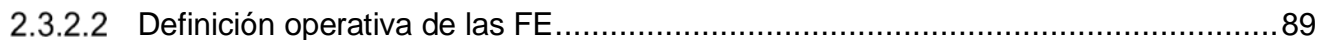

2.3.3 Teorías de la consciencia .................................................................. 92

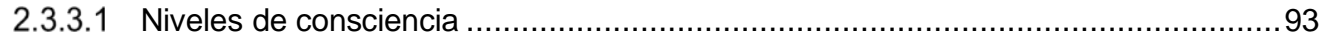

2.3.3.2 Modelo del espacio de trabajo neuronal global .......................................... 96

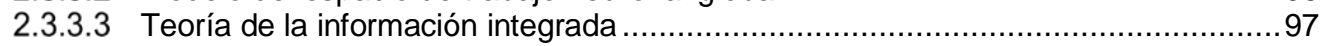

2.3.3.4 Modelo de consciencia artificial para un análisis de la consciencia humana...........98

2.3.3.5 Cinco axiomas de consciencia para su aplicación práctica................................100

2.4 EATR 4. Modelos de interacción humano-robot humanoide .......................................102

2.4.1 Metodologías centradas en el usuario ..................................................... 103

2.4.2 Elementos integrales de la metodología Diseño Centrado en el Usuario............... 103

2.4.3 Elementos integrales de la metodología UX ............................................. 104

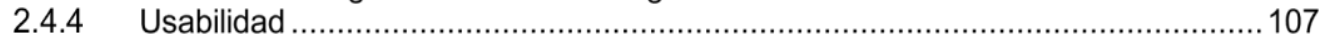

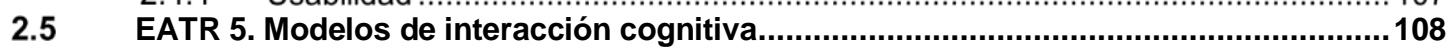

2.5.1 Interacción humano robot y la socialización con los humanoides.........................108

2.5.2 Robot humanoide NAO ................................................................ 111

2.5.3 Las emociones en el contexto de la cognición .................................................. 114

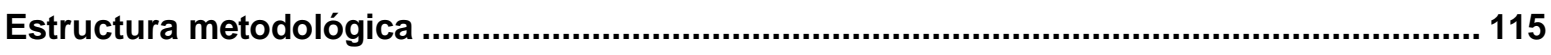

Método ...............................................................................................................115

3.2 Diseño de investigación .......................................................................................115

Participantes ............................................................................................................117

3.3.1 Criterios de inclusión y exclusión de niños con TEA en enfoque cualitativo...........118

3.4 Procedimiento y bases para la implementación del modelo de interacción ..................120

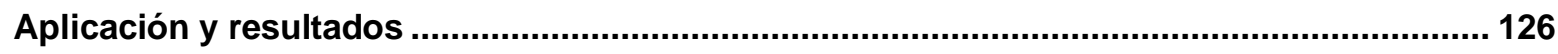

Etapa de investigación A: preparar ..................................................................126

4.1.1 Observación y descripción naturalista ................................................... 127

4.1.2 Resultado 1. Observación y descripción naturalista ............................................... 127

4.1.3 Resultado 2. Obtención de información básica ............................................... 129

4.1.4 Resultado 3. Sensibilización con responsables............................................. 130

4.1.5 Resultado 4. Establecimiento de rapport con los niños...................................... 132

4.1.6 Resultado 5. Comunicación verbal y no verbal ............................................... 133

4.1.7 Resultado 6. Mapa de empatía ................................................................ 135

4.1.8 Identificación de códigos básicos de interacción ................................................ 138

4.2 Etapa de investigación B: conceptualizar .................................................................145

4.2.1 Consulta a expertas de educación especial .............................................. 145

4.2.2 Ejercicios para poner en práctica las FE en interacción humano-humano..............148

4.2.2.1 Vehículos de significación en interacción humano-humano................................ 148

4.2.2.2 Vehículos de comunicación en interacción niño-robot .....................................149

4.2.3 Tareas para poner en práctica las FE de niños con TEA ................................149

Etapa de investigación C: aplicar ...........................................................................152

4.3.1 Actividades de la interacción humano-humano .............................................. 152

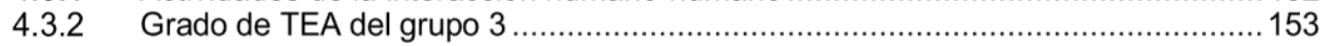

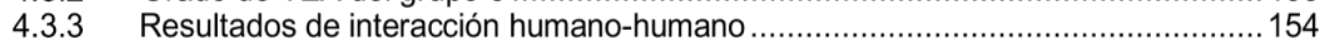

4.4 Aplicación de axiomas de consciencia a las tareas de FE..........................................155

4.5 Condiciones primarias para las FE en interacción niño-robot.............................................157

4.5.1 Bases para la interacción niño-robot, repertorios básicos.................................. 158

4.5.2 Resultados de interacción niño-robot y repertorios básicos ...............................158

4.5.3 Análisis del comportamiento durante interacción niño-robot ...............................159

4.5.4 Análisis del desempeño en pruebas de interacción humano-humano y niño-robot 160

Modelo de interacción cognitiva .................................................................................... 162

5.1 Propuesta de niveles de interacción basados en el proceso de significación...............163

5.1.1 Niveles de interacción...................................................................................... 164 
5.1.2 Nivel 0. Interacción por impronta...................................................... 164

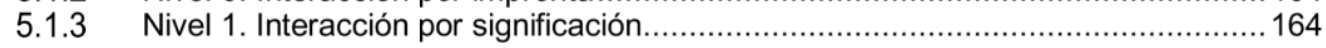

5.1 .4 Nivel 2. Interacción por comunicación ..................................................... 165

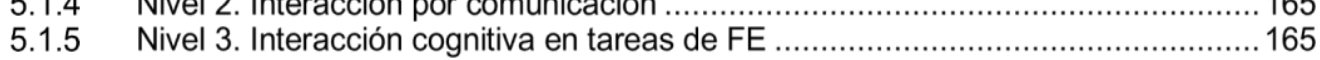

5.2 Propuesta de un modelo de interacción....................................................................166

5.2.1 Variables del modelo de interacción ........................................................ 168

5.2.2 Descripción de unidades de interacción básica................................................ 169

5.2.3 Definición de variables del modelo de interacción........................................... 171

5.2.4 Modelo de interacción jerárquico-estructural cognitiva .................................... 174

5.2.5 Definición de las tareas del modelo .......................................................... 176

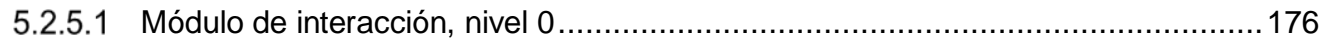

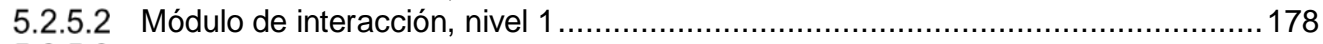

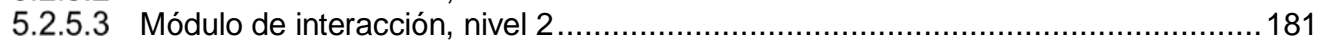

5.2.5.4 Módulo de interacción, nivel 3 ....................................................... 183

Aplicación del modelo en interacción de niños con TEA y el robot humanoide..................... 186

Etapa de investigación D: comprobar .............................................................186

6.1.1 Análisis de interacción semiótica de niños con TEA y un robot humanoide ............187

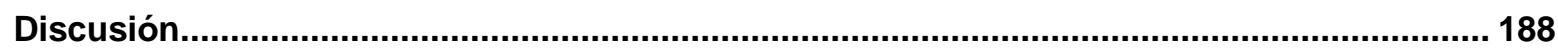

7.1 Integración gráfica de conceptos clave..................................................................193

7.2 Alcance de los elementos de anclaje teórico referenciales ............................................195

7.3 Activación del despertar de la consciencia en vigilia ..............................................198

7.4 Niveles de conducta a partir de las reacciones instintivas, FE y metacognición...........199

7.5 Niveles de interacción niño-robot ..............................................................................201

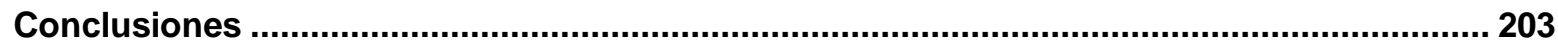

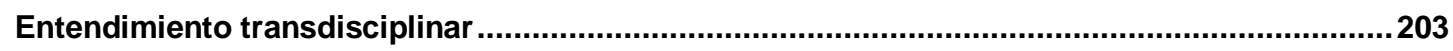

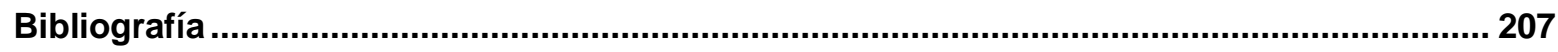

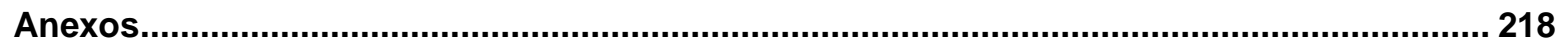

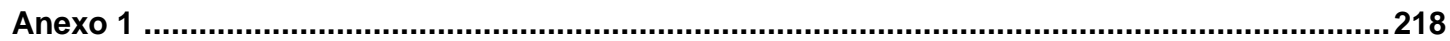

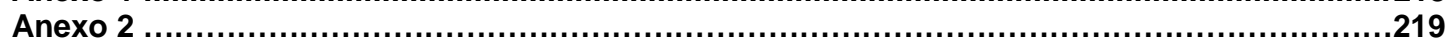

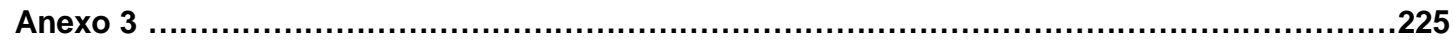

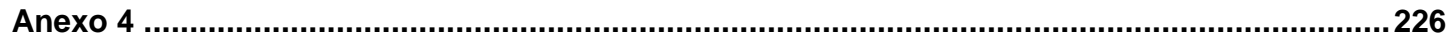

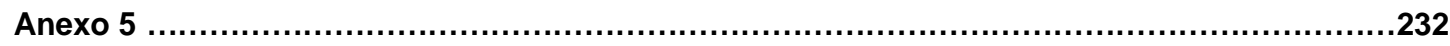

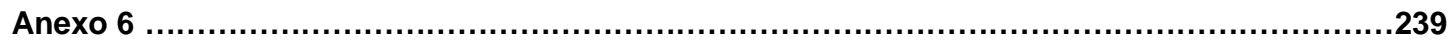

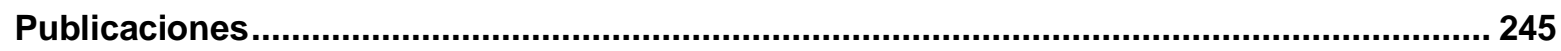

Currículum vitae de la autora ........................................................................................ 255 


\section{Índice de Figuras}

Figura 1. Parámetros del objeto de estudio $\quad 19$

Figura 2. Robot humanoide en una interacción con niños diagnosticados con TEA 32

Figura 3. Relación entre las áreas de conocimiento involucradas en esta investigación 40

Figura 4. Clasificación de trastorno mental y trastorno del neurodesarrollo 51

Figura 5. Evolución de la literatura del TEA

Figura 6. Niño con TEA grado 3 manteniendo un patrón específico de conducta $\quad 58$

Figura 7. Representación del signo lingüístico descrito por Ferdinand de Saussure 66

$\begin{array}{lc}\text { Figura 8. Triada sígnica de Charles Sanders Peirce } & 68\end{array}$

Figura 9. Integración de las categorías semióticas de Peirce $\quad 69$

Figura 10. Representación de semiosis ilimitada $\quad 70$

Figura 11. Procedimiento para la extracción de la silueta de la persona y desempeño de clasificadores 81

Figura 12. Estados de consciencia $\quad 94$

Figura 13. Representación del modelo de consciencia del espacio de trabajo neuronal global 96

$\begin{array}{ll}\text { Figura 14. Modelo de consciencia de Marvin Minsky } & 100\end{array}$

Figura 15. Robot humanoide NAO 112

$\begin{array}{ll}\text { Figura 16. Fases de la metodología } & 120\end{array}$

$\begin{array}{ll}\text { Figura 17. Elementos desarrollados en la etapa de investigación A } & 121\end{array}$

Figura 18. Elementos desarrollados en la etapa de investigación B 122

Figura 19. Elementos desarrollados en la etapa de investigación C 123

Figura 20. Elementos desarrollados en la investigación durante la etapa D 123

$\begin{array}{ll}\text { Figura 21. Relación de la estructura metodológica con los resultados } & 125\end{array}$

Figura 22. Relación de etapa de investigación A con el EATR $1 \quad 126$

Figura 23. Presentación e inicio de investigación dirigido a familias de niños con TEA 127

$\begin{array}{ll}\text { Figura 24. Sala de trabajo con niños TEA } & 128\end{array}$

$\begin{array}{ll}\text { Figura 25. Sala de trabajo con niños y responsables de niños con TEA } & 128\end{array}$

Figura 26. Sesión con primer grupo de responsables de los niños con TEA 129

Figura 27. Sesión con segundo grupo de responsables de los niños con TEA 129

Figura 28. Caja de trabajo con materiales personalizados $\quad 130$

Figura 29. Saludo, entrega y recepción de caja personalizada 132

Figura 30. Escenario de trabajo durante la primera sesión 133

Figura 31. Observación de coducta de niños con TEA grado $3 \quad 135$

Figura 32. Observación de coducta de niños con TEA grado 2 
Figura 33. Observación de conducta de niños con TEA grado 1

Figura 34. Mapa de empatía de niños con TEA

Figura 35. Relación de etapa de investigación A con el EATR 1

Figura 36. Ejemplo de metodología empleada por David Soto Ríos

Figura 37. Relación de etapa de investigación A con el EATR 1

Figura 38. Estrategias de acercamiento recomendadas por especialistas en educación especial

Figura 40. Códigos de significación empleados en para los ejercicios de interacción

Figura 41. Códigos gráficos empleados durante los ejercicios de interacción 


\section{Índice de tablas}

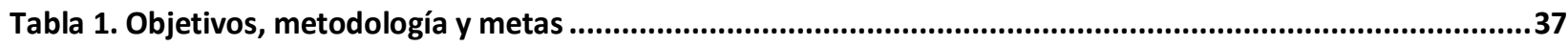

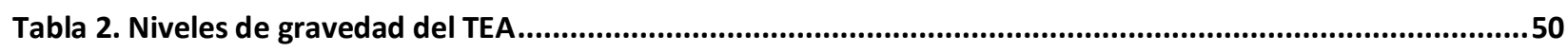

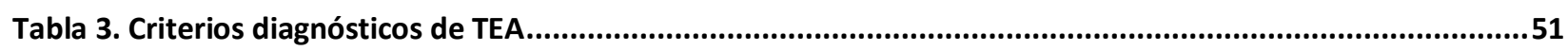

Tabla 4. Ejemplo del uso del sistema de tricotomías de Pearce.............................................................................74

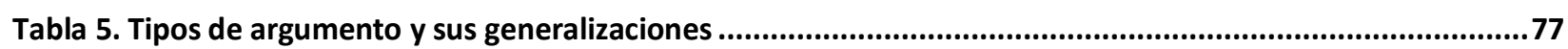

Tabla 6. Clasificación del signo de acuerdo con Umberto Eco...........................................................................79

Tabla 7. Características de los objetos que influyen en la percepción de personas con TEA.................................86

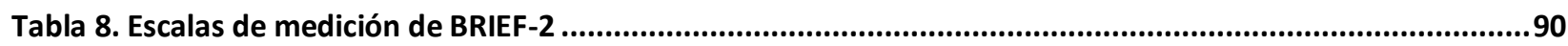

Tabla 9. Definición de axiomas de Igor Aleksander ..................................................................................................101

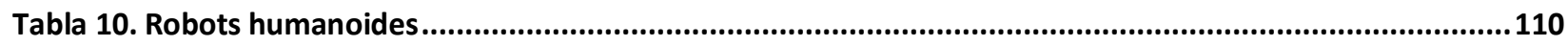

Tabla 11. Robots humanoides autónomos con inteligencia artificial.............................................................113

Tabla 12. Parámetros de inclusión y exclusión de participantes (enfoque cualitativo).......................................118

Tabla 13. Parámetros de inclusión y exclusión de los niños con TEA para el enfoque cuantitativo.......................119

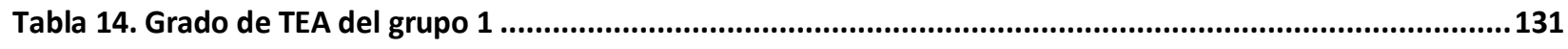

Tabla 15. Resumen de resultados de aproximación naturalista .......................................................................137

Tabla 16. Descripción de aportaciones de tesis de licenciatura .............................................................................140

Tabla 17. Resultados del grupo de trabajo 2 a partir de la dirección de tesis de licenciatura ..............................141

Tabla 18. Guía para la aplicación de resultados...........................................................................................142

Tabla 19. Ejemplo de asignación de puntajes de factibilidad de tareas para FE..................................................150

Tabla 20. Tareas para ejercitar FE usando códigos básicos de comunicación........................................................151

Tabla 21. Asignación de grado de TEA a participantes a partir de los puntajes de SCQ ......................................153

Tabla 22. Características de los objetos que influyen en la percepción ................................................................157

Tabla 23. Comportamiento de los niños antes, durante y después de las interacciones.......................................161

Tabla 24. Niveles de interacción del robot asociado a niveles de TEA .............................................................163

Tabla 25. Variables empleadas para la representación de la unidad de interaccón ...........................................169

Tabla 26. Variables de identificación de cada módulo de interacción .............................................................172

Tabla 27. Características del modelo de interacción nivel 0 .................................................................................176

Tabla 28. Características del modelo de interacción nivel 1 .................................................................................178

Tabla 29. Características del modelo de interacción nivel 2 ................................................................................181

Tabla 30. Características del modelo de interacción nivel 3 ..................................................................................183

Tabla 35. Resumen de aportación de tesis de Soto (2018) ....................................................................................219

Tabla 36. Extracto de resultados de estudio contextual de niños de preescolar (Soto, 2018)............................220 
Tabla 37. Resumen de aportación de tesis de Ramsés Salazar. .

Tabla 38. Extracto de resultados de estudio contextual de niños de preescolar de la tesis de Ramsés Salazar....221

Tabla 39. Resumen de aportación de tesis de Omar Gómez González (2020).............................................222

Tabla 40. Extracto de resultados de estudio contextual de niños de preescolar de la tesis Gómez (2020)...........223 


\section{Preámbulo}

Esta tesis es la conclusión formal de una serie de estudios que he realizado desde el año 2009. Mi aproximación al trabajo con personas con diversidad funcional inició mientras buscaba nuevos campos de estudio en los cuales - como diseñadora y psicóloga- pudiera aportar mis conocimientos que beneficiaran directamente a los usuarios con dicha condición. Durante este camino, he coincidido con el apoyo de colegas, estudiantes, y personas que trabajan directamente o no con niños con diversidad funcional. Particularmente, el involucramiento de mis estudiantes y tesistas ha beneficios a los niños que así lo han requerido, con quienes hemos tenido la fortuna de convivir y relacionarnos. Cabe destacar que la mayor parte del trabajo se ha realizado en la Universidad Tecnológica de la Mixteca; con población oaxaqueña de la región Mixteca (UTM), de los Valles Centrales y de la Costa.

Lo realizado ha estado enfocado en la elaboración de materiales didácticos destinados a resolver ciertas problemáticas que viven los niños en las escuelas de educación especial, quienes han tenido que adaptarse a la poca adecuación de los espacios, mobiliarios, juegos o instrumentos que regularmente son elaborados para personas neurotípicas ${ }^{1}$. Entre los resultados obtenidos a lo largo de estos años se encuentra la propuesta y dirección del proyecto de construcción de una sala multisensorial para personas con discapacidad, la cual $-\mathrm{y}$ hasta el momento de la realización de esta investigación - sigue en funcionamiento. Denominada Ve'endi, que en lengua mixteca significa "casa de luz". En su desarrollo participaron colegas de diferentes vertientes del diseño, estudiantes y personal de mantenimiento de la UTM, quienes aportaron sus conocimientos para nutrir y crear la sala de estimulación multisensorial para una escuela de educación especial del estado de Oaxaca. La primera en su tipo construida en el Estado y que a la fecha sigue en funcionamiento. El proyecto fue financiado por el actual Programa para el Desarrollo Profesional Docente, para el Tipo Superior (PRODEP), que en su momento se llamaba PROMEP. En esta labor tuve la oportunidad de aportar mis conocimientos profesionales como psicóloga y, al mismo tiempo, como diseñadora. A partir de los resultados obtenidos de esa sala multisensorial (Palacios-Villavicencio et al., 2012), el enfoque de los trabajos se fue matizando hacia la exploración de los procesos mentales que subyacen a la

1 Neurotípico es un término que se ha empleado para hablar de las personas que, de acuerdo con datos estadísticos, responden neurológicamente de manera similar. Desde el TEA se ha defendido el uso de la palabra neurotípico para diferenciar las reacciones y respuestas neurológicas que pueden dar unos y otros a partir de una configuración neuronal específica que no necesariamente condiciona a un estado de incapacidad o discapacidad sino de diversidad funcional neurológica. 
conducta de los niños en condiciones de desventaja funcional dentro de las escuelas regulares y especiales.

En 2015 -en el marco de trabajo del Cuerpo Académico Integración Multidisciplinaria del Diseño en México, del cual soy coordinadora- dirigí un proyecto en el que, en colaboración con colegas de otras instituciones, se creó una RED Académica con el apoyo económico del PRODEP, llamada: "Tecnologías interactivas para atender Necesidades Educativas Especiales (NEE)". El primer proyecto desarrollado se llamó: Atención a niños con Necesidades Educativas Especiales mediante el desarrollo de recursos didácticos con tecnologías interactivas.

El proyecto actual tiene su origen en el análisis y la observación que previamente había realizado de los resultados de la sala de estimulación multisensorial, de la cual obtuve las siguientes premisas, y, que son las bases para el inicio de la tesis doctoral que presento:

Premisa 1. Sin importar cuál sea la diversidad funcional que viven los niños con NEE, es indispensable fortalecer su integración y estimulación sensorial. Esto les ayudará a desarrollar de mejor manera sus habilidades cognitivas, motoras, de lenguaje, de socialización, y de cualquier otra índole que les conduzca a un desarrollo integral. Por lo cual, es importante contar con una herramienta diagnóstica para determinar el nivel de involucramiento que pueden tener los niños al trabajar con ellos ${ }^{2}$.

A partir de lo anterior, determiné qué tipo de herramienta podía ayudar para que áreas —no especializadas en el trabajo con niños con diversidad funcional- pudieran insertar, de una manera más natural y certera, materiales o prototipos para niños con estas características. Así, surgió la propuesta de crear un proyecto que permitiera la creación de estos instrumentos de trabajo, y, que pudiera ser continuada como parte de mi tesis doctoral. De esta manera, se determinó que el centro del proyecto fuera el desarrollo de una herramienta que facilitara el seguimiento del estado en el que se encontraban los repertorios básicos de los niños.

Consideré los repertorios básicos debido a que son una condición primaria que cualquier persona debe tener para iniciar la adquisición de conductas de adaptación o para comenzar

\footnotetext{
${ }^{2}$ Aunque la integración y estimulación sensorial fue una propuesta hecha por Jean Ayres a partir de sus observaciones con niños en 1979, la necesidad señalada de contar con una herramienta diagnóstica apunta al sentido transdisciplinario descrito en el manifiesto de Basarab Nicolescu (Nicolescu, 2002). Lo anterior con el fin de agregar otras miradas, es decir, las de otras disciplinas que faciliten la creación de nuevas herramientas de apoyo, las cuales contribuyan no sólo a tener una visión completa de las necesidades de los niños en la casa o en la escuela, sino a diseñar, construir y desarrollar nuevos objetos, herramientas, juegos o instrumentos enfocados en resolver las mismas problemáticas de los niños o personas con esta diversidad funcional.
} 
cualquier entrenamiento, aprendizaje o interacción. Entre ellos se encuentra la atención, la imitación y el seguimiento de instrucciones. Estos repertorios básicos son parte de las conductas adaptativas de las personas, y, se desarrollan de manera natural en la mayoría de ellas. Sin embargo, en otras, con determinada diversidad funcional, no se instauran adecuadamente, y es necesario proveerles de herramientas para que las adquieran. En la vida adulta, su inducción ayuda de manera sustancial a los niños para adquirir nuevas conductas, moldeables y socialmente adaptadas (Király et al., 2013).

De esta manera - con una visión transdisciplinar-, en la propuesta se involucraron la robótica y la interactividad, en la que se involucró el codirector de esta tesis. Teniendo como objetivo planificar tareas robóticas con acciones reactivo/cognitivas, y diseñar recursos didácticos con tecnologías interactivas enfocadas en la intervención psicoeducativa para la adquisición de repertorios básicos (atención, imitación y seguimientos de instrucciones) para niños con NEE. La inclusión de un "robot humanoide" ayudaría a establecer un criterio único de interacción con los niños, al tiempo que usaban la tecnología.

El primer proyecto de esa RED inició en 2015, y, finalizó en 2017; es decir, un año antes y uno después de que iniciara formalmente los estudios de doctorado. Tomarlo como base ha sido fundamental para el desarrollo de esta investigación.

Entre los resultados de ese primer proyecto fue que las primeras planeaciones se realizaron considerando instrucciones sencillas para niños diagnosticados con Lento Aprendizaje (LA), con Discapacidad Intelectual (DI), con Síndrome de Down, y con Trastorno del Espectro Autista (TEA) (Arias-Aguilar et al., 2017; Palacios-Villavicencio et al., 2015). Cada una de ellas fue probada con niños neurotípicos, obteniendo resultados positivos y aceptación de los niños para interactuar con el robot. Sin embargo, al realizar las pruebas con los niños con NEE las instrucciones no eran entendidas adecuadamente y, en ocasiones, el robot se mantenía hablando mientras los niños ya ni siquiera lo veían. El robot parecía gustarles, pero las instrucciones eran muy largas y tuvieron que ser simplificadas. Una vez adecuadas las instrucciones, las respuestas fueron replanteadas y se logró el objetivo. Los resultados obtenidos dieron pauta a la segunda premisa:

Premisa 2. La exploración diagnóstica de los repertorios básicos que tienen instaurados los niños con NEE son una guía para determinar qué tipo de acciones pueden ejecutar y qué tipo de materiales se pueden desarrollar para ellos, con el fin de ayudarles a tener una mejor integración en el entorno educativo o social. 
Y de aquí, surge un nuevo planteamiento: una vez teniendo el diagnóstico de los repertorios básicos, y, aunque ya se tenía una referencia de cómo empezar a trabajar con los niños con NEE, pero surgieron algunas preguntas de investigación: cognitivamente ¿cómo se puede ayudar a reforzar o adquirir esos repertorios que aún no tienen bien instaurados?, o, incluso teniéndolos ¿de qué manera se les puede ayudar a mejorar o aprovechar sus repertorios básicos?

Entonces, para definir el sentido de la tesis delimité el alcance de ésta empezando por los usuarios mi elección se inclinó por los niños con Trastorno del Espectro Autista por dos razones. La primera está relacionada con los acercamientos que tuvimos con los niños con TEA y el robot humanoide, en donde me di cuenta del alto grado de aceptación de los niños con el robot, interés que no suelen tener con las personas. Dicha situación me llevó a considerar al robot humanoide como un intermediario de comunicación. La segunda, es porque teniendo a un robot frente a los niños con TEA en una situación experimental el robot mismo me permitiría extraer la siguiente información: a) precisar el nivel de acercamiento y de contacto; b) el tiempo durante el cual los niños mantienen la mirada), y c) de otros detalles que podrían ser medidos con la misma precisión en todos los usuarios.

En ese sentido, y considerando la población de estudio se consideraron las tres problemáticas que viven los niños con TEA: 1) la interacción social, 2) la comunicación, y 3) la flexibilidad cognitiva. Esta delimitación planteó la necesidad de explorar la flexibilidad cognitiva, una condición mental de los niños con TEA que ya ha sido explorada en otros estudios, con otras herramientas. Me refiero a la flexibilidad cognitiva que está íntimamente relacionada con el uso de las funciones ejecutivas (FE). Se trata de un constructo mental, que la psicología emplea con el fin de explicar el uso que el cerebro da a la información que recibe para: a) organizar, b) planear, y c) controlar la conducta. A partir de esta nueva delimitación, se llegó a una nueva premisa:

Premisa 3. La instauración de los repertorios básicos en los niños con TEA son una condición inicial para el uso y adaptación de sus FE permitiéndoles estar en contacto con el entorno, (en un mayor o menor grado del control de sus reacciones conductuales). EI uso de un robot humanoide facilitará poner en práctica y explorar las tres problemáticas con las que viven la mayoría de las personas con TEA, la interacción social, la comunicación y la flexibilidad cognitiva. 
Hasta este planteamiento la propuesta era realizar un modelo de interacción cognitiva. Pero, se decidió empatar las FE asociadas a los niveles de consciencia en las tareas puestas a prueba durante las interacciones niño-robot. Así, inicialmente, el tema que se exploraría se basaba en dos aspectos:

1. Las funciones ejecutivas, $y$

2. La interacción social de los niños con TEA con un robot humanoide

Pero al considerar la adecuación del marco teórico de (Laureano-Cruces et al., 2013, 2015, 2018) se agregó un elementos más:

\section{La consciencia}

A partir de los elementos antes enunciados, de las premisas dilucidadas, de la delimitación semántica y del tipo de usuarios, la determinación del objeto de estudio se centró en las tres problemáticas que viven regularmente los niños con TEA: 1) los patrones de comportamiento relacionados con las actividades e intereses repetitivos y restringidos; 2) el deterioro de la comunicación e interacción social, y 3) el deterioro en su flexibilidad de pensamiento. Las problemáticas fueron fundamentales para plantear los parámetros del objeto de estudio de la Figura 1.

La imagen se divide en tres secciones horizontales: en la parte superior están las tres características diagnósticas de los niños con TEA. En la parte central, se muestran las dimensiones empírica, teórica, metodológica y epistemológica asociadas a las características de los niños y a algunos de los enfoques teóricos con mayor relevancia para esta investigación. La parte inferior señala la relación del marco teórico desarrollado por (Laureano-Cruces et al., 2013, 2015, 2018) y su relación con las características diagnósticas del TEA. Las flechas en color hacen un seguimiento de las relaciones encontradas en otros estudios, que se han expuesto en las premisas dos y tres.

La ilustración tiene por objeto mostrar a grandes rasgos las relaciones encontradas entre los distintos elementos que finalmente componen esta tesis. 


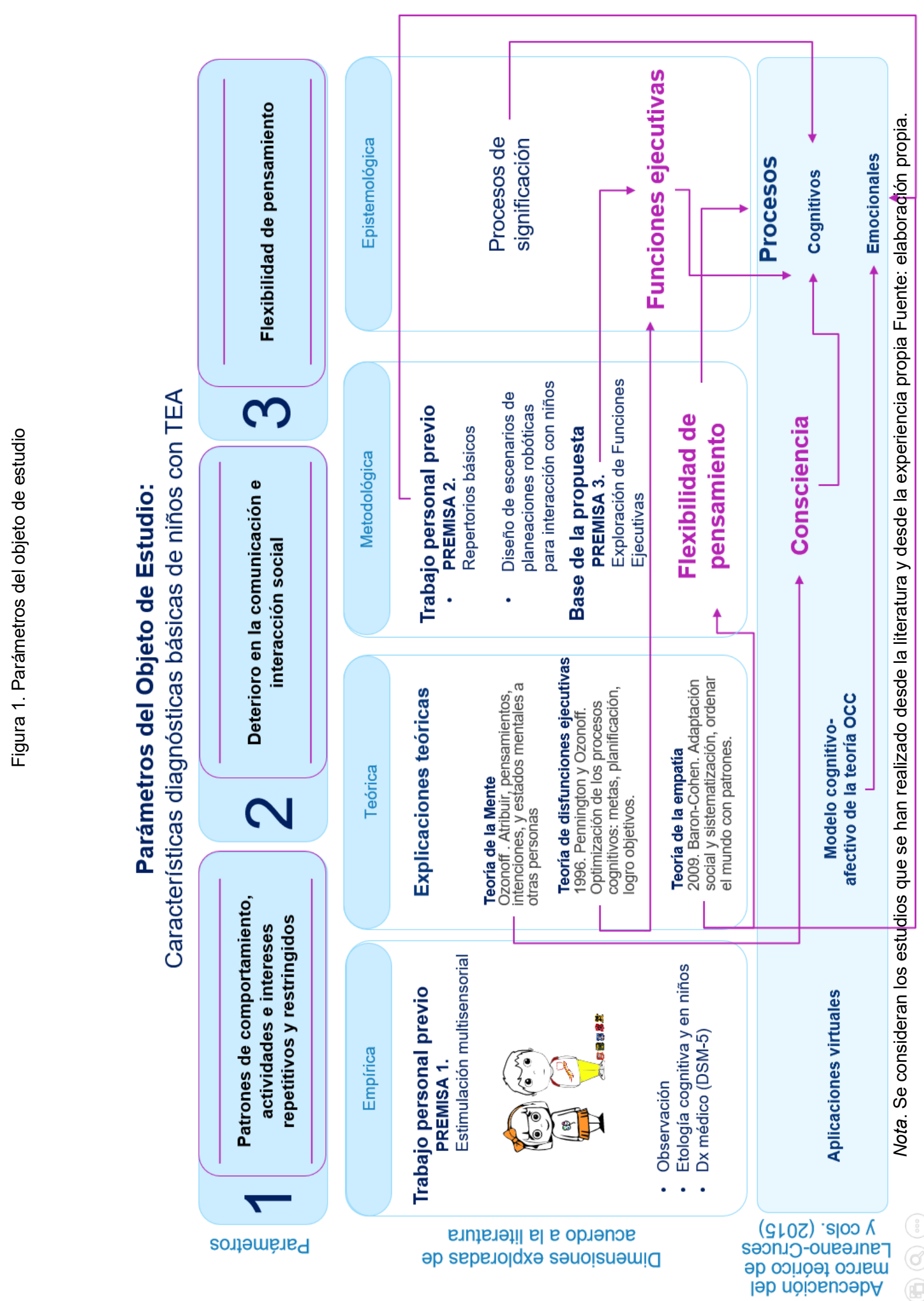


Tomando en cuenta las anotaciones previas, la premisa de la tesis doctoral es:

Premisa 4. Los niños con TEA presentan primordialmente tres tipos de problemas: patrones de comportamiento como actividades e intereses repetitivos y restringidos; deterioro de la comunicación e interacción sociales, y deterioro en su flexibilidad de cognitiva (ver Figura 1). Su exploración ha estado mediada por aspectos empíricos, teóricos, metodológicos y epistemológicos desde distintas áreas del conocimiento y con diversos tipos de intervenciones: terapéuticas, sociales, legislativas o tecnológicas, entre otras. Las explicaciones teóricas más importantes del comportamiento del TEA han enfatizado la falta de interacción social de los niños con otras personas, debido a: 1) un deficiente sistema de interpretación de las intenciones y del estado mental de otros individuos; 2) la carencia de la optimización de sus FE relacionadas con la capacidad de mantener una disposición apropiada de solución de problemas para el logro de una meta futura, y 3) una deficiente adaptación social relacionada con la falta de empatía debido su alta recurrencia de patrones detectados por sus actividades e intereses restringidos y repetitivos.

Una de las vías explicativas que se pueden tomar para estos tres factores es la exploración y el análisis de la conducta de los niños en condiciones experimentales, que implique la socialización dirigida bajo el seguimiento de la conducta basado en un modelo afectivo-cognitivo que tenga por intermediario un "sujeto" con menor carga significativa que la que implican las personas, pero que permita la simulación de las acciones de una persona en interacción.

Así, la premisa cuatro condujo a plantear la propuesta de desarrollar escenarios de interacción cognitivos de niños con TEA y un robot humanoide, con los cuales se pudiera medir y analizar los patrones de comportamiento de los niños mientras interactúan bajo condiciones experimentales "como si" se tratara de una interacción con una persona.

La particularidad es que la interacción se realizó explorando el uso de las FE que los niños ponen en práctica por medio de vehículos de comunicación ${ }^{3}$ desarrollados para dicho fin. Éstos

\footnotetext{
${ }^{3}$ Los vehículos de comunicación empleados en esta tesis fueron creados como juegos de manipulación (manual) que sirven como medio para interactuar con los niños con TEA. Se emplearon para poner en práctica actividades mentales que requerían de FE para su uso. Para su creación el diseño fue la base para la creación de los vehículos de comunicación y medio de integración de las disciplinas que intervinieron en la tesis.
} 
fueron elaborados considerando la significación de interés de los niños con TEA y el nivel de consciencia que tienen de sí mismos, y del otro, durante las interacciones. En este caso, "el otro" es el "robot humanoide" que funciona como vehículo de interacción asistido 4 .

Finalmente, a partir del diseño del modelo cognitivo de interacción y valorando los datos que arrojaron las pruebas de interacción, se integra el modelo cognitivo. Para lograr una interacción más empática con los niños se emplea la caracterización conductual afectiva del robot que implica su capacidad de comunicación verbal (pronunciación, comandos vocales y onomatopeyas ${ }^{5}$ ) y no verbal (expresión corporal y de ojos).

Las herramientas que tanto mi directora como mi codirector de tesis han aportado para el desarrollo de esta investigación han sido esenciales para el adecuado desarrollo de ésta. Los resultados de esta investigación son para mí realmente placenteros y, por demás, interesantes.

La pretensión inicial cuando empecé a relacionarme con proyectos para niños con diversidad funcional era identificar de qué manera se les puede ayudar, y, al mismo tiempo, entender los procesos mentales que están detrás de su original y natural conducta espontánea. Conducta tan sincera que, por reflejo o proyección, deja al descubierto muchos de los vicios mentales y conductuales que regularmente las personas neurotípicas generamos a lo largo de nuestra vida, pero que aprendemos a enmascarar con regularidad.

${ }^{4}$ El nombre atiende a que se emplea en la interacción, pero es manipulado de manera remota a través del control de una persona con la técnica Mago de Oz. Ésta es empleada en interacción para simular, ante el usuario, que el sistema (en este caso el robot humanoide) tiene una conducta autónoma, aunque su control dependa de otra persona en tiempo real.

${ }^{5}$ Se refiere a la calidad de la dicción, el uso de instrucciones verbales y de gestos o remedos. 


\section{Introducción}

La búsqueda del significado a través del estudio de los signos ${ }^{6}$ es para el diseño un quehacer cotidiano que brinda las bases teóricas para explicar y, posteriormente, utilizar la simbolización que los seres humanos tienen del mundo.

Para las personas neurotípicas el reconocimiento de estas claves o códigos podría ser una tarea con relativa sencillez; sin embargo, fuera de ese grupo estadísticamente regular o neurotípico, existen poblaciones en las que las claves de intercambio comunicacional se encuentran flanqueadas por barreras invisibles a simple vista y que requieren de una exploración más cercana para entender el sentido que le dan a su entorno. Tal es el caso de las personas diagnosticadas dentro del trastorno del espectro autista (TEA ${ }^{7}$.

La problemática que viven las personas, y particularmente los niños con TEA, se ve afectada por la falta de mecanismos existentes que ayuden a superar alguna de las tres condiciones que caracterizan e impiden su integración social: 1) alteración cualitativa en la interacción social recíproca; 2) alteración cualitativa de la comunicación; y 3) patrones de conducta, intereses y actividades limitadas, repetitivas y estereotipadas. El grado de afectación está determinado por la ayuda que requieren en el ámbito de la comunicación y de la socialización: 1) Grado 1, requieren ayuda, 2) Grado 2, requieren ayuda notable, y 3) Grado 3, requieren ayuda muy notable (Asociación Americana de Psiquiatría, 2014). En ese sentido, la facilidad de uso y el acceso a los códigos de comunicación (con o sin tecnología) pueden ser determinantes para que una persona con TEA se integre más fácilmente a su entorno.

En esta investigación se presenta una aproximación para el estudio del autismo o TEA empleando un robot humanoide como vehículo de interacción asistida. Inicia con la exploración de los códigos de comunicación viables para interactuar con ellos, con el fin de generar un modelo de interacción que facilite, por un lado, el estudio del trastorno, y, por el otro, el apoyo o entrenamiento que incida directamente en las problemáticas asociadas.

${ }^{6}$ Saussure, lingüista suizo y Charles S. Peirce, filósofo norteamericano, a principios del siglo XIX, fundaron (por separado) las bases de lo que actualmente se conoce como ciencia general de los signos, denominada como semiología desde la perspectiva de Saussure y semiótica desde el enfoque de Peirce (Crow, 2008).

${ }^{7}$ En la clasificación y diagnóstico de enfermedades mentales existen dos instituciones que se han validado mutuamente a nivel internacional: la clasificación internacional de enfermedades (CIE) promovida por la OMS (última edición: décima o CIE-10), y el manual diagnóstico y estadístico de los trastornos mentales versión 5 (Asociación Americana de Psiquiatría, 2014). Ambas incluyen un padecimiento relacionado con la poca o nula capacidad de comunicación y la falta de interés en el mundo, tienen una categoría en la que se inscriben rasgos de personas con autismo, según el CIE-10 o con Trastornos de Espectro Autista, según el DSM-5. En el presente documento se nombrará indistintamente TEA o autismo. 
El seguimiento durante la investigación se fundamenta en la observación, la abstracción y la visualización del comportamiento de los niños para proponer un modelo de interacción cognitiva. En ese sentido, la visualización formó un papel primordial con el fin de identificar los nodos centrales para el desarrollo de la propuesta final. A lo largo de la tesis se trabajó con ese proceso en el que el diseño cumple la función de informar a través de la síntesis visual. De acuerdo con Isabel Meirelles (2013) la visualización se compone de infografías y diseño de la información en las que se combinan, entre otros, ilustraciones, símbolos y diagramas para comunicar. En el caso de esta tesis, la visualización se ha empleado en tres sentidos:

1) Para analizar semióticamente el comportamiento de los niños durante sus interacciones con otros, lo cual es presentado teóricamente en el capítulo 2 y aplicado en el capítulo 4 (ver apartado 4.5.2);

2) Como una técnica para evidenciar la relación transdisciplinar de la investigación que facilitó abordar el tema desde distintas perspectivas (capítulo 2, revisar discusión), y

3) Para proponer una vía de trabajo a través de un modelo de interacción que puede ser aplicado con tecnología sofisticada y onerosa como un robot humanoide, o con dinámicas adaptadas en un salón de clases o en la casa.

Mathías Shapiro (2010) comenta que la visualización se compone de preguntas, datos visuales y el contexto que confluyen en una historia. Esta tesis inicia con una primera condición que ha ido madurando durante más de 70 años en la literatura, es decir, desde la primera descripción que hizo Leo Kanner de las personas autísticas (Artigas \& Paula, 2012). Consiste en las tres problemáticas asociadas al diagnóstico que actualmente se agrupan en la definición de un trastorno. No obstante, la pregunta básica y constante que guio la investigación no necesariamente fue lo que marcaba la literatura, sino la siguiente interrogante ¿qué dicen los niños a través de lo que no dicen o de lo que sí hacen? Asociada a esta sencilla pregunta una serie de interrogantes se me presentaron a lo largo del texto, las cuales fueron las linternas que iluminaron el camino de esta investigación. Así, lo importante fue saber ¿qué dicen sus posturas?, ¿qué hace que sus condiciones sean adecuadas o no para interactuar?, ¿qué gritan en silencio? Lo anterior tomando como base explicativa la observación constante para lograr la propuesta de un modelo de interacción cognitiva.

Por otro lado, la parte teórica fue el sustento que dio forma a la propuesta que se presenta. Ésta se integró a la visualización directa del comportamiento de los niños. En ese sentido, se 
consideró que la visualización no solo fue una técnica, fue una forma de ver y analizar la vida y el entorno de los niños. Fue un guiño en medio de los datos para evidenciar lo no evidente. En donde el diseño enfocó ángulos que, en otros casos, probablemente seguirían invisibles.

La visualización no sólo son datos y más datos, es sobre todo la representación de variables relacionadas que indican nuevas rutas de trabajo, de posibles soluciones. A través del modelo de interacción cognitiva, se aporta una nueva ruta para que los niños con TEA fortalezcan y ejerciten lo que por natura no les fue entregado, pero que, a través de la práctica, pueden adquirir para bien de sí mismos y para el beneplácito de las demás personas cercanas a ellos y su proceso de maduración.

Como investigadora parto de esa delimitación referencial basada en los estudios previos que han explicado las bases del comportamiento de los niños con TEA y que forman parte de los referentes directos de este trabajo. 


\subsection{Delimitación referencial}

EI TEA ha sido abordado desde distintas posturas teóricas que han facilitado la integración de un panorama de lo que sucede con las personas que lo padecen, por ejemplo, Baron-Cohen y sus colaboradores (Charman et al., 2000; Frith \& Baron-Cohen, 1987; Peterson et al., 2015; Robertson \& Baron-Cohen, 2017) han documentado la relación que existe entre los patrones perceptuales de reconocimiento ${ }^{8}$ y la falta de empatía. A partir de estas contribuciones desarrolló su teoría de empatización-sistematización, en la que explica que las personas, por naturaleza, tienden a buscar y adaptarse contextualmente a partir de los patrones cognitivos de reconocimiento de su mundo circundante. Baron-Cohen (2009) relaciona la falta de empatía con la necesaria dependencia que algunas personas tienen hacia patrones específicos. Dicho comportamiento lo ha asociado con las actividades repetitivas, la poca tolerancia al cambio y la fijación en ciertos objetos que suelen mostrar las personas con TEA.

Otras teorías que se han desarrollado para explicar los procesos del TEA son: 1) la teoría de la mente (Baron-Cohen et al., 1985; Call \& Tomasello, 2008; Pedreño et al., 2017; Premack \& Woodruff, 1978), relacionada con la incapacidad para interpretar pensamientos, creencias intenciones y deseos de otros; 2) la teoría del déficit de FE (Ahmed \& Stephen Miller, 2011; Ozonoff et al., 1991; Papazian et al., 2006; St. John et al., 2018; Tirapu-Ustárroz et al., 2005), que implica la falta de habilidades para dirigir la conducta hacia una meta incluyendo planificación, flexibilidad cognitiva, memoria de trabajo, monitorización e inhibición, entre otras; 3 ) la teoría del déficit intersubjetivo (Hobson, 1993), basada en el aspecto emocional y afectivo, sostiene que las personas con TEA carecen de un mecanismo psicológico primario que los predispone para implicarse en interacciones afectivas; y 4) la teoría de coherencia central (Frith \& Happé, 1994; López \& Leekam, 2007), sostiene que en la condición del espectro autista, las personas procesan la información a partir de los detalles y no de forma global como las personas neurotípicas. Ésta última está relacionada con la teoría de empatización-sistematización (Baron-Cohen, 2002).

8 Existe una gran diferencia entre el "reconocimiento de patrones en sistemas computacionales" y los "patrones humanos de reconocimiento". El primero parte de la perspectiva computacional en la que se considera la extracción de información de los objetos a partir de sus propiedades y de las relaciones entre ellos empleando procesos y herramientas de la ingeniería, de la computación y las matemáticas (Gómez Gil, 2018). Mientras que los patrones humanos de reconocimiento (Yin, 2008), generalmente se refiere a un proceso de entrada de información estimulante o patrón y coincidencia con la información en la memoria a largo plazo de una persona, quien depende del conocimiento que tenga y de su experiencia para identificar la categoría a la que pertenece la estimulación recibida. Esta segunda apreciación parte de las teorías explicativas del reconocimiento cognitivo y la categorización perceptiva que una persona realiza para interpretar su entorno. En lo sucesivo, en este trabajo los patrones de reconocimiento se referirán a la percepción humana, no a los sistemas computacionales. 
Las teorías propuestas hasta ahora han servido como base para procedimientos de intervención terapéutica y para concebir de una mejor manera a personas con TEA. Sin embargo, hasta el momento aún no se ha logrado entender la lógica del pensamiento de las personas con TEA cuando se desestructura su entorno y ellos no son capaces de adecuarse al mismo, flexibilizando su conducta ante el cambio. Por tal motivo, en este proyecto se describen, estudian y analizan los patrones de comportamiento de niños con TEA desde la perspectiva de la teoría de déficit de $\mathrm{FE}^{9}$ (FE) y de la teoría de la mente (ToM), que implica la falta de habilidades para dirigir la conducta hacia una meta en la primera, y la falta de anticipación al pensamiento de los otros, en la segunda. Esta última tiene influencia de la consciencia, como se verá más adelante.

El término de FE se emplea como un constructo teórico para comprender la organización cognitiva o las actividades mentales complejas relacionadas en la planificación y la organización mental para alcanzar metas (Bock et al., 2019; Calle Sandoval, 2017; Papazian et al., 2006; Tirapu-Ustárroz et al., 2005).

De acuerdo con Stuss y Benson (Tirapu-Ustárroz et al., 2005), en la base de las FE se encuentra la autoconciencia o autoanálisis, a través del cual la persona valora sus experiencias subjetivas para emplearlas en la resolución de problemas y guiar la toma de decisiones de su presente. Así, la significación se hace evidente cuando la persona adquiere el conocimiento de lo que le rodea y lo dota de significados que posteriormente evoca en su memoria. Ese proceso de significación se relaciona con el nivel de consciencia que el individuo tiene de sí mismo y de los otros, y, de la interpretación cognitiva y emotiva que da a su entorno.

Los patrones humanos de reconocimiento, así como la significación del mundo, son para las personas con TEA un blanco útil desde el que se les puede ayudar a descifrar símbolos de la cotidianidad o adaptarse en sus contextos de vida. Sin embargo, la complejidad de dicha tarea no puede ser objeto de estudio de una sola área. Desde la perspectiva de esta investigación se integran tres:1) el diseño, en el que se enfoca el análisis del proceso de significación desde la semiótica, y que está en concordancia con otras áreas disciplinares; 2) la psicología cognitiva asociada al estudio de la cognición humana, las emociones y, en el nivel más elevado, los afectos, y 3) la robótica, utilizada como herramienta de exploración de la conducta de los niños. A partir de éstas se retoman las herramientas necesarias para formular un marco teórico referencial que analiza el uso de las FE en niños con TEA. Tales aspectos se plantean a partir de interacciones

\footnotetext{
${ }^{9}$ Los conceptos teóricos que se marcan en negritas son solo una referencia de su participación en este proyecto. En el cuerpo de la tesis se incluye una descripción más amplia.
} 
de los niños o de los usuarios con un robot humanoide (por ser altamente significativo para ellos) en el que se implementaron escenarios cognitivos que contemplan tareas para ejercitar memoria de trabajo, atención, inhibición, flexibilidad cognitiva, planificación y monitorización.

De acuerdo con algunos estudios exploratorios propios y previos a este trabajo (AriasAguilar et al., 2017; Palacios-Villavicencio et al., 2015; Soriano Herrera et al., 2019), se corroboró la alta atracción que tiene los niños con TEA hacia la tecnología y especialmente hacia el robot humanoide $\mathrm{NAO}^{10}$ (nombre del robot humanoide con el que se trabaja en esta investigación). Debido al gran interés que mostraron hacia el robot, éste fue considerado como un signo de intermediación para establecer contacto y comunicación con ellos; y, fue empleado para facilitar la interacción con los niños con TEA, corroborando los resultados positivos que se mencionan en otros estudios (Breazeal, 2003b; Huijnen et al., 2017; Kozima et al., 2007; Lemaignan et al., 2017; Robins et al., 2005).

El uso de NAO, como vínculo entre los niños y sus evaluadores, acortó la distancia de interacción social que suelen interponer los niños con TEA con las personas. A partir de esto se buscó identificar sus comportamientos sociales y, al mismo tiempo, poner en práctica sus $\mathrm{FE}^{11}$ a través de ejercicios creados especialmente para ello.

Considerando estos aspectos preliminares, la investigación fue formulada a partir de cinco etapas:

1. Caracterización diagnóstica de niños con TEA

2. Proceso de significación de niños con TEA

3. Caracterización de las FE

4. Propuesta de un modelo de interacción cognitiva

5. Integración y puesta a prueba del modelo de interacción cognitiva

${ }^{10}$ Creado en 2008 por la empresa francesa Aldebarán robotics, NAO es uno de los robots humanoides que más se ha difundido en el mundo para la investigación, educación y atención médica. Hasta el momento se han utilizado más de 13,000 robots en más de 70 países, y se ha empleado con mucho éxito con niños con TEA (Giullian et al., 2010).

${ }^{11}$ Asociada con la capacidad para modificar un pensamiento o la acción de acuerdo con los cambios que se produzcan en el ambiente (Martin, 2015). 


\subsection{Alcance y delimitación semántica}

La implementación de mecanismos que ayuden a los niños con TEA a superar alguna de las tres condiciones que los caracterizan e impiden su integración social, es uno de los objetivos primordiales de las intervenciones terapéuticas y de las investigaciones actuales. Las mediaciones pueden ser de diversa índole; sin embargo, en esta tesis el objetivo principal es la utilización de la tecnología (el robot humanoide) para establecer una investigación transdiciplinaria, en la cual el diseño, la psicología y, de manera instrumental, la robótica son las herramientas básicas.

El límite semántico se estableció para definir la propuesta de un modelo de interacción cognitivo para ejercitar las FE de niños con TEA, puestas en práctica a través del uso de un robot humanoide como vehículo de interacción asistida. Su aplicación experimental se centra en la adecuación de un modelo de consciencia asociado al uso de las FE. Sería ideal poder llegar a una intervención terapéutica o psicológica comprobada; sin embargo, el alcance de la tesis no propone llegar a ese nivel. No obstante, los resultados sí aportan indicadores de uso para esquemas o programas de intervención psicoterapéutica y arrojan datos para la implementación de la inteligencia artificial (IA), enfocada en el uso de robots como medio de socialización de niños con TEA.

El desarrollo de la investigación se fundamenta a partir del marco teórico referencial descrito en cinco apartados definidos como elementos de anclaje teórico referenciales (EATR). El objetivo de exponerlos de esta manera es brindar una estructura teórico-multidisciplinaria -que soporte el objetivo al que se quiere llegar con la investigación —, a fin de contribuir con una aportación transdisciplinar.

Los EATR brindan, en sí mismos, la delimitación semántica que va de la mano de cada una de las cuatro etapas de investigación previamente formuladas; así como una etapa de integración.

1. Caracterización diagnóstica de niños con TEA. Se parte del diseño universal e incluyente, la discapacidad y la determinación diagnóstica del TEA. Se parte de la adecuación del diseño universal e incluyente de personas con discapacidad y se consideran los criterios diagnósticos del DSM-5, la teoría de la Mente (ToM) propuesta por Premack (Premack \& Woodruff, 1978), y la teoría de la empatía propuesta por Baron-Cohen (2012) como base explicativa. Ambas teorías son enlazadas con la teoría de las FE. 
2. Proceso de significación de niños con TEA. En este apartado se realizó el análisis y selección de signos de significación potenciales para activar la atención selectiva de los participantes. El proceso se expone desde la perspectiva del diseño, de la cognición y de la percepción, y posteriormente se enlaza al proceso de toma de consciencia. A través de ellos se explican los procesos de significación que siguen para reconocer e interpretar los estímulos circundantes, entendido como el fenómeno de la consciencia.

3. Caracterización de las FE y su relación con la flexibilidad adaptativa ${ }^{12}$. Se retoma la clasificación de FE realizada por Flores-Lázaro y Ostrosky-Shejet (2012), y se evalúan a partir de los parámetros de las pruebas BANFE (Flores et al., 2014) y BRIEF-2 (Gioia et al., 2015). Los resultados se relacionan con los elementos de significación identificados en los participantes del estudio y estos a su vez son vinculados con distintos niveles de consciencia planteados por lgor Aleksander y adaptados por Laureano-Cruces y colaboradores (Laureano-Cruces et al., 2013, 2015, 2018). A partir de estos elementos, la delimitación está dada por las FE, los niveles de significación y los niveles de consciencia.

4. Modelo de interacción cognitiva. La delimitación del modelo de interacción está dada por los parámetros de la interacción humano-humano y por la interacción niño-robot humanoide. El modelo se desarrolló a partir de la observación de la interacción con los usuarios y se adecuó a todos los niveles de TEA, con el fin de identificar a los usuarios más funcionales, o de menor grado de afectación, con quienes se puede llegar al nivel más alto del modelo con base en la metacognición.

\footnotetext{
12 Es la posibilidad de admitir y tolerar los cambios que se producen en el ambiente o el entorno. La adaptación implica
} cambios en el pensamiento y la acción, desarrollando tolerancia a la frustración. 


\subsection{Planteamiento}

Como se ha mencionado, el TEA es un padecimiento en el que las personas tienen afectadas tres áreas primordialmente: 1) alteraciones de la interacción social, 2) en la comunicación, y 3) la flexibilidad de pensamiento.

Actualmente, no existen cifras generales que engloben la incidencia del TEA a nivel mundial, sin embargo, en términos generales, se ha detectado que existe una proporción de incidencia 1:160, en la que la mayoría de los niños afectados son del sexo masculino en una relación de1:5 (niña/niño) (Christensen et al., 2019). Se han propuesto múltiples enfoques terapéuticos para ayudar a la integración social de las personas que viven con TEA, entre ellos intervenciones conductuales, como el análisis aplicado de la conducta (A.B.A.) (Mrachko \& Kaczmarek, 2017; Peters-Scheffer et al., 2011), que ha sido de los más exitosos para el manejo del TEA. Aunque no existe hasta el momento un enfoque que sea totalmente efectivo (Mulas et al., 2010), su resultado depende, en gran medida, de las condiciones y la gravedad del TEA de las personas que lo viven.

Baron-Cohen (2011) explica que la proporción de niños y niñas (1:5) que presentan TEA se debe al nivel de testosterona. En los niños el nivel es más elevado y lo define como una forma extrema de pensamiento masculino sistemático. Mientras que las niñas, quienes regularmente tienen menores niveles de dicha hormona, se detecta mayor inclinación por la empatización (Baron-Cohen et al., 2011). Aportando con ello los elementos que integran su propuesta teórica empatización-sistematización (Baron-Cohen, 2009)

Aún no se tiene respuesta de la relación que existe entre el bajo comportamiento social de los niños TEA y la falta de interés que denotan ante el mundo circundante. Se han investigado, de alguna manera, los mecanismos que se activan en una persona cada vez que realiza una tarea; sin embargo, no se han identificado qué estrategias pueden emplearse con los niños con TEA cuando sus patrones de comportamiento repetitivos e intereses restringidos son activados, lo cual impide la culminación de una tarea de forma exitosa. Tampoco está documentado si la poca capacidad de atribuir estados mentales a los demás forma parte de un mecanismo "desinhibitorio" que evita que presten atención a los estímulos relevantes del entorno y de las personas.

Se tiene conocimiento de que la capacidad de los seres humanos para realizar tareas de principio a fin dependen del adecuado nivel de sincronía de los componentes básicos de las FE como el control inhibitorio, la memoria de trabajo y la flexibilidad cognitiva (Rebollo \& Montiel, 
2006; Tirapu-Ustárroz \& Luna-Lario, 2011). No obstante, todos parten de la misma condición: prestar atención, aspecto que ha sido precisado por los estudios del fenómeno de la consciencia (Barttfelda et al., 2015; Dehaene et al., 2011; Giacino, 2005; Hutchinson, 2019); los cuales han sido adecuados al estudio del autismo (Grisdale et al., 2014; Huang et al., 2017; Morin, 2006, 2011). Es decir, se ha descrito que el punto inicial es la existencia de algo suficientemente fuerte y significativo en el ambiente para ser considerado como un estímulo capaz de atravesar la barrera del acceso consciente (Dehaene, 2015). En el caso de los niños con TEA es, precisamente, la atención la que está difusa, por lo que encontrar un estímulo atractivo adquiere relevancia inmediata.

Los niños con TEA tienen alterado el reflejo de la atención; hecho que dificulta el reconocimiento de ciertos signos significativos, necesarios para dar una respuesta asertiva y congruente de acuerdo con las exigencias del entorno, rara vez tienen intereses externos que los motiven a seleccionar, organizar e interpretar un estímulo. No obstante, se ha detectado que los robots humanoides son una forma grata, interesante y novedosa de llamar su atención (Breazeal, 2003b; Hong et al., 2016; Liu et al., 2015; Yun et al., 2016). En 2019 (Soriano Herrera et al., 2019) identificaron que para los niños es más atractivo trabajar con un robot humanoide que simula la interacción humano-humano, que con una persona o con un agente virtual.

En la experiencia que se ha tenido en la interacción de NAO con niños con TEA (Figura 2) se ha detectado que para los infantes resulta muy novedoso. La sencillez del diseño del "robot humanoide" favorece a que los niños no se pierdan "perceptualmente" en su aspecto, formas o colores. En algunas pruebas que se han realizado con NAO y con los niños con TEA se identificó que por su naturaleza NAO es un estímulo de gran atracción para los niños favoreciendo su papel como guía y como incentivo a imitar (Arias-Aguilar et al., 2017; Palacios-Villavicencio et al., 2015) Esto propicia que los pequeños interactúen con él y sigan sus instrucciones. 
Figura 2. Robot humanoide en una interacción con niños diagnosticados con TEA

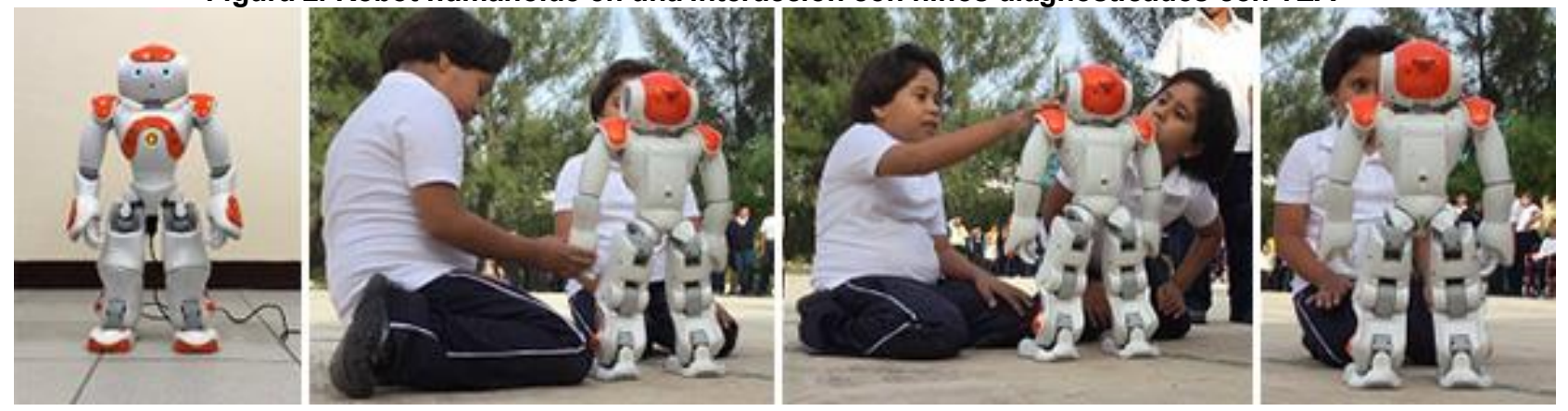

Nota. Primer contacto establecido de dos hermanos gemelos con TEA grado 3 y un robot humanoide durante la presentación del robot en su escuela primaria de educación especial en 2016. Fuente: elaboración propia.

Uno de los métodos más efectivos, que se han documentado, para modificar la conducta en niños con TEA es el análisis aplicado de la conducta (ABA), basado en promover acciones mediante refuerzos positivos a partir de la supresión de las consecuencias positivas (Medavarapu et al., 2019; Mulas et al., 2010; Peters-Scheffer et al., 2011). Se ha descrito que, para aplicar adecuadamente el método ABA se deben establecer los repertorios básicos ${ }^{13}$ (Galindo et al., 2009; Rebollo \& Montiel, 2006; Robins et al., 2005). Particularmente en el equipo con el que se ha trabajado esta tesis se desarrollaron tres de esos repertorios: 1) atención, 2) imitación, y 3) seguimiento de instrucciones (Arias-Aguilar et al., 2017); identificando que el establecimiento de los repertorios básicos es necesario porque facilita la adquisición de otras conductas de adaptación como la socialización e independencia personal.

De acuerdo con la literatura, actualmente se siguen explorando argumentos que permitan complementar e incluso refutar o validar alguna de las teorías propuestas. En este proyecto se buscó ampliar la explicación de la teoría de la mente y la línea de la teoría de déficit de funciones ejecutivas (FE), que implica la falta de habilidades para dirigir la conducta hacia una meta, de la que la consciencia también forma parte. Como se mencionó en la delimitación referencial, la autoconciencia o autoanálisis es la forma a través del cual la persona valora sus experiencias subjetivas para emplearlas en la resolución de problemas y guiar la toma de decisiones de su presente.

La integración de la consciencia y su relación con las FE - a partir de la significación que los niños con TEA dan a un entorno determinado durante la interacción cognitiva con NAO, y,

${ }^{13}$ Cuando los repertorios básicos no son adquiridos de manera natural, la inducción de los mismos, ayuda de manera sustancial a los niños para adquirir conductas nuevas, moldeables y socialmente adaptadas (Király et al., 2013), como es el caso de niños con TEA (Girardot et al., 2009). 
considerando la teoría de la mente-, permite explorar los diversos escenarios en los que los niños se identifican con los estados mentales de otros.

Concretando la problemática, más allá de lo que subyace al TEA, el desarrollo de los infantes seguirá dependiendo de las herramientas que tengan para adaptarse (de la mejor manera) a su entorno. La enseñanza de habilidades, la estimulación e integración sensorial, personal o social, permitirá un manejo más digno y certero dentro de la sociedad. Así, la aportación de esta tesis está enfocada en el desarrollo de escenarios artificiales que ayuden al niño a adecuarse a situaciones que requieren de su flexibilidad adaptativa y del control de su baja tolerancia a la frustración.

Con el uso de un robot humanoide como vehículo de interacción asistida con niños con TEA (Ackovska et al., 2017; Warren et al., 2015; Zheng et al., 2013), se ha facilitado la observación de la socialización de los niños con el robot mientras ejecutan tareas de FE. A partir de dichas interacciones se propuso un modelo de dificultad creciente que permite poner en práctica las FE de los niños, considerando su grado de afectación de TEA. El modelo se asocia con la inducción y el análisis de las reacciones cognitivas de los niños. Los escenarios implementados con el robot humanoide NAO, con el que se ha buscado un intercambio social de comunicación recíproca, acortaron la distancia que suelen interponer los niños con TEA cuando se encuentran en situaciones que no entran en su repertorio de intereses.

Con ello se buscó identificar los patrones de conducta que permitan predecir comportamientos sociales negativos en los niños y, al mismo tiempo, identificar las FE que se activan o desactivan cuando requieren poner en práctica su flexibilidad adaptativa con el entorno. La conducta de los niños fue analizada a través del proceso de significación de la semiótica.

\subsection{Justificación del problema}

Con la inclusión de la tecnología en la educación se han ampliado las expectativas de mejora en la atención a la discapacidad (Ortega, 2014). Su incursión ha logrado establecer nuevos recursos didácticos para aumentar las posibilidades de aprendizaje de los usuarios, a partir del uso de códigos auditivos/verbales, visuales, icónicos/simbólicos, táctiles y quinestésicos.

Antes de que el sistema educativo se planteara la necesidad de facilitar el acceso al aprendizaje de los estudiantes, el mundo se organizaba con base en las necesidades de las mayorías. Excluía la incorporación de personas que salían de la norma (estadística) y que por falta de un equipo sensorial, motriz o cognitivo era imposible adecuarse a su entorno. 
Actualmente, la llamada tecnología educativa tiene mayores posibilidades de ser puesta al servicio de la educación (Tentori et al., 2015).

La creación de escenarios artificiales para el uso de las FE en niños con TEA, asociados a reacciones emocionales y cognitivas, pretende aportar soluciones en tres ámbitos: 1) un impacto positivo de la tecnología robótica aplicada a la educación especial a través de la manipulación de ambientes artificiales; 2) la identificación de procesos de significación y de comunicación como producto del diseño multisensorial, visual y auditivo, puestos en práctica con usuarios especiales, y 3) la comprensión del estado emocional y cognitivo de niños con TEA en contextos hipotéticos de consciencia artificial y consciencia humana relacionados a través de escenarios de interacción. 


\subsection{Objetivos, metas y metodología}

A continuación, se exponen los objetivos e hipótesis que dieron pauta al desarrollo de esta investigación, y, esquemáticamente, se muestra su relación con la metodología, las técnicas y las metas. En el capítulo dos y tres se menciona de manera explícita el establecimiento del marco teórico referencial y metodológico. En la Tabla 1 se pueden apreciar las relaciones de los tres aspectos metodológicos.

\subsubsection{Objetivo general}

Describir, visualizar y analizar el comportamiento de niños con TEA y su flexibilidad adaptativa, a partir del empleo de sus FE y el nivel de consciencia mientras interactúan con un robot humanoide empleado como vehículo de interacción asistida para generar un modelo de interacción cognitiva.

\subsubsection{Objetivos específicos}

1. Identificar, examinar y caracterizar los comportamientos restringidos y repetitivos de los usuarios, el grado de interacción social recíproca, y el grado de alteración de la comunicación social de niños con TEA de grado 1, 2 y 3 . Lo anterior con el fin de establecer los parámetros susceptibles para la implementación interactiva niño-robot humanoide.

2. Identificar el grado de interacción social recíproca y el grado de alteración de la comunicación social de los niños con TEA candidatos a participar en la investigación. Diagnóstico psicométrico del uso de las FE y de la disposición de socialización de los participantes.

3. Definir, adaptar y aplicar las actividades de desempeño ejecutivo relacionadas con las FE que pueden ser implementadas en interacción humano-humano.

4. Describir y adaptar los criterios mínimos para formar una condición básica en el establecimiento de una interacción niño-robot humanoide a partir de interacciones humano-humano.

5. Caracterizar y analizar el desempeño ejecutivo de los niños con TEA estableciendo las bases de la simulación interactiva niño-robot humanoide considerando tareas de significación, de comunicación y de interacción cognitivo- afectiva en el uso de FE. 
6. Evaluar el desempeño de los niños con TEA en repertorios básicos (atención, imitación y seguimiento de instrucciones) a partir de la interacción niño-robot humanoide.

7. Evaluar el desempeño de los niños con TEA en el uso de FE a partir de la interacción niño-robot humanoide asociadas a un nivel de consciencia.

8. Diseño y desarrollo de modelo de interacción niño-robot humanoide integrado en niveles de interacción. 


\subsubsection{Relación de objetivos específicos y metodología}

Tabla 1. Objetivos, metodología y metas

\section{Objetivos específicos}

Metodología

\begin{tabular}{c} 
Metodología \\
\hline Etapas Técnicas / herramientas
\end{tabular}

Etapa 1

Definición de usuarios Observación no
participante

\section{Metas}

Obj. 1 Caracterizar los comportamientos restringidos y repetiti
los usuarios (niños con TEA)
Aplicación de pruebas psicométricas destinadas interacción social recíproca y el grado de alteración de la comunicación social de los niños con TEA candidatos a participar en la investigación. Diagnóstico psicométrico del uso de las FE y de la disposición de socialización de los participantes

\section{al diagnóstico, grado de}

Etapa 2 Selección de muestra
TEA, uso de FE y nivel de socialización. Escenarios de interacción con NAO y niños con TEA
1. Lista de comportamientos restringidos $y$ repetitivos de los niños con TEA.
2. Muestra de niños con TEA diferenciados por su grado de alteración de la comunicación social (capítulo 3 )

3. Comprobación diagnóstica de participantes a través de perfil psicométrico (capítulo cinco)
Obj. 3 Definir, adaptar y aplicar actividades de desempeño ejecutivo para explorar FE en interacción humano-humano
Etapa 3. Bases para la implementación del modelo de interacción
Técnicas y herramientas de usabilidad
4. Gestión del desarrollo materiales didácticos para explorar FE a través de vehículos de significación (productos de tesis de licenciatura, Capítulo 4.)

5. Guía de procedimiento de desempeño ejecutivo para la interacción considerando actividades de $\mathrm{FE}$ (Anexo 4)

Obj. 4 Describir y aplicar criterios de interacción humano-humano para interacciones niño-robot humanoide.

Obj. 5 Caracterizar, evaluar y analizar el desempeño ejecutivo de los niños con TEA de nivel 1 y nivel 2.

Obj. 6 Evaluar el desempeño en repertorios básicos (atención, imitación y seguimiento de instrucciones) de niños con TEA a partir de la interacción niñorobot humanoide

Obj. 7 Evaluar el desempeño en FE de niños con TEA a partir de la interacción niño-robot humanoide
Procedimiento de desempeño ejecutivo para interacción humanohumano

Etapa 4 Implementación y evaluación de interacción humano-humano y niño-robot humanoide
Obj. 8 Correlacionar y visualizar la relación de objetivos 4,5 y 6 para integrar una explicación del proceso de significación de los niños con TEA

Obj. 9 Diseño del modelo de interacción niño-robot humanoide
Etapa 5. Aplicación y propuesta de interacción
Adaptación de protocolo de repertorios básicos

Manual de procedimiento de desempeño FE para interacción niño-robot humanoide
6. Caracterización de conductas del desempeño ejecutivo en interacción humano-humano (resultados en Capítulo 5)

7. Caracterización de conductas en la interacción niño-robot humanoide en repertorios básicos (resultados en Capítulo 5)

8. Caracterización de conductas del desempeño ejecutivo en interacción humano-humano (resultados en Capítulo 5)

Técnicas de visualización

9. Resultados de interacción (resultados en Capítulo 5)

Herramientas del modelo cognitivo asociado a niveles de consciencia y FE
10. Modelo de interacción (resultados en Capítulo 6) 


\subsection{Hipótesis}

El empleo de un robot humanoide (NAO) como un vehículo de interacción asistido para explorar, caracterizar y visualizar el uso de las FE, la flexibilidad adaptativa de niños con TEA asociados a su nivel de consciencia - permitirá la implementación de un modelo de interacción cognitiva.

\subsubsection{Hipótesis nula}

La interacción afectiva implementada en un robot humanoide (NAO), a través del diseño de escenarios de interacción cognitiva, no favorece la exploración de las FE y la flexibilidad adaptativa de niños con TEA ni facilitan el análisis de las reacciones emocionales, las reacciones cognitivas y los patrones de comportamiento manifestadas por los mismos niños.

\subsubsection{Hipótesis alternativa}

La interacción afectiva implementada en un robot humanoide (NAO), a través del diseño de escenarios de interacción cognitiva, favorece la interacción con los niños TEA al presentarse como un estímulo significativo y relevante que logra captar su atención. No incide en el mejoramiento del uso de las FE y la flexibilidad adaptativa de niños con TEA ni favorece el análisis de las reacciones emocionales, las reacciones cognitivas y los patrones de comportamiento manifestadas por los mismos niños. 


\subsection{Aportaciones al diseño}

El campo de interacción humano-robot se deriva del campo humano-computadora. El diseño de escenarios comunicación destinados a establecer una relación entre niños con TEA y un robot humanoide se basó en la exploración de tres aspectos medibles y ponderados por la relación humano-computadora: 1) eficiencia, 2) eficacia, y 3) satisfacción. El diseño de estos escenarios se realizó con el fin de encontrar hallazgos para facilitar el uso de las FE y la flexibilidad adaptativa de los niños.

Como ya se mencionó en el preámbulo, entre las características diagnósticas de las personas con TEA (sobre todo en la primera infancia) uno de los mayores problemas que viven tanto los niños como sus familias es la baja tolerancia al cambio o flexibilidad adaptativa, así como su bajo interés y disposición para socializar con las personas. La problemática se ha estudiado desde distintos enfoques, y desde el ámbito del diseño la aportación se ha centrado en las posibilidades que ofrece la "visualización" para brindar distintas miradas del fenómeno.

El trabajo que se presenta es de carácter transdisciplinario. Parte del diseño como eje rector que estructura la problemática y brinda una aproximación integradora. En la Figura 3 se señalan cuatro momentos clave: diseño, inteligencia artificial asociada a la robótica y psicología relacionada con la cognición y el comportamiento etológico. En el transcurso de la exposición de la tesis se describe cada uno.

El diseño aportó los elementos para elaborar los materiales que sirvieron como vehículos de significación y de comunicación, los cuales surgieron a partir de las pruebas elaboradas para la creación de materiales didácticos desarrollados por estudiantes de licenciatura. En la Figura 3, los elementos marcados como R1, R2, R3, R4 y R5 representan los resultados de las fases de investigación.

- R1, asociado a la etología como acercamiento a los niños con TEA.

- R2, representa las herramientas y objetos desarrollados para implementar las interacciones con los niños y con el robot humanoides.

- R3, relacionado con la psicología. Corresponde a las tareas que se desarrollaron para las

FE y que fueron probadas por medio de interacción humano-humano. A partir de estos se establecieron niveles de complejidad creciente de las tareas.

- R4, corresponde a la aplicación de los cinco axiomas de Igor Aleksander. A partir de los resultados se propuso un modelo de interacción cognitiva.

- R5, es la propuesta de una interacción por niveles. 
Figura 3. Relación entre las áreas de conocimiento involucradas en esta investigación

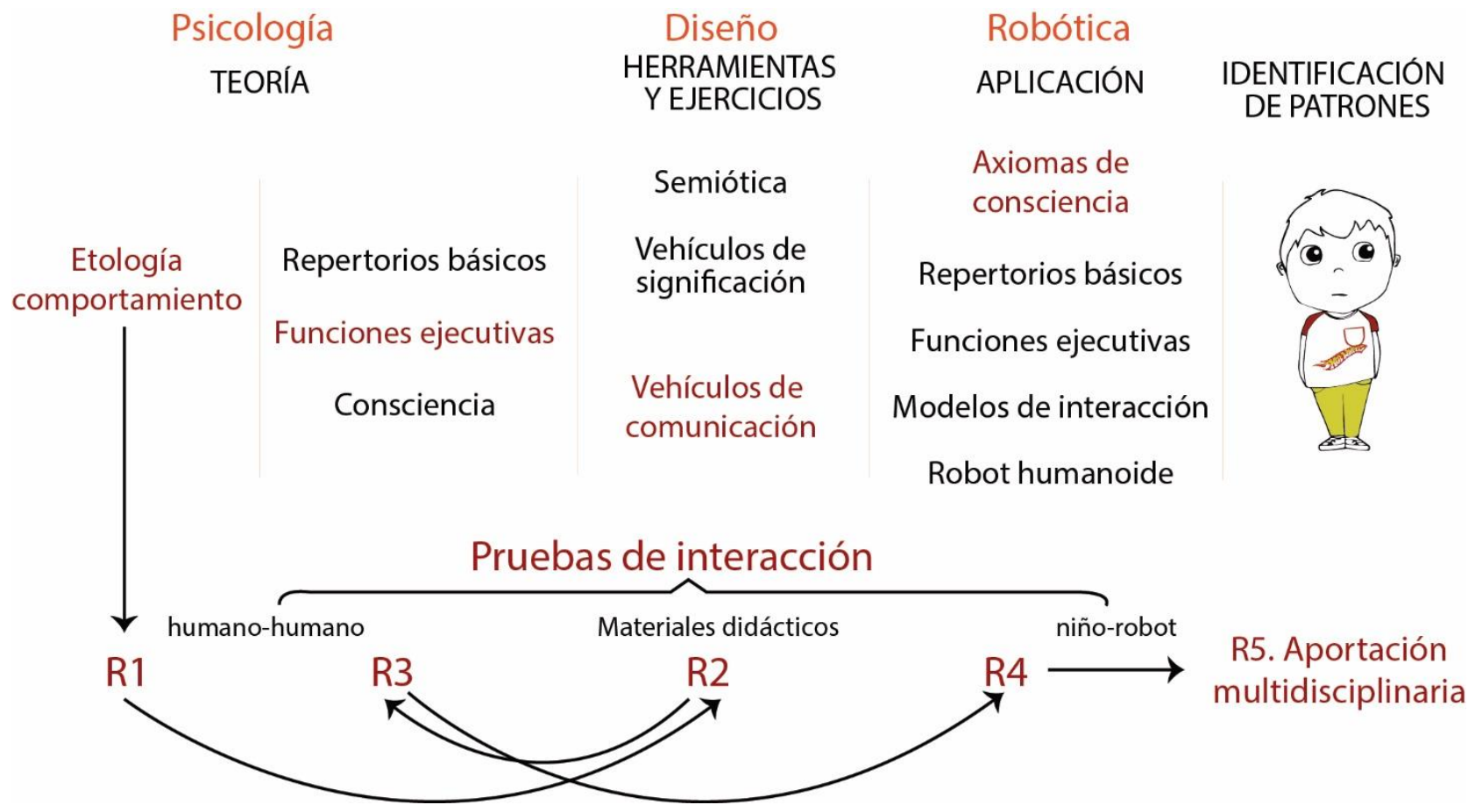

Nota. Datos complementarios. Se presenta la relación de las áreas de investigación en el proyecto: Psicología, Diseño, y Elementos de robótica. En color rojo se marcan los resultados enumerados como R1, R2, R3, R4 y R5. Fuente: elaboración propia.

1. Identificación del proceso de significación de los usuarios para establecer los modelos mentales que podrían ser empleados para la creación de los escenarios implementados en el robot humanoide.

2. Diseño de objetos llamados vehículos de comunicación o materiales didácticos para el desarrollo de las FE de los niños con TEA. En esta etapa se especificó el perfil de los usuarios, las tareas que requerían hacer y los escenarios de uso.

3. Un tercer momento en el que se denota la participación del diseño combinado con la psicología, parte de la visualización de la información ofrecida a los niños para que fuera significativo para ellos interactuar en un mismo espacio con una persona ajena a su contexto cotidiano. En ese sentido, la visualización de los comportamientos de los niños permitió que se integraran los cinco niveles de consciencia de Igor Aleksander (Aleksander, 2005). Así, la identificación de los signos significativos para los niños fue una tarea que dependió de la forma en la que se estableció la relación primaria con ellos para posteriormente hacer una 
propuesta del modelo mental que favorecería la interacción entre los niños y el robot humanoide.

4. El cuarto momento aborda el análisis de los resultados, en los que se integran los datos psicométricos y la caracterización diagnóstica de los usuarios, del desempeño ejecutivo, de las tareas de FE, del desempeño que tuvieron en las tareas de repertorios básicos (atención, imitación y seguimiento de instrucciones) a partir de la interacción niño-robot humanoide, y de las evaluaciones de FE en interacción con el robot humanoide. 


\subsection{Estructura de la tesis}

La estructura de la tesis se compone de ocho capítulos. En el capítulo uno se presenta la introducción y la base de la estructura metodológica. En el capítulo dos, se desarrollan cinco apartados denominados elementos de anclaje teórico referenciales (EATR). En ellos se describen las perspectivas teóricas relacionadas con: los criterios diagnósticos del TEA, las teorías que lo explican, los procesos de significación asociados a la percepción, la cognición, la atención y el fenómeno de la consciencia. También se menciona el uso y la importancia de las FE en la vida de las personas, particularmente para las personas con TEA. Y, finalmente, se presentan las bases para el desarrollo de un modelo de interacción cognitiva adaptado a tareas dirigidas por un robot-humanoide empleado como un vehículo de interacción asistida.

El capítulo tres desglosa el método, la definición de variables, la hipótesis y los parámetros de inclusión-exclusión de los usuarios participantes, así como el procedimiento. Además, se expone el proyecto de investigación presentado como un diseño no experimental transversal de tipo causal-correlacional aplicado desde un enfoque mixto cualitativo-cuantitativo.

En el capítulo cuatro se realiza la descripción y el seguimiento de la implementación del modelo de interacción; en ese capítulo se describe la implementación de: repertorios básicos, tareas para ejercitar las FE y los niveles de consciencia centrados en los axiomas de lgor Aleksander. Además, se presentan los resultados previos de la comprobación de las hipótesis relacionadas con evaluación psicométrica, la evaluación de la interacción con los niños.

En el capítulo cinco se presenta la configuración del modelo de interacción. Se explican cuatro niveles basados en el análisis semiótico: impronta, significación, comunicación y de FE. Allí también se definen las variables y los módulos de interacción que integran las FE empleadas durante la actividad asistida con un robot humanoide.

En el capítulo seis se muestra el resultado de las interacciones de los niños con TEA y el robot-humanoide.

En el capítulo siete, se desarrolla la discusión basada en los resultados y en los EATR planteados en el capítulo tres; se mencionan las aportaciones al diseño y al objeto de estudio.

Finalmente, en el capítulo ocho, se presentan las conclusiones y se sugieren algunas líneas futuras de investigación. La bibliografía y los anexos se muestran en la última parte de este escrito. 


\section{Elementos de anclaje teórico referenciales}

El desarrollo de las ideas y la construcción de esquemas de investigación para edificar el conocimiento están estrechamente enlazados con los referentes teóricos a los que se apegan para su discernimiento. En esta investigación esos referentes teóricos se denominan elementos de anclaje teórico referenciales (EATR). El objetivo de exponerlos de esta manera es brindar una estructura teórica transdisciplinaria ${ }^{14}$ que soporte el proceso de abducción ${ }^{15}$ (Aguayo W. Pablo, 2011; Eco, 1989) al que se quiere llegar, dejando pautas para continuar con el desarrollo de otras líneas de investigación en las distintas áreas.

Como se mencionó en la introducción, los EATR que integran esta sección se centran en las disciplinas involucradas en los procesos que acompañan el comportamiento de niños con trastorno del espectro autista (TEA) en el uso de sus FE suscitadas a partir de interacciones con un robot humanoide. La estructura del capítulo sigue el planteamiento expuesto en la introducción en la que se consideran cinco etapas de la investigación: 1) caracterización diagnóstica; 2) proceso de significación; 3) definición y adecuación de FE relacionadas con niveles de consciencia; 4) definición de sistemas interactivos puntualizando la interacción niño-robot humanoide, y 5) bases para el desarrollo de un modelo de interacción cognitiva. Cada una de ellas se suscribe a alguna de las dimensiones empírica, teórica, metodológica o epistemológica del objeto de estudio que integran la investigación, y que fueron esquematizados en la introducción en la Figura 1 del preámbulo.

- EATR 1. Caracterización diagnóstica: apuntes para el diseño universal, incluyente y la discapacidad. Este apartado inicia con apuntes para el diseño universal e incluyente. Se presentan datos básicos para definir la discapacidad y las medidas que se han tomado desde el diseño para hacerlo universal e inclusivo. Se describen las características y criterios diagnósticos del TEA, y, se expone como

${ }^{14}$ La transdisciplina descrita en el manifiesto de Nicolescu (Nicolescu, 2002), es un punto al que la ciencia se ha ido acercando cada vez con mayor velocidad en los últimos tiempos. En el ámbito de la educación la transdisciplina reevalúa "el rol de la intuición, de lo imaginario, de la sensibilidad y del cuerpo, en la transmisión de conocimiento" de cualquier disciplina a partir de la apertura a los distintos saberes que configuran una nueva visión de un mismo objetivo y con ello diversas formas de resolverlo (Obra consultada en español publicada el 6 de noviembre de 1994. Con el comité de Redacción: Lima de Freitas, Edgar Morin y Basarab Nicolescu).

15 "La abducción permite inferir algo de tipo distinto a lo que hemos observado directamente y, con frecuencia, algo que sería imposible observar directamente, la inducción sólo permite inferir la existencia de fenómenos iguales a los que hemos observado en casos similares. De este modo, con la abducción podemos ampliar el alcance de la semejanza entre individuos, mientras que con la inducción sólo podemos ampliar el conjunto de individuos semejantes" (Aguayo W. Pablo, 2011, p. 8). 
una de las discapacidades que, socialmente, ha tenido una progresión de incidencia ascendente de más de 70 años.

- EATR 2. Proceso de significación en el TEA. En este apartado se exponen los elementos básicos del proceso de la significación y la comunicación desde el punto de vista de la semiótica. El proceso se relaciona, en el capítulo cuatro, con la selección y desarrollo de herramientas empleadas en el diseño de los vehículos de comunicación para facilitar las tareas de interacción de los niños con TEA y el robot humanoide. Los conceptos y procesos que se describen son la base para explicar los distintos niveles propuestos en el modelo cognitivo de interacción.

- EATR 3. Cognición, FE y consciencia. Se establece el estado del arte relacionado con la definición y adecuación de FE relacionadas con el procesamiento sensorial, perceptivo, la atención, cognición y el acceso consciente. Se expone su participación en la capacidad de una persona para dar relevancia o no a los estímulos internos, circundantes y planificar en torno a ellos. Se delimitan las FE que se pueden evaluar en los niños con TEA en una condición de interacción con el "robot humanoide".

- EATR 4. Modelos de interacción humano-humano y niño-robot humanoide. En este apartado se presentan la definición de sistemas interactivos y las características que, de acuerdo con la literatura, se consideran para la planeación de interacciones humano-humano y niño-robot humanoide para el establecimiento de un modelo de interacción cognitiva.

- EATR 5. Modelos de interacción cognitiva. En este apartado se presentan las bases para el desarrollo de la interacción cognitiva relacionada con la consciencia de los niños con TEA, centrados en el uso de sus FE. Se retoma la aproximación que propone Laureano-Cruces al modelo de consciencia de Igor Aleksander y de Marvin Minsky (Laureano-Cruces et al., 2013, 2015, 2018). 
2.1 EATR 1. Caracterización diagnóstica. Apuntes para el diseño universal e incluyente, discapacidad y el trastorno del espectro autista

Antes de que el sistema educativo planteara la necesidad de facilitar el acceso al aprendizaje de los estudiantes que requirieran apoyos extra, el mundo se organizaba de acuerdo con las necesidades de las colectividades. Se excluía la incorporación de personas que salían de la norma (estadística) que, por falta de un equipo sensorial, motriz o cognitivo, era imposible adecuarse a su entorno. Daumas Maurice (1996) lo ejemplifica perfectamente en su breviario de las grandes etapas del progreso técnico, en el que expone las necesidades que cubrían los objetos utilitarios, que eran adecuados por las mayorías, desde épocas primitivas hasta su desarrollo actual.

Hoy en día la tecnología ha marcado la pauta del desarrollo de nuevos objetos que satisfacen las necesidades humanas. Por ello, ha sido importante establecer metodologías que permitan, de manera más amplia, ofrecer soluciones adecuadas al mundo en el que viven más de mil millones de personas con discapacidad (Elsabbagh et al., 2012; Organización Mundial de la Salud, 2019). Lo que significa alrededor del 13\% de la población mundial.

Clarkson \& Coleman (2015) mencionan que desde hace más de treinta años, se ha desarrollado un enfoque de diseño en el que se favorece la inclusión de un mayor número de personas, como una alternativa para reducir las barreras y las dificultades de las personas que viven con discapacidad.

La problemática del TEA claramente está dentro de los parámetros actuales de la discapacidad y, por lo tanto, el tipo de diseño que se proyecta para dicha población debería ser considerada como especial. Debido a ello, este apartado inicia con la exposición de la tendencia actual de hacer productos $u$ objetos con carácter universal e inclusivo, sobre todo considerando que el Trastorno del Espectro Autista es una de las discapacidades que mayor crecimiento ha tenido en los últimos 50 años (Agostini et al., 2017; OMS, 2019).

\subsubsection{Principios del diseño universal o inclusivo}

El diseño universal e inclusivo, es una propuesta desarrollada desde hace algunos años con el fin de asegurar que los productos o servicios respondan a las necesidades de la mayor parte de la audiencia, independientemente de la edad o habilidad de la que se trate.

La investigación en diseño inclusivo implica el desarrollo de herramientas y directrices con el fin de que los productos o tecnologías sean accesibles para un amplio rango de la población. 
El diseño universal es un término acuñado por Ronald L. Mace, en 1984 en EE.UU. Describió principios de aplicación a los productos que posteriormente propusieron él y un grupo llamado "defensores del diseño universal" (Connell et al., 1997).

Estos principios coinciden en gran parte con algunas otras metodologías como la del diseño centrado en el usuario, que actualmente dirigen el desarrollo de productos tecnológicos. El otro término y postura desarrollada con un enfoque similar es el diseño inclusivo, propuesto en Inglaterra (Clarkson \& Coleman, 2015). Su objetivo también es el de optimizar los recursos de diseño para beneficiar a un mayor número de personas.

Ambas posturas, tanto el diseño universal como inclusivo, dieron origen a la regulación legislativa en beneficio de las personas y del uso de los productos considerando un mayor rango de habilidades para su uso eficiente; por tal motivo, en esta investigación se nombran indistintamente, y es considerada como una perspectiva del diseño que favorece la adecuación de los productos basados en capacidades físicas, cognitivas o sensoriales, lo cual ha permitido visibilizar las limitaciones individuales y favorecer el uso de diversos canales sensoriales o de apoyo físico para beneficio de todos.

El concepto es relevante para esta investigación por razones que sobrepasan la obviedad: la población clave con la que se trabajó — personas con TEA-, tiene características bien definidas de acuerdo con parámetros diagnósticos; sin embargo, también presentan un amplio rango de características sensoriales, perceptuales, de destreza motriz, cognitiva y de intereses fijos poco flexibles, que los lleva a ser parte de un grupo no homogéneo con un rango de posibilidades y necesidades diversas (Hasegawa et al., 2015; Moya Albiol et al., 2019; Rivière, 1997; Tirapu-Ustárroz \& Luna-Lario, 2011), colocándolas en un sector de la discapacidad. Elemento que abordaré a continuación.

\subsubsection{Discapacidad}

Definir la discapacidad inevitablemente remonta a un dilema social en el que se cree que una persona que no está física o mentalmente como la mayoría de las personas es discapacitada o minusválida ${ }^{16} \mathrm{o}$, por otro lado, puede llevar a la idea de que todos los seres humanos, en

\footnotetext{
${ }^{16}$ Al respecto, se considera que la definición de discapacidad tiene un recorrido histórico que se debería revisar para entender los distintos enfoques que la sociedad ha dado al término y cómo éste se ha asociado con el bienestar social de una persona (Palacios, 2015).
} 
determinado momento de su vida, se encuentran en situaciones en las que no tienen la misma capacidad que otros para responder o adaptarse al entorno ${ }^{17 .}$

La Organización Mundial de la Salud (OMS, WHO por sus siglas en inglés) considera que la discapacidad es un término general que abarca las deficiencias, las limitaciones de la actividad y las restricciones de la participación. Como se describió al inicio de este capítulo, se ha considerado a la discapacidad como una dificultad que limita la realización de determinadas tareas o acciones para participar en situaciones vitales dentro de la sociedad en la que vive.

\subsubsection{Concepto de salud y enfermedad}

La clasificación internacional de enfermedades (CIE en español, o ICD por sus siglas en inglés) fue conferida a la Organización de Naciones Unidas (ONU) en 1948 por el Instituto Internacional de Estadística. A partir de ese momento la ONU se encarga del seguimiento del contenido de la publicación que refleja a nivel mundial los avances que se tienen en el ámbito de la salud y de la ciencia médica. La CIE ha sido adoptada por los más de 100 países pertenecientes (WOH, 2018). La última edición fue publicada el 18 de junio de 2018, denominada CIE-11 y asociada a la Clasificación Internacional del Funcionamiento, de la Discapacidad y de la Salud (CIF) aprobada en 2001 (Organización Mundial de la Salud \& Organización Panamericana de la Salud, 2001).

El concepto de la salud y la enfermedad que maneja la CIF es interesante e importante, debido a que desde esta perspectiva se propone la intervención y análisis de los resultados obtenidos. Para la CIF, la salud y la enfermedad son consideradas como un continuo que depende de tres características:

1. Funciones y estructuras

2. Actividades

3. Nivel de participación

Este enfoque asume que cuando una persona con funciones o estructuras limitadas (considerada con discapacidad) tiene oportunidad de realizar todas sus actividades de manera independiente, sin ayuda de los demás y su nivel de participación social tampoco se ve imposibilitado, entonces la persona no debería ser vista con discapacidad.

17 Un ejemplo del uso del término se encuentra en las personas con sordera profunda, a quienes en determinados contextos se les segregaba bajo la premisa de que no tenían capacidad para aprender. Mientras que, en otros contextos, como el caso de la isla Viña de Martha ubicada en Inglaterra, convivían personas no oyentes y normo oyentes compartiendo un lenguaje de señas que les permitía comunicarse, logrando que ninguno de los dos grupos se viera a sí mismo o a los demás como discapacitados (Deutcsh, 2003). 
A través de los años, y del conocimiento que se ha tenido de las personas con TEA, se ha identificado que, desde esta perspectiva de la CIF, las personas diagnosticadas dentro del TEA no deberían ser consideradas con una discapacidad si logran desarrollarse plenamente y, sobre todo, si logran ser independientes en su inserción y participación social.

\subsubsection{Trastorno del Espectro Autista}

Han transcurrido más de 70 años desde que Leo Kanner (Artigas \& Paula, 2012) describió por primera vez los rasgos del perfil autista. Entre los rasgos que él presentó, tres de ellos se han mantenido como rasgos fundamentales del autismo: aislamiento o pobre socialización, conductas repetitivas-estereotipadas y poca tolerancia al cambio (Artigas \& Paula, 2012; Asociación Americana de Psiquiatría, 2014; $\mathrm{WOH}, 2018)$. Actualmente, los criterios diagnósticos se agrupan en el TEA que, dicho sea de paso, es una condición que considera tantas variaciones como personas lo padecen.

Se ha descrito que los individuos diagnosticados con TEA presentan problemas de comunicación y dificultades para entender los códigos que emplean en su ambiente cotidiano y ocasional. Echeburúa (2014, p. 66) define los trastornos mentales como "patrones de comportamiento de significación clínica asociados a: un malestar emocional o físico de la persona, a una discapacidad, al deterioro en el funcionamiento cotidiano o a la pérdida de libertad". Internacionalmente existen dos clasificaciones válidas para determinar el tipo y grados de autismo. Una de ellas es dada por la Clasificación Internacional del Enfermedades, CIE versión 11 (WOH, 2018) y la otra es considerada en el manual de diagnóstico y estadística de enfermedades mentales DSM, versión 5 (Asociación Americana de Psiquiatría, 2014). Cada una de ellas tienen un esquema para determinar las características de las personas con TEA ${ }^{18}$, como se describe en el siguiente apartado.

18 Es preciso comentar que si el TEA no fuera considerado como una enfermedad tampoco formaría parte de los diagnósticos tipificados en el DSM o la CIF ni se abrirían opciones legislativas, educativas o de salud para su atención. Sin embargo, creo que si el TEA fuera catalogado como un estado continuo de salud enfermedad ayudaría a que la sociedad normalizara el comportamiento e incrementara su tolerancia hacia estas personas. Y se vería solo como una forma más de percibir el mundo propio y circundante. 


\subsubsection{Incidencia del TEA}

EI TEA es una condición que presenta uno de cada 160 habitantes en el mundo. La OMS (2019) reporta que la mayoría de los niños afectados son del sexo masculino en una proporción 1:4 o 1:5 (Christensen et al., 2019).

En los últimos diez años se ha detectado un incremento en la prevalencia del TEA (BaronCohen, 2012; Málaga et al., 2019). Esto a su vez, también ha elevado el interés por dar seguimiento a las tasas de incidencia de TEA en varias partes del mundo. Actualmente, solo se cuenta con un registro continuo desde 2010 en EE. UU, por lo que sus datos son tomados como un referente de incidencia. Del año 2000 a 2010 la proporción incrementó de 1:150 a 1:68, es decir, hubo un incremento del 54\%. La última cifra reportada en 2014 fue de 1:54 (Redfield et al., 2014). Mientras que en Europa a través del programa Autism Spectrum Disorders in the European Union iniciado en 2015, la incidencia detectada fue de 1:89 (AESDU, 2019). En México, el primer estudio formal y validado que se ha publicado acerca de la prevalencia de personas con TEA fue realizado en 2016 por Erik Fombonne considerando una población mixta rural y urbana (Fombonne et al., 2016, p. 1671) en la que se detectó una incidencia de 1:115.

De acuerdo con datos del Instituto Nacional de Estadística, Geografía e Informática (INEGI, 2014) alrededor de 190 mil niños de 0 a 9 años están en la condición del espectro autista, de ellos 152 mil son niños y 38 mil son niñas, manteniendo una proporción de género de 1:5.

El alza en las cifras, que hasta el momento se han registrado en varias partes del mundo, han impulsado investigaciones en el tema, durante más de 50 años (Artigas \& Paula, 2012; Chen et al., 2019; Posada-de la Paz et al., 2005). Las investigaciones han dado pauta al desarrollo de teorías y estudios multidisciplinarios que favorecen, por un lado, la explicación del trastorno y, por el otro, la identificación de estrategias o alternativas para atender a la población afectada.

En el caso de la conducta, cuando se habla de un "espectro" se refiere a la gran variedad de características, signos y síntomas similares, pero no idénticos, que afectan a las personas diagnostican con TEA. La coincidencia de algunos rasgos típicos de dichos signos o síntomas permite agruparlos en un solo diagnóstico, como se explica a continuación.

\subsubsection{Clasificaciones internacionales diagnósticas del TEA}

EI DSM-5 surgió como una necesidad de contar con un instrumento con que se pudieran medir las enfermedades o alteraciones de la conducta. Desde su creación en 1952 a la fecha se han publicado cinco ediciones (Barrio, 2009), y en cada una se han modificado algunas de las tipificaciones de las enfermedades mentales. La última versión (Asociación Americana de 
Psiquiatría, 2014) incluyó un cambio en los criterios diagnósticos del autismo, reduciendo los tipos de autismo a uno solo llamándole "trastornos del espectro autista" definidos como un parámetro no homogéneo de conductas pero con rasgos similares que los agrupan. Debido a que no tienen parámetros homogéneos, se considera la existencia de tantos tipos de TEA como personas, es decir, no existen casos iguales sino casos que comparten rasgos de comunicación, socialización y conductas repetitivas en tres niveles de gravedad determinados por el compromiso de ayuda que necesitan: requieren ayuda, requieren ayuda notable o requieren ayuda muy notable (Asociación Americana de Psiquiatría, 2014, p. 125) como se muestra en la Tabla 2.

Tabla 2. Niveles de gravedad del TEA

\begin{tabular}{|c|c|c|}
\hline Nivel de gravedad & Comunicación social & Comportamientos restringidos y repetitivos \\
\hline $\begin{array}{l}\text { Grado } 3 \\
\text { Necesita ayuda muy } \\
\text { notable }\end{array}$ & $\begin{array}{l}\text { Respuesta mínima a socializar con otras } \\
\text { personas, causandoles alteraciones } \\
\text { graves del funcionamiento. }\end{array}$ & $\begin{array}{c}\text { Inflexibilidad del comportamiento. Pesencia de extrema } \\
\text { dificultad para enfrentar los cambios y sus } \\
\text { comportamientos restringidos y repetitivos. Interfiere } \\
\text { notablemente en el funcionamiento en todos los } \\
\text { ámbitos, con dificultades para cambiar el foco de } \\
\text { atención. }\end{array}$ \\
\hline $\begin{array}{l}\text { Grado } 2 \\
\text { Necesita ayuda } \\
\text { notable }\end{array}$ & $\begin{array}{l}\text { Presentan deficiencias en las aptitudes } \\
\text { de comunicación verbal y no verbal. } \\
\text { Incluso con ayuda in situ tienen } \\
\text { limitaciones en el Inicio de la interacción } \\
\text { social, presentando respuestas } \\
\text { reducidas o poco comunes. }\end{array}$ & $\begin{array}{l}\text { Mantiene los mismos comprtamientos del grado } 3 \text { en } \\
\text { menor medida. No llegan a ser extremos, pero sí } \\
\text { resultan evidentes para el observador casual. La } \\
\text { manifestación de dicha conducta interfiere con el } \\
\text { funcionamiento en diversos contextos. Presenta } \\
\text { dificultad para cambiar el foco de atención }\end{array}$ \\
\hline $\begin{array}{c}\text { Grado } 1 \\
\text { Necesita ayuda }\end{array}$ & $\begin{array}{l}\text { Sin ayuda in situ las deficiencias en la } \\
\text { comunicación causan problemas } \\
\text { importantes. Puden parecer que tienen } \\
\text { poco interés en mantener la interacción } \\
\text { social. }\end{array}$ & $\begin{array}{l}\text { La inflexibilidad del comportamiento causa interferencia } \\
\text { significativa con el funcionamiento en uno o más } \\
\text { contextos. Los problemas de organización y } \\
\text { planificación dificultan la autonomía. }\end{array}$ \\
\hline
\end{tabular}

Nota. A menor grado de afectación mayor disposición de interacción (grados 1-3 siendo 1 el de menor afectación). Información retomada del Manual diagnóstico y estadístico de enfermedades mentales", American Psychiatric Association (2014) Edit.Panamericana.

EI TEA es considerado un trastorno o perturbación psíquica que involucra un síndrome: alteraciones en la cognición, la emoción o el comportamiento, y/o disfunción en los procesos psicológicos biológicos o del desarrollo, dificultando su integración a la vida social o laboral. Se ubica dentro de los trastornos del neurodesarrollo y es caracterizado por iniciar en el periodo de crecimiento, lo que implica que haya rezagos en el desarrollo de acuerdo con la edad cronológica de las personas provocándoles alteraciones en diversas áreas del funcionamiento intelectual (Figura 4). 
Figura 4. Clasificación de trastorno mental y trastorno del neurodesarrollo

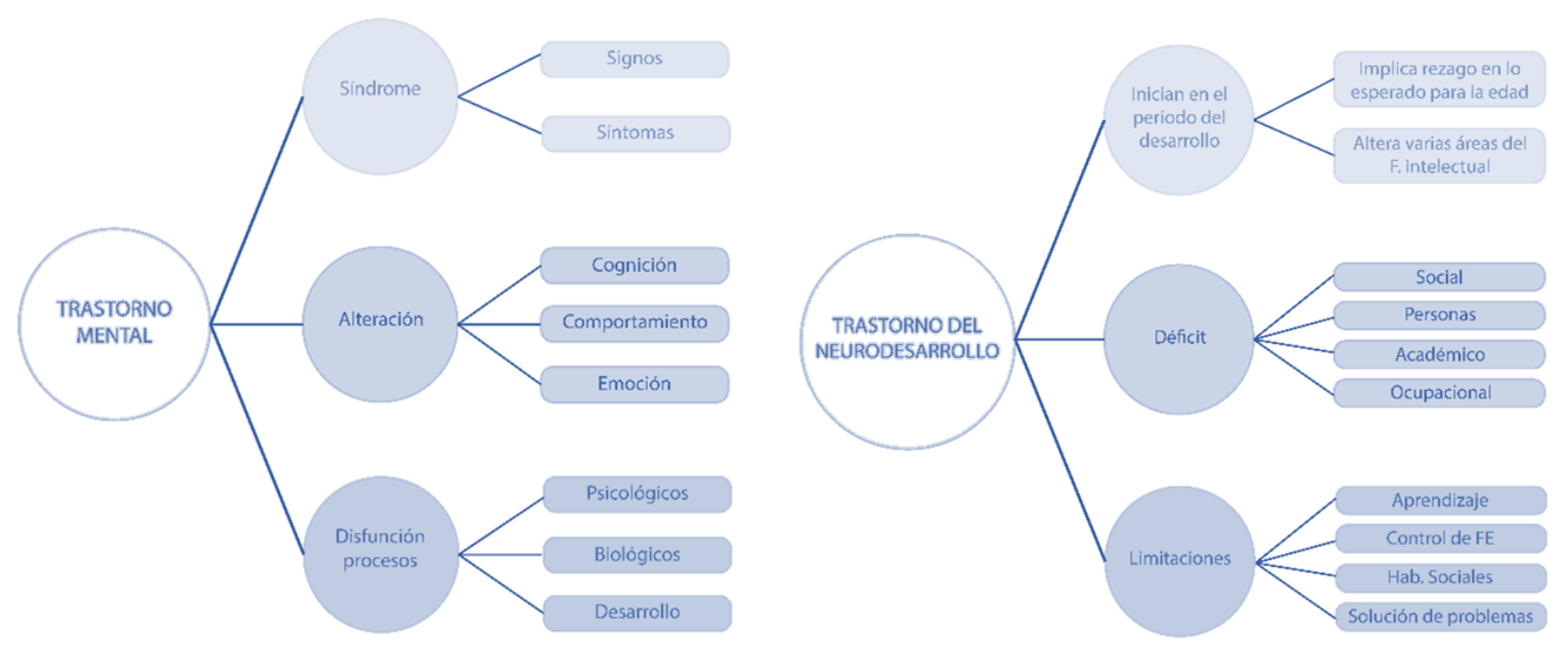

Fuente: elaboración propia.

Otras de las problemáticas que viven las personas con TEA se presentan en el ámbito social, personal, académico u ocupacional; ocasionándoles limitaciones en el aprendizaje, en el control de las FE, las habilidades sociales y la solución de problemas. En la Tabla 3 se presentan los cinco criterios diagnósticos considerados en el DSM-5.

\section{Criterio A}

Tabla 3. Criterios diagnósticos de TEA

Deficiencias persistentes en la comunicación social y en la interacción social en diversos contextos, manifestado por lo siguiente, actualmente o por los antecedentes (los ejemplos son ilustrativos, pero no Criterio B exhaustivos).

Patrones restrictivos y repetitivos de comportamiento, intereses o actividades, que se manifiestan en dos o más de los siguientes puntos, actualmente o por los antecedentes (los ejemplos son ilustrativos, pero

\section{Criterio C} no exhaustivos).

Los síntomas deben de estar presentes en las primeras fases del período de desarrollo (pero pueden no manifestarse totalmente hasta que la demanda social supera las capacidades limitadas, o pueden estar

\section{Criterio D} enmascarados por estrategias aprendidas en fases posteriores de la vida).

\section{Criterio E}

Los síntomas causan un deterioro clínicamente significativo en lo social, laboral u otras áreas importantes del funcionamiento habitual.

Estas alteraciones no se explican mejor por la discapacidad intelectual (trastorno del desarrollo intelectual) o por el retraso global del desarrollo. La discapacidad intelectual y el trastorno del espectro autista con frecuencia coinciden; para hacer diagnósticos de comorbilidades de un trastorno del espectro autista y discapacidad intelectual, la comunicación social ha de estar por debajo de lo previsto para el nivel general de desarrollo.

Fuente: Clasificación del DSM-5 (APA, 2014). 
Las discapacidades que están dentro del trastorno del neurodesarrollo comparten algunas características generales, que en ocasiones pueden estar combinadas o en comorbilidad, es decir que dos o más trastornos se asocian a la misma persona de manera simultánea o desfasada. La comorbilidad es una de las razones por las que en esta investigación se consideró realizar una exploración psicométrica aplicada directamente a los niños o a través de sus familias. El objetivo fue validar y determinar en qué medida los niños participantes tenían rasgos característicos del diagnóstico del TEA. Con ello se aseguró tener un parámetro de comparación unificado, para posteriormente correlacionarlo con los resultados finales obtenidos de las interacciones robot humanoide-niño. De momento, sólo se expone esta cuestión como una necesidad que se tuvo durante el estudio. En el capítulo siguiente, donde se presenta el marco metodológico, se fundamentan las pruebas empleadas, el procedimiento de aplicación y su interpretación.

\subsubsection{Implicaciones diagnósticas del TEA}

Tanto la CIE-11 como el DSM-5, adoptaron el término TEA para definir los rasgos autistas que presentan algunas personas. Es definido como un trastorno del desarrollo neurológico caracterizado por tener deficiencias persistentes en la capacidad de iniciar y mantener la interacción social recíproca y la comunicación social, y por una gama de patrones de comportamiento e intereses restringidos, repetitivos e inflexibles. Estas peculiaridades pueden causar deterioros en todas las áreas de la vida de una persona, ya sea en lo individual, en el círculo familiar, social, educativo, laboral u otras esferas importantes de funcionamiento.

Por su parte, el DSM-5 (Asociación Americana de Psiquiatría, 2014, p. 128) define el TEA como un trastorno del desarrollo neurológico manifestado a través de comportamientos repetitivos, notable dificultad para comunicarse y para la interacción social. De acuerdo con los criterios diagnósticos del DSM-5, los sujetos que están dentro del espectro autista tienen dos características sobresalientes, que coinciden con los criterios A y B de la Tabla 3: 1) alteración cualitativa en la interacción social recíproca y en la comunicación, y 2) patrones de conducta, intereses y actividades limitadas, repetitivas y estereotipadas. Dichas particularidades en ocasiones se convierten en una barrera infranqueable para comunicarse, interpretar o acompañar a las personas que lo padecen.

En este contexto, resulta conveniente identificar las habilidades que requieren ser fortalecidas en las personas que viven en la condición del autismo. Por esta razón la tesis siguió un esquema en el que se buscó en todo momento interactuar con los niños o usuarios con TEA, desde sus propias habilidades y fortalezas, más que desde sus carencias. A partir de este 
enfoque, lo primero que se buscó fue identificar los procesos que subyacen a la conducta de las personas que viven con dicha circunstancia, aplicando un enfoque naturalista que, al estar implementado en entornos naturales, implica un control compartido entre el niño y el terapeuta; además, se utilizan contingencias naturales y una variedad de estrategias de comportamiento (Schreibman et al., 2015; Szumski et al., 2019). Este enfoque es un tipo de intervención no biológica, dirigida, entre otras, a las relaciones interpersonales, la comunicación y el juego (Medavarapu et al., 2019, p. 12; Myers et al., 2007). Una de las técnicas que se han empleado para colectar y analizar los datos que surgen de las intervenciones naturalistas es la etología cognitiva $^{19}$ (Osborne-Crowley, 2020; Perinat Maceres, 1980; Tinbergen, 1975), como se describe en el capítulo cuatro. De tal forma que uno de los elementos clave por los que empezó la exploración e identificación de habilidades fueron los procesos de significación de la población con la que se trabajó. Las bases fueron tomadas de las conductas y procesos mentales que describen las propuestas teóricas relacionadas con el TEA.

\subsubsection{Teorías relacionadas con el TEA}

En la delimitación semántica se introdujeron las teorías propuestas para exponer algunos de los procesos mentales que explican los patrones de comportamiento del TEA. Como se ha mencionado previamente, fue en 1943 cuando Leo Kanner documentó los primeros 11 casos de niños que tenían conductas estereotipadas y rasgos muy parecidos a los que ahora se incluyen en el diagnóstico de las personas con TEA. A lo largo de estos 70 años o más, se han definido diversas teorías que señalan la condición y las implicaciones conductuales de quien las vive. En la Figura 5, se presenta un diagrama con algunas de las teorías más importantes registradas hasta ahora, y que tienen incidencia en este trabajo.

${ }^{19}$ El término etología fue usado por primera vez por Isidore Saint Hilaire en 1859 para enfocar el estudio de los animales en sus hábitats naturales. Uno de los trabajos más reconocidos al respecto fue realizado por Korand Lorenz en 1935 (Jaynes, 1969). Por otro lado, la etología cognitiva abarca también el estudio del comportamiento, pero incluye también el de los humanos. Desde el enfoque cognitivo se considera que, aunque la cognición y el comportamiento dependen en gran medida del contexto, lo importante es establecer una conexión clara entre lo que ocurre naturalmente en la vida cotidiana y los experimentos que se realizan en condiciones más controladas. Por lo que se puede aprender observando, describiendo y midiendo lo que hacen las personas en una situación natural pero en un laboratorio diseñado para ello (Kingstone et al., 2017). 
Figura 5. Evolución de la literatura del TEA

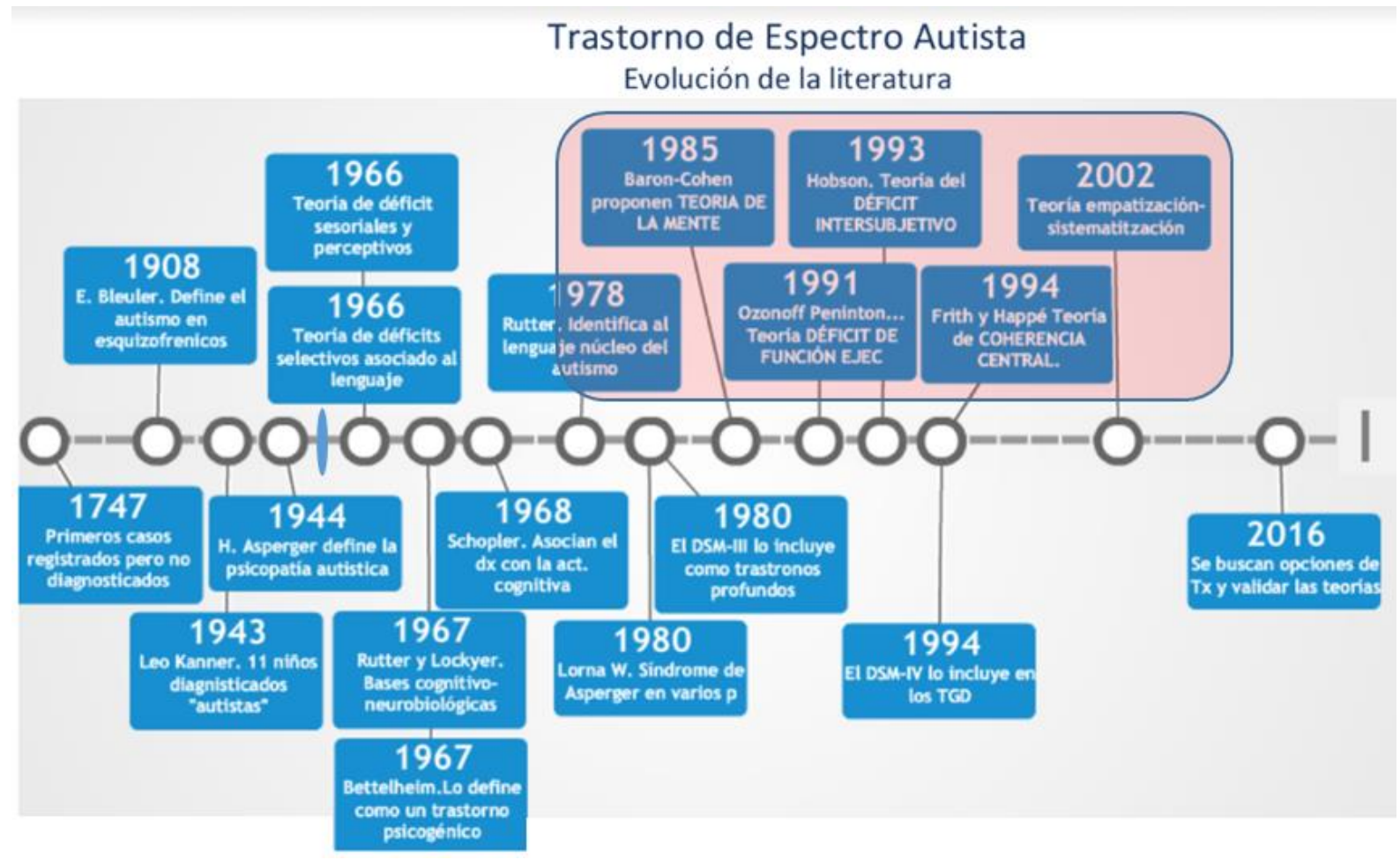

Nota. Se muestra esquemáticamente la evolución de la literatura en relación con el TEA. Enmarcados en un recuadro de color se aprecian las teorías que son consideradas en este proyecto. Fuente: Elaboración propia con información de Murillo 2014.

Debido a que las teorías que se han desarrollado para explicar la conducta de personas con TEA, han sido ya muy exploradas, el objetivo de revisarlas en este trabajo es sólo presentar las bases desde las que se parte para validar la propuesta de la investigación sin pretender agotar o exponer de manera exhaustiva cada una. Para cubrir el fin de revisarlas a profundidad se recomienda revisar de manera específica los materiales que se mencionan en la Figura 5.

\subsubsection{Teoría de la mente}

La teoría de la mente asociada al TEA, surgió a partir de una investigación realizada con chimpancés por parte de Premack y Woodruff (1978), dicho estudio exploraba la relación de los estados mentales que se atribuían a los chimpancés (con respecto a sí mismos y/o a los demás). Fue precisamente este mecanismo el que da el nombre de teoría de la mente (ToM). El procedimiento explorado por Premack y Woodruff demostró que los chimpancés eran capaces de identificar un problema y, al mismo tiempo, darle una solución. Las pruebas fueron presentadas por medio de escenas grabadas en video y las soluciones en fotografías. El proceso 
mental que tenía que realizar el chimpancé, era identificar el conflicto y luego inferir que éste podía ser solucionado con alguna de las opciones mostradas en las fotografías.

Entre las asociaciones que los investigadores hicieron a través de su experimento se encontraba la identificación de los propósitos, creencias, simulaciones, dudas e incluso adivinanzas. Mientras que los procesos mentales que exploraron estaba la cognición, la conciencia y la intencionalidad. La propuesta la presentaron como una teoría por dos razones: la primera era que la interpretación de los estados mentales de otros no surge a partir de lo que se observa sino por lo que se infiere. $Y$, en segundo lugar, porque esa interpretación puede emplearse para hacer predicciones, específicamente sobre el comportamiento de otros organismos (Premack \& Woodruff, 1978, p. 515).

Este mismo escenario lo usaron para identificar cómo reaccionaban niños regulares comparados con niños con retraso mental. Los resultados fueron interesantes debido a que evidenciaron que algunos niños no lograban inferir que había un problema y menos que ellos pudieran elegir la solución, como incluso los chimpancés lo habían conseguido.

A partir de estos resultados, en 1985 Baron-Cohen y sus colaboradoras (Baron-Cohen et al., 1985) adaptaron una metodología para identificar si los niños con TEA eran capaces de imputar creencias a otros a partir de una escena planteada con un paradigma de juego con títeres. Ellos identificaron que para que una persona fuera capaz de reconocer lo que otras personas desean, quieren, sienten o creen, es decir, que pongan en práctica la ToM, como la describió Premarck, es imposible sin la capacidad de formar "representaciones de segundo orden" y del juego simulado (Baron-Cohen et al., 1985, p. 38). A partir de estos dos datos, Baron-Cohen asocia la carencia con la baja sociabilidad debido a la falta de reconocimiento y predicción de lo que otros harán.

Tanto el estudio de Premack como el de Baron-Cohen, desataron una serie de investigaciones que colocaron nuevos matices al problema planteado de la asociación de la ToM con el TEA. Esto se ve reflejado en el trabajo de Call y Tomasello (2008), quienes 30 años después de la publicación de Premack, mencionan que en este lapso de tiempo se describieron varias formas en la que los organismos pueden comprender el funcionamiento psicológico de los demás, incluso, llegaron a la conclusión de que a pesar de que existe evidencia de que los chimpancés entienden los objetivos, las intenciones, las percepciones y el conocimiento de los demás, hasta ese momento no había evidencia experimental de que entendieran las creencias falsas (Call \& Tomasello, 2008, p. 190). No obstante, debido a esos resultados la ToM y su asociación con las personas con TEA se ha mantenido y se ha ratificado lo descrito por Baron- 
Cohen, además de identificar que su presencia está asociada al coeficiente intelectual o al nivel de TEA.

Szumsky y colaboradores (2019), plantearon un estudio en el que identificaron si la ToM podría aplicarse utilizando programas naturalistas para desarrollar habilidades sociales. En su programa consideraron la intervención de otros niños para promover la interacción, evaluando el efecto de aplicar la ToM de esta manera sobre el funcionamiento social de los niños con TEA en situaciones interactivas. En la discusión de su estudio manifiestan que sus resultados demuestran que las intervenciones conductuales basadas en técnicas naturalistas y el entrenamiento entre pares se encuentran entre los métodos más efectivos para mejorar las habilidades sociales de los niños con TEA.

Pedreño (2017, p. 2402) menciona que desde sus inicios se han identificado distintos niveles dentro del concepto de la ToM, uno de ellos es el concepto de Tager-Flusberg y Sullivan quienes presentan dos procesos diferenciados: el primero llamado cognitivo-social, basado en la comprensión conceptual de la mente como un sistema de representación; y, el segundo, el componente social-perceptual o empático relacionado con el sistema afectivo y basado en el juicio rápido del estado mental de otro a partir de sus expresiones faciales, gestos, tono de voz, movimientos y acciones. Como se verá más adelante, este aspecto es retomado dentro de la teoría de la empatía (véase el EATR 4).

\subsubsection{Teoría de la empatización-sistematización}

Richard Gross (Gross, 2012, p. 479) menciona que un punto débil de la ToM es que aunque las personas con TEA tuvieran la capacidad de identificar las creencias, intenciones o el estado mental de otras personas, les faltaría el ingrediente de la respuesta emocional para lograr ser empáticos con ellas. Siendo ese uno de los motivos por los que la teoría de la empatizaciónsistematización propuesta por Baron-Cohen (2009) ha sido una de las teorías auxiliares para explicar el TEA.

La base de esta teoría es la empatía, que es definida como el "impulso para identificar las emociones y pensamientos de otra persona y responder a ella con una emoción apropiada" (Baron-Cohen, 2002, p. 248). Y la sistematización, entendida como el impulso para analizar las variables que intervienen en un sistema (Baron-Cohen, 2002); ese impulso recae en la habilidad de sistematizar u organizar algo de acuerdo con un sistema propio o dado. Baron-Cohen, identificó que, en promedio, los hombres tendían a sistematizar de manera más espontánea que las mujeres. 
La teoría sustenta que, en general, el cerebro masculino es más propenso a la organización sistemática, mientras que el femenino tiene mayor disponibilidad para socializar y entender a otros. Este dato se relaciona con varios factores: biológicos, genéticos y hormonales, ligados al sexo (Baron-Cohen, 2012), hallazgos neurológicos que muestran que algunas áreas son más grandes o pequeñas en los hombre que en las mujeres o que incluso presentan diferencias respecto a las personas con TEA (Gross, 2012).

La teoría de la empatización-sistematización explica que las personas, por naturaleza, tienden a buscar y adaptarse contextualmente a partir de los patrones cognitivos del reconocimiento de su mundo circundante. (Baron-Cohen, 2009) asocia la falta de empatía con la necesaria dependencia o no que algunas personas tienen hacia patrones específicos. Dicho comportamiento la ha relacionado con las conductas repetitivas, la poca tolerancia al cambio y la fijación en ciertos objetos que suelen mostrar las personas con TEA.

Como ejemplo, se puede pensar en alguien a quien le encanta tener acomodada la ropa por colores. El patrón específico de esa persona sería el orden de los colores. Si alguien llegara a introducir una pieza morada oscura entre la ropa blanca la persona con patrones específicos no podría comprender ni ser empática con la otra que dejó la prenda de color oscuro entre la ropa clara. El motivo no importaría. Si fue por descuido, por error, por falta de tiempo, de atención, porque no quiso hacerlo adecuadamente o porque se iba a caer y soltó la prenda en ese lugar; cualquier motivo sería visto igual de grave y molesto, por la persona de patrones específicos.

En el ejemplo anterior, la persona que tiende a ser en exceso sistemática es más probable que no pueda ser empática con otros, si los otros no actúan como ella pretende o desea. Pero eso no sucedería con alguien que no tiene patrones específicos tan marcados o de los que dependa tanto para sentirse bien. Si la persona es menos dependiente de patrones específicos, es más probable que pueda entender la conducta de esa persona que acomodó mal la ropa. Es probable que ni siquiera note el cambio o incluso que no le importe acomodar la ropa por colores. Regularmente, las personas con TEA tienden a crear patrones específicos de los que dependen en extremo y eso les hace ser poco empáticos con las personas que no ven o que no comparten esos patrones específicos con ellos. En la Figura 6 se muestra la imagen de un niño con TEA grado 3 que tiene un patrón específico centrado en las siluetas de los animales. 
Figura 6. Niño con TEA grado 3 manteniendo un patrón específico de conducta
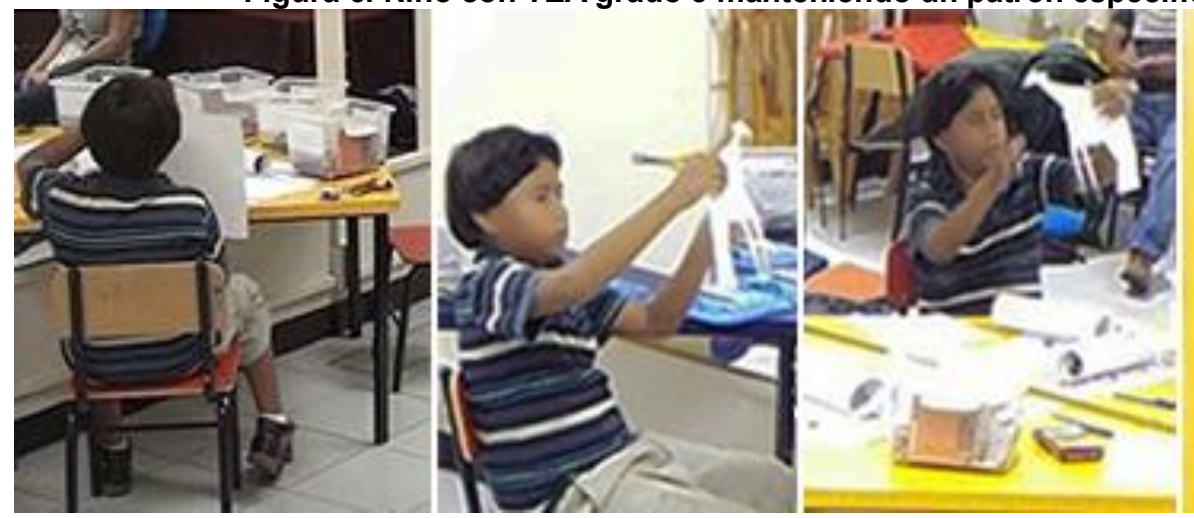

Nota. Recorte de silueta de jirafa. De izquierda a derecha se muestra el proceso del delineado de la silueta que fue abandonada por presentar un error en el recorte.

Para que él realice la silueta de un animal solo necesita una hoja de papel y unas tijeras. Él elabora la silueta del animal sin trazar una sola línea, pero si al momento de estar cortando la silueta hay un detalle que le sale mal, abandona la hoja, la tira y vuelve a empezar el recorte.

Existen dos componentes principales de la empatía: una es cognitiva y la otra afectiva (Warrier \& Baron-Cohen, 2018, p. 1). La primera se caracteriza por tener un reconocimiento visual del estado mental de otra persona. Este tipo de empatía está asociada directamente con la ToM y con el reconocimiento de la emoción del otro. Mientras que la empatía afectiva implica una respuesta al estado mental del otro. Es decir, en la primera solo se reconoce, no necesariamente se entiende, mientras que en la segunda se reconoce y se responde a ella ${ }^{20}$. En el ejemplo que se puso, de la persona y la ropa de colores, si no es TEA, puede ser que su empatía cognitiva le lleve a pensar "está bien, no pasa nada. Se iba a caer y se le olvidó dejar la prenda en su lugar", pero si siente además empatía afectiva pensará "está bien, no pasa nada. Veré si está bien después de la caída".

En el ejemplo del niño con TEA y su recorte de siluetas, dado que es nivel tres, su grado de empatía no le alcanzaba para ser empático-cognitivo ni empático-afectivo. No soportaba el más mínimo error, ni de él mismo. Aventaba la hoja ante la menor equivocación. Y con el fin de que no se desesperara y rompiera en llanto o frustración, la familia procuraba tenerle siempre hojas blancas o de colores listos para cuando él las necesitara. En esa situación, el niño no podría

${ }^{20}$ Baron-Cohen (Baron-Cohen \& Wheelwright, 2004) realiza una diferencia entre simpatía y empatía de acuerdo con la filosofía moral de Adam Smith. Describe la simpatía como la experiencia, con un componente afectivo, del "sentimiento de compañerismo" suscitado ante el estado emocional del otro. Su explicación es que surge a partir de la angustia que genera el estado del otro y de querer ayudarle o - yo agrego - de acompañarle en el sentimiento tomando el mismo estado emocional del otro. Es por ello por lo que comenta que la simpatía puede implicar los elementos cognitivos y afectivos de la empatía. 
ser empático-afectivo, si alguien de alguna manera estropeaba o se metía con su recorte él se podría enojar mucho y ese podía ser el motivo para soltar una rabieta incontrolable.

En 2017, Laura Hull y sus colaboradores (2017) desarrollaron una revisión sistemática de 13 estudios hechos con población con TEA, con el fin de comparar las características de hombres y mujeres en cuanto a sus impedimentos sociales y de comunicación, de comportamientos e intereses restringidos y repetitivos, y de su coeficiente intelectual. En relación con la empatía, la sistematización y los rasgos autistas corroboraron lo descrito por Baron-Cohen desde 2002. Es por eso por lo que los estudios posteriores realizados con respecto a esta teoría siguen vigentes, casi después de veinte años. Y se aplican perfectamente a casos como el narrado del niño de las siluetas.

\subsubsection{Teoría del déficit de las funciones ejecutivas}

Otra de las teorías en las que se basa esta investigación y que se relaciona estrechamente con la ToM, es la teoría de la disfunción ejecutiva (Ahmed \& Stephen Miller, 2011; Ozonoff et al., 1991). Fue propuesta por Ozonoff en 1991 quien consideraba que las FE estaban relacionadas a la ToM, pero involucraban un sistema neurológico separado. Su propuesta se fundamentó en estudios de la neuropsicología cognitiva, en la que se había identificado un patrón de discapacidades cognitivas relacionadas con déficits en la función ejecutiva. Es decir, identificó una relación de la "capacidad de mantener un conjunto apropiado de resolución de problemas para alcanzar una meta futura" (Ozonoff et al., 1991, p. 1083).

Para su planteamiento, Ozonoff (1991, p. 1083) se apoyó de los resultados de otros estudios para determinar el nivel de déficit que tienen las personas con TEA respecto al uso de sus FE. Su objetivo era examinar si existía un deterioro de la función ejecutiva en individuos autistas jóvenes y, sobre todo, relacionar dichos resultados con los déficits de la teoría de la mente. Entre los instrumentos que utilizó para realizar las pruebas de FE, se encuentra la torre de Hanoi, que involucra la planificación y la inhibición. Como se revisa en el siguiente capítulo, la torre de Hanoi sigue siendo una herramienta ampliamente utilizada con personas con TEA o incluso neurotípicas.

Lo más interesante del estudio es que a partir de la propuesta se abrió la posibilidad de asociar el TEA con un déficit subyacente de la corteza prefrontal, otorgándole el nivel de daño primario involucrado en aspectos cognitivos y afectivos a la vez (Flores-Lázaro \& Ostrosky-Shejet, 2012; Flores et al., 2014; Ozonoff et al., 1991). Este aspecto llevó al mismo tiempo a identificar el deterioro prefrontal generalizado como el responsable de causar disfunción en una amplia 
variedad de dominios neuropsicológicos, relacionados a través de los sistemas cerebrales involucrados en el proceso (Tirapu-Ustárroz \& Luna-Lario, 2011) .

Como señaló Ozonoff desde hace treinta años, la construcción de un repertorio de estrategias de organización y planificación para las personas con TEA puede ser de gran ayuda para que ellos logren retroalimentarse de sus errores y aprendan a generar estrategias más eficaces para la solución de problemas.

Aunque originalmente Ozonoff (1991) asoció las FE exclusivamente con el diagnóstico del espectro autista, o autismo en su momento, ahora se tiene conocimiento de que éste no es propio ni exclusivo del TEA. Se considera que la propuesta no necesariamente mantuvo eco en la literatura como teoría de las disfunciones ejecutivas, debido a que, desde ese ángulo, la disfunción estaría asociada a un estado de enfermedad y, por lo tanto, todos los que presentaran variaciones en esas FE serían asociados también a una enfermedad proveniente de un mal funcionamiento cerebral. No obstante, la propuesta sigue vigente desde el continuo de salud debido a que el desarrollo de la corteza prefrontal se asocia al desarrollo de las FE no sólo en las personas con TEA, sino en todas las personas.

A partir de entonces se ha descrito que las FE son un elemento importante para la estructuración, orden y desarrollo del pensamiento de cualquier persona. Y están implicadas en la resolución de problemas para alcanzar una meta futura. (Esto se revisará en el EATR 3, en el que se presentan sólo como FE y no como disfunciones ejecutivas).

Dentro de la FE, la atención ha cobrado especial relevancia debido a que las personas con TEA presentan alteraciones en este aspecto de la cognición y dificultades para captar la totalidad de una realidad compleja (Tirapu-Ustárroz \& Luna-Lario, 2011, p. 222). Relacionado a ello, el tema que se aborda en el EATR 2 se centra en la revisión de una propuesta de análisis del uso de los signos como un sistema dinámico que favorece el encadenamiento de ideas a partir de la significación del mundo.

Para hacer uso de un lenguaje común se tienen que identificar sus elementos constituyentes, entender su significado y tener la capacidad de usarlos con un sentido similar al de los demás. Pero, como se ha visto en párrafos anteriores, para las personas con TEA, los signos que les podrían permitir entender a otros no siempre son suficientemente claros para ellos y, menos aún, para entender su uso. Sin este conocimiento, la identificación de lo que pasa alrededor y su interpretación se dificulta mucho para poder socializar y tener las ventajas y beneficios que acarrea esta habilidad. 


\subsubsection{Intervenciones naturalistas: etología cognitiva y regulación del comportamiento}

Como se mencionó en el apartado 2.1.3.3, el enfoque naturalista se aplica en contextos sociales naturales. Schreibman (2015) comenta que, desde el principio, éstos se implementan en ambientes interactivos, como el juego y las rutinas diarias, y se involucran estrategias de enseñanza dirigidas al niño, como el uso de materiales preferidos por el infante (pag. 2412). Dentro de este enfoque, se han adaptado los estudios etológicos como una herramienta de análisis del comportamiento de los niños. Osborne-Crowley (2020) comenta que cuando se combina el estudio de tareas simples, en los niños con TEA, con tareas más naturalistas se pueden determinar mejor qué procesos cognitivos discretos contribuyen a procesos sociales más complejos y de qué manera.

Los estudios etológicos adaptados al comportamiento humano se remontan a los primeros descubrimientos que realizaron investigadores como Korand Lorenz y Nikkolaus Tinbergen $($ Griffiths, 2008)21. En 2015, Connie Kasari (Kasari et al., 2015) realizó un estudio en el que aplicaron una intervención conductual del desarrollo naturalista a la que llamaron JASPER para medir: atención conjunta, juego simbólico, participación y regulación. La particularidad del estudio es que era aplicada con niños con TEA a través de su familia (madre o padre según informan). En sus resultados reportaron datos favorables en la diversidad del juego y la participación conjunta iniciada por el niño.

Es importante mencionar que aunque la etología originalmente fue descrita en animales se han realizado diversos estudios enfocados al comportamiento de niños, entre ellos niños con TEA (Grandgeorge et al., 2014; Osborne-Crowley, 2020; Pegoraro et al., 2014; Perinat Maceres, 1979, 1980, 1982); su sentido básico es el estudio biológico del comportamiento descrito por Tinbergen en 1963, mencionado en (Perinat Maceres, 1982).

Particularmente, en psicología este campo se ha asociado al estudio de la psicobiología y el desarrollo humano. La diferencia fundamental entre el estudio del comportamiento en los animales y del comportamiento de los niños, se basa primordialmente en comportamientos instintivos y su interpretación depende sobre todo de la observación y de la capacidad de las personas para definir las conductas que observan. Tal es el caso de K. Lorenz cuando descubrió el principio de impronta biológica en sus gansos. Este aspecto, no necesariamente ocurre con las

\footnotetext{
${ }^{21}$ Konrad Lorenz, Nikolaas Tinbergen y Karl Von Frisch, obtuvieron el premio Nobel de Fisiología y Medicina en 1973 por su aportación acerca de la organización y obtención de patrones de comportamiento individual y social https://www.nobelprize.org/prizes/medicine/1973/lorenz/biographical/
} 
personas, quienes desde muy pequeñas empiezan con un equipo biológico propenso al aprendizaje más complejo por moldeamiento social, como lo describen (Rizzolatti \& Sinigaglia, 2016) para mostrar los mecanismos que intervienen en el desarrollo de funciones cognitivas que pueden incluir la comprensión de acciones y emociones.

Los estudios en etología que aquí se retoman enfatizan la precisión empática definida por Katherine Osborne-Crowley (2020), como la capacidad de comprender con precisión los pensamientos y sentimientos de los demás. Por esta razón el recurso de la etología se emplea para describir los comportamientos básicos que adquieren los niños con TEA y que no necesariamente son moldeados por el contexto en el que están, sino que surgen como un aspecto particularizado de su propia conducta en condiciones naturales. Como lo que Lorenz denominaba "patrones fijos de conducta" y que en los criterios diagnósticos del DSM-5 se describen como "Patrones restrictivos y repetitivos de comportamiento, intereses o actividades" (ver Tabla 3). Aunque, es importante marcar que a diferencia de los patrones en animales que por lo regular se mantienen fijos, en los niños, desaparecen o son modificados conforme van creciendo.

En el capítulo cuatro se presenta las características de la observación conductual de los niños desde la observación naturalista. 


\subsection{EATR 2. Proceso de significación y comunicación}

En la condición del espectro autista es primordial entender los procesos de significación y el uso que le dan en su vida cotidiana. En esa etapa, los signos son uno de los elementos cruciales que, de alguna manera, se han abordado a lo largo de este escrito. Son los elementos básicos involucrados en la construcción de los procesos mentales superiores implicados en las FE. Por tal motivo, en esta investigación los signos son el elemento decisivo que se transmite en el lenguaje común y socializado, y que no logran identificar con facilidad las personas con TEA, incluyéndose a sí mismos, a los otros y a los contextos en los que se desarrollan.

Este EATR se centra en ese proceso de significación, de la comunicación, y en la teoría semiótica como un elemento para explicar las relaciones semiótico-cognitivas resultantes.

\subsubsection{La significación y el TEA}

El estudio de los signos - como un quehacer constante del diseño — brinda las bases teóricas fundamentales para explicar, entender y utilizar la simbolización que se emplea en los procesos de comunicación. La búsqueda del significado del entorno es una de las ramas que han dado sentido a distintas áreas del diseño, desde lo gráfico hasta lo proyectual, bi o tridimensional. Tener un adecuado conocimiento de la cadena de significación — que puede acarrear la combinación de imágenes, palabras, música o cualquier otro elemento del diseño- favorece el uso de la comunicación efectiva. Conocer el efecto provocado por los distintos estímulos que forman parte de un mensaje, es primordial para lograr captar la atención de quien se desea atraer.

Los colores, objetos, sonidos, texturas, voces, personas, en fin, todo lo que está en el contexto y pasa a través de los sentidos tienen un punto en común que son las claves de la significación. Éstas ayudan a interpretar, comprender y compartir la visión del mundo con otras personas o con el entorno. Gracias a ellas se logra dar sentido a las cosas que suceden a cada instante, a las relaciones, a la forma en la que se interactúa con otros y a identificar cómo nos podemos desempeñar en la vida misma.

Identificar las claves que permiten la comunicación intersubjetiva e incluso, intrasubjetiva, es decir, entre personas o de la persona hacia sí misma, es una tarea que frecuentemente se persigue como una práctica de perfeccionamiento en el ámbito de la semiótica. A través del tiempo, los procesos de significación en los seres humanos han sido objeto de estudio de la lingüística de Saussure (Zecchetto, 2005); la filosofía pragmática (Peirce, 1987); la cognición (Gross, 2012) o la percepción (Goldstein, 2011), entre otras. 
En diseño, el estudio de los signos se ha empleado como base fundamental de la semiótica (Elizondo, 2012). Los signos, la forma en la que se organizan, se relacionan, y el contexto en el que aparecen, son los elementos básicos para dotar de significado lo percibido. En esa misma línea, en el caso de las personas con TEA, el entendimiento de los signos suele ser gradual y muchas veces su uso depende del apoyo externo que reciban para interpretarlos antes de poder emplearlos socialmente. Aunque hay que recordar que se trata de un espectro en el que coexisten múltiples reacciones. Es decir, no existen límites o fronteras conductuales fácilmente detectables entre un caso y otro. Tal como ocurre con el espectro de luz en donde no es fácil distinguir una longitud de onda de otra. Incluso aunque se mida la longitud de onda con un espectrómetro, perceptualmente no se alcanzan a notar las diferencias graduales, lo mismo sucede con la conducta de las personas con TEA.

Las dificultades que viven las personas con TEA inciden de manera considerable en la primera infancia. Cuando los niños con TEA apenas empiezan a desarrollar estrategias para comunicarse e interactuar con su entorno, la facilidad de uso y el acceso a los signos de comunicación, con o sin tecnología, pueden ser determinantes para que se integre a su entorno social. Por lo anterior, en el siguiente apartado se proponen los elementos de significación, de comunicación y de la semiótica con el fin de conocer las posibilidades de interpretación que tienen las personas con TEA.

\subsubsection{Teorías posibles para explicar la significación en las personas con TEA}

Uno de los autores que ha relacionado de manera exitosa la semiótica con la cognición y la interacción es Carlos Scolari (2004). Scolari ha desarrollado un modelo llamado: semio-cognitivo de las interacciones digitales, el cual está fundamentado en la aplicación semiótica a la interacción, abordada desde tres ángulos: 1) parte de la postura de U. Eco $(1993,2000)$ centrada en la semiótica interpretativa y en el análisis narrativo desde el punto de vista del lector; 2) hace uso de los modelos mentales propuestos por Donald Norman, para explicar la forma en la que se da sentido a las cosas "mediante la experiencia, la formación y la instrucción" (Norman, 1988), y 3) emplea la metáfora, descrita por Bettetinni en 1984 (Scolari, 2004, p. 55), como un elemento que facilita la conversación entre un enunciador y un enunciatario.

Como se revisó en el EATR 1, a las personas con TEA les cuesta trabajo hacer una selección circunstancial o una selección contextual para completar el significado de la mayoría de los mensajes que están ocultos o que incluso parecen evidentes para los demás. Baste con 
este ejemplo para afirmar lo que no sería posible para las personas con TEA, (retomo el ejemplo a partir del cual Eco $(1993,2000)$ reflexiona):

“(1) Tendremos que volver a llevar a Juanito al zoológico,

y (2) Tendremos que volver a llevar el león al zoológico"

En cada caso sería responsabilidad del lector o del oyente asignar el valor diferencial que le llevaría a inferir a qué contexto se refiere cada frase que estructuralmente parecen casi iguales. En el primer caso se podría pensar en la perspectiva de una familia hacia el aprendizaje de su hijo; en el segundo, en la necesidad de los cuidadores o domadores de un león ${ }^{22}$.

Hacer tal inferencia sería casi imposible para las personas con TEA porque no actualizan sus contextos de manera rápida o automática, ni logran entender los dobles significados, ni las intenciones de otros para inferir sus pensamientos.

Como se ha mencionado previamente en el EATR 1 con la ToM, para los niños con TEA mantener las cosas que les rodean sin grandes cambios les hace tener una estabilidad que genera poca tensión y angustia. Cuando cambian las circunstancias de algo conocido por algo desconocido, para ellos es motivo de descontrol y ansiedad. Por lo que hacer una nueva significación tan compleja les llevaría mucho tiempo. En lugar de ello, tienden a mantener una imagen constante, contra la que comparan lo que viven día con día. Esa imagen constante bien puede ser icónica, indicial o — con mucho trabajo de condicionamiento de por medio—, simbólica.

De manera predominante en este EATR se fundamenta en el desarrollo de las aportaciones de dos autores que formalizaron el estudio de los signos a través de la semiótica ${ }^{23}$. La primera fue elaborada por el lingüista Suizo Ferdinand de Saussure en 1916, y la segunda por el filósofo norteamericano Charles Sanders Peirce, cuya aportación se basa en las relaciones semiótico-cognitivas originadas a partir del proceso de significación. Ambas empleadas con el fin de explicar el uso y construcción que hacemos de la significación y de la comunicación.

En síntesis, para la construcción del marco referencial que sustente el proceso de significación de las personas con TEA se exponen dos líneas: 1) la división más elementan de los signos propuesta por U. Eco (1989) impronta o huella, indicio y síntoma, y 2) el desarrollo de

22 El ejemplo y análisis contextual es de Umberto Eco (1993, pp. 25-26).

${ }^{23}$ Aunque a esta ciencia Saussure le llamó semiología, en este texto se considera el término de semiótica para ambas propuestas debido se centran en el estudio del signo y que son las ideas de Pearce las que se siguen de manera más puntal para el desarrollo de esta tesis. 
la propuesta semiótica de Ferdinand de Saussure (Zecchetto, 2005) como ámbito comparativo y de Charles Sanders Peirce $(1974,1987,1998)$ como base explicativa del proceso de significación.

\subsubsection{Dos teorías para una ciencia en común: la semiótica}

\subsubsection{Saussure y su semiología}

Las ideas de Saussure con respecto al estudio de los signos fueron publicadas post mortem por dos de sus alumnos en 1916, llevan el título de Curso de lingüística general. El curso fue impartido por Saussure en tres periodos entre 1906 y 1911. A través de su cátedra estableció las bases para una ciencia dedicada al estudio de los signos en el seno de la vida social, dándole el nombre de semiología (Zecchetto, 2005, p. 19).

La base del sistema de signos que concibe Saussure considera un componente material (que es la imagen que se tiene o forma de un objeto representado) y un componente mental que corresponde a la definición o concepto abstracto que tenemos de esa imagen (ver Figura 7). El proceso de significación se lleva a cabo cuando mentalmente por una "asociación psíquica" coinciden los dos componentes. Al componente material se le da el nombre de significante y al componente mental, de significado (Chandler, 1998).

Figura 7. Representación del signo lingüístico descrito por Ferdinand de Saussure

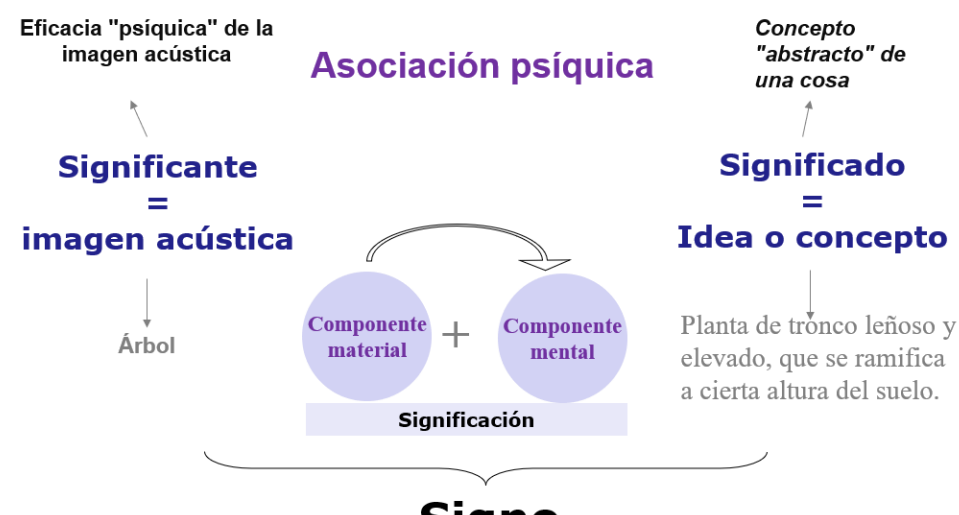

Signo

Fuente: elaboración propia.

Saussure considera tres características básicas del signo: arbitrariedad, su significado se otorga socialmente sin lazos naturales que lo unan a su presencia. Linealidad a través del tiempo, solo puede ser pronunciado uno detrás de otro, no de forma simultánea. Inmutabilidad, una vez que se asigna, es aceptado socialmente y sin cambiar su uso o ser cuestionado, se mantiene. Su 
permanencia continúa hasta que con el paso del tiempo pueda mutar a través de convenciones, para dar paso a otros signos que serán adoptados socialmente.

\subsubsection{Peirce y su semiótica}

Charles Sanders Peirce ${ }^{24}$ pretendía elaborar una teoría general a través de la cual se pudiera comprender y describir la totalidad del mundo. De acuerdo con él, la base de lo que actualmente se conoce como ciencia general de los signos o semiótica (Crow, 2008; Peirce, 1974) se representa a través de un sistema formado por triadas de categorías que explican los elementos involucrados en el proceso de significación.

Peirce consideraba que todo hecho semiótico se explica por los estados mentales del ser humano quien de forma permanente teje significaciones a partir de otras concepciones aprendidas personalmente y compartidas en sus normas culturales. Sus elementos constituyentes parten de "una división del signo que toma en cuenta una triple relación: consigo mismo, con el objeto al cual alude y con el interpretante" (Zecchetto, 2005).

La exposición gráfica de estas relaciones se representa en las Figuras 8 y 9 y se justifica de la siguiente manera ${ }^{25}$ :

"2.243. Los signos pueden dividirse según tres tricotomías: primero, según que el representamen en sí mismo sea una mera cualidad (cualisigno), un existente real (sinsigno) o una ley general (legisigno); segundo, según que la relación del signo con su objeto consista en que el signo tenga algún carácter en sí mismo (ícono) o en alguna relación existencial con ese objeto (índice) o en su relación con un interpretante (símbolo);

tercero, según que su interpretante lo represente como un signo de posibilidad (rhema)

\footnotetext{
${ }^{24}$ Peirce fue un reconocido matemático que obtuvo el grado con tan solo 20 años. Se especializó y escribió en áreas como la física, la astronomía, la psicología y la filosofía. Fue amigo cercano de William James quien se orientaba a estudios relacionados con la consciencia y con quien se cree realizó trabajos conjuntos. De Peirce no existe una fecha exacta de las publicaciones acerca de la semiótica, pero sus escritos fueron comprados a su muerte por la Universidad de Harvard, además de contar con la evidencia de que entre 1903 y 1911 mantuvo correspondencia con una persona llamada Lady Viola Welby, a quien explicaba los pormenores de su teoría llamada semiótica (Zecchetto, 2005).

25 Algunas citas irán acompañadas de cifras que de acuerdo con la edición de la obra Lógico semiótica, de Peirce editada por Armando Sercovich en la editorial Taurus 1987, remiten al "número de párrafo de correspondiente a la confusa y parcial edición de los trabajos filosóficos y lógicos de Peirce, realizada por el Departamento de Filosofía de la Universidad de Harvard en 1931, reeditada hasta hoy sin modificaciones [...] de la «Peirce Edition Proyect», por la Universidad de Indiana, dirigida por el profesor Christian J. W. Kloesel con la colaboración del profesor Max H. Fish" (Peirce, 1987, p. 7).
} 
o como un signo de hecho (dicisigno), o como un signo de razón (argumento)." (Peirce, 1987 , p. 249). ${ }^{26}$

Figura 8. Triada sígnica de Charles Sanders Peirce
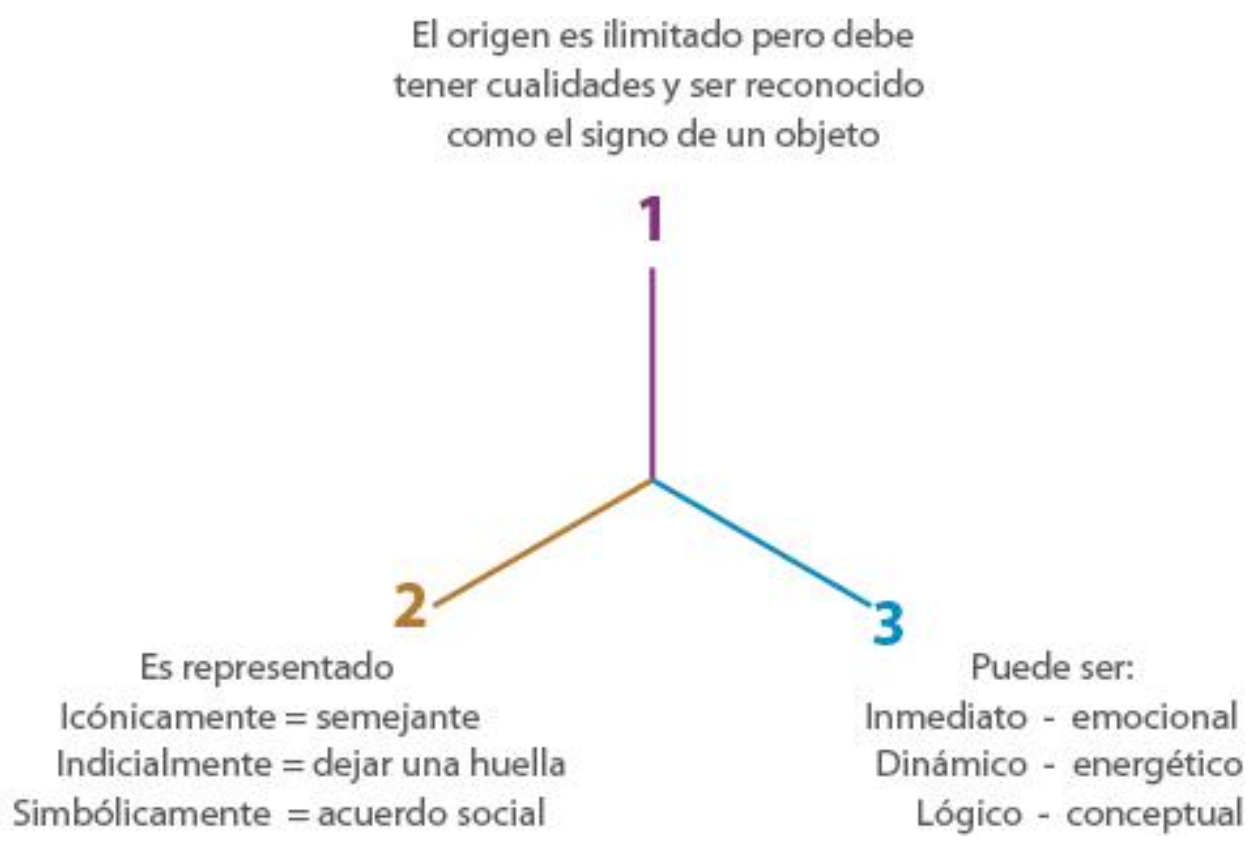

Fuente: elaboración propia.

Las tres categorías marcadas en negritas son nombradas por Peirce (1987) como: primeridad, secundidad y terceridad, a partir de ellas "lo real es pensado y abarcado desde los componentes indispensables que le dan significado al resto" (Zecchetto, 2005, p. 78). Éstas forman la triada más importante del proceso de semiosis: pirmeridad, secundidad y terceridad.

Primeridad. Es una cualidad de lo percibido, aún antes de que pueda considerarse como signo, y, es definida como "el modo de ser de aquello que es tal como es positivamente y sin referencia a ninguna otra cosa" (Peirce, 1987, p. 110). Esta definición se refiere al principio, al momento donde inicia el conocimiento. Zecchetto (2005, p. 50).

Secundidad. Son los hechos tangibles en donde se aplican las cualidades percibidas durante la primeridad a algo concreto, que en palabras de Peirce (1987, p. 110) son "el modo de ser de aquello que es tal como es, con respecto a una segunda cosa, pero con exclusión de toda tercera cosa". Este segundo momento se concentra en los fenómenos existentes y en lo posible

${ }^{26}$ Con el fin de enfatizar el concepto al que alude cada definición agregué palabras cursivas entre paréntesis como una aportación propia y remarqué algunas palabras en negritas con el mismo fin. 
realizado (Zecchetto, 2005, p. 50) en donde se reúne el fin de lo ocurrido en la primeridad. Este momento de la significación representa la idea de intencionalidad (Zecchetto, 2005, p. 53).

Terceridad. Se refiere a las leyes que rigen y validan lo percibido en la primeridad y que es concretado en la secundidad. Peirce la define como "el modo de ser de aquello que es tal como es, al relacionar una segunda cosa y una tercera entre sí" (Peirce, 1987, p. 110). En la terceridad se valida lo percibido. En la Figura 9, se observa la relación que tienen las categorías del sistema de signos de Peirce.

Figura 9. Integración de las categorías semióticas de Peirce

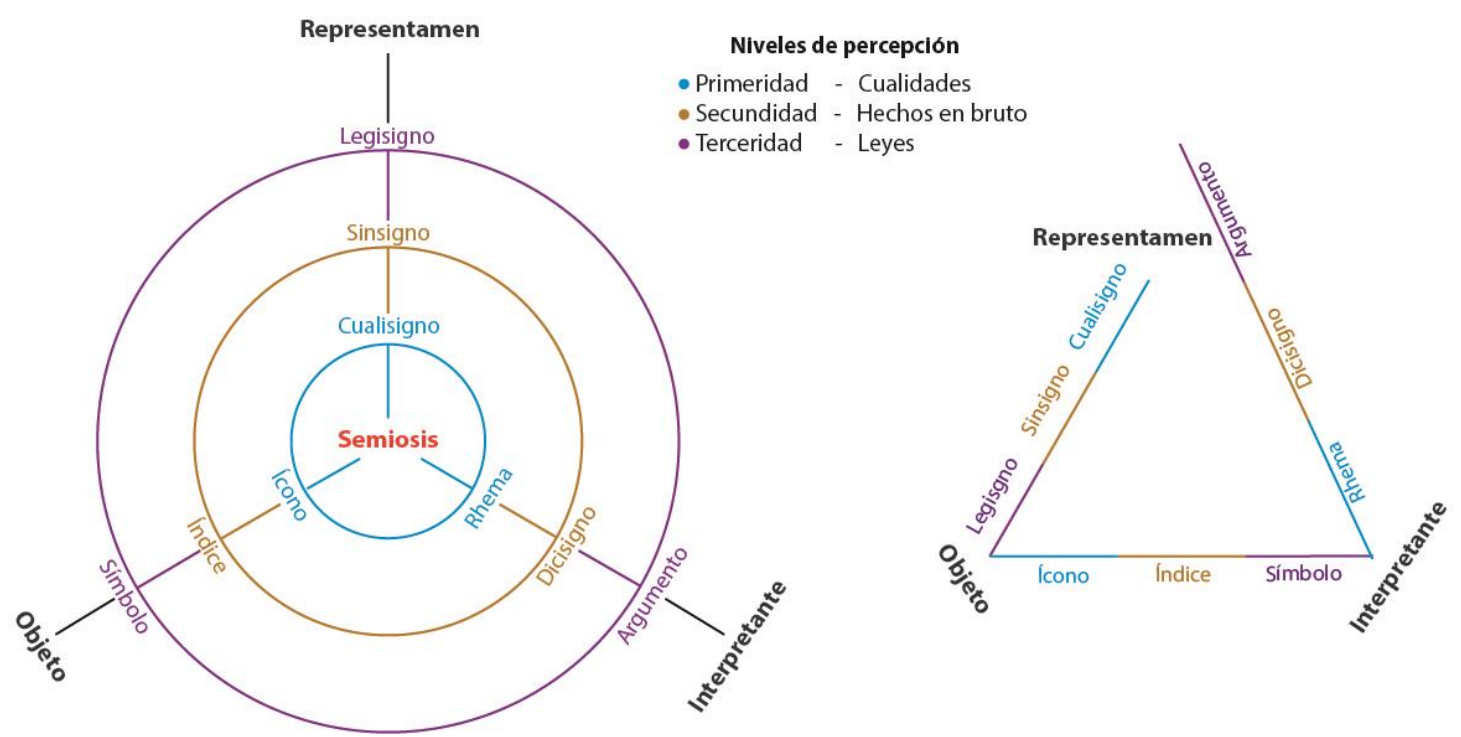

Nota. Del lado izquierdo se muestran los niveles de integración del signo. Del lado derecho se presenta la base para la semiosis ilimitada considerando los distintos niveles para la integración del significado de lo percibido. Fuente: elaboración propia.

En el centro de la representación se encuentra la semiosis, entendida como la construcción del significado que se da a medida que se integran los tres elementos enunciados: 1) representamen, 2) objeto, e 3) interpretante. Estos elementos ayudan a dar forma a lo que se percibe, se materializa y se comparte con otros. El representamen es producto de la arbitrariedad de quienes lo crean (Zecchetto, 2005, p. 58) y es definido por Peirce como: "2.274. Un primero que está en tal relación triádica genuina con un segundo, llamado objeto, como para ser capaz de determinar a un tercero, llamado su interpretante, a asumir con su objeto la misma relación triádica en la que él está con el mismo objeto» (Peirce, 1987, p. 14). 
La Figura 10 representa el proceso de la semiosis ilimitada en donde se conjuntan las categorías y niveles del proceso de significación. El inicio es central y expansivo. Como se puede observar, la semiosis (punto rojo) inicia con el representamen (marcada con una flecha azul), se dirige al objeto y concluyen con el interpretante. Si el proceso de encadenamiento de la semiosis continua, entonces ese mismo interpretante se convierte en el representamen para dar pauta a una nueva significación y así sucesivamente. Las categorías de primeridad, secundidad y terceridad se mantienen como parte de cada elemento que integran la semiosis y se dividen dentro de cada categoría según corresponda. En los siguientes párrafos se explica cada elemento.

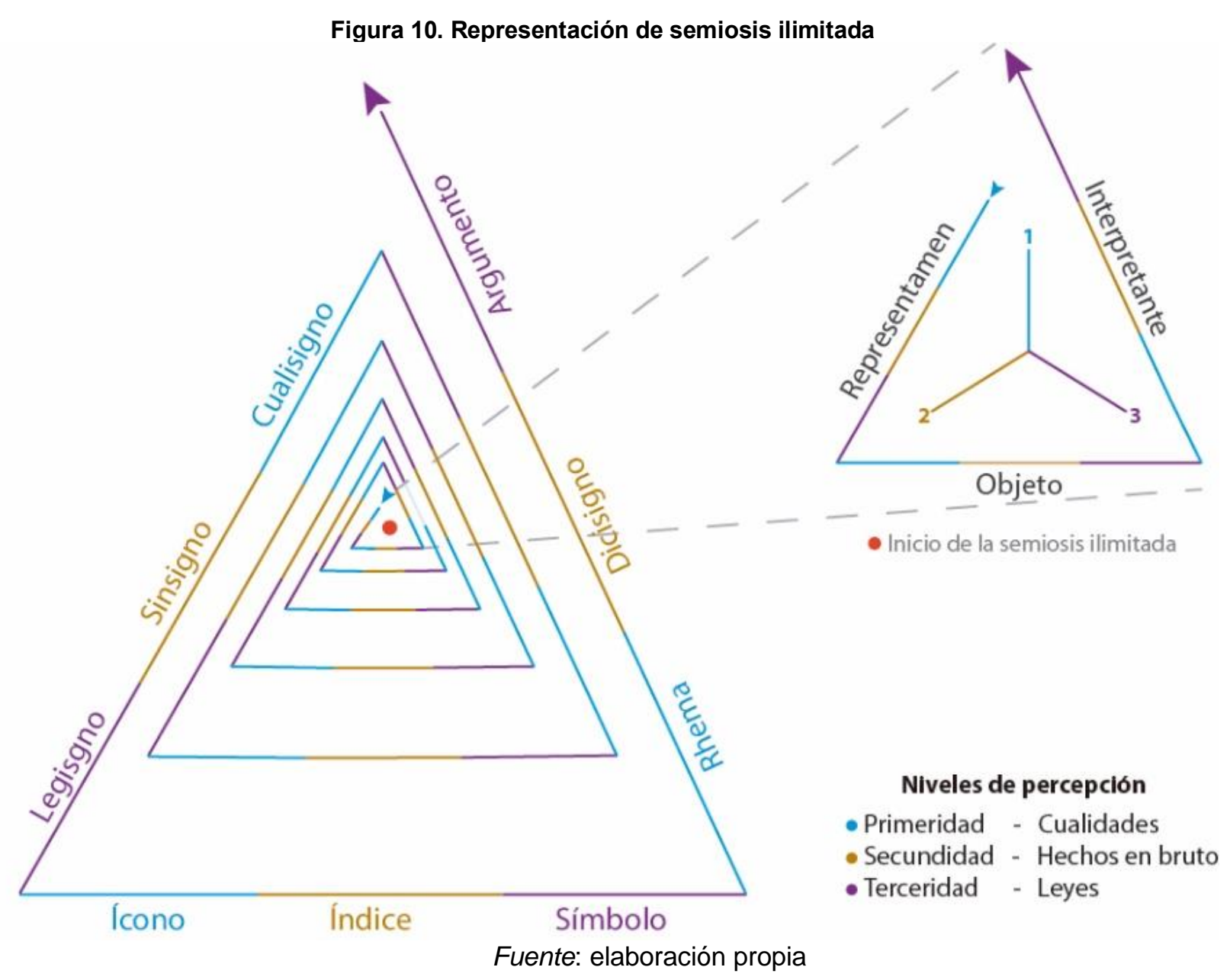




\subsection{Elementos del signo: representamen, objeto e interpretante}

Peirce asume que el representamen empieza como una posibilidad de serlo y solo se convertirá en signo cuando entre en contacto con las otras dos categorías: el objeto y el interpretante, haciendo una triada indisoluble. Considerando que, si no están en contacto las tres entidades, no existirá signo alguno ni su representación, ni su interpretación.

Así, la relación que se establece entre el representamen, el objeto y el interpretante depende de lo que se reconozca como signo. Para Peirce "Un signo es un reprensentamen con un interpretante mental (2.274)" es, por lo tanto, una mera posibilidad de ser signo (Peirce, 1987, p. 14). Esta categoría, el representamen, es sólo una realidad teórica y mental, integrada por tres elementos: cualisigno, sinsigno y legisigno.

El cualisigno es definido como algo que es en sí mismo, que se remite a su propia naturaleza, sin identidad alguna y que es la mera cualidad de una apariencia. Se trata del signo en su aspecto de cualidad (Zecchetto, 2005, p. 63).

El sinsigno, se remite a la relación con su objeto y puede estar formado por varios cualisignos [como posibilidad de uso] que provienen de una clase particular asociada al objeto que representan (2245) (Peirce, 1987, p. 249). Zecchetto lo define como la presencia concreta del signo (2005, p. 64).

El legisigno es la norma o modelo sobre la cual se construye un sinsigno (Zecchetto, 2005, p. 64) esa ley es instituida por las personas, por lo que Peirce (1987) comenta que "2.246. Todo signo convencional es un legisigno", no es un objeto único, sino un signo general que, por un acuerdo, tiene que ser significante de algo (Peirce, 1987, p. 249).

Ese primer nivel identificado como parte del representamen puede ser captado a través de la estimulación de cualquier índole: sensorial, auditiva, táctil, visual, gustativa, imaginativa o incluso energética. Sea real o artificial, su origen no importa, lo que importa es la traducción que se hace de éste. De ahí que Peirce (1987) lo explique como algo que, para alguien, se refiere a otra cosa en algún aspecto o carácter (Carta a Lady Welby, del 23 de diciembre de 1908 en (Peirce, 1987, p. 12). Ese reconocimiento del signo dependerá de quién lo lea y del bagaje de información que tenga para leerlo o interpretarlo.

Por otro lado, el objeto protagoniza la segunda tricotomía del signo compuesto por: ícono, índice y símbolo (ver Figura 9). El objeto es el sentido de la existencia del representamen, es por ello por lo que todas las cualidades determinadas como parte de éste se concretan en el objeto, que es a partir del cual toma forma y se da realidad material a lo percibido, a lo imaginable o a lo inimaginable (Peirce, 1987, p. 11). 
Un ícono es un signo que remite al objeto que él denota, de acuerdo con sus características propias; "un signo que está determinado por su objeto dinámico en virtud de su propia naturaleza interna" (Peirce, 1974, p. 94). Son semejanzas que sirven para transmitir ideas de las cosas que representan simplemente imitándolas (Peirce, 1998). Se refiere a la representación del objeto a partir de las características de su forma, por lo que recurre a la semejanza del objeto que representa, pero solo aplicará para aquellos øbjetos que sí tengan un referente material, aunque se trate de una cualidad, por ejemplo, del color como cualidad. Ese objeto puede ser cualquier cosa, sea una cualidad, un existente individual o una ley, que se convierte en un ícono de algo en la medida en que es como esa cosa y es empleado como un signo de ella. (2.248) (Peirce, 1987, p. 250).

Un índice es un signo que se refiere al objeto que denota en virtud de que es realmente afectado por ese objeto. Es "indicativo, y remite a alguna cosa para señalarla" e indicar la presencia del signo (Zecchetto, 2005, p. 65). Es la marca dejada por un objeto que toma como el indicador del tipo de signo que se trata. Peirce (1974) lo señala de la siguiente manera "signo determinado por un objeto dinámico en virtud de estar en una relación real con él” (p.94). Son las características o marcas que deja el signo asociados a su presencia (Peirce, 1998).

Un símbolo es un signo que se refiere al objeto que él denota, por medio de una ley, por lo común una asociación de ideas generales que hace que el símbolo sea interpretado como referido a ese "objeto" (2.249) (Peirce, 1987, p. 250). Esas ideas generales se elaboran a través de convenciones o acuerdos sociales, por lo que los símbolos son totalmente arbitrarios: "signo que es determinado por su objeto dinámico solamente en el sentido de que así será interpretado. Por lo tanto, depende de una convención, de un hábito, o de una disposición natural de su interpretante, o del campo de su interpretante (el campo del cual el interpretante es una determinación)" (Peirce, 1974, p. 94).

La tercera tricotomía es encabezada por el interpretante. Considerando que "cada signo debe tener su interpretabilidad, una que le sea propia, antes de obtener un intérprete" (Peirce, 1974, p. 9), el interpretante forma parte de la relación triádica de los pensamientos de naturaleza basada en las leyes. Teniendo la posibilidad mental de representar algo. Es de dos tipos: inmediato, cuando representa lo que revela la correcta comprensión del signo mismo, y es dinámico, cuando se ajusta al efecto real del signo en relación con su objeto e incluye todos los interpretantes posibles de la realidad que representa (Peirce, 1974, p. 65). Es decir, cuando se muestra mentalmente materializado con una forma o soporte y un significado propio. Una vez que 
se asocia con su objeto y se le asigna un significado propio, el interpretante puede tomar el papel del representamen e iniciar una nueva semiosis. Sus componentes son:

Rhema, "es un signo de posibilidad cualitativa" (Peirce, 1987, p. 251) su definición no es clara y puede asociarse a varios objetos por las cualidades que comparten entre sí. En este nivel de la primeridad sólo aporta detalles de lo que puede llegar a ser. Se centra sólo en las cualidades del objeto que representa, pero parte de lo significado por la triada del representamen y por la del objeto.

Dicisigno, "es un signo que, para su interpretante, es un signo de existencia real.", pero para interpretarlo, depende de un rhema que le otorga la descripción de las posibilidades que tiene de ser representado a través de un objeto específico. Se basa sólo en las cualidades del objeto que representa y en su existencia real.

Argumento, "es un signo que, para su interpretante, es un signo de ley que es comprendido como representación de su objeto" por sus características de existencia real, y como representación de su objeto en su carácter de signo. En este nivel, el objeto ya está materializado a través del objeto y puede ser visualizado como ícono, índice o símbolo.

Las características del interpretante de adquirir el valor del significado de acuerdo con el objeto que representa y de acuerdo al representamen que le indica las primeras sensaciones e imágenes mentales, hacen que sea el elemento que lleve la triada de Peirce (Peirce, 1987) a tener un carácter infinito entendida como semiosis.

En la Figura 8, la semiosis se presenta como un triángulo continuo que es visto como un proceso de semiosis ilimitada. Cada ciclo de la semiosis inicia con un representamen, pasa por un objeto y finaliza con un intrepretamen. Sin que se pierda el continuo de significación, el inicio de la siguiente semiosis es el representamen que surge de la argumentación que se haya dado en el interpretamen y el resultado de esa argumentación toma el lugar del nuevo representamen.

Lo que se determina en primera instancia, como signo real o imaginario que asocia a un interpretante con el objeto, depende de cómo se relacione consigo mismo, cómo se relaciona con otros signos y cómo se relaciona con el contexto en el que se presenta. Así, ante diversas circunstancias, ese mismo signo puede adquirir nuevos significados para la misma persona 0 incluso para otras personas. En la Tabla 4 se muestran las categorías descritas en este apartado relacionado con la semiótica. 
Tabla 4. Ejemplo del uso del sistema de tricotomías de Pearce

\begin{tabular}{|c|c|c|c|}
\hline & $\begin{array}{l}\text { Relación de } \\
\text { comparación }\end{array}$ & $\begin{array}{c}\text { Relación de } \\
\text { funcionamiento }\end{array}$ & Relación de pensamiento \\
\hline & $\begin{array}{c}\text { Todas las } \\
\text { posibilidades } \\
\text { lógicas vistas como } \\
\text { cualidades }\end{array}$ & Hechos en bruto & Relacionado a las leyes \\
\hline & Representamen & Objeto & Interpretante \\
\hline Primeridad & 1. Cualisigno & 4. Ícono & 7. Rhema \\
\hline \multicolumn{4}{|l|}{$\begin{array}{l}\text { Es una } \\
\text { posibilidad }\end{array}$} \\
\hline Secundidad & 2. Sinsigno & 5. Índice & 8. Dicisigno \\
\hline \multicolumn{4}{|l|}{$\begin{array}{l}\text { Es un } \\
\text { existente } \\
\text { real }\end{array}$} \\
\hline Terceridad & 3. Legisigno & 6. Símbolo & 9. Argumento \\
\hline
\end{tabular}

Nota. El ejemplo es aplicado a la experiencia en primera persona, basada en la descripción del caso Uai. Fuente: elaboración propia.

\subsubsection{Tres formas de inferencia}

De manera ordinaria las personas no construyen conocimiento de forma sistemática, objetivada, controlada, ni experimental; como regularmente sucede desde la ciencia. Sin embargo, el desarrollo del conocimiento no necesariamente es como ocurre desde la perspectiva de la ciencia. Por tal motivo, la pregunta es: ¿qué nombre se le puede dar al conocimiento que genera una persona cualquiera para sí misma?, ¿qué implicaciones puede tener ese conocimiento? o ¿de qué manera puede afectar ese conocimiento al entendimiento y a la forma en la que uno se conduce en la vida cotidianamente?

En el caso de las personas con TEA, una de las teorías que describen su comportamiento se enfocan en la ToM que involucra la capacidad de las personas de identificar las creencias falsas a partir la interpretación de pensamientos, deseos o intenciones de otros (Baron-Cohen et al., 1985; Call \& Tomasello, 2008; Pedreño et al., 2017; Premack \& Woodruff, 1978), ¿pero qué hay de las creencias, deseos e intenciones de sí mismos?, ¿o de qué manera generan conocimiento para sí mismos a partir de lo que perciben del mundo?

Una respuesta a esta pregunta está en la ToM que se enfoca en dos niveles de complejidad (de primero y de segundo orden), como se expone en el EATR 1. Ambos niveles explican un tipo de inferencias que hacen las personas para generar un conocimiento inmediato que sirve como base para la toma de decisiones. Sin embargo, si las personas con TEA no son capaces de generar creencias del comportamiento de otros, ¿de qué manera explicar las 
creencias de las que parten para generar el conocimiento que las lleva a tomar una decisión o a comportarse de determinada manera?

Partiendo del concepto de lo que significan las creencias, de acuerdo con Peirce, se entiende que es la actitud de tener por verdadero algo sin importar lo que ese algo sea "la teoría atómica, o el hecho de que hoy es lunes, o el hecho de que esta tinta es bastante negra o lo que [se] desee" (Peirce, 1987, p. 133).

De acuerdo a esa postura de Peirce (Kerlinger \& Lee, 2013, p. 6), existen cuatro métodos para generar conocimiento:

1. Método de la tenacidad. En el que influyen las creencias pasadas ya establecidas, a partir de las cuales las personas generan "sus verdades" por lo que a medida que pasa el tiempo, aumentan su validez e incluso pueden generar nuevo conocimiento, aunque lo que creen sea falso.

2. Método de autoridad. Que se determina por la influencia y el valor que se les da a las figuras de autoridad reconocidas, o incluso menciona Kerlinger, por las posibles sanciones que puedan generar no seguir la regla. Por ejemplo, si una persona en la que se confía mucho afirma algo, el otro lo acepta como válido. O incluso, aunque no se confíe mucho en alguien, si un grupo de personas afirman (invariablemente) la veracidad de algo, aunque la persona piense diferente al grupo, terminará aceptando la verdad de los otros o dudando de su verdad, por coerción social.

3. Método a priori o de la intuición. Determinado por la inclinación natural de juzgar los hechos a partir de lo que "parece" más razonablemente cierto.

4. Método de la ciencia. Caracterizado por ser autocorrectivo, experimental y verificable, de tal forma que independientemente de quien diga, concluya o compruebe un hecho, el resultado sea el mismo.

Esta clasificación evidencia que la generación del conocimiento es una actividad que se lleva a cabo en todo momento, aunque su alcance sea sólo individual, como ocurre con las creencias, los prejuicios o los introyectos ${ }^{27}$. Por otro lado, una línea que tienen en común los cuatro métodos que Peirce (1987) propone que, para generar conocimiento, es necesaria la inferencia (que es empleada para explicarse a sí mismos lo que sucede en el mundo o para

\footnotetext{
${ }^{27}$ Son pensamientos, creencias o modelos impuestos por otros (regularmente por figuras de autoridad) que se asumen
} como verdad o valores sin ser refutados o cuestionados. 
socializar el conocimiento que se adquiere a través de las creencias comprobadas, refutadas o experimentadas), como ocurre en la ciencia.

Al respecto, Peirce (1987, p. 237) expone tres formas de inferencia en el argumento que es la última parte del primer ciclo de semiosis (ver Figura 9): inducción (razonamiento de lo particular a lo general), deducción (razonamiento de lo general a lo particular) y abducción (razonamiento que se explica de acuerdo a las posibilidades respecto a un cuerpo de creencias). Las tres forman parte del método que se dirige hacia el esclarecimiento de hechos a través de la comprobación, sea cual sea el medio. Las vías que se reconocen son producto del razonamiento o, dicho de otra manera, son las que generan conocimiento.

Tanto la inducción como la deducción son dos métodos, ampliamente conocidos por dirigir el pensamiento científico. De acuerdo con Kerlinger (Kerlinger \& Lee, 2013, p. 16) el razonamiento deductivo es el proceso de trasladar la generalización de un contexto amplio a una situación más específica (Kerlinger \& Lee, 2013, p. 15), mientras que el razonamiento inductivo "parte de un hecho particular hacia un enunciado general o hipótesis". Considerando las mismas definiciones, pero empleando la inferencia a partir de un razonamiento coloquial, Peirce (Eco \& Sebeok, 1989, p. 20) los explica de la siguiente manera:

En primer lugar, la deducción, «que depende de nuestra confianza en la habilidad de analizar el significado de los signos con los que, o por medio de los que, pensamos»; en segundo lugar, la inducción, «que depende de nuestra confianza en que el curso de un tipo de experiencia no se modifique o cese, sin alguna indicación previa al cese»; y, en tercer lugar, la abducción, «que depende de nuestra esperanza de adivinar, tarde o temprano, las condiciones bajo las cuales aparecerá un tipo determinado de fenómeno» (8.384- 388).

El argumento está compuesto de tres proposiciones: caso, resultado y regla, y tres permutaciones o distribuciones distintas de acuerdo con el tipo de argumento del que se trate, como se muestra en la Tabla 5. 
Tabla 5. Tipos de argumento y sus generalizaciones

\begin{tabular}{l|l|l}
\multicolumn{1}{c}{ Deducción } & \multicolumn{1}{c}{ Inducción } & \multicolumn{1}{c}{ Abducción } \\
\hline Regla & Caso & Regla \\
\hline Todas las judías de este saco son blancas & Todas las judías son de ese saco & Todas las judías de este saco son blancas \\
\hline Caso & Resultado & Resultado \\
\hline Todas las judías son de ese saco & Todas las judías son blancas & Todas las judías son blancas \\
\hline Resultado & Regla & Caso \\
\hline Todas las judías son blancas & Todas las judías de este saco son blancas & Todas las judías son de ese saco
\end{tabular}

Nota. Ejemplo de Umberto Eco. Fuente: (Garibay Rubio, 2017)

Peirce (1974, p. 40) propuso el concepto de la abducción como un método filosófico de reflexión desde el que explica el significado de los conceptos (Garibay Rubio, 2017) que tomamos por ciertos cotidianamente a través del sentido común (Aliseda-Llera, 1997) o que pueden ser aplicados como método de razonamiento científico (McNabb, 2018). De manera coloquial y cotidiana, la abducción es aquello que "permite formular una predicción general, pero sin garantía alguna de éxito en el resultado" (Eco \& Sebeok, 1989). Ésta es una forma de pronosticar a través de un método que conduce «la única esperanza posible de regular nuestro futuro comportamiento de manera racional» (2.270) (Peirce, 1987, pp. 258-259).

Desde su aplicación en la ciencia, para Peirce (Peirce, 1974) lo importante es emplear los signos conocidos para investigar los hechos del mundo. Respecto a los cuatro métodos descritos por Peirce, Kerlinger (Kerlinger \& Lee, 2013, p. 6) comenta que éstos sirven para resolver las dudas originadas en las creencias que forman las directrices de las que se parten para conocer el mundo. Las creencias a su vez son entendidas como una "regularidad en el pensamiento", que se mantiene a través de una fijación de la creencia que llega a sustituirse por un hábito. Pero cuando esa creencia se pierde, aparece una duda-creencia descrita como una irritación e incertidumbre por lo que se busca su eliminación con el establecimiento de una nueva creencia a través de un proceso cognitivo (McNabb, 2018).

De acuerdo con Garibay Rubio (2017, p. 16), las funciones de la abducción se pueden definir como sigue:

1. Asigna un rol de confirmación teorética a la explicación en donde sus consideraciones explicativas contribuyen a hacer algunas hipótesis más creíbles que otras, guiando la inferencia. 
2. "Es siempre una explicación con respecto a un cuerpo de creencias", menciona Aliseda en Garibay Rubio (2017, p. 16), a partir del cual se desarrollan hipótesis que explican el hecho.

3. Es una inferencia que parte de premisas explicativas que ayudan a generar conclusiones.

4. Se refiere a posibilidades, por lo que las explicaciones pueden ser verdaderas o falsas.

5. Puede ser vista como un producto terminado como el argumento explicativo o como un proceso explicativo.

Es importante mencionar que de las tres divisiones del argumento, la abducción es la "única clase de argumento que da comienzo a una nueva idea" (Peirce, 1987, p. 237). Con esto se coloca como el punto desde el que el interpretamen se convierte en representamen para iniciar una nueva significación (ver Figura 8). Llegando a los siguientes elementos de análisis:

1. De los cuatro métodos para generar conocimiento, tres de ellos (de la tenacidad, de autoridad y a priori o de la intuición) no dependen de la comprobación de resultados, como sí lo requiere la ciencia.

2. Las creencias son un reflejo de lo que se asume como verdadero sin importar el medio por el que se compruebe.

3. De los tres tipos de argumento, el de inferencia abductiva sea el único medio para generar nuevas ideas, y que además sea visto como única esperanza posible de regular el comportamiento de manera racional.

4. El argumento es del interpretamen la categoría que, una vez confirmada la significación, es el que se convierte en un nuevo signo pasando de ser un interpretamen a un representamen.

Se concluye que quizá es la inferencia abductiva la forma en la que infieren las personas con TEA. Que sin tener certeza del resultado que obtendrán, ajustan su conducta a lo que creen que deben responder a partir de la argumentación a la que llegan por medio de la significación que surge de su interpretación de los signos que les rodean. Lo cual les permite emitir su conducta de la manera más ajustada posible a lo esperado socialmente, misma que es reforzada 0 desechada de acuerdo con el resultado que obtengan de su respuesta. De acuerdo con Garibay podrían ser tres los tipos: explicativas, de contrastabilidad y de economía (Garibay Rubio, 2017, p. 12). 


\subsubsection{Proceso de significación y comunicación}

De acuerdo con lo que se ha descrito hasta ahora, el signo es el elemento básico a través del cual se puede interpretar el mundo. Es importante hacer la distinción entre comunicación y significación. Aunque los dos procesos están estrechamente ligados no necesariamente conducen al mismo sitio cuando se pretende establecer alguna relación recíproca o compartida con otros.

El habla es un acto individual, lo que la posibilita es un fenómeno social. De ahí que me atrevo a decir que, para las personas con TEA lo más complicado no es aprender o reconocer los signos, sino darles una utilidad social. Un ejemplo de ello lo encuentro en un diálogo con $\mathrm{Alev}^{28}$, quien entra en algo que él llama "ataque de nervios" porque quiere que le compren una tarjeta de videojuegos, pero no sabe cómo explicarle a su mamá qué contenido tiene dicha suscripción. Su problema no es de significación, sino de comunicación.

A pesar de que se considera que ambos forman parte del mismo proceso, se puede hacer una división de los signos que conforman cada etapa del proceso. Es decir, para la significación que comunica, la división básica relacionada al objeto se divide en ícono, símbolo e índice. Mientras que para la división de lo que únicamente significa retomo la clasificación de Umberto Eco (1976), en la que identifica signos naturales y signos artificiales como describe la Tabla 6.

Tabla 6. Clasificación del signo de acuerdo con Umberto Eco

\begin{tabular}{|c|c|c|c|}
\hline \multirow{5}{*}{ Signo } & \multirow[t]{2}{*}{ Naturales } & Índices & $\begin{array}{l}\text { Huellas o improntas } \\
\text { Indícios }\end{array}$ \\
\hline & & Síntomas & \\
\hline & \multirow[b]{3}{*}{ Artificiales } & Productivos & Homosubstanciales \\
\hline & & 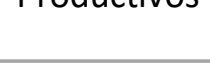 & Heterosubstanciales \\
\hline & & Sustitutivos & $\begin{array}{l}\text { Símbolos lingüisticos } \\
\text { Índices vectores } \\
\text { Signos visuales }\end{array}$ \\
\hline
\end{tabular}

Nota. Elaboración propia con información de (Eco, 1973, p. 64)

\footnotetext{
${ }^{28}$ Alev es un joven con TEA de 23 años, con quien, desde hace varios años, mantengo comunicación constante vía
} telefónica, por mensajes o por charlas de voz. 
De ella se extraen tres tipos: huella o impronta, indicio y síntoma. Que para su explicación retomo la descripción que Eco (2000) detalla en un análisis hecho en el tercer capítulo de la obra de Voltaire llamada Zadig, en cual menciona los casos más elementales del signo, empezando por la impronta o huella 29 .

Impronta. Es el caso más elemental de un signo, es un tipo de índice que toma el carácter de signo en el momento en el que el intérprete decide suponer que lo que observa es un signo. U. Eco (1989) menciona que "Interpretar una impronta significa ponerla en correlación con una posible causa física. Esa causa física no es imprescindible que sea real: puede ser simplemente posible, dado que se puede reconocer una marca incluso en las páginas de un manual", (Eco, 1989, p. 281) pero que de acuerdo con la experiencia uno se remite a sus causas posibles. En su definición, una impronta actúa como una expresión-tipo que puede ser asociada a alguna posible causa física. Eco menciona incluso que se podría hablar de improntas en los casos en los que una computadora hace el reconocimiento de un objeto a través de las marcas o huellas que deja. El caso que pone es el de la instrucción que se da a una computadora para que "reconozca la marca de un vaso de vino tinto sobre una mesa dándole las instrucciones precisas".

Al considerar el caso de Eco (1989), retomo el ejemplo de un artículo en el que participé en 2017 para desarrollar un sistema "reconocedor de posturas" para ser adaptado a la identificación de personas con TEA (Cervantes Martínez et al., 2017). El sistema consistió en aplicar un enfoque basado en clasificadores que pudieran recuperar la información de una persona (considerando varias posturas) en el ambiente (Figura 11). De ellas se extrajeron descriptores, coordenadas, ejes, ángulos y distancia, entre otras, para obtener clases que el sistema registrara automáticamente empleando clasificadores especializados.

\footnotetext{
${ }^{29}$ Umberto Eco las nombra indistintamente, pero debido al uso práctico que se le da en la investigación se le denomina exclusivamente como impronta.
} 
Figura 11. Procedimiento para la extracción de la silueta de la persona y desempeño de clasificadores

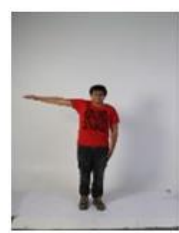

(a)

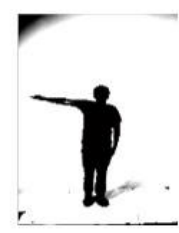

(b)

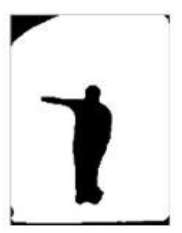

(c)

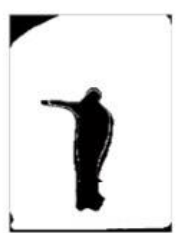

(d)

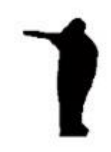

(e)

\begin{tabular}{lc} 
Clasificador & Exactitud \\
\hline SVM & 91 \\
\hline Knn & 90.3 \\
\hline Bayes & 90.3 \\
\hline Bayes ingenuo & 83.9
\end{tabular}

Bayes ingenuo $\quad 83.9$

Nota. Sistema de reconocimiento de posturas, Fuente "Hacia un sistema de reconocimiento de posturas para personas con trastorno del espectro autista" por Cervantes et. al., 2017, Tecnologías emergentes para un mundo inteligente. El profesional de TIC y la transdisciplina, p 37-42 (http://www.aniei.org.mx)

Esto quiere decir que, en el reconocimiento de la impronta, se lleva a cabo un procesamiento automático de esa expresión-tipo y que depende de la experiencia de quien la observa para que sea relacionada con su posible causa física. En el caso de las personas con TEA, la impronta se da cuando lo que ven o perciben se parece "a algo" que ellos identifican como una expresión-tipo, de lo que podrían aceptar o rechazar automáticamente considerando el criterio de que les atrae o que les disgusta.

Indicio. Se trata del segundo tipo de signo básico que también está relacionado con el índice. Eco lo explica de la siguiente manera:

Los indicios, por otra parte, son objetos dejados por un agente exterior en el lugar donde sucedió algo, y, de alguna manera, se reconocen como vinculados físicamente a ese agente. De modo que a partir de su presencia real o posible, puede advertirse la presencia pasada, real o posible del agente. (1989, p. 282)

La diferencia con la impronta es que los indicios sí están relacionados con un objeto en particular, el cual se detecta a través de una marca que el objeto deja a su paso. Es decir, hay una dependencia causal. Por ejemplo, cuando se conduce en la carretera y se pasa por el mismo lugar en el un zorrillo dejó una marca pestilente, aunque al momento de pasar ya no esté el mamífero la marca que dejó en el aire permanecerá durante un largo rato.

Síntoma. Los síntomas conservan una contigüidad, presente o pasada, y de relación causal con el referente (Eco, 1976, p. 64, 1989, p. 282). En los síntomas la causa y el efecto están completamente relacionadas, por lo que la presencia del efecto remite indiscutiblemente a la causa. Como en el caso del sarampión, los "signos y síntomas" que la describen son: Fiebre, tos seca, resfrío, dolor de garganta, ojos inflamados y manchas blancas diminutas con centro blanco azulado ${ }^{30}$. En términos médicos: todos, excepto el último, son los signos; las manchas

30 Datos mostrados en la página: https://www.mayoclinic.org/es-es/diseases-conditions/measles/symptomscauses/syc-20374857 
blancas son los síntomas que confirma invariablemente el sarampión. Es decir, si lo que se describe es sarampión, forzosamente aparecen las manchas, y es quizá el criterio confirmatorio de la enfermedad.

Como se puede observar, la identificación de estos tres tipos de signos depende de que haya alguien que los lea como tal. Una impronta requiere de la experiencia de alguien que relaciona lo que conoce con lo que ve, es una relación tácita o sobreentendida por la persona. En el caso del índice, la marca que puede dejar el objeto invariablemente se reconocerá si esa marca (olfativa, visual o de cualquier otra índole) es característica del objeto. $Y$ en el síntoma, el reconocimiento del signo se dará por la experiencia de quien es capaz de identificar una causa con su efecto que invariablemente aparecerán contiguos.

Todo lo que se observa en el entorno puede indicar "algo" que podría ser o no interpretado por alguien de manera subjetiva sin que exista una intención de comunicar. Un proceso de significación, de acuerdo con Umberto Eco, es "cualquier intento de establecer el referente de un signo [que] lleva a definirlo en los términos de una entidad abstracta que representa una convención cultural" (2000, p. 111).

Esta clasificación se retoma en el capítulo cuatro para nombrar los niveles de interacción que se describen entre los niños con TEA y el robot humanoide.

\subsubsection{Explicación semiótica de la percepción}

El grupo Mu (Grupo MU, 1993, p. 81), en su tratado del signo visual, propuso un modelo global de codificación visual, en el que plantean el proceso de decodificación que lleva a una persona a reconocer las formas de los objetos a través de entidades perceptibles. A este proceso le dio el nombre de repertorio y se refiere a la atribución del sentido de las cosas que se adquiere al pasar por tres niveles de codificación: el primer nivel se remite netamente a las sensaciones evocadas por el objeto; el segundo nivel se centra en los procesos perceptivos que agrupan lo percibido de acuerdo con el color, la forma o textura (por poner un ejemplo), y el tercer nivel, se basa en los procesos cognitivos en los que se integra el significado completo de las cosas y genera para sí mismo repertorios que posteriormente serán la base de las semiosis. En dicha atribución, el sentido conduce desde el aspecto perceptivo-sensitivo hasta llegar al ámbito cognitivo. Refiriéndose a éstos como niveles de codificación.

Por su parte, Umberto Eco (Zecchetto, 2005, p. 213) en un esfuerzo por explicar el vínculo que existe entre el proceso semiótico, la cognición humana y la idea de signo, realizó una comparación interesante que se relaciona con la división elemental de los signos (impronta, 
indicio y síntoma). Comenta que cuando se requiere un proceso de reconocimiento en el que no es claro lo que se observa, pero sí es interpretado por las personas, se está frente a una actividad pre-categorial en la que el conocimiento empírico abarca todas las posibilidades de interpretación y de designación de esquemas, en donde el requisito fundamental es que sea realmente percibido. A ese proceso lo considera un proceso de semiosis primaria (Zecchetto, 2005, p. 214) que depende de la información previa que poco a poco va tomando forma hasta ser identificado como el signo de algo.

Al respecto, Joan Costa, menciona que "el significado de las cosas está potencialmente en los esquemas mentales de los individuos. Es la pantalla interna de conocimientos donde los estímulos del entorno proyectan en ella significados" (Costa, 2003, p. 54), mientras que la comunicación reside en la capacidad de recibir, decodificar e interpretar algo que otro individuo concibió, codificó y emitió.

En los tres casos, el primer contacto con el mundo surge a través de la percepción, llamada por Peirce como la recepción pasiva. Mientras que el conocimiento del mundo se genera por la facultad activa del razonamiento (McNabb, 2018). Es a través de la recepción pasiva y no de la facultad activa del razonamiento como las personas con TEA (primordialmente los de mayor grado de afectación) conciben al mundo. En el siguiente apartado se retoman algunas de estas ideas que se relacionan con la alteración del sistema sensorial perceptivo de las personas con TEA. 


\subsection{EATR 3. Cognición, funciones ejecutivas y consciencia}

\subsubsection{Bases del procesamiento sensorial perceptivo}

Las "funciones ejecutivas podrían depender en gran parte del desarrollo gradual del lenguaje, de la rapidez en el procesamiento de la información y de la capacidad de atención y de memoria", Anderson 2005 en (Ardila, 2012, p. 208). La maduración de las áreas sensoriomotoras y asociativas, implicadas en el desarrollo, dependen en gran medida de la cantidad y calidad de las experiencias de aprendizaje que proporciona el medio ambiente (Flores et al., 2014, p. 3). Por lo cual, es esperado que el desarrollo de las FE de las personas con TEA se encuentre alterado dado el repertorio de conductas cíclicas que suelen tener y la poca flexibilidad que presentan.

\subsubsection{Percepción}

Uno de los elementos primordiales para comprender cómo percibimos es preguntarse qué percibimos. Al respecto, Feldman (2003), Griffiths y Warren (2004) en Palmer (2019) comentan que los objetos o cosas son las unidades de nuestro mundo percibido que se pueden categorizar en tres aspectos: 1) se perciben como unidades o paquetes con coherencia espacial y temporal; 2) regularmente se les percibe como cosas con existencia independiente y con propiedades inmutables, y 3) sus propiedades, percibidas como constantes, son las que nos hacen creer que los objetos no cambian, aunque cambien bajo distintas condiciones. Estas propiedades que la mayoría identifica con estabilidad y constancia, las personas con TEA las perciben a diferentes ritmos y con significados distintos bajo diferentes condiciones.

De manera regular, la agrupación de las partes en los objetos unificados (aunque estén en constante cambio y ubicación), se agrupan para ser distinguidos como parte del mundo de forma tridimensional (Handel, 2019, p. 10). Sin embargo, la velocidad del procesamiento en las personas con TEA no está regularizado. Robertson y Baron-Cohen (2017) han planteado la necesidad de explorar si las problemáticas asociadas al lento procesamiento de varias modalidades sensoriales que presentan las personas con TEA se enfocan realmente en el procesamiento sensorial o en los mecanismos cognitivos de orden superior. Identificar el origen de la problemática (sensorial o cognitiva) podría ayudar a redirigir el enfoque y, por lo tanto, las alternativas de apoyo para estas personas. 


\subsubsection{Atención}

Como presentó en el capítulo uno, el nivel de participación en la realización de tareas, dependen de la capacidad de sincronizar los componentes básicos de las propias FE. No obstante, para poder activarlas todas estar en torno a un elemento básico: prestar atención en los dos sentidos, de lo sensorial a lo cognitivo o de lo cognitivo a lo sensorial. Este proceso es en primera instancia inobservable pero se infiere a partir de otras conductas observables (Soprano, 2014, p. 17).

Para que se lleve a cabo el proceso de la atención se requiere que la persona primero filtre la información relevante del ambiente. Melo Florian (2011, p. 211) comenta que "desde el punto de vista de las neurociencias, la atención se puede definir como la capacidad de un sujeto de enfocar la conciencia a un solo estímulo ambiental, manteniendo los contenidos de conciencia, y excluyendo otros que causen distracción”. Este proceso es el que mantiene la mente autoconsciente favoreciendo que la información se organice a diferentes niveles con las FE, incluidas las emociones.

Tanto la percepción como la atención son dos procesos que están alterados en las personas con TEA. En esta investigación, los dos procesos son considerados para facilitar el contacto y la comunicación con las personas que formaron parte del estudio. Por lo que se hacen dos acotaciones respecto a cada término para su aplicación operativa.

\subsubsection{Elementos para la aplicación operativa de la percepción y la atención}

Una implicación importante de la percepción es que lo que se conoce influye en lo que se percibe, y deja huella. Esta afirmación, aunque parezca lógica, y con poco sentido de mencionarse, cuando se trabaja con personas con TEA es importante identificar qué tipo de objetos pueden atender y, por lo tanto, a través de qué objetos pueden estar dispuestos a conocer lo que les rodea.

Ya se ha mencionado de la dificultad que tienen las personas con TEA de imaginar y diferenciar los propios pensamientos y emociones de lo que piensan y sienten otras personas, esto los coloca en una situación de poca empatía cognitiva (Warrier \& Baron-Cohen, 2018). Estas alteraciones, mencionan Caroline Robertson y Baron-Cohen (2017), están acompañadas de hasta el $90 \%$ de alteraciones perceptivas con implicaciones en todos sus sistemas sensoriales. Por lo que las características de dichos objetos son importantes para asegurar que estarán dentro de alcance perceptivo tratando de disminuir el "ruido" que interfiera con el seguimiento de las FE. Las características generales de los objetos se consideraron a partir de las observaciones que reportan Robertson y Baron-Cohen (2017, pp. 672-673) como se describe en la Tabla 7. 
Dentro de la atención, la percepción juega un papel primordial debido a que es la puerta o filtro a través de la cual atraviesan todos los sentidos circundantes e internos. La atención es la que ordena los múltiples estímulos del ambiente o de sí mismo. Así, para entender el mecanismo que se sigue (desde que el estímulo interno o externo entra en contacto con los sentidos hasta hacerlo consciente), la identificación de la atención es realmente relevante.

Como se mencionó en el planteamiento en el capítulo 1, la atención y la autoconciencia (o autoanálisis) son los ingredientes esenciales para poner en práctica las FE. A través de éstos, la persona valora sus experiencias subjetivas para emplearlas en la resolución de problemas y guiar la toma de decisiones de su presente (Stuss y Benson en Tirapu-Ustárroz et al., 2005).

Tabla 7. Características de los objetos que influyen en la percepción de personas con TEA

\begin{tabular}{|c|c|c|c|}
\hline $\begin{array}{l}\text { Modalidad } \\
\text { sensorial }\end{array}$ & $\begin{array}{c}\text { Aspectos percibidos o alterados por las } \\
\text { personas con TEA }\end{array}$ & $\begin{array}{l}\text { Consideraciones para diseñar } \\
\text { las tareas de FE }\end{array}$ & $\begin{array}{l}\text { FE en la que } \\
\text { se aplicó }\end{array}$ \\
\hline Visual & $\begin{array}{l}\text { Se han identificado tres niveles en los } \\
\text { patrones de observación: } 1^{\circ} \text { Tienden a } \\
\text { centrarse en detalles como el color, el } \\
\text { contraste y la orientación. } 2^{\circ} \text { Después } \\
\text { perciben el tamaño, la densidad o la } \\
\text { complejidad del contorno. } 3^{\circ} \text { Se centran en } \\
\text { características de contenido semántico } \\
\text { como el texto, o identificación de caras. }\end{array}$ & $\begin{array}{l}\text { 1․ Colores básicos y } \\
\text { complementarios } \\
2^{\circ} \text { Tamaño } \\
3^{\circ} \text { Contornos de objetos bien } \\
\text { definidos (uso de figuras } \\
\text { geométricas) }\end{array}$ & $\begin{array}{l}\text { Repertorios } \\
\text { básicos y FE }\end{array}$ \\
\hline $\begin{array}{l}\text { Percepción } \\
\text { táctil }\end{array}$ & $\begin{array}{c}\text { Se han identificado alteraciones en las } \\
\text { características temporales del } \\
\text { procesamiento sensorial. }\end{array}$ & $\begin{array}{l}\text { Objetos fácilmente reconocibles. } \\
\text { Los elementos táctiles estuvieron } \\
\text { supeditados a los visuales }\end{array}$ & \\
\hline $\begin{array}{l}\text { Percepción } \\
\text { auditiva }\end{array}$ & $\begin{array}{c}\text { Se ha detectado retraso en las latencias de } \\
\text { las respuestas auditivas sobre todo en } \\
\text { estímulos sociales complejos como los } \\
\text { sonidos del habla, lo cual podría tener } \\
\text { implicaciones de orden superior en la } \\
\text { comunicación }\end{array}$ & $\begin{array}{c}\text { Se hicieron pruebas con la voz del } \\
\text { robot para asegurar que se } \\
\text { entendiera su pronunciación y } \\
\text { expresión }\end{array}$ & Todas \\
\hline $\begin{array}{l}\text { Integración } \\
\text { multisensorial }\end{array}$ & $\begin{array}{l}\text { Presentan problemas en relación con el } \\
\text { tiempo para discernir entre un estímulo y } \\
\text { otro, entre los eventos sincrónicos con los } \\
\text { asincrónicos. Esto se ha detectado sobre } \\
\text { todo cuando se han explorado con } \\
\text { mecanismos audiovisuales, se considera } \\
\text { que es debido a la integración de estímulos } \\
\text { provenientes de varias vías sensoriales. }\end{array}$ & $\begin{array}{l}\text { Se dejó un tiempo determinado } \\
\text { entre la presentación de un } \\
\text { estímulo y otro. Se dieron tres } \\
\text { oportunidades para responder el } \\
\text { mismo ejercicio a excepción de la } \\
\text { escala de metacognición en la que } \\
\text { la prueba BANFE-2 tiene el } \\
\text { parámetro de hacer cinco ensayos. }\end{array}$ & Todas \\
\hline $\begin{array}{l}\text { Procesamiento } \\
\text { temporal }\end{array}$ & $\begin{array}{l}\text { Han reflejado problemas asociados a } \\
\text { varias modalidades sensoriales. } \\
\text { Particularmente, se ha observado en } \\
\text { respuestas evocadas retrasadas en el } \\
\text { dominio auditivo y en la integración de } \\
\text { múltiples estímulos locales } \\
\end{array}$ & $\begin{array}{c}\text { Solo en una prueba (en la que se } \\
\text { emplea el efecto stroop) se usaron } \\
\text { dos canales sensoriales al mismo } \\
\text { tiempo (visual y auditivo) }\end{array}$ & Stroop \\
\hline
\end{tabular}

Nota. En las dos primeras columnas se presentan datos de Robertson y Baron-Cohen (2017) relacionadas con la modalidad sensorial y su descripción. Las siguientes columnas describen la aplicación que se da a la información para el desarrollo de los objetos empleados en la evaluación de las FE que se describen en el capítulo 4 . El efecto stroop es un tipo de interferencia semántica. 


\subsubsection{Funciones ejecutivas, bases neurológicas}

En la introducción y en el capítulo 1 se comentó la importancia de las FE para comprender y organizar cognitivamente las actividades mentales complejas con el fin de lograr metas planificadas (Bock et al., 2019; Calle Sandoval, 2017; Papazian et al., 2006; Tirapu-Ustárroz et al., 2005). En este apartado se amplía la explicación con un enfoque práctico que relaciona los mecanismos involucrados en la consciencia y, particularmente, el acceso consciente que depende de la atención y de la cognición.

Las FE se han descrito como un sistema encargado de constituir "las capacidades mentales esenciales para llevar a cabo una conducta eficaz, creativa y aceptada socialmente" Lezak, 1982 en (Tirapu-Ustárroz et al., 2005, p. 177). En ese sistema se involucra además la facultad a través de la cual una persona plantea una meta, establece una estrategia y la lleva a cabo (González Osornio, 2015); sea cual sea la complejidad, si se implican acciones encaminadas al logro de una meta se habla de una FE.

Neurológicamente, el desarrollo de las FE se ha relacionado con la maduración de los hemisferios cerebrales, particularmente de la corteza ${ }^{31}$, y dentro de esta estructura la corteza prefrontal (Flores-Lázaro \& Ostrosky-Shejet, 2012, p. 14; González Osornio, 2015). Ardila (2012, p. 188) señala cinco etapas de maduración: del nacimiento hasta los tres años se presentan cambios topográficamente difusos; de los cuatro a los seis años hay cambios a nivel frontotemporal izquierdo y frontal derecho; de los ocho a los 10 años las conexión neuronales de las regiones temporales y frontales del hemisferio derecho; de los 11 a los 14 años inician los cambios en los lóbulos prefrontales, y de los 15 en adelante hay una mayor maduración bilateral en lóbulos prefrontales.

De manera congruente, otros autores han identificado los cambios morfológicos con implicaciones en la FE. Se ha reportado que éstas empiezan a desarrollarse durante el primer año de vida (Martos Pérez \& Paula Pérez, 2011; Tirapu-Ustárroz \& Luna-Lario, 2011, p. 223). Presenta picos de maduración entre los 2 y los 5 años, con constancia entre los 12 (TirapuUstárroz \& Luna-Lario, 2011) y los 14 años, que muestra estabilización a los 18 años (Martos Pérez \& Paula Pérez, 2011, p. S148).

Gardiner (2017) reporta que las FE se han conceptualizado desde tres ángulos: 1) desde un marco unitario en el que se considera la medición de las FE individualizada a partir de los

${ }^{31}$ Considerada como la estructura cerebral más desarrollada de los humanos. Contiene alrededor de 100.000 millones de neuronas formando una capa de 2 a 5 milímetros que cubre la superficie del cerebro. En ella se llevan a cabo las funciones de mayor complejidad de la conducta humana (Guyton y Hall. Tratado de fisiología médica, 13e Elsevier). 
procesos comunes que las unen; 2) como una estructura de componentes que considera grupos de FE, que se han medido de manera independiente y que siguen patrones diferenciados en los que su grado de maduración dependen de la edad y de la etapa de desarrollo de la persona, y 3) como una estructura integradora, que incluye FE separadas pero que en determinada edad 0 proceso se integran; los cuales forman un sólo sistema: primero desde el desarrollo de las habilidades básicas, y ,después, por componentes de manera jerárquica e interrelacionada.

Estos tres esquemas, representan la forma en la qua las FE se interrelacionan entre sí. Sobre todo cuando una persona - a edades tempranas o tardías - requiere la utilización de actividades mentales básicas, superiores o complejas para programar, regular, o controlar sus acciones encaminadas al logro de una meta (García Rodríguez \& Gonzalez Ramírez, 2014). La medición de las FE dentro de esos modelos incluye datos relacionados con la conducta, la cognición, los cambios neuroanatómicos y neuronales (Eleni A. Demetriou et al., 2019).

Los esquemas descritos se basan en el uso de la memoria de trabajo, en los sistemas atencionales (como marcadores somáticos), y en la organización de las FE a sistemas simples, integrados o jerárquicos (Eleni A. Demetriou et al., 2019; Flores-Lázaro \& Ostrosky-Shejet, 2012; Tirapu-Ustárroz \& Luna-Lario, 2011).

Una división importante que es preciso considerar es la clasificación de las llamadas FE frías o calientes, que atienden a la premisa de ser procesos cognitivos (frías), o procesos mediados por demandas afectivas y motivacionales (calientes) (Eleni A. Demetriou et al., 2019). Entre las FE frías están la memoria de trabajo, la planificación y la inhibición. Mientras que las que involucran aspectos afectivos está la toma de decisiones afectiva, y descuento por demora (Kouklari et al., 2019). De ellas, las más exploradas en personas con TEA han sido las relacionadas con los procesos cognitivos (E. A. Demetriou et al., 2018).

\subsubsection{Delimitación conceptual de las funciones ejecutivas}

Las FE no necesariamente se refieren a un proceso unitario sino a un constructo en el control de habilidades de alto orden que influyen en habilidades como la atención, la memoria y las habilidades motoras (González Osornio, 2015). Partir de un sistema que involucre tanto las FE frías como las calientes podría beneficiar la obtención de resultados integrales. Soprano (2014, pp. 22-23) ha descrito que la investigación se dirige hacia el estudio de la integración de las funciones cognitivas, relacionadas con aspectos emocionales y conductuales involucrados en la resolución de problemas de modo eficaz, sobre todo cuando se trata de situaciones nuevas. 
Debido a que no existe un consenso para determinar las FE (E. A. Demetriou et al., 2018; Martos Pérez \& Paula Pérez, 2011; Tirapu-Ustárroz \& Luna-Lario, 2011) su definición ha dependido en gran parte del enfoque que se da a la estructura organizacional involucrada $o$ al modelo que se emplea para explicarlas. En esta investigación la guía que se decidió tomar proviene de dos pruebas psicométricas especializadas en el diagnóstico de las FE:

1. BRIEF-2. Evaluación conductual de la función ejecutiva (Gioia et al., 2015).

2. BANFE-2. Batería neuropsicológica de FE y lóbulos frontales (Flores et al., 2014).

Ambas pruebas han sido utilizadas ampliamente para evaluar las FE que se reportan en estudios previos (Alsaedi et al., 2020; Gardiner et al., 2017; Glenne Øie et al., 2020). BRIEF desde el ámbito internacional y BANFE desde un enfoque y adecuación para población mexicana (Flores-Lázaro \& Ostrosky-Shejet, 2012; Flores et al., 2014).

Tomar los parámetros de estas dos pruebas para definir las FE facilitó la comparación de los resultados al interior de la muestra y dio uniformidad a los datos de los usuarios con los que se trabajó. Además, las dos pruebas son sensibles a la aplicación de niños con TEA, primordialmente BRIEF-2 que es la que se emplea de manera directa en este trabajo.

\subsubsection{Definición operativa de las FE}

Dada la acotación anterior, en esta investigación las FE son consideradas como el "conjunto de procesos responsables de dirigir, guiar y controlar las funciones cognitivas, emocionales y conductuales" (Gioia et al., 2015). Esta definición es presentada en la prueba BRIEF-2 que incluye las FE centradas en los procesos cognitivos fríos y calientes con sendas escalas de medición como se muestra en la Tabla 8 (en color verde las frías conductuales, 1-2; en color rojo las calientes emocionales, 3-4, y en azul, las frías cognitivas, 5-9). En la Tabla 8 se muestra la estructura de la prueba y los parámetros que mide.

BRIEF-2 considera nueve FE descritas como escalas clínicas: inhibición, supervisión de sí mismo, flexibilidad, control emocional, iniciativa, memoria de trabajo, planificación/ organización, supervisión de la tarea y organización de materiales. A partir del análisis de las nueve escalas se detectan tres índices de regulación de la persona en estudio (conductual, emocional y cognitivo), y un índice global que sintetiza todas las escalas clínicas ${ }^{32}$.

\footnotetext{
${ }^{32}$ En este apartado sólo se definen las escalas clínicas. Las escalas de validez y los índices se describen en el capítulo de aplicación y resultados.
} 
Tabla 8. Escalas de medición de BRIEF-2

BRIEF-2

\begin{tabular}{|c|c|}
\hline \multirow[t]{2}{*}{ Escalas de validez } & Inconsistencia \\
\hline & Negatividad \\
\hline \multirow{9}{*}{ Escalas clínicas } & 1. Inhibición \\
\hline & 2. Supervisión de sí mismo \\
\hline & 3. Flexibilidad \\
\hline & 4. Control emocional \\
\hline & 5. Iniciativa \\
\hline & 6. Memoria de trabajo \\
\hline & 7. Planificación y organización \\
\hline & 8. Supervisión de la tarea \\
\hline & 9.Organización de materiales \\
\hline \multirow{4}{*}{ Índices } & Índice de regulación conductual \\
\hline & Índice de regulación emocional \\
\hline & Índice de regulación cognitiva \\
\hline & Índice global de función ejecutiva \\
\hline
\end{tabular}

Fuente: (Gioia et al., 2015) con modificaciones.

En la definición operativa de las FE, se consideraron las nueve escalas clínicas del BRIEF2, y dos aspectos de BANFE-2. El primero es la metacognición — descrita más adelante-, y el segundo es la medición de autoconsciencia del cuestionario neuropsicológico del daño frontal. BRIEF-2 valora aspectos conductuales, emotivos y cognitivos. En la versión anterior se examinaba el aspecto metacognitivo como un índice. Recientemente, ha sido considerado como el factor más importante para explicar la función social en niños con TEA (Torske et al., 2018). Sin embargo, como en la versión 2, fue estimado dentro del índice de regulación cognitiva en la que, al mismo tiempo, se evalúan otras FE (Tabla 8), por tal motivo, en esta investigación la prueba de metacognición que incluye BANFE-2 se empleó como complemento. 
Las escalas clínicas ${ }^{33}$ en el BRIEF-2 "refieren problemas en distintos tipos de conductas relativas a nueve dominios de funcionamiento ejecutivo" (pag. 49) como se describe a continuación:

1. Inhibición (Inh). Se fundamenta en la evaluación de "problemas para controlar impulsos, para regular el comportamiento adecuadamente y para frenar la conducta en el momento apropiado". Se considera una FE fría porque requiere el impulso premeditado de la persona. El control inhibitorio - además de regular y controlar la tendencia a generar respuestas impulsivas_-, es básico para regular la conducta y la atención (BANFE-2).

2. Supervisión de sí mismo (Smi). El aspecto más importante de esta escala es medir los problemas que la persona en estudio presenta para "darse cuenta y ser consciente del efecto de la propia conducta en los otros". El darse cuenta está relacionado con la identificación de otros en su entorno inmediato y ésta involucra la ToM revisada anteriormente.

3. Flexibilidad (Fle). Refleja la presencia de problemas para "cambiar libremente de una situación, actividad o aspecto de un problema a otro si las circunstancias así lo requieren". De acuerdo con BANFE-2, esta capacidad está relacionada con la habilidad para identificar estrategias cognitivas para la solución de problemas y saber usar la alternativa de cambiar el foco de atención, con el fin de emplear otros procedimientos.

4. Control emocional (Cem). Explora la facilidad para "regular o modular adecuadamente las respuestas emocionales".

5. Iniciativa (Ini). Evalúa las dificultades para "iniciar tareas o actividades de forma autónoma e independiente o para generar nuevas ideas, respuestas o estrategias de resolución de problemas".

6. Memoria de trabajo (Mtr). Valora problemas para mantener temporalmente la información en la mente con el objetivo de completar una tarea o de mantenerse en una actividad". Cuando las tareas requieren que la información se mantenga activa, la memoria de trabajo permite conservarla mentalmente mientras se

${ }^{33}$ Las citas entrecomilladas de este apartado tienen como referencia el manual BRIEF-2 (Gioia et al., 2015, pp. $12-$ 13). Solo las citas que no correspondan a BRIEF-2 serán referenciadas con sus respectivas autorías. 
analiza, selecciona e integra (BANFE-2) al espacio de trabajo o uso donde se requiera.

7. Planificación y organización (Pla). Evidencia dificultades para "anticiparse a situaciones futuras, ordenar y priorizar la información, plantear objetivos y secuenciar los pasos necesarios para lograrlos y comprender y comunicar las ideas principales o los conceptos clave". Esta capacidad se relaciona con la facilidad para implementar estrategias o procedimientos enfocados en lograr una meta en el menor tiempo posible y con el menor esfuerzo (BANFE-2)

8. Supervisión de la tarea (Sta). Evalúa la presencia de problemas para revisar su trabajo, para valorar su ejecución durante y después de realizar la tarea y para asegurarse de la consecución del objetivo.

9. Organización de materiales (Org). Refleja problemas para mantener orden y organización en la zona de estudio, trabajo o juego y las cosas propias de quien se evalúa. Esta FE permite clasificar los estímulos en grupos de categorías semánticas lo que facilita el aprendizaje de la información BANFE-2.

10. Metacognición. Se refiere al control y regulación de los propios procesos cognitivos. A través de ella se valora la capacidad para desarrollar una estrategia de memoria que considera un control metacognitivo y la habilidad para predecir el propio desempeño (Flores et al., 2014).

Las nueve escalas de FE de BRIEF-2 se pueden emplear para hacer una comparación y análisis (por separado) de los puntajes obtenidos en los índices de regulación conductual, emocional y cognitiva. O se puede emplear el puntaje del índice global de función ejecutiva que evalúa de manera general el índice de disfunción ejecutiva.

En cuanto a la escala diez; ésta se considera como una medición del desarrollo de una estrategia de memoria, de la predicción de juicios de desempeño real y proyectado (Flores et al., 2014). La metacognición es una de las FE de mayor jerarquía cognitiva y se ha valorado como una función ejecutiva supervisora de la propia conducta (Tirapu-Ustárroz \& Luna-Lario, 2011), asociada con la edad y la conducta social (Torske et al., 2018).

\subsubsection{Teorías de la consciencia}

La explicación de la consciencia — desde el punto de vista humano y desde el contexto de lo artificial - es importante debido a que ambas posturas convergen en el mismo objeto de estudio 
durante esta investigación. Las dos perspectivas se relacionan, y guían el camino hacia la explicación de cómo se comportan las personas con TEA en escenarios artificiales donde practican sus FE mientras interactúan con un robot humanoide.

En el EATR 2 se mencionaba que tanto el estudio de las emociones como el fenómeno de la consciencia, estuvo relegado por los primeros paradigmas de la propia psicología. En su proceso de validación, el estudio de la consciencia tuvo que superar tres obstáculos. El primero, fue dotarla de una definición que retomara de las distintas posturas, pero sobre todo que la hiciera asequible para su estudio. El segundo, fue el hecho de que era posible manipularla experimentalmente, lo cual facilitó tener un mejor control en su descripción para ser replicada experimentalmente. $\mathrm{Y}$ el tercero, es que se validó el fenómeno subjetivo (que tanto había despreciado el conductismo), pero dándole un nuevo enfoque con la definición del acceso consciente relacionado con la capacidad de atender los estímulos internos o externos. Estos tres elementos la condujeron del ámbito filosófico al terreno experimental del laboratorio (Dehaene, 2015; Dehaene \& Changeux, 2011).

\subsubsection{Niveles de consciencia}

La neurología es uno de los recursos que más se han utilizado para ampliar el campo de estudio de la consciencia. En los últimos diez años se han aportado evidencias de los distintos estados y condiciones que facilitan su descripción (Dehaene et al., 2017; Glannon, 2013; Koch, 2018; Oizumi et al., 2014). Actualmente, se han descrito más de siete estados (Glannon, 2013), que van desde el mantenimiento de la vida de una persona con o sin autonomía fisiológica (estado de coma) hasta llegar a la expansión de la mente (Laureys et al., 2004).

Con el fin de tener el esquema general de los componentes de la consciencia y ubicar el marco de referencia en este trabajo, en la Figura 12 se representan los estados de la consciencia en estado fisiológico antes y después de la vigilia/despertar.

La referencia relacional son dos correlatos neurofisiológicos: 1) la consciencia del entornodel sí mismo que implica el contenido de la consciencia, y 2) el nivel de excitación-alerta o estado de la consciencia. Ambos conceptos también son empleados para explicar los mecanismos bajo los cuales se rige la conducta del control ejecutivo de personas regulares y con TEA (Eleni A. Demetriou et al., 2019; Silva et al., 2015). 
Figura 12. Estados de consciencia

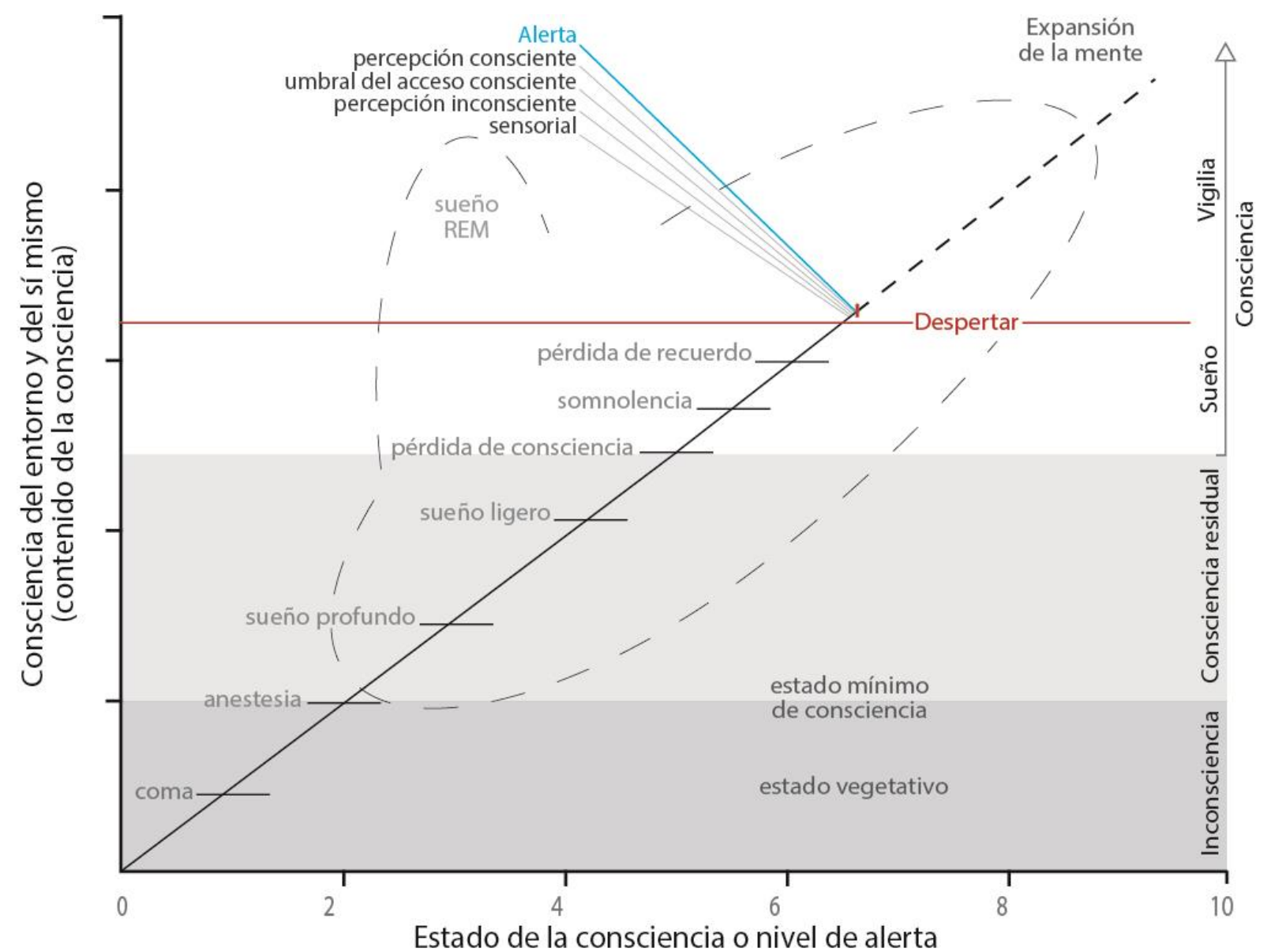

Nota. Diagrama de adaptación propia de conceptos que explican el estado de consciencia desde la perspectiva de "Self-consciousness in non-communicative patients", por Laureys, Steven et al., 2004, Consciousness and Cognition 16 (3) p. 724.,y con adecuaciones incorporadas del Stanford Institute for Neuro-Innovation\&Translational Neuroscience (https://web.stanford.edu/group/maciverlab/Concious.html)

Como se puede observar en la Figura 12; el nivel o estado de consciencia se representa como un mecanismo continuo, marcado con una línea diagonal ascendente que relaciona la consciencia del entorno y del sí mismo con el nivel de excitación-alerta o estado de la consciencia $^{34}$. La zona delimitada con un óvalo de línea punteada es la zona en la que de manera

${ }^{34}$ Los tres estados asociados a la fase de inconsciencia son: 1) el coma, caracterizado porque no tienen el ciclo de sueño-vigilia, ni conciencia del sí mismo o del entorno (Gosseries et al., 2014); 2) el estado vegetativo, durante el cual sí hay presencia de sueño-vigilia, pero no hay conciencia del sí mismo o del entorno, ni respuestas conductuales sostenidas reproducibles y con propósito a estímulos externos en donde se vive una vida desprovista de actividad intelectual o intercambio social (Dehaene, 2015, p. 253), 3) el estado mínimo de consciencia, aquí, el espectro de respuesta es fluctuante, y va desde la no respuesta hasta respuestas verbalizadas, inteligibles de comunicación. Es 
regular las personas experimentamos ese continuo de consciencia, incluido el sueño (Laureys et al., 2007). Horizontalmente se presentan tres sombreados en gris que delimitan la inconsciencia (en donde hay ausencia de respuesta a estímulos internos y externos), la consciencia residual (estado temporal fisiológico y reversible con desconexión parcial de la consciencia, como sucede durante el sueño), y la consciencia (momento en el que hay respuesta y atención al entorno e incrementa el estado de alerta). Las pequeñas barras horizontales marcadas sobre la línea diagonal indican una aproximación del momento en el que aparece cada estado que señalan. En la etapa más profunda (parte inferior de la figura) se encuentra el estado patológico, y en la parte superior, la fase de la consciencia con la que se relacionan las FE.

La fase de consciencia en la que se enmarca esta investigación se divide en sueño y vigilia. Durante el sueño se conserva un poco de consciencia, pero es en la vigilia, delimitada con el despertar, a partir de la cual el organismo está más receptivo y listo para atender los estímulos de manera más eficiente. Como se observa en la Figura 12, la consciencia después del despertar inicia con las sensaciones que ingresan a la percepción, primero inconsciente y después consciente, atravesando el umbral del acceso consciente (Soprano, 2014).

El nivel de alerta es un parámetro que se relaciona con el nivel de atención que se presta a los estímulos internos o circundantes (Dehaene, 2014). Actualmente, en la definición básica de la consciencia se incluyen al menos tres estados referenciales (Dehaene, 2015, p. 26): vigilia (identificada como nivel de consciencia) que implica estar despierto o dormido (en la Figura 12 se marca como el despertar); atención, encargada de focalizar los recursos mentales sobre cierta información específica, y el acceso consciente, proceso mediante el cual la información (que es atendida) puede ingresar a la percepción consciente y volverse comunicable a los demás.

Desde las neurociencias "la atención se puede definir como la capacidad de un sujeto de enfocar la conciencia a un solo estímulo ambiental, manteniendo los contenidos de conciencia, excluyendo otros que causen distracción, diferenciándolos directamente de la conciencia". Sin embargo, es importante diferenciar la atención, el estado de alerta y la concentración. La primera,

por ello por lo que su inclusión en la Figura 12 se comparte entre la fase uno y dos. Cabe destacar que estos tres estados están dentro de los trastornos de la conciencia que, aunque no se integran en este estudio, sí se consideran en el espectro de la consciencia global. Para una revisión de estos estados ver (Giacino, 2005; Gosseries et al., 2014; Laureys et al., 2007). En la fase de consciencia residual están dos de las cuatro etapas del sueño, definido este último como un estado temporal fisiológico y reversible con desconexión parcial de la consciencia. Ahí se consideran la somnolencia, el sueño ligero y el sueño profundo, estados durante los cuales se presentan poca actividad consciente. Y como cuarta etapa se tiene el sueño MOR, en el que hay presencia de un estado de consciencia muy similar al que se presenta en vigilia. En esta misma fase de consciencia residual se encuentra el caso especial que se comparte con la fase de consciencia: el síndrome del cautiverio en el que están algunas personas que tienen todas las capacidades cognitivas activas, pero no pueden moverse (Dehaene, 2015). 
implica la percepción de un estímulo aislado; el segundo es la capacidad de respuesta ante cualquier estímulo ambiental, y el tercero, la concentración, período de tiempo en el cual se mantiene la atención (Melo Florián, 2011, p. 221).

El Modelo del espacio de trabajo neuronal global, (Global neuronal workspace model, GNW por sus siglas en inglés), propuesta por el equipo de Stanislas Dehaene (Dehaene, 2014; Dehaene \& Changeux, 2011; Dehaene \& Naccache, 2001), es una de las teorías más actuales con correlatos neurológicos; a través de ésta se integran las FE como parte del continuo de consciencia en los seres humanos (Figura 13).. A continuación, se explica con más detalle.

\subsubsection{Modelo del espacio de trabajo neuronal global}

La toma de consciencia de uno mismo, y de otros, forma parte de un proceso que se relaciona con la maduración de las sensaciones y los sentidos, que se dirigen hacia la integración sensorial encargada de captar y organizar los estímulos experimentados del propio cuerpo y del entorno. Cada sistema actúa como un filtro que reduce la información antes de hacerla consciente (Gross, 2012).

Figura 13. Representación del modelo de consciencia del espacio de trabajo neuronal global

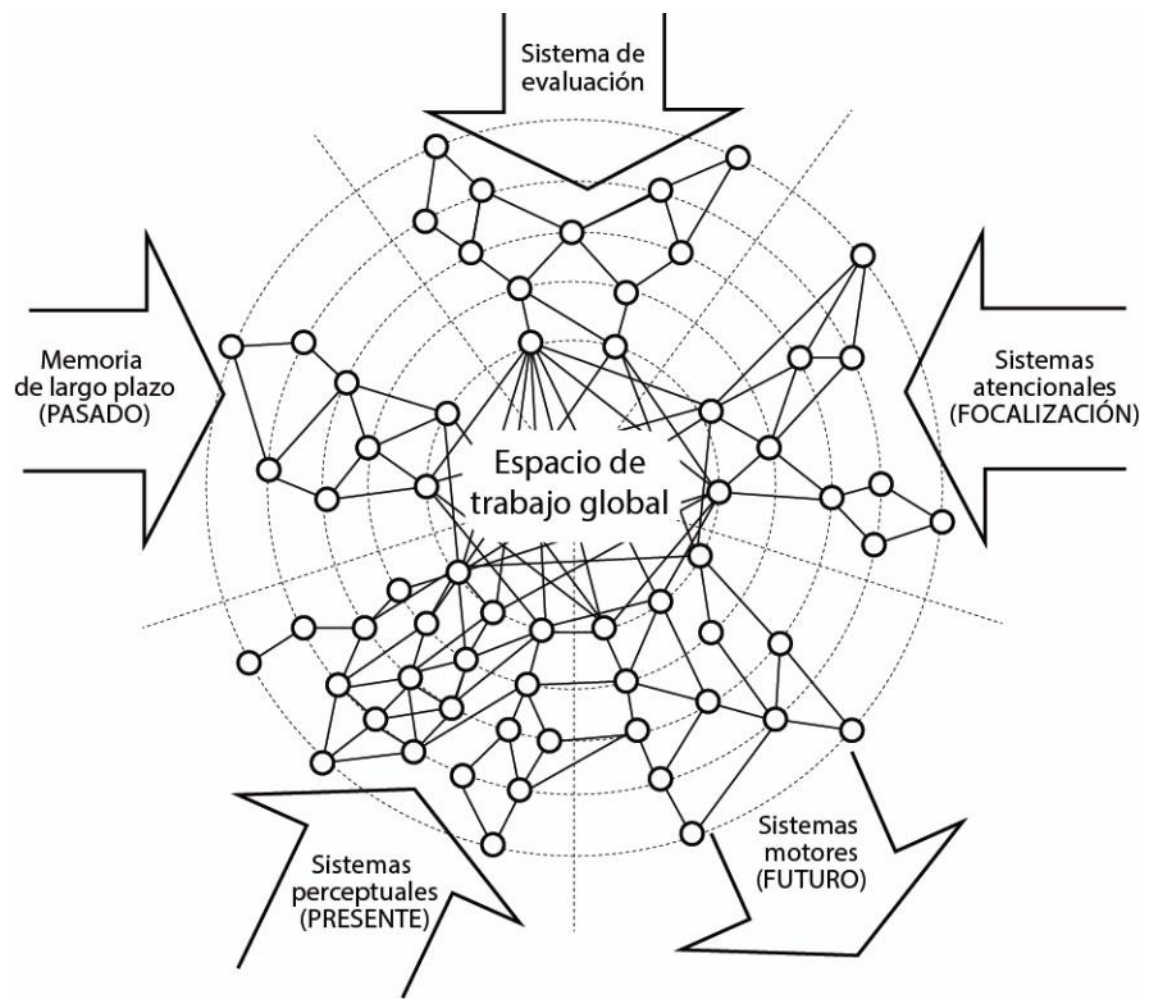

Fuente: (Dehaene et al., 2011, p. 207). 
El Modelo del espacio de trabajo neuronal global (GNW) se refiere al proceso que se sigue desde el espacio neuronal inconsciente al espacio consciente (Dehaene, 2015, p. 231). Es una adaptación del modelo presentado por el psicólogo Bernard Baars en (1988); en dicho modelo se sugiere que la experiencia consciente implica un espacio de trabajo global, un intercambio de información central que permite la interacción de diversos procesadores especializados y, que a su vez, obtienen acceso al espacio de trabajo global para transmitir un mensaje a todo el sistema.

La teoría ha sido refinada y apoyada con evidencias neurológicas por el equipo de Dehaene (Dehaene \& Changeux, 2011) y otros (Baars, 2005; Barttfelda et al., 2015) para explicar cómo la consciencia es el proceso global en el que de manera masiva, pero ordenada, el cerebro comparte información (Dehaene, 2015; Dehaene et al., 2011) entre las distintas áreas que se involucran en una misma experiencia.

Algunos estímulos se pueden procesar de manera inconsciente e incluso pueden ser sensibles al control ejecutivo. Sin embargo, Rohaut y Naccache (2017) mencionan que de acuerdo con la GNW, los procesos cognitivos que requieren consciencia se asocian a tres propiedades del procesamiento consciente:

1. Hay un mantenimiento activo de representaciones mentales en la memoria de trabajo.

2. Existe un procesamiento estratégico.

3. Hay presencia de comportamiento espontáneo intencional.

Estas tres propiedades activan, entre otras, las áreas corticales prefrontales. En el modelo teórico de la GNW no se considera que el proceso de toma de consciencia sea lineal, sino que la amplificación neuronal de la información sensorial se distribuye globalmente a través de redes generalizadas que involucran áreas frontoparietales (Hutchinson, 2019) que, como se revisó en el apartado 2.3.1, están ampliamente involucradas con las FE. En este proceso de activación de la consciencia, la atención es considerada como un mecanismo que contribuye a la focalización de la información mejorando la selección del procesamiento de los estímulos sensoriales.

\subsubsection{Teoría de la información integrada}

Otra de las teorías que se han desarrollado para explicar la consciencia de amplio espectro es la teoría de la información integrada (IIT) de Guilo Tononi (Koch, 2018; Oizumi et al., 2014; Tononi, 2015). La IIT utiliza una técnica llamada zap y zip, que consiste en la estimulación masiva provocada por un pulso de energía magnética aplicada sobre el cráneo. Con ello se estimula el 
cuero cabelludo y éste, a su vez, induce una breve corriente eléctrica en las neuronas provocando una perturbación que reverbera por un momento (zap) y luego se extingue. El resultado de la estimulación es recogido a través de un registro electroencefalográfico que arroja datos mapeados de acuerdo con las zonas estimuladas. Estos datos son procesados con un algoritmo que los comprime (zip). La técnica ha permitido comparar la respuesta de personas de tres grupos: grupo 1, despierta con plena consciencia; grupo 2, en estado vegetativo, y, grupo 3, personas catalogadas con estado mínimo de consciencia (EMC, ver Figura 12). Con ello han corroborado un "índice de complejidad perturbadora" que mide si la personas está o no consciente; también identificaron una correlación entre el índice y el nivel de consciencia, incluso con las personas con un EMC identificaron quienes estaban conscientes, pero no podían comunicarse con los demás (Koch, 2018).

La gran diferencia entre la teoría IIT y GNW es el punto de partida. La GNW en gran parte considera que el cerebro trabaja a través de módulos que pueden dar inicio con la actividad consciente cuando se activan los sistemas sensoriales y comparten la información a todos los sistemas, si la información es relevante para otros sistemas y se mantiene activa, entonces se hace consciente. Pero si sólo es relevante para un sistema permanece inconsciente, y si es suficientemente relevante para el sistema, se pueden ejecutar otras acciones (Koch, 2018). Eso explicaría que haya actividades que se realizan de manera automática (inconsciente) o de manera reflexiva (consciente). Mientras que la IIT considera la experiencia misma en la que se postula que, cualquier mecanismo complejo e interconectado, cuya estructura codifica un conjunto de relaciones de causa y efecto, tendrá las propiedades para aportar cierto nivel de conciencia.

\subsubsection{Modelo de consciencia artificial para un análisis de la consciencia humana}

Como se mencionó en el capítulo 1, en esta investigación se emplea un robot humanoide como un vehículo de interacción asistido para trabajar con niños con TEA. Es decir, su conducta no es autónoma. En este sentido me remito a la reflexión de Florián Melo a partir de Gardner (2011): complementar las representaciones mentales con procedimientos metodológicos de la ciencia de la computación es una acercamiento de utilidad interdisciplinaria a partir de la cual, en algún momento, podría surgir una tendencia unitaria.

Por tal motivo, se emplea la teoría de Marvin Minsky para contextualizar el alcance de la propuesta relacionada con la consciencia humana, y de manera directa se utiliza la de Igor Aleksander (Aleksander, 2005, 2009) para concretar los niveles de consciencia en la práctica de las FE con los niños con TEA. 
Ambas posturas han sido empleadas por Laureano-Cruces. Aunque de la primera sólo presenta una "primera aproximación del modelo de Minsky" (Laureano-Cruces et al., 2013). La segunda ha sido aplicada - entre otras temáticas - como un planteamiento para establecer una relación entre el fenómeno de la consciencia y entre los síntomas presentados por pacientes con Alzheimer; lo anterior durante la realización de tareas cognitivas (Laureano-Cruces et al., 2015), y en un modelo en el que simulan una "sociedad de animales compuestos por individuos con comportamientos relativamente complejos en un sistema de multi-agentes" ${ }^{\text {"35 }}$ (Laureano-Cruces et al., 2018, p. 55). En los tres trabajos — entre otros, que aquí no se mencionan — la investigadora asocia el fenómeno de la consciencia con las emociones como se describe en el EATR-5.

Conviene destacar que las enormes aportaciones de Marvin Minsky, en el ámbito de la inteligencia artificial (IA), y particularmente de la consciencia artificial (Sampedro, 2016), apenas están delineadas en este trabajo. Sin embargo, no está de más recordar que este científico, además de ser considerado el padre de la IA, fue un gran propulsor y creador de la sinergia para la investigación en esa materia que a la fecha continúa creciendo.

En la Figura 14 se presenta el modelo de Minsky y los parámetros que considera para determinar la relación de la consciencia. Ésta inicia con impulsos instintivos e innatos, y finaliza con la aparición de la reflexión autoconsciente en la que intervienen valores y esquemas sociales aprendidos mediante la experiencia.

En el diagrama, que es una modificación de Minsky (2006) y Laureano-Cruces (2013), la base del esquema y del comportamiento se redefine como sistema de comportamiento instintivoemotivo. Es instintivo, asociado a la expresión de las emociones. Este último aspecto considerado desde la descripción básica de Paul Ekman (Ekman \& Oster, 1981). La parte superior del esquema y del comportamiento de una persona relacionada con los aspectos aprendidos socialmente, se le asigna el término cognitivo-afectivo. Este último sugerido en un análisis de aplicación por Mora-Torres (Mora-Torres et al., 2011).

${ }^{35}$ Laureano-Cruces (2013) retoma la teoría multi-agente propuesto por Minsky en su obra The socity of mind, en la que representa el proceso de la consciencia como un conjunto de autonomías formadas por agentes. De las cuales, la de mayor jerarquía está representada por las emociones. 
Figura 14. Modelo de consciencia de Marvin Minsky

Sistema de valoración social - Cognitivo-afectivo

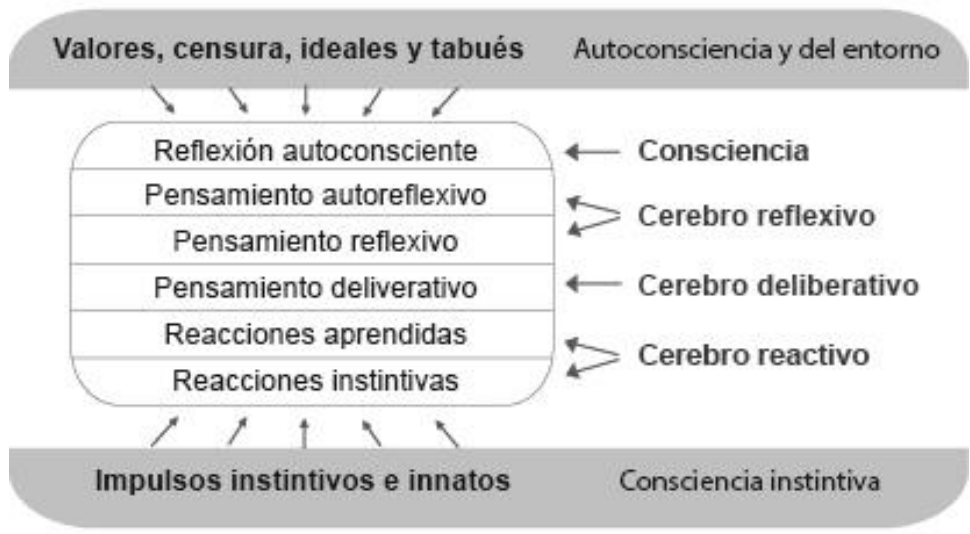

Sistema de comportamiento - Instintivo-emotivo

Fuente: Marvin Minsky (2006) con modificaciones

A pesar de que el propio Minsky (2006) afirma que el modelo no podría apegarse del todo a la realidad de nuestros cerebros, porque éstos "no son tan arreglados" (p. 46) u ordenados; visualizarlos así facilita plantear la forma en la se integra el sistema de creencias propio, que involucra lo que otros piensan de nosotros y viceversa. A partir de ello la toma de consciencia se puede considerar en dos niveles: 1) la consciencia, y 2) autoconsciencia, en la que se incluye la capacidad de considerarse a sí mismo y al entorno en donde se podría hablar de una consciencia de tipo social instintiva (como se describe en la Figura 14). Es el mismo nivel donde se encuentran las FE frías o cognitivas revisadas en la sección 2.3.

\subsubsection{Cinco axiomas de consciencia para su aplicación práctica}

Igor Aleksander $(2005,2009)$ propone un modelo para definir y aplicar la consciencia en sistemas artificiales. No obstante, igual que Minsky (2006), su base teórica se fundamenta en las reacciones humanas. Aleksander expone las reacciones humanas como una propuesta para adentrarse a la consciencia de los animales y de las máquinas. Incluso ese es precisamente el tema que da título a su libro (2005): The World in My Mind, My Mind in the World: Key Mechanisms of Consciousness in People, Animals and Machines (El mundo en mi mente, mi mente en el mundo: mecanismos clave de la conciencia en humanos, animales y máquinas). Su propuesta es definida por él como un "método axiomático / introspectivo", que descompone el concepto de ser consciente en elementos que tienen transiciones razonablemente claras en arquitecturas neuronales" (Aleksander, 2009, p. 22). 
Aleksander (2009), desarrolla un sistema basado en cinco axiomas (Tabla 9), los cuales se refieren a elementos de la consciencia traducidos como mecanismos neuronales que indican "presencia, imaginación, atención, volición y emoción" (2009, p. 25). El uso que se le da a los axiomas en este trabajo es referencial y tiene el fin de explicar desde un modelo práctico la conducta de las personas con TEA. Para una revisión de aplicación de los axiomas revisar el trabajo de Laureano-Cruces y sus colaboradores (Laureano-Cruces et al., 2013, 2015, 2018). Mientras que para una referencia completa de los axiomas revisar (Aleksander, 2005, 2009; Chrisley et al., 2008).

En la Tabla 9 se presentan los axiomas de Aleksander, y más adelante, en el capítulo 4 se muestra su aplicación asociada a las FE. En el capítulo 6 se describen los resultados de su incorporación a la interacción del robot y niños con TEA.

Tabla 9. Definición de axiomas de Igor Aleksander

Axioma 1

Definición

Condición de uso.

Axioma 2

Definición

Condición de uso

Axioma 3

Definición

Condición de uso

Axioma 4

Definición

Condición de uso

Axioma 5
Definición

Condición de uso

\author{
Mecanismo neuronal \\ Presencia \\ "Siento que estoy cenrado en un mundo exterior".
}

El "mundo exterior" debe representarse "fenomenalmente" como no afectado por las acciones.

Imaginación

"No sólo puedo recordar la experiencia pasada, sino también la imaginación ficticia".

Las estructuras que representan la experiencia pueden perdurar sin información sensorial como resultado de las propiedades generalizadoras.

\section{Atención}

"Sólo soy consciente de lo que atiendo".

Se considera un tipo de atención distinta al estado de alerta. Es decir, que no sólo implican un tiempo de reacción o una activación de tipo si-no.

\section{Volición}

"Puedo seleccionar lo que quiero y puedo actuar para obtenerlo".

Se refiere a la voluntad de hacer algo, en donde se establece un sistema de control dirigido por esquemas de control internos o externos.

\section{Emociones}

"Puedo evaluar los resultados de planificar diferentes acciones de acuerdo con la experiencia previa".

La emoción junto con la volición son dos aspectos que dirigen la conducta a partir de lo que se desea y de lo que se siente.

Fuente: elaboración propia con información de Aleksander $(2005,2009)$ 
Hasta aquí se han revisado los elementos de la consciencia que son esenciales para identificar si la información interna o externa de un individuo está presente para el individuo mismo. Sin embargo, darse cuenta de que existe un mundo al interior o al exterior de sí es sólo una parte de la regulación del comportamiento de una persona o de un agente. Otra parte se encuentra en la activación del sistema emotivo-afectivo descrito en la Figura 14. Este sistema, así como la consciencia y las FE, crea una estructura jerárquica que se activa en su forma más compleja a medida que se incrementan los niveles de atención y del estado de alerta de una persona. En los siguientes EATR se describen las bases que se han empleado para establecer relaciones interactivas cognitivas con las personas con TEA y, posteriormente, se presenta un modelo para incluir los afectos en las interacciones cognitivas.

\subsection{EATR 4. Modelos de interacción humano-robot humanoide}

No hace mucho tiempo y desde el ámbito del diseño, el mundo sólo se organizaba con base en las necesidades de las mayorías. Se excluía la incorporación de personas que salían de la norma (estadística) por falta de un equipo sensorial, motriz o cognitivo que pudiera adecuarse. Se consideraba que las personas de corta edad tendrían un crecimiento progresivo y que, poco a poco, irían adquiriendo las habilidades necesarias para incorporarse al mundo normalizado.

En el caso de las personas mayores se asumía que la adaptación a su entorno no era necesaria debido a que se encontraban en el declive de su vida, por lo que sólo se aseguraba la provisión de sus necesidades básicas, en el mejor de los escenarios.

Actualmente, el mundo está organizado en torno a la mejor adecuación de los productos, servicios o espacios que faciliten la vida de las personas. Una clave para lograrlo se enfatiza con las metodologías del diseño centradas en el usuario; de aquí surge la Interacción humanocomputadora, el diseño interactivo o el diseño humano-robot.

Por otro lado, emplear técnicas y metodologías de la interacción humano-computadora ( $\mathrm{HCl}$, por sus siglas en inglés) para evaluar la interacción humano-robot (HRI) es una vía que desde sus inicios ha ofrecido grandes ventajas (Breazeal, 2004; Dağlarlı et al., 2017; Jyoti \& Lahiri, 2020; Wiltshire \& Fiore, 2014). En este apartado se presentan las bases de su argumentación.

Para resolver el diseño de los vehículos de comunicación la alternativa empleada fue recurrir a los principios de la interacción basada en el Diseño Centrado en el Usuario (User Centered Design, UCD) y el Diseño de Experiencia de Usuario (o User Experience Desing, UX). 
Mientras que para el diseño de la interacción con el robot se retoman los principios del diseño de interacción humano-robot (HRI), como se describe a continuación.

\subsubsection{Metodologías centradas en el usuario}

Como se ha mencionado, las metodologías UCD y UX se han empleado para incluir al usuario como una parte central del proceso de investigación y del desarrollo de productos. Ambas metodologías se han aplicado predominantemente a experiencias interactivas digitales (Alanwood \& Beare, 2015). En la actualidad, se emplean para el desarrollo de otros productos que no necesariamente son digitales o de desarrollo de software (Trujillo Suárez et al., 2016).

Ambas metodologías son consideradas multidisciplinarias debido a las diversas áreas que intervienen como: antropología, neurociencias, computación, psicología, entre otras. Veamos cada una de las definiciones:

UCD, se puede definir como "el campo multidisciplinario que estudia las relaciones entre las personas y las computadoras, proponiendo métodos para diseñar y evaluar sistemas interactivos" (Muñoz Arteaga et al., 2015, p. 2) que involucra "al usuario final en diferentes fases del proceso de diseño para crear un sistema sensible al entorno y a las tareas que debe llevar a cabo" (Alanwood \& Beare, 2015, p. 177).

Por otro lado, UX se define como "un conjunto de métodos aplicados al proceso de diseño de experiencias interactivas [...] que hace de la experiencia de los usuarios su principal preocupación" (Alanwood \& Beare, 2015, p. 14). En las siguientes dos secciones se describen las características de cada una.

\subsubsection{Elementos integrales de la metodología Diseño Centrado en el Usuario}

La UCD es una metodología iterativa que facilita estar en constante contacto con los usuarios antes de proyectar una solución para la problemática detectada. (Harper et al., 2008) propusieron una versión extendida que incluye los siguientes conceptos básicos para su aplicación.

1. Entendimiento. En esta etapa lo más importante es identificar el problema que se pretende abordar a partir de las necesidades y adecuaciones para los usuarios en estudio, con el fin de identificar la viabilidad de la investigación. Es justo en este proceso cuando el conocimiento de distintas áreas puede ayudar a tener una perspectiva integral. 
2. Investigación. Esta es la etapa que brinda un mayor acercamiento a los usuarios desde el contexto en el que se desenvuelven cotidianamente. La sugerencia es acudir al o a los sitios de desarrollo natural de los usuarios para observar, anotar, conjeturar, preguntar, interactuar con ellos y analizar las rutas que toman ordinariamente para resolver problemas similares a los que interesa abordar en la investigación.

3. Diseño. Es importante considerar que en esta fase se hace una visualización del producto adecuado para los usuarios. La decisión se basa en los datos recabados en la etapa de entendimiento y de las observaciones obtenidas en la investigación. La parte más importante de este paso es considerar y visualizar qué tipo de producto se puede proyectar para integrar los datos obtenidos de los usuarios en la fase uno y dos, a partir de la cual se ha obtenido un esquema completo de las necesidades.

4. Desarrollo. El desarrollo aplica para la elaboración del prototipado rápido o de baja fidelidad que se desea probar con los usuarios antes de iniciar el desarrollo formal de los productos finales. Esta etapa se realiza con el fin de tener la oportunidad de revisar con el usuario los detalles y propuestas generadas en la etapa de diseño. Estas revisiones se hacen de manera temprana con el fin de optimizar el tiempo y evaluar los diseños conforme se vayan desarrollando o requiriendo. Lo que permite alternar las evaluaciones con el proceso del diseño, haciendo que el proceso sea iterativo.

5. Evaluación. Evaluar finalmente el diseño o las propuestas que se hayan realizado para el cliente o usuario. Probar si es adecuado, si cumple las expectativas o si es del agrado de los clientes, siempre será importante aprender del error para mejorar.

En el capítulo cuatro se describirá cómo se integró la UCD a la metodología general de esta investigación, así como la descripción de los instrumentos y procedimientos.

\subsubsection{Elementos integrales de la metodología UX}

Una particularidad de la metodología UX es que busca que el diseño realmente logre impactar al usuario suscitándole sentimientos y actitudes asociados al sistema o producto (Alanwood \& Beare, 2015, p. 177). Disfrutar de la interacción es uno de los aspectos que más pueden ayudar a que una persona se mantenga realizando una misma actividad. Recientemente, Irena Papadopoulos y sus colaboradores (2020) realizaron una revisión de la literatura relacionada con el uso de los robots humanoides y no humanoides de asistencia social; e incluyeron como uno de sus parámetros de comparación, la UX durante la interacción niño-robot. Reportaron que el 
uso de un robot como mediador ayuda a mejorar la motivación, la participación de los estudiantes, las respuestas de alegría y placer y, además, despierta la curiosidad de los niños, quienes mantienen una mejor conexión con las actividades que realizan.

De acuerdo con Peter Morville (2016), la UX debería cubrir seis aspectos de manera adecuada para dar calidad a los productos y, por lo tanto, mejorar la experiencia del usuario: útil, usable, deseable, localizable, accesible, creíble y valiosa. Estos parámetros se describieron originalmente para ser aplicados a productos de interacción web. Sin embargo, con el fin de adecuarlos a otros sistemas interactivos - como el uso de los robots-humanoides - y, particularmente, a la problemática de este trabajo, se formularon las siguientes preguntas con base a las (siete) propuestas de Morville (2016).

Útil. Que sea útil. ¿En qué medida es útil el empleo de un robot humanoide para trabajar con niños con TEA? ¿Lo más importante del desarrollo de esta investigación es el uso del robot humanoide entendida y empleada como una herramienta o es el proceso a través del cual se usa la herramienta?

¿Qué criterios deberían cubrir el modelo generado al final de la tesis para que la propuesta sea realmente útil? ¿Es posible dar utilidad o rentabilidad social al uso de un proceso 0 herramienta para cualquier población de personas con TEA, incluso en aquellas que tienen acceso a menos recursos tecnológicos como la población oaxaqueña o mixteca?

Usable. Que pueda ser usado por los usuarios meta del sistema. Como bien menciona Peter Morville (2016), para que un producto sirva no es suficiente con que sea usable. Como se verá más adelante, la "usabilidad" favorece que un producto sea eficaz (que haga lo que promete hacer); eficiente (que lo haga rápido y bien), y que sea satisfactorio para quien lo usa (que le guste). De estos tres aspectos la pregunta constante que se planteaba era: ¿cómo lograr que un producto cubra esos tres aspectos para varios usuarios que tienen un amplio rango de intereses y conductas repetitivas en extremo? A partir de lo anterior surgen otros cuestionamientos: 1) ¿será necesario hacer varios productos para satisfacer a más de un usuario?; 2) ¿tendremos que concentrarnos en un usurario para hacer una propuesta que cubra específicamente sus gustos y preferencias? Para hacerlo eficaz y tal vez eficiente se podían utilizar los ejercicios de alguna de las pruebas psicométricas estandarizadas que existen en el mercado; sin embargo, complicaba todo el hecho de encontrar una que les gustara o que lograra sobrepasar su casi infranqueable línea de conductas repetitivas y estereotipadas. Como se describió en el EATR 3, la alternativa fue las pruebas psicométricas, empleadas como herramientas para conocer mejor a los niños. 
Deseable. Lograr que el producto sea deseado. La primera pregunta de manera casi inmediata tuvo una respuesta favorable antes de iniciar esta tesis: ¿a los niños con TEA les gustaría o si desearían trabajar con el robot? Este planteamiento se hace en la premisa tres y se describe que la primera vez que se presentó el robot humanoide con un grupo de niños con TEA, incluyendo niños con nivel tres de acuerdo con DSM-5, fue un éxito. Y como complemento, la literatura ha marcado varios ejemplos en los que se constata este hecho (Papadopoulos et al. 2020). Los niños se acercaron al robot en cuanto pudieron, aunque de manera cotidiana parecían no tener interés por las cosas de su entorno inmediato (ver Figura 12). Este punto además impulso la inserción de un modelo de emociones que pudiera comprobar o dar mayor certeza en cuanto al tipo de afectos despertados durante la interacción de los niños con TEA. Este aspecto se revisa con mayor detalle en el último capítulo.

El cuarto punto: hacer que un producto sea fácilmente localizable, lo anterior se aplica directamente a los sitios web o sistemas digitales interactivos. Sin embargo, también generó algunas preguntas interesantes: ¿de qué manera se podía asegurar que el producto, modelo 0 tareas de FE estuvieran al alcance de los usuarios?, ¿qué estrategias se tenían para mantener localizables las tareas con las cuales los niños pudieran practicar sus FE?, ¿sería necesario que las tareas estuvieran presentes con o sin el robot?

El siguiente punto: accesible. El concepto está fundamentado en la idea de eliminar barreras de uso para las personas que tengan alguna discapacidad. $Y$ la pregunta inmediata es ¿la propuesta servirá para otros niños que no tengan TEA o alguna otra discapacidad?, ¿qué perfil deberían tener los niños neurotípicos para verse beneficiados con los resultados de la investigación que se desarrolla en esta tesis?

Lo creíble, aspecto importante dentro de esta investigación; por lo cual la pregunta central fue: ¿hasta qué punto los niños con TEA consideran creíble que el robot humanoide pueda interactuar con ellos?, ¿qué es más probable para los niños con TEA: que el robot humanoide sea un juguete, o algo similar a una persona?, ¿es posible determinar el grado de credibilidad que tiene el robot frente a ellos?, ¿el problema asociado al TEA de la ToM influirá de alguna manera en la credibilidad que los niños tienen del robot? Si consideramos la forma particular de ver y recibir la interacción social de los niños con TEA, creo que el tema antes mencionado es uno de los más útiles con respecto al conocimiento que se tenga de la conducta de estos infantes. También se consideró que sería interesante comparar la actitud que tienen los niños neurotípicos de diversas edades con la actitud que presenten los niños con TEA. ¿Creen y confían en lo que 
les dice el robot?, ¿en quién confiarán más, en las personas o en el robot durante una situación de interacción?

Finalmente, el término de valioso es el último factor sugerido para hacer que el diseño sea realmente una experiencia afectiva para el usuario. Sin embargo, debido a las condiciones del producto y el tipo de usuarios con los que se trabaja, el concepto no es aplicable durante esta investigación (sólo volveré a él en el sentido de "satisfacción", el cual será abordado desde el enfoque de la "usabilidad").

\subsubsection{Usabilidad}

Una de las dimensiones prácticas de la UX que sugiere atender Morville (2016) para dar calidad a una interacción, es la "usabilidad". Como se mencionó previamente, ésta se aplica al desarrollo de productos y busca cumplir con tres parámetros: eficiencia, eficacia y satisfacción. Son tres términos que parecen sencillos de cubrir, y lo son en determinada manera, pero lo más importante de aplicarlos es que al integrarlos en el desarrollo de un producto se asegura que durante todo el proceso se vaya tomando como referencia de utilidad la opinión de los futuros usuarios. De hecho, una de las prácticas recomendadas de este proceso es explorar las necesidades de los stakeholders o todos los posibles usuarios que estarán en contacto con el producto.

A nivel internacional se han aprobado dos estándares de calidad para evaluar los productos que son elaborados bajo los parámetros de la "usabilidad" empleada por la Asociación de profesionales de experiencia de usuario ([UXPA], 2018) por sus siglas en inglés.

En 2019, el registro ISO relacionado con la interacción fue actualizado como ISO 9241210:2019 con el nombre de "Ergonomía de la interacción humano-sistema. Parte 210: Diseño centrado en el ser humano para sistemas interactivos" (ISO, 2019). Por lo que su definición abarca un sistema interactivo como el que se establece entre el robot humanoide y los niños.

Considerando estos puntos y la aportación que hace esta investigación al diseño; en el siguiente apartado se explica y se describe la aplicación práctica que se dio a los vehículos de comunicación desarrollados como materiales didácticos para el desarrollo de las FE de los niños con TEA.

Tanto la experiencia de usuario como la "usabilidad" son dos aspectos que se consideran básicos para cubrir uno de los retos de la tecnología robótica de servicio o de compañía: la implementación de mecanismos que mejoren la comunicación a través de la empatía, la comprensión y las estrategias sociales de las máquinas o sistemas informáticos con las personas, como se describe en la sección 2.5 . 


\subsection{EATR 5. Modelos de interacción cognitiva}

Como se mencionó en la introducción de esta investigación, en este apartado se presentan los fundamentos para el desarrollo de la interacción cognitiva considerando la relación humano-robot, la socialización y el aspecto afectivo en el que se integran los procesos emocionales y cognitivos de los niños con TEA.

\subsubsection{Interacción humano robot y la socialización con los humanoides}

El diseño de los primeros robots estuvo limitado al uso industrial. La realización de tareas específicas en esta área fue, de alguna manera, una tarea resuelta con bastante fluidez (ver Tabla 10); aunque el desarrollo de sus procedimientos no era tan sencillo. Por otro lado, el diseño de "robots de servicio" para labores más cotidianas, requería que se considerara la capacidad de éstos para percibir emociones, necesidades, sentimientos e intenciones de sus interlocutores (Wiese et al., 2017). Además, había que determinar si los robots podían involucrarse con las personas de manera interpersonal a través de la comunicación verbal y no verbal (Breazeal et al., 2008), al mismo tiempo de ser empáticos, afectivos y con habilidades cognitivas bien desarrolladas para responder con credibilidad social.

La aceptación de los robots por parte de las personas depende de los contextos y de la idea que se tenga de ellos. En ese sentido, la manera en la que éstos sean conceptualizados dirigirá la forma en cómo se establece una relación con ellos, llevándolos a preconcebir un modelo mental de su interlocutor llamado robot. El desarrollo de la tecnología, la amplitud de acciones y habilidades que se fueron agregando a los robots llevó al mismo tiempo a desarrollar distintos modelos mentales que se tradujeron en paradigmas de la interacción humano robot (HRI, por sus siglas en inglés). Entre los primeros paradigmas que surgieron de la HRI (Breazeal, 2004) y que a la fecha siguen vigentes, se encuentran los siguientes:

1. El robot como herramienta. El modelo mental de éste se basa en que la persona sólo utiliza al robot para resolver ciertas tareas, por lo que deja al robot sólo como objeto con un uso específico al que se debe supervisar.

2. El robot como extensión o cyborg. El paradigma y por lo tanto, el modelo mental se fundamenta en la fusión física de la persona y sus habilidades con las del robot que se inserta a su cuerpo. A medida que lo acepta, el robot se convierte en una extensión de sí mismo. 
3. El robot como ávatar. En esta condición el ávatar forma parte de un escenario de apoyo para la persona. El robot es alguien con quien se puede comunicar y mantener una relación virtual. Puede parecer real, pero se queda en el ámbito no materializado.

4. El robot sociable. Este tipo de robot conduce a un modelo mental que hace que la persona perciba al robot como alguien con quien puede interactuar como si fuera otra persona. Uno de los aspectos que hacen que el robot sea visto como sociable es su antropomorfización y su capacidad de comunicación. Es decir, si el robot tiene una cabeza, la persona piensa que el robot piensa; si tiene ojos, boca y oídos, la persona asume que pude ver, escuchar y hablar; si tiene piernas, la persona asume que puede caminar. A medida que la persona descubre más parecido entre sí misma y el robot, más habilidades parecidas a las propias adjudicará al robot. En el aspecto de la comunicación: si el robot es capaz de establecer una comunicación en la que intervenga la anticipación, el afecto y la retroalimentación, es más fácil para la persona asumir que se trata de alguien con capacidad cognitiva y de comunicación con la que se puede relacionar como si fuera otra persona.

En la Tabla 10 se muestran algunos de los primeros robots en la historia de la robótica humanoide. El reto inicial era darles movilidad y autonomía, por lo que se centraban más en el mecanismo y la funcionalidad antes que en la estética.

Uno de ellos, Aimo, fue perfeccionado durante más de 30 años. La compañía Honda responsable de su creación, en 2018, notificó su decisión de no seguir perfeccionando su prototipo (Infoabe, 2018). Esto con el fin de implementar nuevos modelos centrados en otras habilidades de tipo social.

Uno de los usos que se ha dado a la robótica ha sido su integración en actividades de tipo terapéutico, de investigación o con fines médicos. Como se ha mencionado en el apartado 2.1., el uso que se le dio al robot en esta investigación fue el de un vehículo de interacción asistido con el fin de intervenir con los niños con TEA en tres aspectos: interacción social recíproca, comunicación y patrones de conducta repetitivos y estereotipados.

Existen múltiples investigaciones que han publicado el uso del robot humanoide con niños con TEA (Ackovska et al., 2017; Huijnen et al., 2017; Warren et al., 2015; Zheng et al., 2013) en la Tabla 10, se muestran algunos de los robots humanoides que se han producido hasta el momento, entre ellos, dos de los ejemplares que más se han empleado para trabajar con niños son: Kaspar (Marino et al., 2019; Ochoa-Guaraca et al., 2017; Wainer et al., 2014) y el robot NAO (Anzalone et al., 2015; Boren \& Liles, 2016; Chevalier et al., 2017; Mavadati et al., 2016). 
Tabla 10. Robots humanoides

\begin{tabular}{|c|c|c|}
\hline Nombre & Imagen & Descripción \\
\hline $\begin{array}{l}\text { Wabot 2, } 1980 \\
\text { Universidad de } \\
\text { Waseda, Japón }\end{array}$ & & $\begin{array}{l}\text { Fue equipado con una cámara colocada en la cabeza lo que le } \\
\text { permitía leer una partitura y cinco dedos en las manos con } \\
\text { motricidad fina para tocar un teclado electrónico. }\end{array}$ \\
\hline Genghis, 1980 & & \\
\hline $\begin{array}{l}\text { Rodney Brooks del } \\
\text { Instituto } \\
\text { Tecnológico de } \\
\text { Massachusetts, } \\
\text { EE.UU. }\end{array}$ & & $\begin{array}{l}\text { El robot simulaba a un animal de seis patas, su particularidad es } \\
\text { que tenía comportamientos que lograba por medio de } \\
\text { controladores simples y descentralizados. }\end{array}$ \\
\hline $\begin{array}{l}\text { Cog, } 1993 \\
\text { Rodney Brooks del } \\
\text { Instituto } \\
\text { Tecnológico de } \\
\text { Massachusetts, } \\
\text { EE.UU. }\end{array}$ & & $\begin{array}{l}\text { Este robot era capaz de rastrear caras, sujetar objetos entre sus } \\
\text { dedos y jugar con un Slinky. El objetivo de su creador era explorar } \\
\text { la cognición del robot mismo. }\end{array}$ \\
\hline $\begin{array}{l}\text { Kismet, } 1998 \\
\text { Cinthya Breazeal. } \\
\text { Instituto } \\
\text { Tecnológico de } \\
\text { Massachusetts, } \\
\text { EE.UU. }\end{array}$ & & $\begin{array}{l}\text { Kismet fue un robot formado por un busto, su cabeza estaba } \\
\text { equipada con grandes ojos, cejas, orejas y prominentes labios. Fue } \\
\text { de los primeros robots capaces de demostrar interacciones } \\
\text { sociales y emocionales con humanos. Lograba establecer la } \\
\text { empatía a través de sus conversaciones y de sus reacciones } \\
\text { faciales. }\end{array}$ \\
\hline Aimo, (1986-2018) & & $\begin{array}{l}\text { Fue un robot creado y actualizado durante más de } 30 \text { años por } \\
\text { Honda. Inició como una plataforma con dos pies y poco a poco le } \\
\text { agregaron mayores características físicas, cognitivas y sociales. } \\
\text { Era capaz de saltar, correr, bailar, reconocer rostros y comprender } \\
\text { el habla. }\end{array}$ \\
\hline $\begin{array}{l}\text { Kaspar, } 2005 \\
\text { Universidad de } \\
\text { Hertfordshire, Reino } \\
\text { Unido, GB }\end{array}$ & & $\begin{array}{l}\text { Kaspar es un robot humanoide del tamaño de un niño. Es capaz de } \\
\text { manifestar expresiones faciales a través de los movimientos de su } \\
\text { rostro y de establecer conversaciones con las personas. Una } \\
\text { particularidad de él es que lo han utilizado en terapia con niños con } \\
\text { TEA. }\end{array}$ \\
\hline $\begin{array}{l}\text { Nao, } 2008 \\
\text { Aldebaran Robotics }\end{array}$ & & $\begin{array}{l}\text { Nao es uno de los robots humanoides que más se ha difundido en } \\
\text { el mundo para la investigación, educación y atención médica. } \\
\text { Hasta el momento se han utilizado más de } 13,000 \text { robots en más } \\
\text { de } 70 \text { países. Fue diseñado para interactuar con las personas. Es } \\
\text { capaz de caminar, bailar, hablar, reconocer caras y objetos. Su } \\
\text { plataforma programable con reconocimiento de voz y diálogo en } 20 \\
\text { idiomas, lo cual facilita que se le pueda emplear en proyectos de } \\
\text { interacción con otros robots o con personas. Este robot también se } \\
\text { ha empleado con niños con TEA. }\end{array}$ \\
\hline
\end{tabular}

Nota. Algunos de los robots humanoides, mostrados en la tabla, se han empleado para socializar con niños, los dos últimos con niños con TEA. Fuente: elaboración propia a partir de (IEEE, 2020; IFR, 2020). 


\subsubsection{Robot humanoide NAO}

El robot NAO fue creado en 2008 por la empresa Aldebaran Robotics y en 2015 sus derechos pasaron a manos de la empresa Softbank robotics. Es un robot clasificado como humanoide debido a sus características físicas antropomórficas que le permiten tener movimientos similares a los de una persona, guiados por 25 actuadores o grados de libertad que le proporcionan autonomía de movimiento.

Fue diseñado para interactuar con las personas por lo que su uso se ha enfocado a la interacción humano-computadora y, específicamente, humano-robot. Mide 58 centímetros y pesa $4.3 \mathrm{~kg}$. Tecnológicamente está equipado con sensores que le permiten interactuar, recibir información y emitir respuestas. Cuenta con dos cámaras, cuatro micrófonos, nueve sensores táctiles, dos sensores de ultrasonidos, 8 sensores de presión, un acelerómetro y un giróscopo. Es interactivo y se puede programar con lenguajes como $\mathrm{C}_{++}$, Python, JAVA, .NET y MATLAB, o con su software gráfico Choreographe que no requiere conocimientos de programación especializados.

En la Figura 15 se presenta el esquema del robot NAO en el que se ubican sus sensores y el equipamiento tecnológico que le brindan la posibilidad de interactuar.

A pesar de tener limitantes de movimientos espontáneos, los robots humanoides se pueden programar para hacer gestos y movimientos complejos de equilibrio como los implicados en el Taichi o para mantener interacciones con movimientos, gestos y posturas, entre otros. El diseño de los robots humanoides como NAO ha evolucionado al diseño de geminoides que son robots androides diseñados como una copia fiel de una persona (Kumazaki et al., 2019; Nishio et al., 2007; Sumioka et al., 2014). Fueron creados con el objetivo de estudiar a fondo la HRI. A diferencia de los robots humanoides, los geminoides tienen un soporte de Inteligencia Artificial (Al) bastante amplio que proporciona mayor poder para su desarrollo cognitivo (ver Tabla 11). 
Figura 15. Robot humanoide NAO

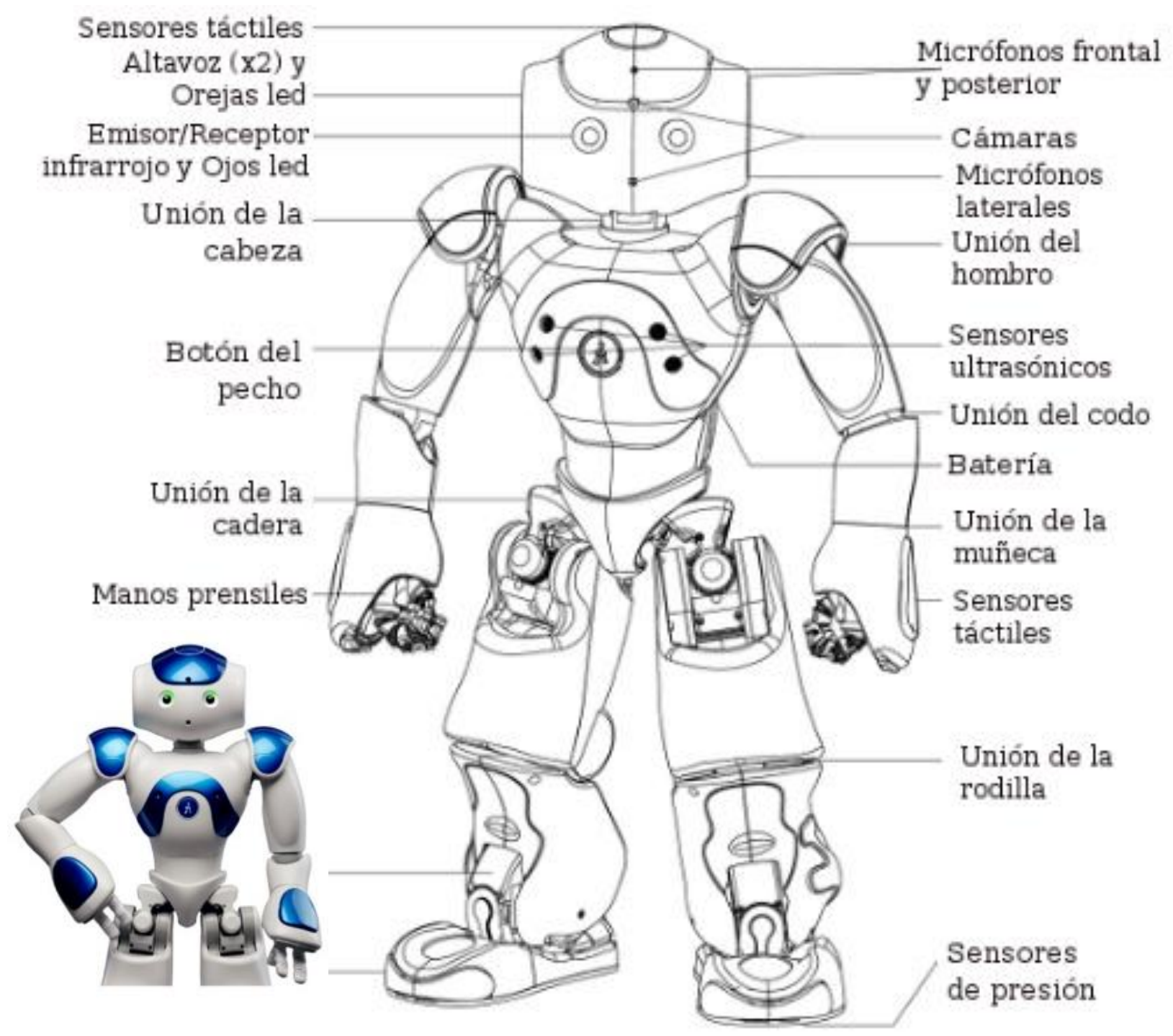

Fuente: https://aliverobots.com/nao/ 
Tabla 11. Robots humanoides autónomos con inteligencia artificial

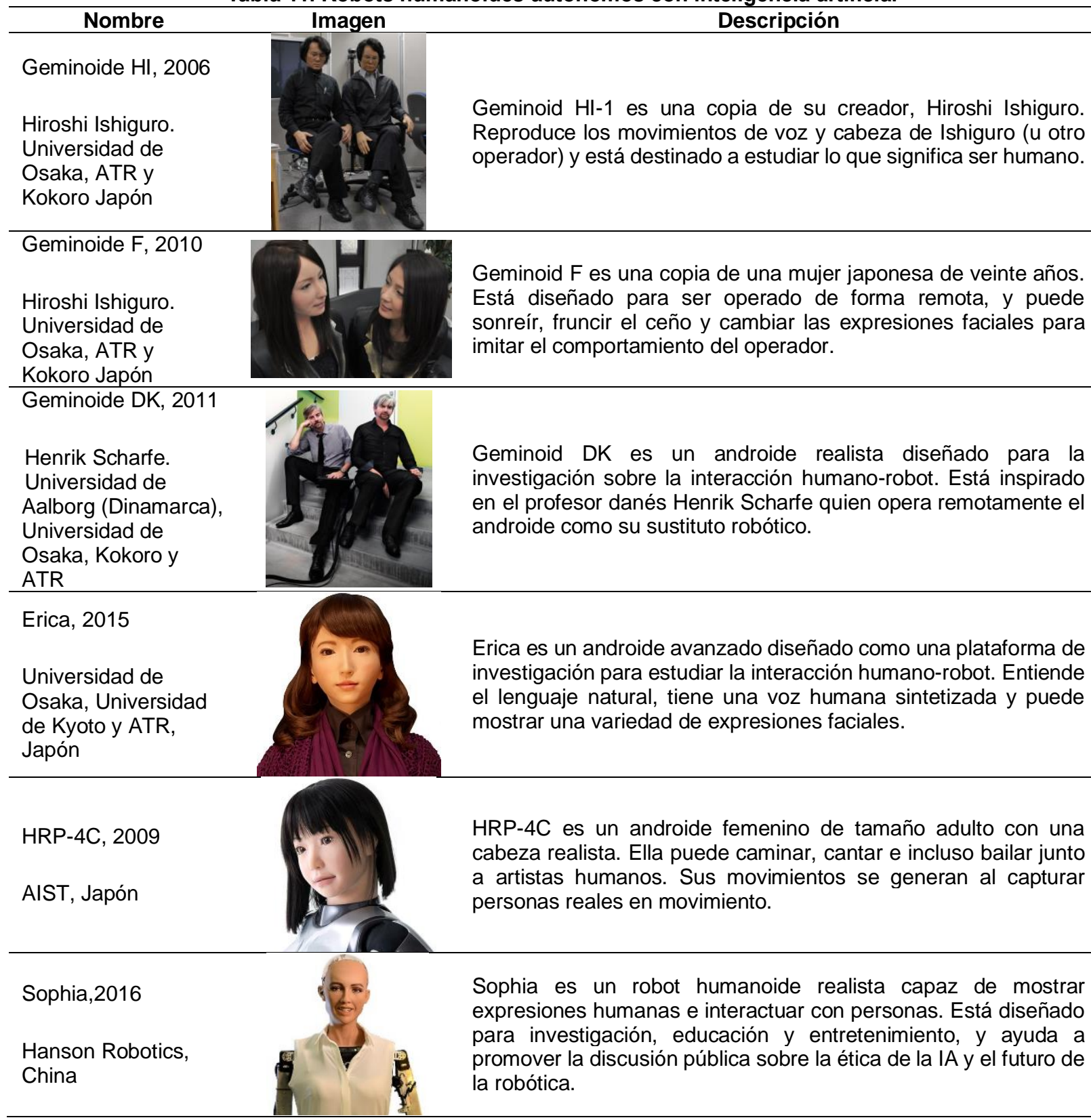

Nota. Tanto los robots androides como los androides geminoides tienen la capacidad de aprender a través de la IA. La diferencia es que los primeros están limitados por su capacidad tecnológica y los segundos, además de tener mucha más tecnología, son una copia exacta de personas reales, incluyendo la capacidad de respuesta cognitiva.

Fuente: elaboración propia a partir de (IEEE, 2020; IFR, 2020). 


\subsubsection{Las emociones en el contexto de la cognición}

La definición de las emociones humanas ha estado plagada de innumerables términos asociados a diversos estados y conductas. El tema evidentemente no es nuevo, lo que ha sido innovador, sobre todo en los últimos años, son las metodologías empleadas para explorarlas y definirlas. En 1956, con el arribo de la IA (Fernández-Caballero et al., 2006), el paradigma conductual de la psicología cambia para dar cabida al nuevo modelo de la cognición que se inclina hacia la descripción de los procesos mentales como procesamiento de información. Con ello se retoman ideas y estudios pendientes de la percepción (Jerome Bruner), la memoria (Hermann Ebninghaus), la conciencia (Wilhem Wundt, William James), incluso la inteligencia (Alfred Binet) que fue redefinida. A partir de entonces, una vez superados los métodos del psicoanálisis y del conductismo, la psicología se adhiere a las ciencias cognitivas en la que participan disciplinas como la lingüística, la neurociencia, la antropología y la filosofía de la mente (Varela et al., 1997).

Algunas áreas de la conducta humana como la atención y la memoria (Donald Broadbent) se empiezan a tratar con bases más experimentales y, particularmente, las emociones se asocian a los procesos cognitivos. Por ejemplo, Nico Frijda en 1956 escribió acerca del entendimiento de las expresiones faciales, pero fue hasta 1986 que fijó su postura con respecto a la relación de las emociones con los proceso biológicos y cognitivos. Al respecto, Paul Ekman, en 1992, también publicó una interesante investigación acerca de las expresiones faciales de las emociones en distintas culturas como se revisará más adelante.

Desde el estudio de la IA, la clasificación de las emociones se ha relacionado con la dinámica de la conducta observable que enfatiza el mecanismo de activación psicológica de la emoción. Esto porque, al ser aplicadas a agentes o robots, lo importante no es lo que pasa dentro, sino lo que se manifiesta a través de las reacciones observables, como las emociones. 


\section{Estructura metodológica}

\subsection{Método}

En el preámbulo se presentaron los parámetros del objeto de estudio y se describieron las pautas consideradas para el desarrollo de esta investigación (Figura 1). Se tomaron en cuenta cuatro enfoques: el empírico, el teórico-semántico, la metodológica y la epistemológica. En este capítulo se destaca el empírico, y la metodológica fundamentada en los elementos teórico-semánticos (expuestos en el capítulo anterior).

Los aspectos descritos en este capítulo son: el diseño de investigación, los participantes, criterios de inclusión-exclusión y el procedimiento. A partir de estos, y considerando los fundamentos empíricos, se propone una estrategia de evaluación de las condiciones de los escenarios para establecer la interacción de los niños con TEA y el robot humanoide.

\subsection{Diseño de investigación}

Definir el tipo de investigación fue un aspecto importante para trazar y esclarecer la ruta que se podía seguir para completar el estudio. Consistió en la aplicación de lo que Hernández Sampieri llama "un plan o estrategia concebida para obtener la información [deseada]" (2014, p. 184), centrado en un enfoque mixto como se describe a continuación.

\section{Enfoque mixto cuantitativo-cualitativo}

La combinación de un enfoque cuantitativo-cualitativo facilitó explorar y analizar la conducta de los niños. Si bien se tenían previos conocimientos del objeto de estudio —en el contexto de los participantes - éstos no eran suficientes para definir el comportamiento natural de los participantes en una condición de trabajo como, por ejemplo, durante la evaluación de sus FE. Por ello, se consideró importante explorar y analizar el objeto desde una aproximación empírica, dividida en dos: primero cualitativa y después cuantitativa.

La aplicación del enfoque cualitativo se realizó con la directriz del comportamiento de los niños de manera individual, con el fin de que la primera aproximación fuera lo más natural posible. Posteriormente, en una segunda etapa, con el conocimiento básico de los niños en situaciones exploratorias de socialización con una persona, se propusieron los escenarios de interacción humano-humano y niño-robot. Esto implicaría la descripción de la conducta de los niños a partir de una exploración que facilitara el acercamiento con los niños; independientemente de los 
grados de gravedad que éstos tuvieran. Cabe señalar que se consideraron los criterios diagnósticos del DSM-5 (Asociación Americana de Psiquiatría, 2014) en el EATR 1.

En esta fase se decidió emplear un método naturalista, definido por ser una intervención no biológica; dirigida, entre otras, a las relaciones interpersonales, la comunicación y el juego (Medavarapu et al., 2019, p. 12; Myers et al., 2007). Se complementó con una aproximación etológica (Osborne-Crowley, 2020; Perinat Maceres, 1980, 1982; Tinbergen, 1975) cognitiva en los niños para iniciar el contacto, descrito en el apartado 3.1.3.8. En el procedimiento se describe la estrategia que se siguió para iniciar esa primera etapa de relación con los pequeños.

Esta forma de aproximación permitió asegurar que los comportamientos natos de los participantes emergieran poco a poco de manera natural, y desde sus propias necesidades de interacción con una persona desconocida (en este caso yo).

El otro enfoque, el cuantitativo, se abordó a partir del establecimiento de hipótesis y variables. Con los datos obtenidos en la primera parte del estudio se corroboraron algunas de las proposiciones teóricas presentadas en el apartado 2.3.1.3 (ver Tabla 7) con respecto al comportamiento y diagnóstico de los niños con TEA.

De manera general, tanto cualitativamente como cuantitativamente se trabajó con resultados escalonados acumulativos; lo cual implicó que los resultados obtenidos en el grupo 1 sirvieran de base para el desarrollo de las actividades del grupo 2, y así sucesivamente. En el capítulo 4 se expone este planteamiento de manera más amplia.

\section{Diseño NO experimental}

Se trabajó con un grupo de niños y se realizó una recolección de datos que implicaban diferentes eventos y condiciones. Esto me llevó a plantear una investigación no experimental medida de manera transversal, que podía ser de tipo exploratorio, descriptivo o correlacional-causal.

Se determinó establecer un diseño transversal de tipo correlacional-causal, con el fin de tener una aproximación más cercana con el objeto de estudio sin llegar a manipular experimentalmente las condiciones naturales de los niños, pero manteniendo la posibilidad de identificar las posibles correlaciones entre las variables que incluso pudieran llegar a ser explicadas en términos de causalidad.

Una característica de la investigación no experimental que se aprovechó es que, a partir de la observación del objeto de estudio en un contexto "semi-natural", se pudieron establecer nuevas preguntas e hipótesis que arrojaron respuestas puntuales acerca de la relación de los eventos o factores asociados al propio objeto de estudio. 
A partir de estas características, la investigación se definió como No experimental, pero sí transversal de tipo causal-correlacional aplicado desde un enfoque mixto cualitativo-cuantitativo.

\subsection{Participantes}

Se trabajó directamente con tres grupos de niños con TEA seleccionados para el enfoque cualitativo (grupo 1) y cuantitativo (grupos 2,3 y 4). Como se explica en el capítulo 4 de la etapa cuantitativa, el grupo 2 fue un grupo de observación con el que se trabajó de manera indirecta a esta investigación. No obstante, los resultados que se obtuvieron sirvieron para tomar decisiones en el desarrollo de esta tesis. Los cuatro grupos se distribuyeron de la siguiente manera.

\section{Grupo de trabajo 1}

Conformado con 15 niños con TEA grados 1, 2 y 3 . Los pequeños fueron contactados por medio de una invitación abierta para asistir a una conferencia y para participar en el proyecto a través de un curso relacionado con las FE en niños con TEA. Las actividades se realizaron en la Universidad Tecnológica de la Mixteca (ver Anexo 1) y fue difundido en redes sociales, en la radio local de la Ciudad de Huajuapan de León, Oaxaca ${ }^{36}$ y a través de la Supervisión 06 de Educación Especial, región mixteca, en el mes de junio de 2017.

\section{Grupo de trabajo 2}

Integrado con 24 niños con la siguiente diversidad funcional: neurotípicos, con TEA o con otra discapacidad. La descripción de este grupo se realiza en el apartado 4.2 Tablas 17 y 18.

\section{Grupo de trabajo 3}

Compuesto con 6 niños con TEA grado 1 y 2. Todos ellos usuarios de la Clínica de Autismo del Centros del Sistema para el Desarrollo Integral de la Familia (DIF), Santa María Huatulco, Oaxaca.

\section{Grupo de trabajo 4}

Formado con 3 niños con TEA grado 1. También usuarios del centro de atención para niñas y niños con autismo (CANNA) DIF Oaxaca.

\footnotetext{
${ }^{36}$ De acuerdo con el informe anual sobre la situación de pobreza y rezago social de la Heroica Ciudad de Huajuapan de León, al momento de iniciar esta investigación, para 2017 se tenía proyectada una población aproximada de 79,579 personas ([SEDESOL], 2015a).
} 
La selección de los dos centros DIF de Oaxaca fue porque ambos manejan un programa similar de atención basado en el establecimiento de repertorios básicos.

\subsubsection{Criterios de inclusión y exclusión de niños con TEA en enfoque cualitativo}

En esta etapa se aceptó que ingresaran al estudio niñas y niños de todos los niveles de TEA sin considerar su rango de edad. Posteriormente, se aplicaron los criterios de inclusión y exclusión presentados en la Tabla 12. (El fin de aceptar inicialmente a todos los niños sin restricciones, fue tener un parámetro amplio para dar inicio y conocer mejor a la población con la que se podía contar para el estudio).

Se inscribieron 21 niños varones, de edad cronológica entre 5 a 21 años, pero todos con un rango de edad mental de 4 a 13 años. Con cada niño se realizó un seguimiento de conducta y socialización. En la Tabla 12 se presentan los criterios de inclusión y exclusión.

Tabla 12. Parámetros de inclusión y exclusión de participantes (enfoque cualitativo)

\begin{tabular}{|c|c|}
\hline Criterios de inclusión & Descripción \\
\hline Número de participantes & 21 \\
\hline \multicolumn{2}{|c|}{ Criterios de inclusión } \\
\hline Número de participantes con los que se trabajó \\
\hline Niños con diagnóstico con TEA o afín & Comprobado por un especialista \\
\hline Rango de edad cronológica de los niños & De 5 a 20 años \\
\hline Grado de autismo & $\begin{array}{c}1,2 \text { o 3 de acuerdo con los criterios } \\
\text { diagnósticos del DSM-5 }\end{array}$ \\
\hline Nivel educativo & Indistinto \\
\hline Disposición para socializar & No relevante \\
\hline Capacidad de comunicación verbal & No relevante \\
\hline \multicolumn{2}{|c|}{ Criterios de exclusión } \\
\hline Niños con diagnósticos diferentes al TEA & 2 \\
\hline $\begin{array}{c}\text { Disponibilidad de tiempo de una hora a la semana en } \\
\text { horario y días laborales }\end{array}$ & 2 \\
\hline No tener un responsable que pudiera responder las \\
pruebas psicométricas
\end{tabular}

Fuente: elaboración propia. 


\subsubsection{Criterios de inclusión y exclusión de niños con TEA en enfoque cuantitativo}

Como se mencionó previamente, de los tres grupos sólo los grupos 3 y 4 fueron incluidos y evaluados directamente en esta investigación. El segundo grupo es descrito en el apartado 4.2 El primer criterio de selección fue que pertenecieran a uno de los centros del DIF 37 : el centro de atención para niñas y niños con autismo (CANNA) o la Clínica de Autismo Huatulco ${ }^{38}$, del estado de Oaxaca. Los criterios de selección se presentan en la Tabla 13. Es importante aclarar que todos los niños participantes llegaron al grupo con un diagnóstico realizado por un especialista. Sin embargo, para corroborar que los participantes sí tuvieran los criterios diagnósticos de TEA descritos por el DSM-5 (revisados en el apartado 2.1.3.2) en la etapa psicométrica se determinó incluir la prueba SCQ para corroborarlo.

Tabla 13. Parámetros de inclusión y exclusión de los niños con TEA para el enfoque cuantitativo

\begin{tabular}{|c|c|}
\hline Parámetro & Descripción \\
\hline Número de participantes en finales & 25 \\
\hline Origen: Clínica de autismo - DIF Huatulco & 19 \\
\hline $\begin{array}{c}\text { Origen: Centro de Atención para niñas y niños con } \\
\text { autismo (CANNA) }\end{array}$ & 6 \\
\hline \multicolumn{2}{|c|}{ Criterios de inclusión } \\
\hline $\begin{array}{l}\text { Estar inscrito en un programa de atención para niños } \\
\text { con TEA en el DIF }\end{array}$ & Avalado por el DIF \\
\hline Niños con diagnóstico con TEA o afín & Comprobado por un especialista \\
\hline Rango de edad mental de los niños & De 6-12 años \\
\hline Nivel educativo & Indistinto \\
\hline Disposición para socializar & No relevante \\
\hline Capacidad de comunicación verbal & $\begin{array}{c}\text { Este criterio solo se aplicó en el último } \\
\text { nivel de dificultad propuesto por el modelo } \\
\text { de interacción. }\end{array}$ \\
\hline \multicolumn{2}{|c|}{ Criterios de exclusión } \\
\hline Niños con diagnósticos diferentes al TEA & 3 \\
\hline Disponibilidad de tiempo en horario y días laborales & 11 \\
\hline
\end{tabular}

Fuente: Elaboración propia

37 En el estado de Oaxaca el DIF cuenta con un programa llamado de Bienestar que atienden a población con TEA en donde realizan valoraciones y pruebas psicoeducativas para mejorar el desarrollo social. Considerando el modelo de atención que siguen y por la accesibilidad a los mismos se eligieron dos centros de atención: uno ubicado en la ciudad de Oaxaca, y el otro en Santa María Huatulco.

${ }^{38} \mathrm{De}$ acuerdo con el informe anual sobre la situación de pobreza y rezago social de la Heroica Ciudad de Oaxaca centro y de Santa María Huatulco, al momento de iniciar esta investigación, para 2017 se tenía proyectada una población aproximada de 272,134 y de 43,811 personas respectivamente ([SEDESOL], 2015b, 2015c). 


\subsection{Procedimiento y bases para la implementación del modelo de interacción}

La descripción que se presenta es un apunte dirigido hacia la integración de las metodologías multidisciplinarias de UX, UCD y el diseño de interacción humano-robot descritos en el apartado 2.4.3. su explicación se apega a los elementos puntualizados en la Tabla 1 del Capítulo uno. En este apartado se describen a grandes rasgos los pasos que se siguieron para el desarrollo de las etapas del estudio ahí mencionadas. Su aplicación se muestra como un resultado a partir del capítulo cinco.

Los principios del diseño universal (revisados en capítulo uno) presentan una gran similitud con los aspectos de la metodología del UCD y algunas necesidades cubiertas por la UX, dirigidas a la mejorar de los productos. Cada metodología tiene sus propios parámetros y procedimientos. Sin embargo, en esta investigación se desarrolló una metodología integrada transdisciplinariamente. Se incluyeron parámetros de la metodología de la UCDe, de la etología cognitiva y técnicas e instrumentos de la robótica. Todas ellas con el fin de integrarse en la visualización del comportamiento de los niños con TEA para proponer un modelo de interacción. Fue evaluada con los parámetros de la Asociación de Profesionales de Experiencia de Usuario (UXPA ${ }^{39}$. Como aplicación se consideró la interacción humano-robot para la implementación de un modelo de interacción cognitiva niño-robot humanoide. En la Figura 16 se presentan las cuatro fases ${ }^{40}$ que la integran: preparar, conceptualizar, aplicar y comprobar.

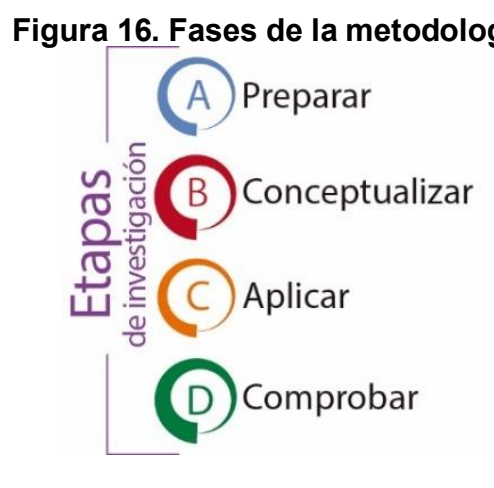

Fuente: elaboración propia.

${ }^{39}$ Los parámetros de evaluación de la UX fueron tomados del formato del reporte de proyectos de usabilidad empleado por la Asociación de Profesionales de Experiencia de Usuario (UXPA, por sus siglas en inglés) denominado: Usability Test Report v2.0.

40 La Real Académica de la Lengua Española define la palabra fase como: "cada uno de los distintos estados sucesivos de un fenómeno", es decir, cada estado es separable uno del otro sin alterar sus componentes, mientras que las etapas son lugares de pausa y desarrollo durante cada fase. En este sentido considero conveniente la utilización de este vocablo para la metodología que desarrollo. 
Las etapas están asociadas a la metodología UCDe y a la implementación de los lineamientos de evaluación de la UXPA (Asociación de Profesionales de Experiencia de Usuario). Como se muestra en las figuras $17-20$, éstas fueron segmentadas en las fases de desarrollo que facilitaron el cumplimiento de los objetivos (apartado 1.5.3). Las técnicas fueron adaptadas de acuerdo con el tipo de información que se requería para complementar las fases de desarrollo. En las siguientes líneas se describen cada etapa.

Etapa A: preparar

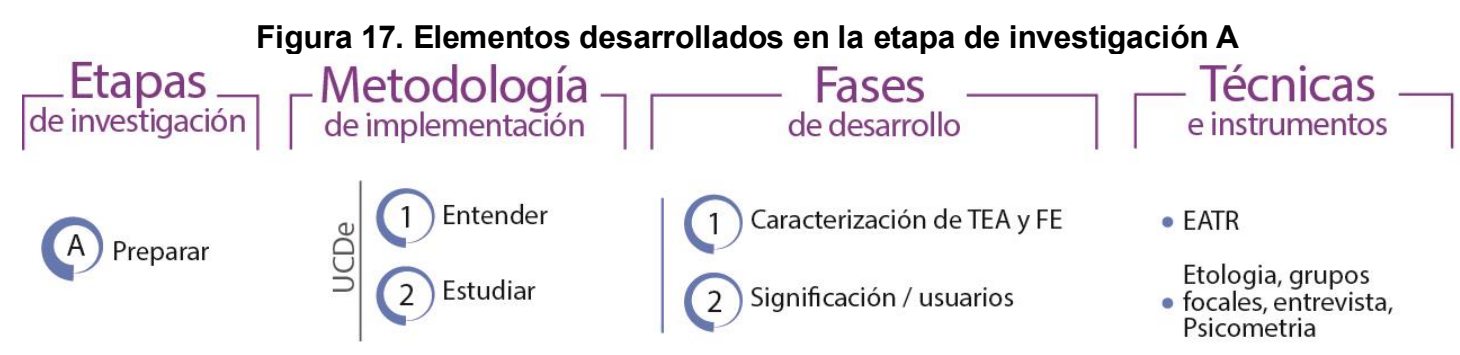

Fuente: elaboración propia

Se adecuaron los dos primeros elementos de la metodología de la UCD en su forma extendida (UCDe) (Harper et al., 2008); es decir, se integraron los elementos de: "entender" y "estudiar", los cuales fueron desarrollados a partir de los EATR y de algunas técnicas de investigación (Figura 17). Esta metodología sugiere que para aproximarse al fenómeno en estudio se considere el trabajo multidisciplinario con el fin de tener distintos ángulos de la problemática. Con ello se cubrieron los objetivos siguientes:

1) Corroborar los criterios diagnósticos del TEA a través de la observación y descripción naturalista, particularmente etológica. Las técnicas empleadas fueron la observación etológica, las entrevistas y grupos focales con los responsables directos de los niños, y la aplicación de la prueba psicométrica SCQ.

2) Determinar el nivel de desarrollo que tenían los niños en las FE. Para ello se emplearon dos instrumentos de evaluación enfocados en las FE: la prueba BANFE-2 y BRIEF-2. 
Etapa B: conceptualizar

Figura 18. Elementos desarrollados en la etapa de investigación B

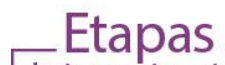

de investigación $\lceil$ de implementación

(B) Conceptualizar

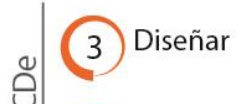

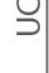
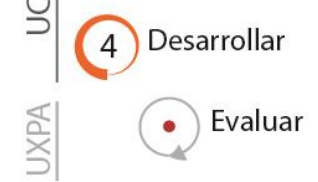

Fases de desarrollo

(1) Selección de tareas para ejercitar FE (psicometría /expertas)

(2) Vehículos de significación: RB

(3) Vehículos de comunicación: FE
Técnicas

e instrumentos

Entrevistas

Psicometría de FE

- Affordance

Fuente: elaboración propia.

Durante esta etapa se conceptualizaron, diseñaron y pusieron a prueba los materiales que servirían para las FE de los niños (Figura 18). Se prepararon materiales adecuados para las pruebas humano-humano y posteriormente se adecuaron a las interacciones niño-robot. Fueron definidas a partir de los resultados de tres fases de desarrollo:

1. Selección de FE a ejercitar, obtenidas por medio de:

- Observaciones del comportamiento con los niños durante la primera etapa.

- Tareas sugeridas por expertas en educación especial.

- Pruebas y FE sugeridas por las pruebas de psicometría enfocadas en el uso de las FE.

2. Conceptualización de vehículos de significación. Consistió en identificar las tareas y los elementos de significación para los niños de acuerdo con las pruebas reportadas (Arias-Aguilar et al., 2017) para la evaluación de repertorios básicos.

3. Conceptualización de vehículos de comunicación. Se adecuaron materiales para ejercitar las FE durante la interacción humano-humano, para ello se consideraron las FE elegidas en la fase 1 de esta etapa B. Se determinó que fueran tareas de complejidad creciente. 
Etapa C: aplicar

Figura 19. Elementos desarrollados en la etapa de investigación $C$

Etapas 「 Metodología Fases de investigación

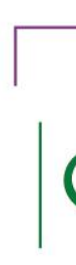
de desarrollo Técnicas e instrumentos
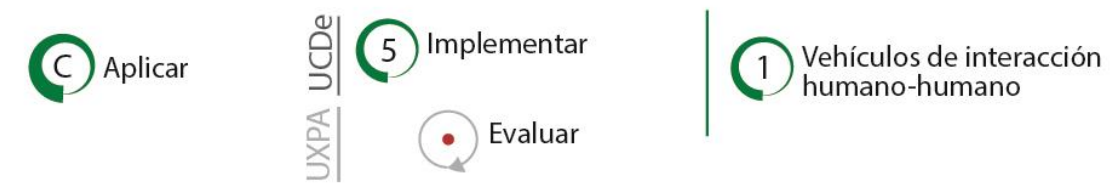

Fuente: elaboración propia.

Esta etapa consistió en la implementación y evaluación de los vehículos de interacción humanohumano. Se prepararon nueve tareas de dificultad creciente. Se realizaron pruebas previas con niños regulares $y$, posteriormente, se pusieron a prueba con 45 niños con TEA de dos unidades de atención del DIF estatal Oaxaca. La evaluación se hizo in situ, los resultados se evaluaron a partir de los parámetros de evaluación de la UXPA: eficiencia, eficacia y satisfacción (Figura 19). Es importante mencionar que para el desarrollo de esta etapa se consideraron las observaciones de las expertas, así como los resultados de tres estudios realizados en tesis de licenciatura (una en computación y dos más en ingeniería en diseño, ver apartado 4.2).

Etapa D: comprobar

Figura 20. Elementos desarrollados en la investigación durante la etapa D

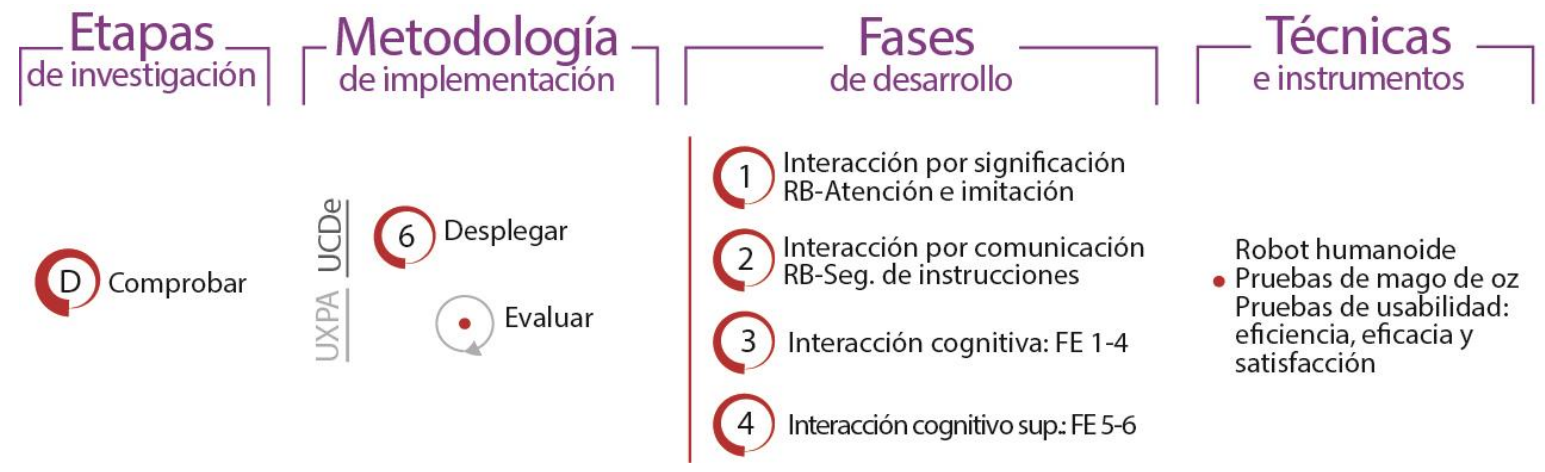

Nota: En las fases de desarrollo se incluyen los repertorios básicos (RB) de atención, imitación y seguimiento de instrucciones (RB-Seg). Las métricas empleadas para evaluar la usabilidad pertenecen a la UCDe y a la UXPA. Fuente: elaboración propia

Esta etapa se basó en adecuar y poner a prueba los materiales evaluados durante la etapa $C$ en la interacción humano-humano. A partir de éstos se ejecutaron las cuatro fases de desarrollo 
enfocadas en los niveles de interacción descritos en el análisis semiótico de las categorías de Peirce (1987), de Umberto Eco (1976) y de Magariños de Morentin (2008). En esta etapa también se integraron los parámetros de la UCDe y las métricas de eficacia, eficiencia y satisfacción de la UXPA (Figura 20).

Como se puede notar, cada etapa tiene una correspondencia con la metodología de implementación, las fases de desarrollo, los instrumentos y las técnicas empleadas. Siguiendo el orden establecido en el apartado 3.3, de acuerdo con el enfoque cualitativo y cuantitativo, los resultados se denominaron resultados escalonados acumulativos debido a que lo que se aplicó al grupo 1 sirvió como base para el desarrollo de las actividades del grupo 2, y así sucesivamente. Esta decisión determinó que las pruebas se realizaran con un grupo a la vez, no con todos los grupos. Lo cual facilitó el escalonamiento y el avance de un grupo a otro.

En los siguientes capítulos se presentan los resultados asociados a las etapas de investigación y su correspondiente desarrollo con los grupos de usuarios con los que se trabajó en cada etapa. En la figura 21 se integra lo mostrado hasta ahora y lo que se abordará en los siguientes tres capítulos siguiendo el orden de los grupos de trabajo de usuarios descritos en el apartado 3.3. De esta manera resumo lo siguiente ${ }^{41}$ :

1. Grupo de trabajo 1: niños con TEA grados 1, 2 y 3 , (Etapa A)

2. Grupo de trabajo 2: niños con diversidad funcional (neurotípicos, con TEA o con alguna otra discapacidad)

3. Grupo de trabajo 3: niños con TEA grado 1 y 2 (Etapa C)

4. Grupo de trabajo 4: niños con TEA grado 1 (Etapa D)

\footnotetext{
${ }^{41}$ Nótese que en la etapa B no se trabajó con usuarios debido a que en esta etapa se llevó a cabo la conceptualización y el desarrollo de los materiales que se emplearían durante las interacciones.
} 


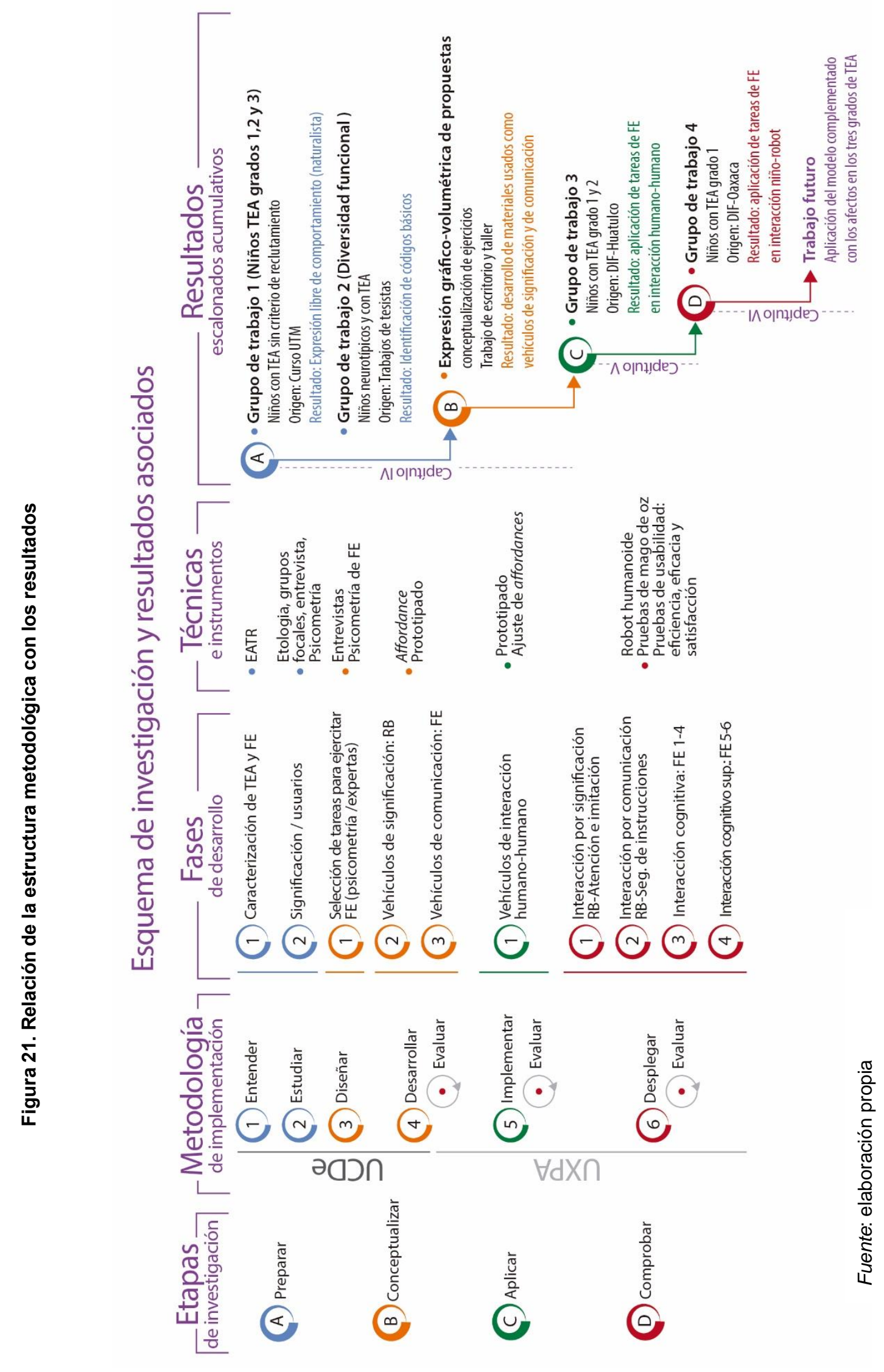




\section{Aplicación y resultados}

Al iniciar la investigación se mencionó que entender, identificar y estudiar son los elementos básicos para: 1) la definición de los usuarios, 2) la identificación de las tareas que éstos deben ejecutar, y 3) los contextos de uso. A partir de ellos se tiene mayor claridad acerca de lo que se diseñará, para quién, con qué objetivo y en qué contexto sería usado por los usuarios.

Abordar este punto con los niños con TEA, fue uno de los factores cruciales para obtener la información adecuada. Por ello, contar con la información empírica y directa contribuyó a dirigir el diseño de las tareas que se pondrían a prueba de manera continua con los niños durante las interacciones.

\subsection{Etapa de investigación A: preparar}

Los resultados que se presentan en esta sección fueron obtenidos a partir del grupo de trabajo 1 de la etapa de investigación A. Están asociados a la metodología de implementación, a las fases de desarrollo, y a las técnicas e instrumentos que se emplearon para lograr el resultado descrito (ver Figura 19 del apartado 3.4). En la Figura 22 señalo la relación de la etapa A, con los EATR 1 descrito en el capítulo 2.

Figura 22. Relación de etapa de investigación A con el EATR 1

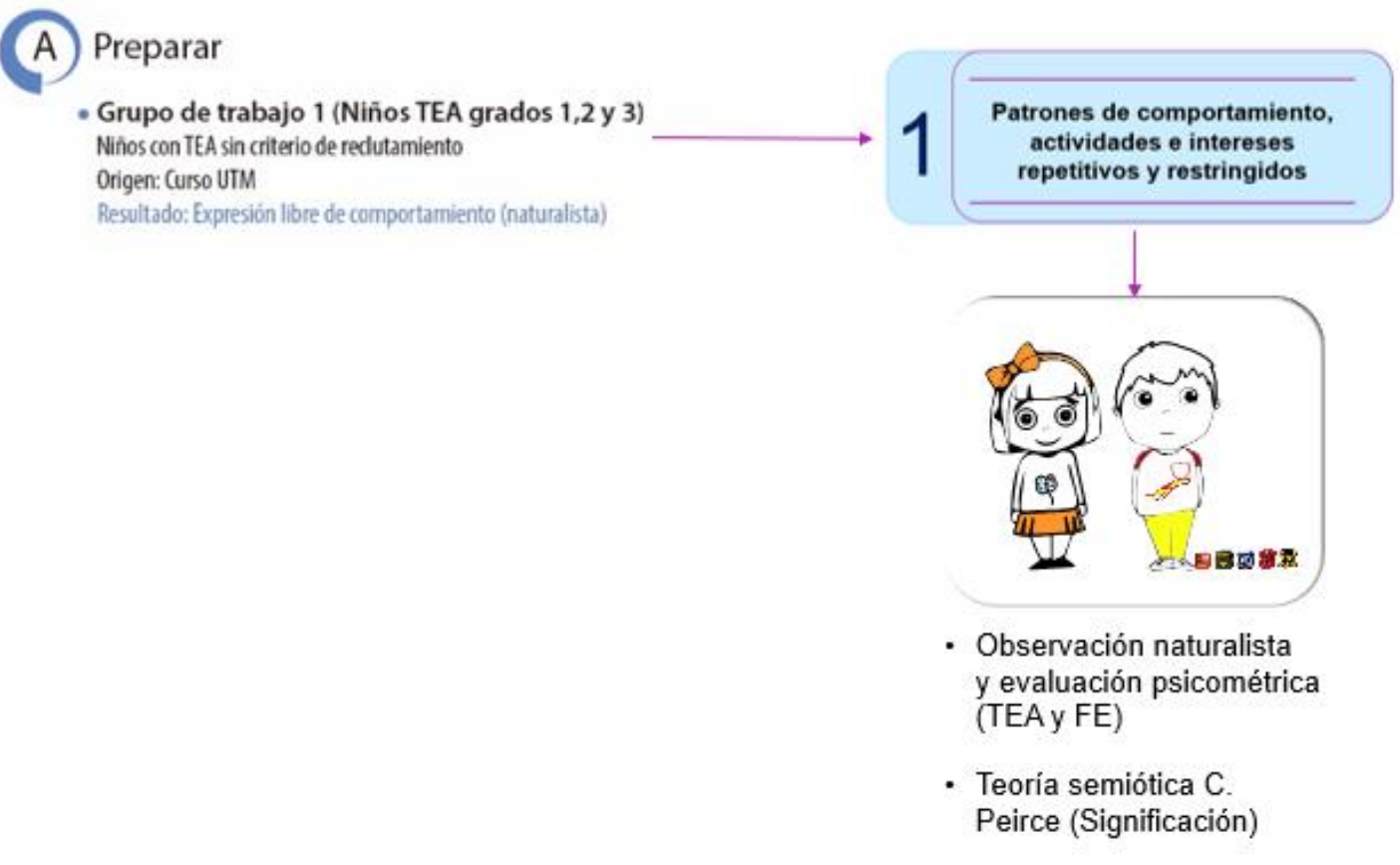

Fuente: elaboración propia 


\subsubsection{Observación y descripción naturalista}

Para su desarrollo se emplearon tres áreas: etología cognitiva, psicología y robótica. En este paso la intervención de la robótica se centró en la delimitación semántica, la viabilidad y el alcance. La viabilidad se realizó a través de una primera exploración con un especialista en robótica. En la Figura 3 del capítulo uno las aportaciones se presentan como parte de los elementos de la psicología $(\mathrm{P})$ y de la robótica $(\mathrm{Er})$. En el R1 se esquematiza la aportación de la etología y el comportamiento y, en el R2, la cognición y las FE.

En cuanto a la aproximación conductual y de comunicación con los niños, el método empleado fue naturalista (apartado 2.1.3.8). La técnica para mantener una aproximación más cercana fue etológica cognitiva (Kingstone et al., 2017; Osborne-Crowley, 2020; Perinat Maceres, 1980). Ambas se emplearon para iniciar el contacto con los niños e identificar las formas en las que se podía establecer una comunicación (partiendo de sus elementos de significación). El desarrollo se segmentó en tres pasos:

1. Habituación, sensibilización y rapport.

2. Identificación de manejo de vocabulario verbal y de signos corporales naturales.

3. Interacciones cognitivas a partir de la comunicación verbal-no verbal y los vehículos de significación.

\subsubsection{Resultado 1. Observación y descripción naturalista}

Como se mencionó en el apartado 3.3, el primer grupo de trabajo fue convocado a través de una conferencia ofrecida en la Universidad Tecnológica de la Mixteca (Figura 23).

Figura 23. Presentación e inicio de investigación dirigido a familias de niños con TEA
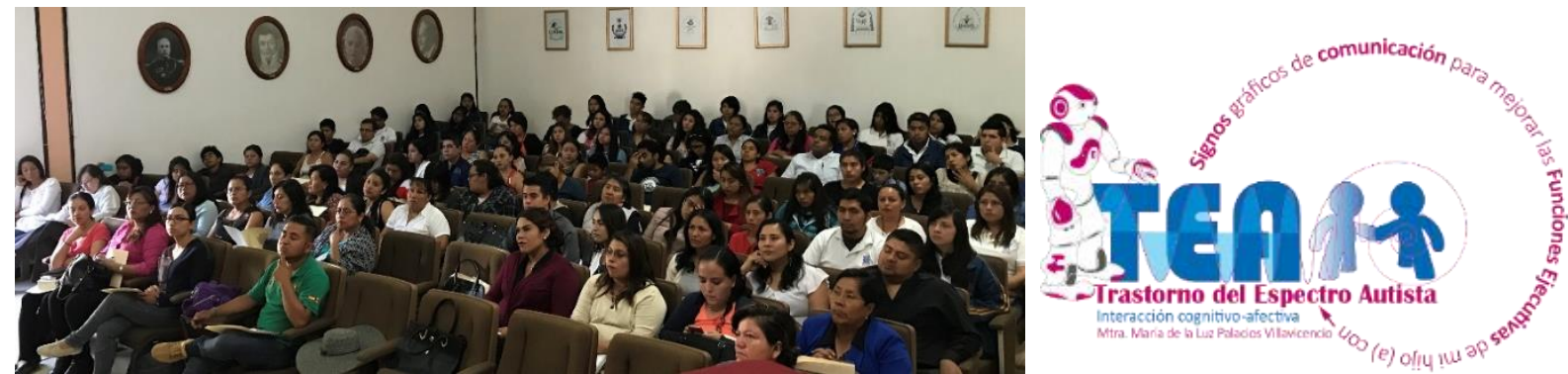

Nota. Se realizó una invitación a asistir a una conferencia y a participar en el proyecto. Del lado izquierdo se muestra la sala de conferencias donde se realizaron las actividades a las que asistieron los interesados en el tema. Del lado derecho está la imagen con la que se promovió el proyecto. Fuente: elaboración propia. 
Durante la conferencia se indicó la forma de trabajo y el lugar en el que se realizarían las sesiones. Se destinó un espacio para atender a los niños. Fue dividido en cuatro secciones, tres para el trabajo individualizado (Figura 24) y uno para el trabajo con los responsables (Figura 25).

\section{Figura 24. Sala de trabajo con niños TEA}
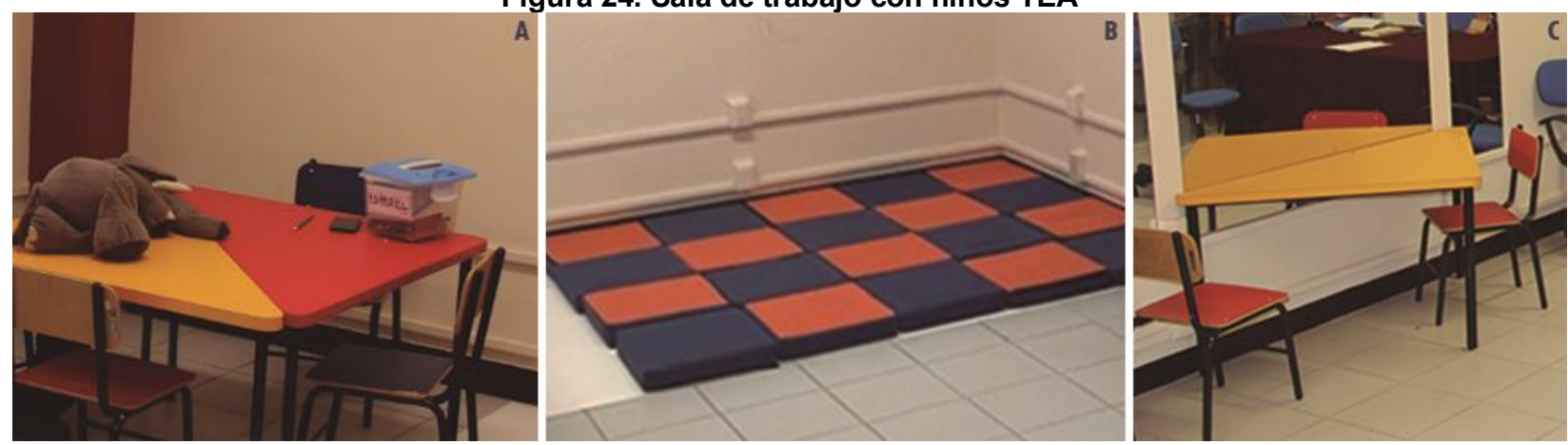

Nota. A) Mesa de trabajo con responsables y niños con TEA; B) Zona de piso para niños; C) Mesa de trabajo individualizado con espejo. Fuente: elaboración propia.

Figura 25. Sala de trabajo con niños y responsables de niños con TEA

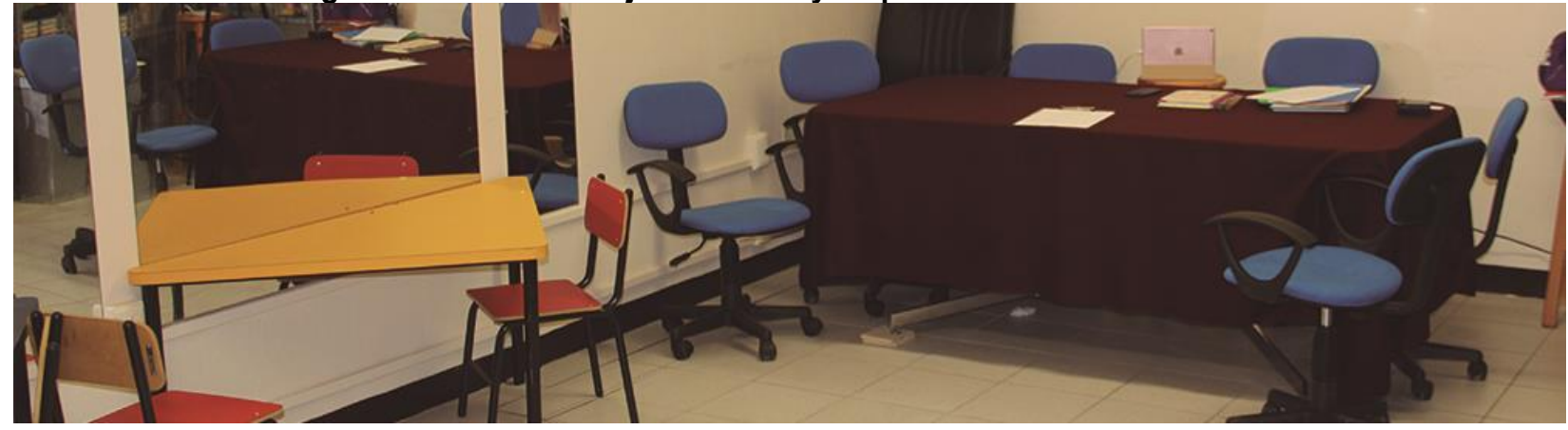

Nota. A la derecha está el área en la que se trabajó con los responsables de los niños. Desde ahí se pueden observar las actividades de los niños en mesa de trabajo con espejo. Fuente: elaboración propia

En las Figuras 26 y 27 se muestra una sesión de grupo con las mamás, papás o responsables de los niños con TEA. El grupo fue dividido en dos, para no saturar el número de participantes. 
Figura 26. Sesión con primer grupo de responsables de los niños con TEA

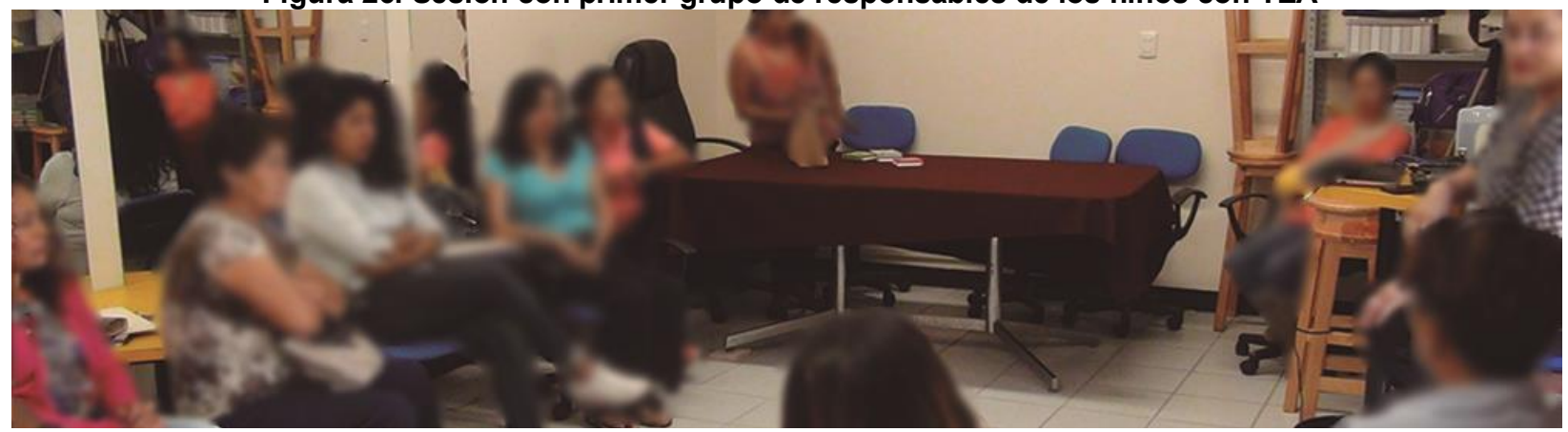

Nota. Intercambio de experiencias mamás y papás con hijos con TEA.

Figura 27. Sesión con segundo grupo de responsables de los niños con TEA

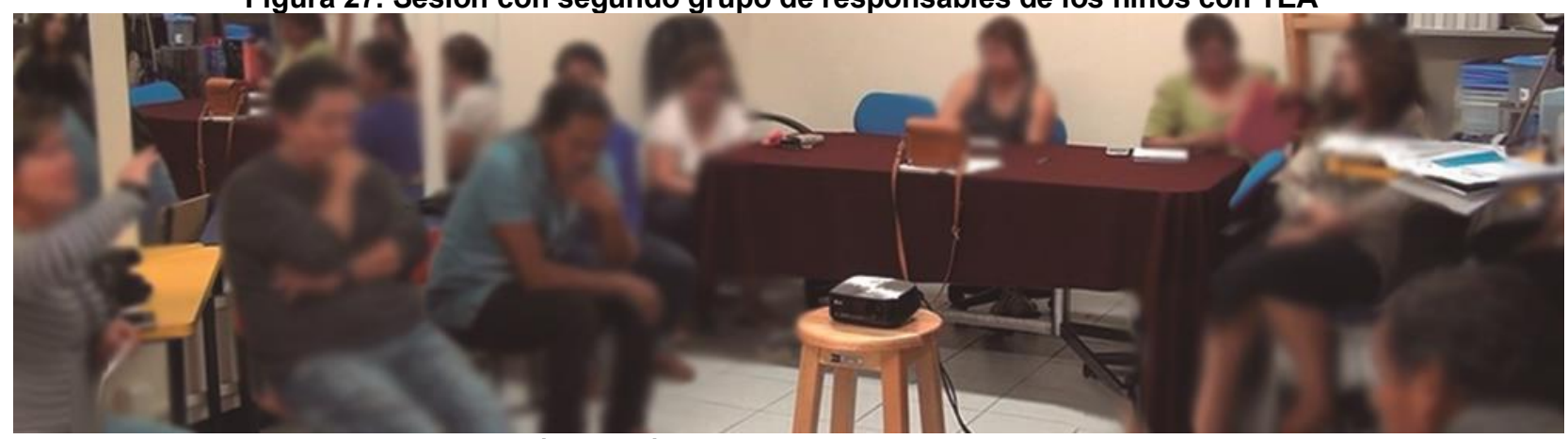

Nota. Intercambio de experiencias mamás y papás con hijos con TEA.

Durante las sesiones se hizo un reconocimiento de los niños con los que trabajaría, de su diagnóstico y grado de autismo. Se pudo identificar si hablaban, interactuaban o socializaban con facilidad. Se obtuvieron datos generales de sus rasgos de TEA. Se particularizó en sus gustos y preferencias. A partir de ello se obtuvieron los datos para preparar el material necesario para iniciar con la fase observacional del comportamiento de los niños.

\subsubsection{Resultado 2. Obtención de información básica}

Durante las sesiones de grupo con las personas responsables de los niños con TEA se obtuvo información acerca de los gustos y preferencias de éstos. Con dicha información se prepararon materiales específicos para cada niño con el fin de incluir objetos en una caja personalizada del agrado de cada infante. Cada caja contenía: 1) objetos comunes, lápices para dibujar y colorear, hojas blancas, hojas con caricaturas del gusto de cada uno, hojas de recorte-pega para armar, tijeras seguras, y 2) dos objetos personalizados de acuerdo con el gusto de cada niño (previamente identificados); por ejemplo, carritos, pegatinas de sus personajes favoritos, algún 
objeto especial como varitas de jacaranda, imagen de la vaquita de nutrileche, papeles brillantes, entre otros objetos especiales. El objetivo fue proporcionarles "algo" atractivo con lo que pudieran entretenerse mientras se trabajaba con la familia o responsables. En la Figura 28 se presenta la muestra de una caja y el nombre personalizado ${ }^{42}$ de cada niño, así como el nombre de su mamá o acompañante. El nombre también fue diseñado con algún elemento de acuerdo con el gusto de los niños.

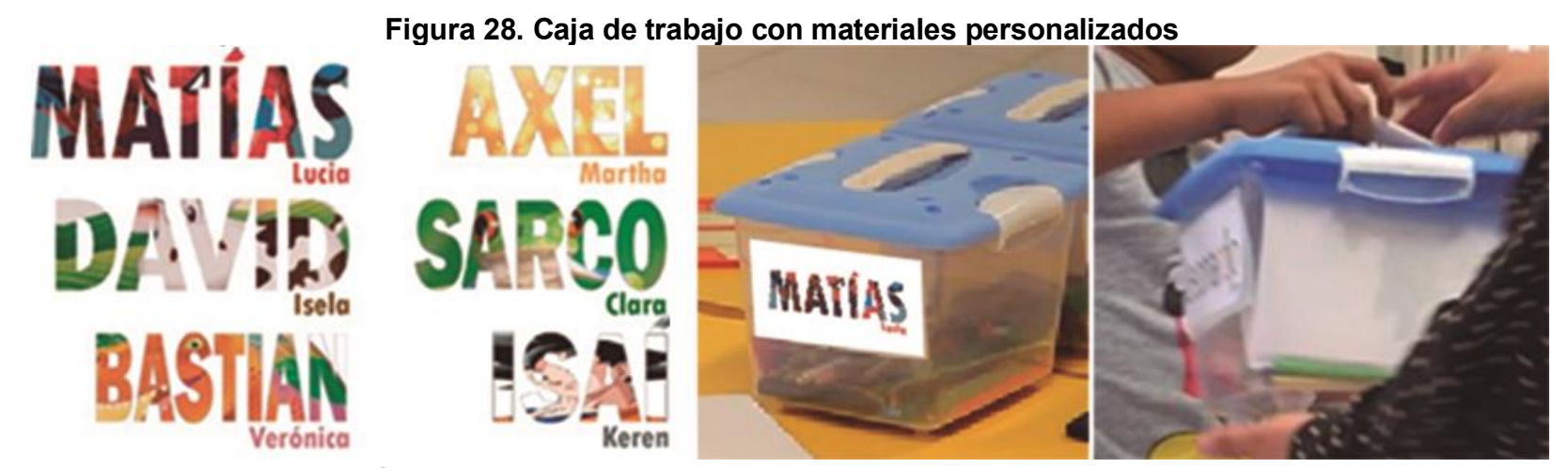

Nota. Al inicio de cada sesión se entregaba una caja de trabajo personalizada a cada niño participante, al finalizar la sesión la regresaban.

El contenido de la caja facilitó que los niños se entretuvieran, pero sobre todo ayudó conocerlos a través de lo que optaban por hacer mientras permanecían "aparentemente solos"; ya que la mamá o papá trabajaba conmigo en una sesión independiente a ellos, pero en el mismo espacio. La reacción de los niños se caracterizó en cuatro categorías:

1. Reconocimiento del lugar y del espacio.

2. Acercamiento espontáneo o por curiosidad.

3. Confianza en la interacción con una persona ajena a ellos.

4. Aprendizaje de dos reglas: saludo al llegar y despedida al terminar la sesión. Ambas se acompañaron de la entrega y recepción de la caja personalizada al inicio y al finalizar la sesión.

\subsubsection{Resultado 3. Sensibilización con responsables}

\section{Grado de TEA del grupo 1}

Como se mencionó previamente (apartado 3.2.1.2), con el fin de corroborar si los niños estaban dentro del diagnóstico con TEA especificados en el DSM-5, se utilizó el "cuestionario de

${ }^{42}$ Los nombres reales fueron sustituidos. 
comunicación social (SCQ)" debido a que es un instrumento psicométrico que proporciona puntuaciones relacionadas con los problemas de interacción social, dificultades de comunicación y conducta restringida, repetitiva y estereotipada (Rutter et al., 2005). Con esta prueba no se identifican diferencias significativas por edad, sexo, nivel de lenguaje, ni coeficiente intelectual, por lo que en este estudio tampoco se marcaron tales diferencias. No obstante, se menciona que todos los participantes que acudieron y formaron parte del estudio fueron varones, no se presentó ninguna mujer.

El parámetro para identificar que una persona presenta o no rasgos de TEA, así como el grado de afectación que tiene, se determina a partir de los puntajes de la prueba SCQ. Los reportes indican que las personas regulares obtienen menos de 5.2 puntos, mientras que las personas con TEA pueden ser detectadas a partir de 15 puntos (Rutter et al., 2005: 10). De esta manera los puntajes mínimos y máximos para ubicar a los participantes de acuerdo con su grado de TEA fueron:

- Grado 1: de 15 a 23 puntos

- Grado 2: de 24 a 29 puntos.

- Grado 3: de 30 a 39 puntos.

En la Tabla 14, se presentan los puntajes de SCQ obtenidos por los participantes del grupo 1 de trabajo asociados al grado de TEA en el que fueron considerados. Los recuadros sombreados de gris indican los parámetros irregulares por edad o por el puntaje. No obstante, esos casos sí fueron considerados en el estudio debido a dos factores: 1) sus rasgos coincidían con la edad de los otros participantes dentro del mismo grado, y 2) por conducta y comportamiento, los rasgos coincidían con el criterio diagnóstico del grado de TEA en el que se colocaron.

Tabla 14. Grado de TEA del grupo 1

\begin{tabular}{|c|c|c|c|c|c|}
\hline Grado & No. & Responsable & Edad & Género & $S C Q$ \\
\hline \multirow{6}{*}{ TEA 1} & 1 & Mamá & 8 & $\mathrm{H}$ & 15 \\
\hline & 2 & Abuelito & 9 & $\mathrm{H}$ & 15 \\
\hline & 3 & Papá & 11 & $\mathrm{H}$ & 17 \\
\hline & 4 & Mamá & 11 & $\mathrm{H}$ & 20 \\
\hline & 5 & Mamá & 10 & $\overline{\mathrm{H}}$ & 23 \\
\hline & 6 & Mamá & 9 & $\mathrm{H}$ & 23 \\
\hline \multirow{5}{*}{ TEA 2} & 1 & Papá & 20 & $\mathrm{H}$ & 24 \\
\hline & 2 & Mamá & 9 & $\mathrm{H}$ & 27 \\
\hline & 3 & Mamá & 6 & $\mathrm{H}$ & 27 \\
\hline & 4 & Mamá & 9 & $\mathrm{H}$ & 29 \\
\hline & 5 & Mamá & 7 & $\mathrm{H}$ & 29 \\
\hline \multirow{4}{*}{ TEA 3} & 1 & Fam. & 7 & $\mathrm{H}$ & 32 \\
\hline & 2 & Mamá - papá & 8 & $\mathrm{H}$ & 33 \\
\hline & 3 & Mamá - papá & 8 & $\mathrm{H}$ & 33 \\
\hline & 4 & Mamá & 5 & $\mathrm{H}$ & 18 \\
\hline
\end{tabular}




\subsubsection{Resultado 4. Establecimiento de rapport con los niños}

Durante la primera sesión fue importante recabar la información del comportamiento de los niños desde la perspectiva de los responsables. Antes de iniciar con las interacciones con los niños, se indicó a los responsables que el contacto con los niños se realizaría por aproximaciones sucesivas. Y que, al llegar al espacio de trabajo, se entregaría a los niños una caja personalizada con objetos atractivos para que pudieran entretenerse, mientras se trabajaba con los adultos. Durante las primeras sesiones, cuando los niños llegaban se les entregaba la caja personalizada y pero no interactuaba directamente con ellos. Con la ayuda de la caja personalizada el contacto fue suficiente para iniciar una etapa de sensibilización y de reconocimiento para establecer el contacto con cada niño. Durante las dos primeras sesiones con los niños se realizaron tres acciones (Figura 29):

1. El Saludo.

2. Recepción de caja de juegos personalizada al arribar al salón de trabajo.

3. Devolución de la caja personalizada al finalizar cada sesión.

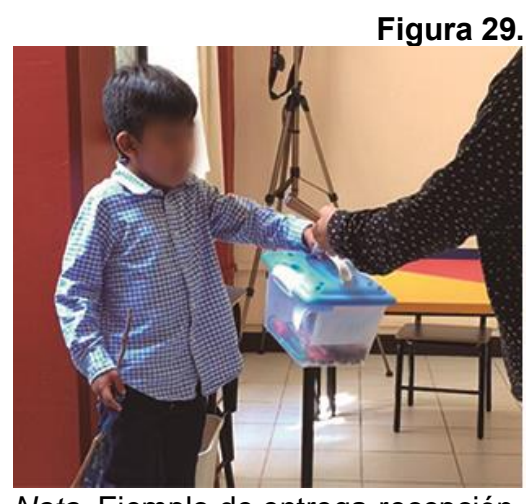

Figura 29. Saludo, entrega y recepción de caja personalizada

Nota. Ejemplo de entrega-recepción de caja de trabajo con diferentes niños. Fuente: elaboración propia

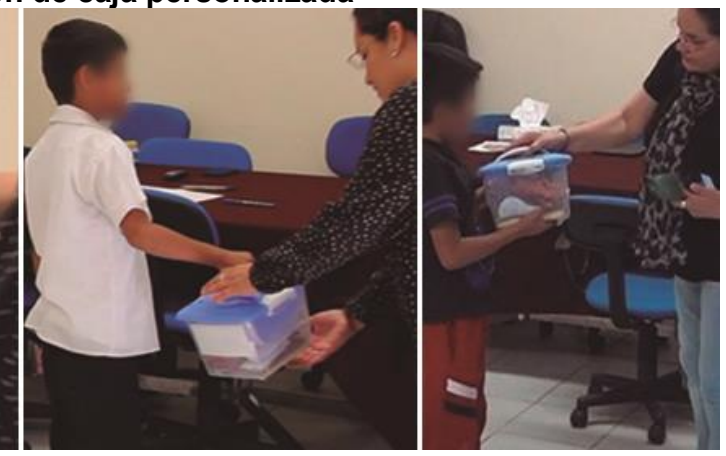

Durante esas dos primeras sesiones con los responsables se realizó la recolección de la información del niño. Mientras tanto, el niño exploraba o se entretenía con las cosas que contenían la caja personalizada (Figura 30). 
Figura 30. Escenario de trabajo durante la primera sesión

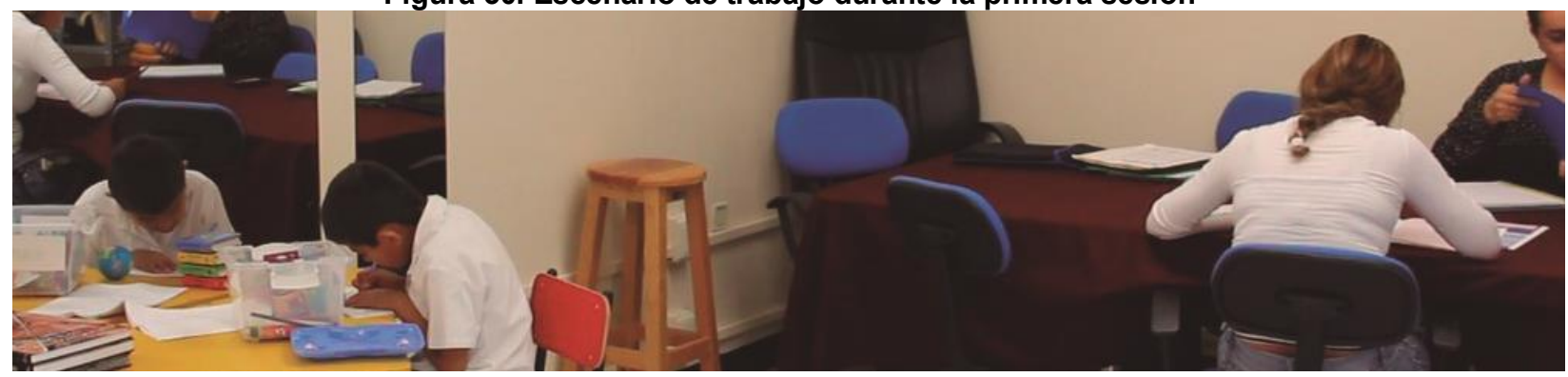

Nota. Se observa la interacción que se establecía con la mamá y la distancia con la que se inició el trabajo con los niños. Fuente: elaboración propia.

\subsubsection{Resultado 5. Comunicación verbal y no verbal}

A través de la construcción de las técnicas de persona (Nodder \& Nielsen, 2013) y mapa de empatía (Gray, 2017) se determinó la personalidad de los tres tipos de usuarios con los que se trabajó. Como se explicó previamente, por las características de los usuarios y la poca disponibilidad que se tenía para contactar un grupo de trabajo, el medio para trabajar con niños de los tres niveles de gravedad fue a través de la invitación abierta (que ya se mencionó). Esto permitió tener un mejor conocimiento de sus habilidades y del potencial de comunicación que se podía establecer con los niños durante las interacciones.

Para conocer el margen de interacción que se podía tener con los niños se identificaron las posibilidades de comunicación por medio del habla y a través de los signos. La exploración se realizó empleando la observación etológica con intervenciones interactivas participantes. Esta forma de aproximación permitió asegurar que los comportamientos natos de los participantes emergieran poco a poco de manera natural, y desde sus propias necesidades de interacción con una persona desconocida.

Durante esta etapa la identificación del tipo de usuarios y el interés de éstos fue lo más importante. Sin embargo, al momento de reconocer este último punto se suscitaron ciertas dificultades debido a que sus intereses son totalmente diversos. Además, había que considerar que a estos niños no sólo les atraen ciertos objetos de manera particular, sino también, lo hacen de forma casi obsesiva; hecho que se señala en los criterios diagnósticos donde se mencionan que los gustos son "limitados, repetitivos y estereotipados" (APA, 2013) Por tal motivo, el inicio de la investigación partió de una base de conocimientos personalizados de cada usuario con base a la información obtenida de las familias o de las personas especialistas (educativas) que 
trabajaban con los niños; de igual manera, se obtuvo información de aquellos que trabajan en la programación con el robot humanoide (las entrevistas fueron independientes).

En las Figuras 31 a la 33 se presentan tres ejemplos de las observaciones que se hicieron con los niños con TEA desde una aproximación naturalista. Como se puede apreciar, el comportamiento de los niños en un espacio de interacción libre se manifiesta de manera espontánea. En este contexto es posible identificar sus intereses genuinos y las posibilidades de comunicación con ellos.

En la Figura 31 se presentan algunos ejemplos de niños de mayor grado de TEA, quienes desde la definición del DSM-5 tienen un nivel severo. Estos pequeños requieren de ayuda muy notable en el aspecto de la comunicación, la socialización, las conductas repetitivas y restringidas. Las imágenes muestran cómo los niños tienden a tener actividades en solitario, durante la mayor parte de las primeras sesiones hacían lo mismo sin mostrar incomodidad o aburrimiento. Su sola presencia y su actividad de "entretenimiento" era suficiente para estar entretenidos y en equilibrio.

En la Figura 32 los niños tienen un nivel moderado de TEA, lo cual quiere decir que también requieren ayuda, pero solo "notable" en el aspecto de la comunicación, la socialización y las conductas repetitivas y restringidas. Estos niños (incluso el joven de la imagen de la izquierda), se pueden entretener con lo que se les presenta, se interesan un poco más en lo que hay en su caja de trabajo, pero su intención $n^{43}$ parece limitada. Pueden quedarse sentaditos si hacer nada o sin intenciones dirigidas. La diferencia entre ellos y los niños de grado 3 es que, los niños con un nivel moderado sí aceptan actividades que están fuera de su rango de intereses restringidos.

En la Figura 33 se muestran algunos ejemplos de niños grado 1 o nivel ligero de afectación que sólo requieren ayuda, pero no una ayuda notable o muy notable como ocurre en los casos anteriores. Este grupo de niños están más dispuestos a trabajar en actividades que implican el uso de su cognición o de la planeación de acciones. Estas características y observaciones fueron aprovechadas al máximo para proponer el modelo cognitivo final de interacción que abarca los tres niveles gravedad del TEA.

${ }^{43}$ La intención se basa en la voluntad de una persona para decidir algo en torno a un fin. De acuerdo con la Real Academia, se involucran la potencia volitiva de rehuír, querer o aborrecer algo. 
Figura 31. Observación de coducta de niños con TEA grado 3
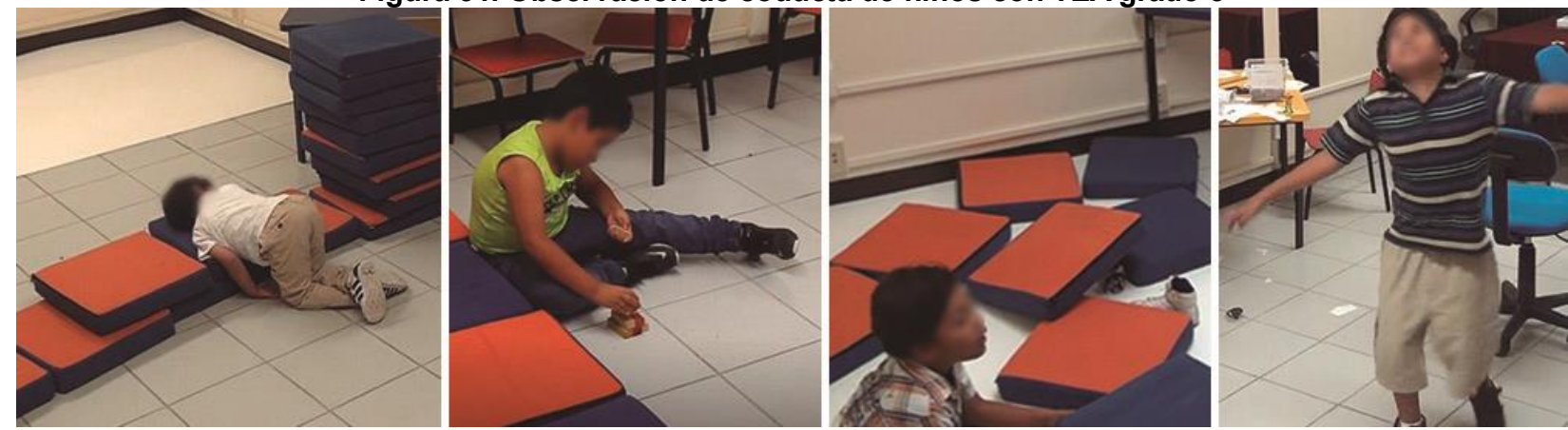

Fuente: elaboración propia

Figura 32. Observación de coducta de niños con TEA grado 2
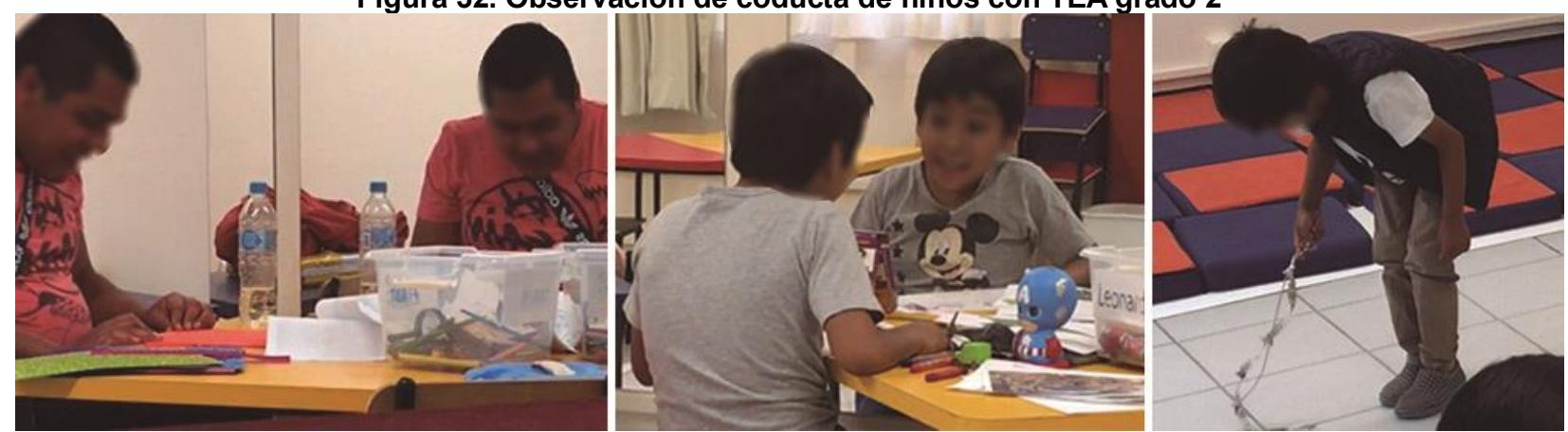

Fuente: elaboración propia

Figura 33. Observación de conducta de niños con TEA grado 1
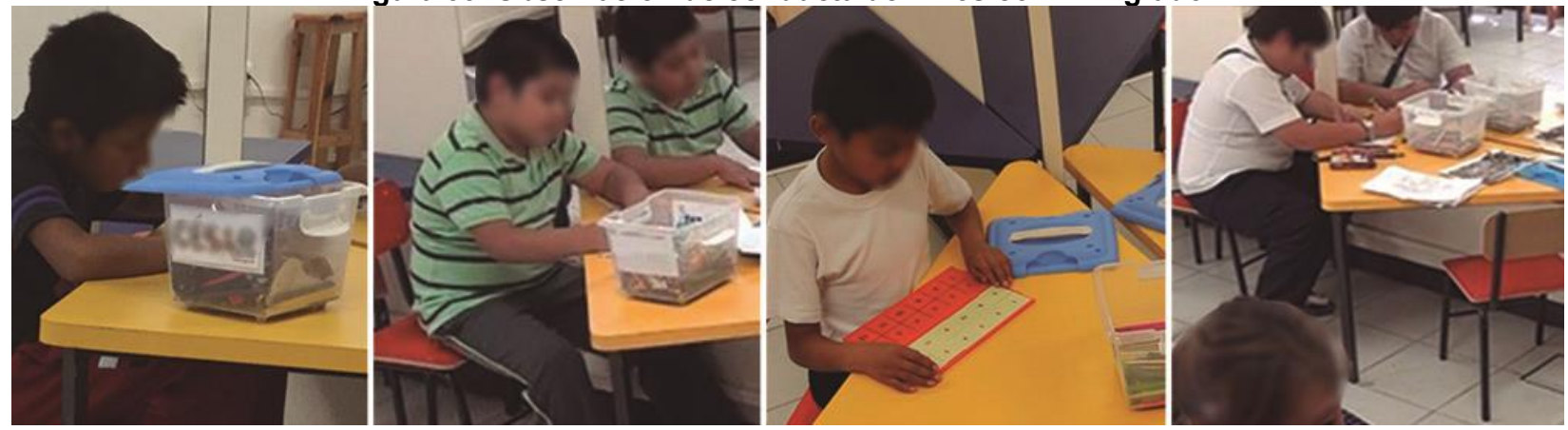

Fuente: elaboración propia

\subsubsection{Resultado 6. Mapa de empatía}

A partir de las interacciones con el grupo 1 (como los ejemplos antes presentados) se consiguió la información básica para hacer un mapa de empatía (Gray, 2017), como se muestra en la Figura 34. A través de éste se plasmaron los rasgos más característicos de los niños con TEA. El mapa de empatía es un reflejo de la generalidad de los niños con los que se trabajó. Se registraron 
datos como la identificación de su diagnóstico, lo que suelen ver de su entorno, qué tipo de cosas parecen significativas, qué suelen hacer o decir ante lo que les parece significativo, qué sucede con sus comportamientos repetitivos o cuando se les asigna una tarea específica, qué actitud toman cuando algo no les agrada o cuando les agrada mucho.

Figura 34. Mapa de empatía de niños con TEA

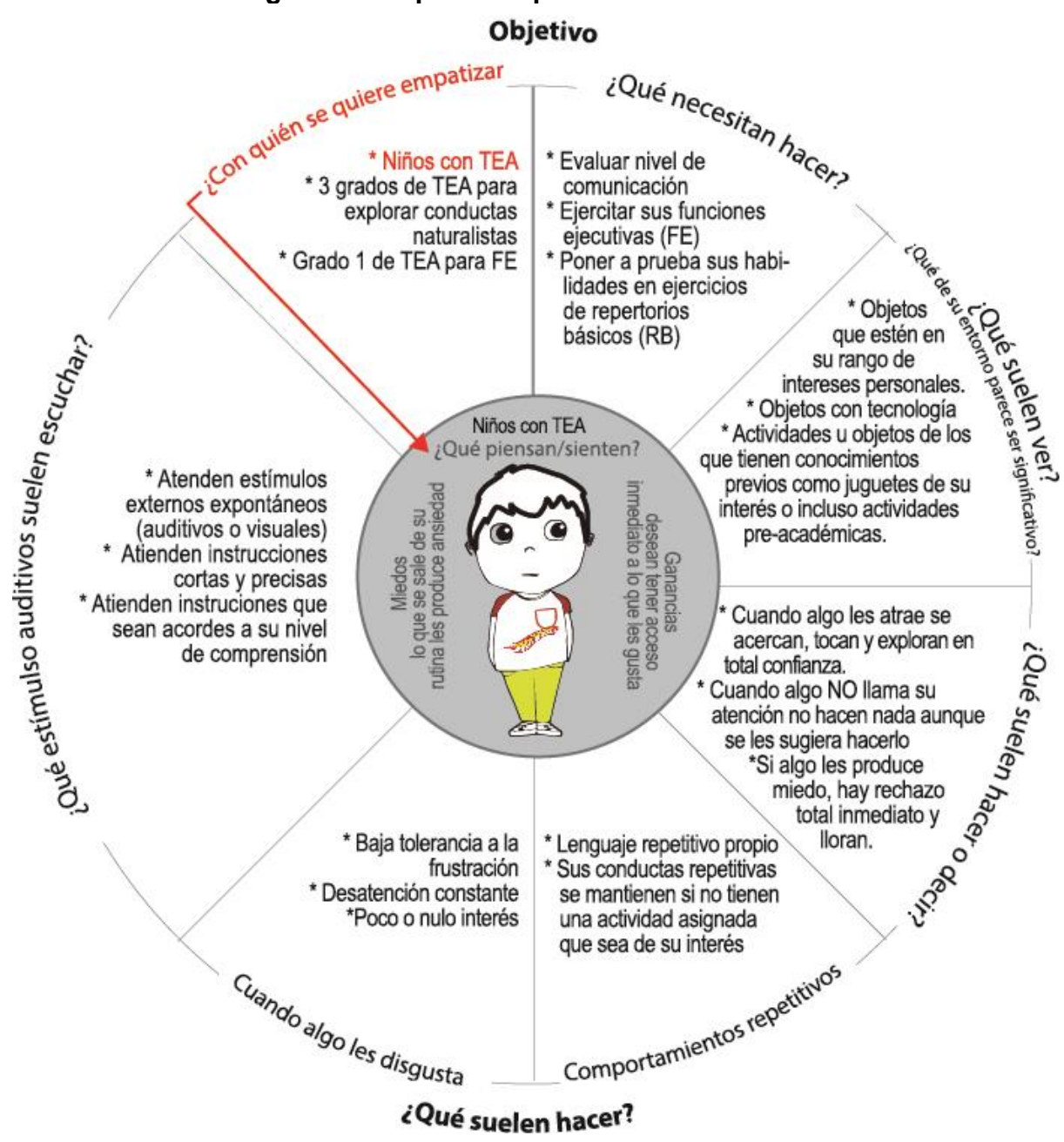

Fuente: elaboración propia a partir del lienzo de empatía de Dave Gray (2017)

Durante esta etapa se corroboró que los intereses de los niños con TEA son diversos y totalmente heterogéneos. Sus gustos en general no distan mucho de lo que puede gustar a cualquier niño, pero tienen la particularidad de que su enfoque de atención está centralizado en algún "extraordinario detalle" del entorno. Con un agravante, no solo gustan de ciertas cosas de manera particular, sino que además les atraen insistentemente, teniendo gustos "limitados, 
repetitivos y estereotipados" (APA 2014). Pero esos detalles y comportamientos no se logran interpretar automáticamente como ocurre con los niños neurotípicos.

De manera sintetizada, en la Tabla 15, se presentan las observaciones con el grupo 1 de niños con TEA.

Tabla 15. Resumen de resultados de aproximación naturalista

\begin{tabular}{|c|c|c|c|}
\hline \multicolumn{4}{|c|}{ Aproximación naturalista } \\
\hline Intervención & Participantes & Actividades & Resultado \\
\hline $\begin{array}{l}\text { Preparación. Consistió } \\
\text { en la preparación de la } \\
\text { familia y se les dio a } \\
\text { conocer cómo se } \\
\text { trabajaría con los niños. }\end{array}$ & $\begin{array}{l}\text { Responsables del } \\
\text { niño (mamás, papás } \\
\text { u otro). }\end{array}$ & $\begin{array}{l}\text { Reunión general } \\
\text { Introducción } \\
\text { Compartir experiencias, llenar } \\
\text { formatos de datos generales para } \\
\text { elaborar técnica "Mapa de empatía". }\end{array}$ & \begin{tabular}{|l|} 
Presentación del proyecto y \\
preparación del escenario de \\
trabajo (Figuras 25-27) \\
Obtención de datos generales de \\
la población con la que se \\
trabajaría. Se particularizó en los \\
gustos y preferencias de los \\
niños (Figura 28-29).
\end{tabular} \\
\hline \multirow{2}{*}{\begin{tabular}{|l|} 
Sensibilización. \\
Centrado en la primera \\
exposición de los niños al \\
contexto de trabajo y a la \\
relación que se estableció \\
primero con la mamá \\
para generar confianza \\
en el niño.
\end{tabular}} & $\begin{array}{l}\text { Responsables del } \\
\text { niño (mamás, papás } \\
\text { u otro) }\end{array}$ & $\begin{array}{l}\text { La interacción solo se realiza con los } \\
\text { responsables del niño. Se aplica } \\
\text { historia clínica y SCQ. }\end{array}$ & $\begin{array}{l}\text { Definición de nivel de TEA a } \\
\text { partir de SCQ (Tabla 14). }\end{array}$ \\
\hline & Niño & $\begin{array}{l}\text { No se interactúa con él } \\
\text { directamente, pero se realizan tres } \\
\text { acciones: } \\
\text { 1) saludo, 2) se proporciona caja de } \\
\text { juegos personalizada, y } 3 \text { ) } \\
\text { despedida en la que el niño regresa } \\
\text { la caja de juegos. }\end{array}$ & Figuras 28,29 y 30 \\
\hline \multirow{2}{*}{\begin{tabular}{|l|l} 
Rapport. Radicó en el & \\
establecimiento directo \\
con los niños y en la \\
generación de un \\
ambiente de empatía y \\
aceptación mutua, entre \\
ellos y yo.
\end{tabular}} & $\begin{array}{l}\text { Responsables del } \\
\text { niño (mamás, papás } \\
\text { u otro) }\end{array}$ & $\begin{array}{l}\text { La mitad de la sesión se desarrolla } \\
\text { con la mamá para completar la } \\
\text { historia clínica. }\end{array}$ & Figura 25 \\
\hline & Niño & $\begin{array}{l}\text { La mitad de la sesión se destina al } \\
\text { niño para iniciar el contacto directo. }\end{array}$ & $\begin{array}{l}\text { Comunicación inicial con los } \\
\text { niños }\end{array}$ \\
\hline $\begin{array}{l}\text { Comunicación verbal y } \\
\text { no verbal. Identificación } \\
\text { de signos verbales, no } \\
\text { verbales y las bases para } \\
\text { los vehículos de } \\
\text { significación. }\end{array}$ & Niño & $\begin{array}{l}\text { La interacción fue directa con el } \\
\text { niño, con o sin la mamá presente } \\
\text { durante las sesiones. } \\
\text { Con cada uno se estableció } \\
\text { comunicación verbal o no verbal de } \\
\text { acuerdo con las características y de } \\
\text { los elementos que a cada niño le } \\
\text { gustaban o por los que tenían } \\
\text { especial atracción. }\end{array}$ & $\begin{array}{l}\text { Comunicación a partir de los } \\
\text { elementos descritos a través de } \\
\text { la técnica "Mapa de empatía" } \\
\text { (Figura 34) y en la observación } \\
\text { no participante realizada durante } \\
\text { las sesiones previas (Figuras 31- } \\
\text { 33). }\end{array}$ \\
\hline
\end{tabular}

Fuente: elaboración propia. 


\subsubsection{Identificación de códigos básicos de interacción}

En esta sección se presentan los resultados del grupo de trabajo 2 con diversidad funcional de la etapa de investigación A. En la Figura 35 se muestra la relación de esta etapa con el EATR 1 descrito en el capítulo 2.

Figura 35. Relación de etapa de investigación A con el EATR 1

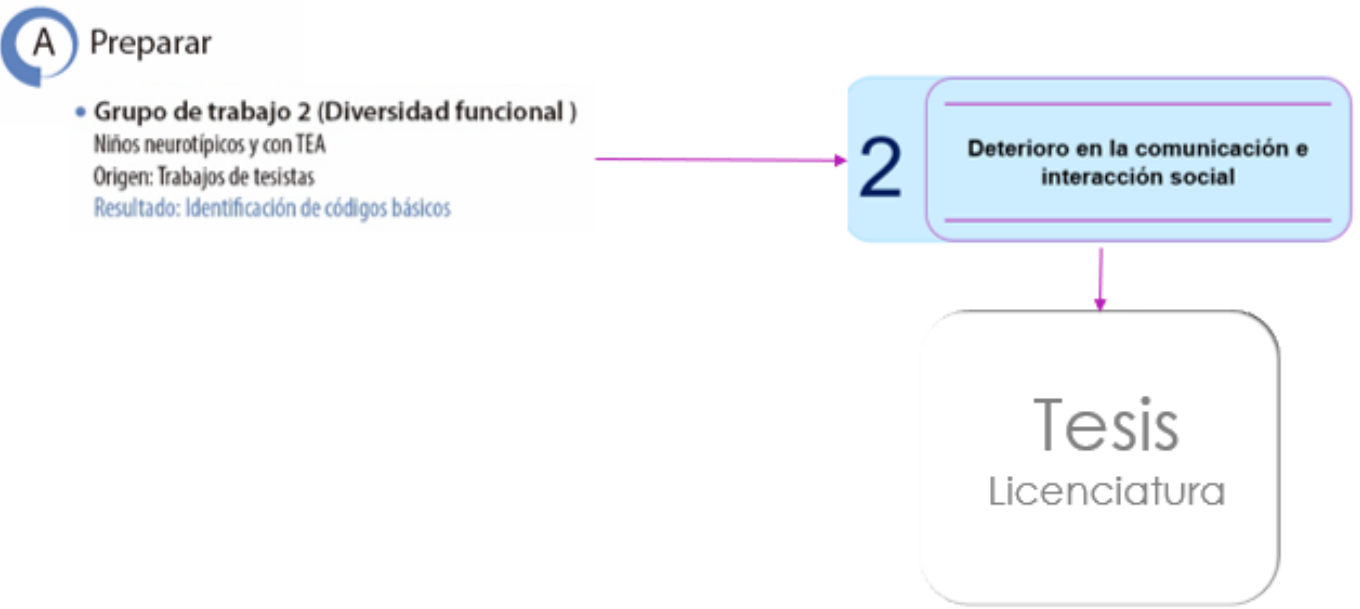

Fuente: elaboración propia.

Antes de iniciar la definición de los ejercicios de las FE se realizó una exploración a grosso modo de las actividades y tareas cognitivas que pueden realizar niños regulares menores de 6 años y niños con TEA. Como herramienta auxiliar consideré los procesos y resultados de la dirección de tres tesis de licenciatura: 1 de ingeniería en computación y 2 de ingeniería en diseño, las tres de la Universidad Tecnológica de la Mixteca.

Con este paso se cubrió el objetivo 3 de la tesis en el que se definieron y adaptaron actividades de desempeño ejecutivo para explorar las FE en interacción humano-humano. Al mismo tiempo se cubrieron dos metas de trabajo con los niños:

1) desarrollo de materiales didácticos para explorar las FE en los niños, y

2) guía de procedimientos para la interacción con los niños.

Cabe destacar que de las tres tesis que se presentan (Ver tabla 16), la segunda y la tercera sí se realizaron como una petición directa del proyecto de niños con TEA, por lo que las observaciones y los resultados del comportamiento de los niños se aplicaron directamente a esta investigación (Sin intervenir en el resultado propio del proceso de cada tesista). En cuando a la 
primera tesis, aunque no inició como una petición expresa para la presente investigación, sus resultados y el proceso de evaluación de los niños neurotípicos fue muy útil para la toma de decisiones; por tal motivo, también fue incluida en este capítulo ${ }^{44}$. Una constante de las tesis fue el uso de la metodología UCDe. En la Figura 36, se presenta el ejemplo de la metodología empleada por David Soto.

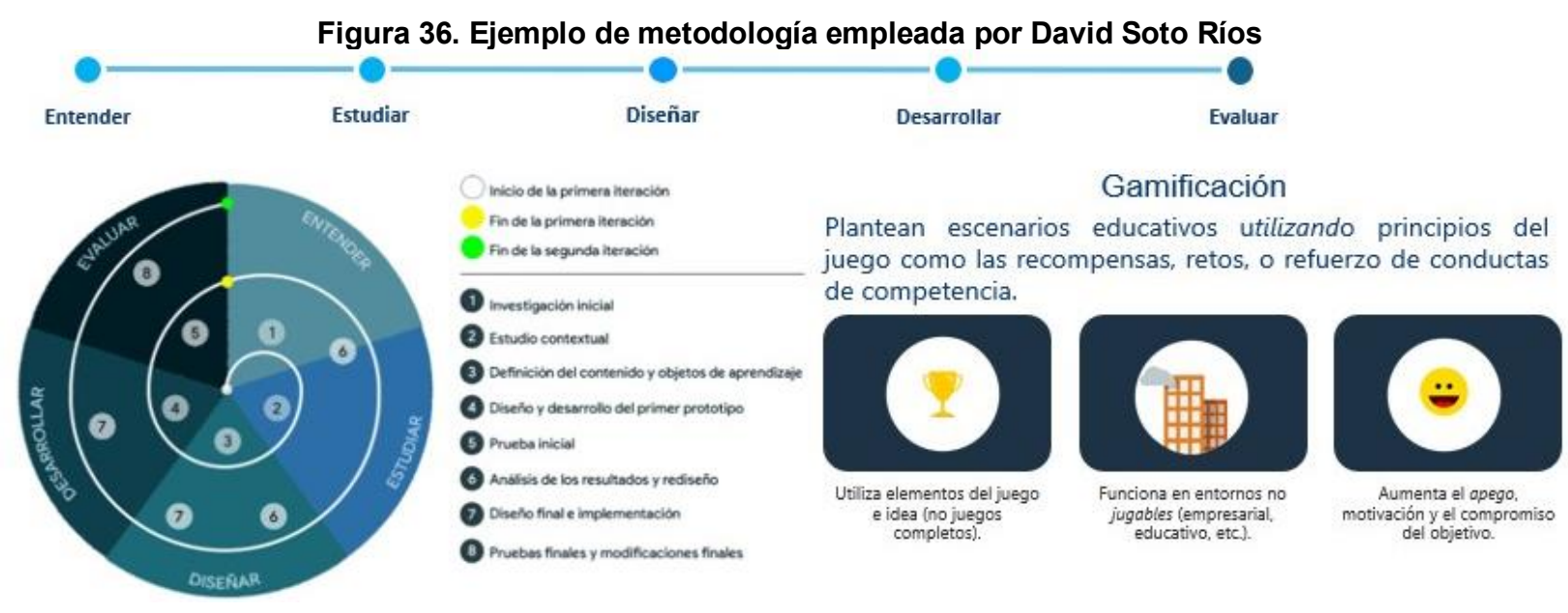

Fuente: Soto (2018) con modificaciones.

Dentro del grupo de trabajo hubo niños neurotípicos y niños con TEA de distintos niveles; sin embargo, debido a que este grupo no fue evaluado directamente para esta investigación, sino a través de las tesis, los datos que se obtuvieron no se reportan como propios. No obstante, se tomaron como referencia para definir los códigos gráficos de comunicación con los que se trabajó en el diseño de las tareas de FE. Algunas tareas diseñadas por los estudiantes se emplearon como base para las interacciones humano-humano. En la Tabla 16 se presenta un resumen de cada tesis.

\footnotetext{
${ }^{44}$ Los resultados, imágenes y datos que se retoman de las tesis de licenciatura fueron empleados con autorización de sus respectivos autores.
} 
Tabla 16. Descripción de aportaciones de tesis de licenciatura

\begin{tabular}{|c|c|c|c|}
\hline Estudiante & $\begin{array}{l}\text { Tesis } 1 \\
\text { David Soto Ríos }\end{array}$ & $\begin{array}{l}\text { Tesis } 2 \\
\text { Ramsés Salazar Mora }\end{array}$ & $\begin{array}{l}\text { Tesis } 2 \\
\text { Omar Gómez González }\end{array}$ \\
\hline \multicolumn{4}{|l|}{ Producto final } \\
\hline Carrera & Ing. en computación & Ing. en Diseño & Ing. en Diseño \\
\hline Título & $\begin{array}{l}\text { Numeritos: implementación de } \\
\text { un juego educativo utilizando } \\
\text { estrategias de gamificación para } \\
\text { adquirir competencias de conteo } \\
\text { y resolución de problemas. }\end{array}$ & $\begin{array}{l}\text { Ármalo: material didáctico } \\
\text { multimedia como apoyo para } \\
\text { estimular la atención de niños } \\
\text { con Trastorno de Espectro } \\
\text { Autista (TEA). }\end{array}$ & $\begin{array}{l}\text { Entivo, dispositivo interactivo para } \\
\text { ejercitar las FE en niños con } \\
\text { trastorno del espectro autista } \\
\text { (TEA) grado } 1 .\end{array}$ \\
\hline Dirección & $\begin{array}{l}\text { Lluvia Morales Reynaga } \\
\text { Codirectora: María de la Luz } \\
\text { Palacios Villavicencio }\end{array}$ & $\begin{array}{l}\text { María de la Luz Palacios } \\
\text { Villavicencio }\end{array}$ & $\begin{array}{l}\text { María de la Luz Palacios } \\
\text { Villavicencio }\end{array}$ \\
\hline $\begin{array}{l}\begin{array}{l}\text { Producto } \\
\text { desarrollado }\end{array} \\
\end{array}$ & Aplicación para computadora & $\begin{array}{l}\text { Aplicación para } \\
\text { dispositivo móvil }\end{array}$ & Juego interactivo de manipulación \\
\hline Objetivos & $\begin{array}{l}\text { Desarrollar un juego educativo } \\
\text { con un enfoque basado en } \\
\text { gamificación para incentivar una } \\
\text { actitud favorable hacia el } \\
\text { aprendizaje de las competencias } \\
\text { conteo y resolución de } \\
\text { problemas en niños de } 1^{\circ} \text { a } 3^{\circ} \\
\text { de preescolar. }\end{array}$ & $\begin{array}{l}\text { Estimular la atención visual } \\
\text { global de niños con TEA a } \\
\text { través de una aplicación } \\
\text { multimedia. }\end{array}$ & $\begin{array}{l}\text { Diseñar un dispositivo interactivo } \\
\text { para ejercitar FE en niños con } \\
\text { TEA grado } 1 \text { Facilitar el uso de la } \\
\text { inhibición y la flexibilidad mental } \\
\text { en niños con TEA. }\end{array}$ \\
\hline Aportaciones $^{45}$ & $\begin{array}{l}\text { Conocimiento acerca de la } \\
\text { forma en la que se relacionan } \\
\text { los niños neurotípicos menores } \\
\text { de } 6 \text { años con la tecnología. } \\
\text { Diseño de técnica persona. }\end{array}$ & $\begin{array}{l}\text { Desarrollo de fotodiario de } \\
\text { niños con TEA grado } 3 \text { y } \\
\text { descripción de posibles } \\
\text { ejercicios básicos para lograr } \\
\text { que los niños realicen } \\
\text { actividades dirigidas. }\end{array}$ & $\begin{array}{l}\text { Descripción del uso de las FE en } \\
\text { niños con TEA de posibles } \\
\text { escenarios para ser adaptados en } \\
\text { interacciones con el robot. }\end{array}$ \\
\hline $\begin{array}{l}\text { Obtención del } \\
\text { grado }\end{array}$ & Titulado en julio 2018 & En proceso de finalización & Titulado en febrero 2020 \\
\hline
\end{tabular}

Nota. Algunos datos del proceso de las tesis, así como los resultados ayudaron a definir las tareas que se pondrían a prueba con los niños con TEA para el uso de sus FE. Fuente: elaboración propia

Los datos de los estudiantes junto con los datos que se obtuvieron del comportamiento de los niños con TEA proporcionaron de certeza las propuestas de las tareas y materiales que podían ser aceptadas y entendidas por los niños con TEA de cualquier grado. En la Tabla 17 se presentan las aportaciones de cada tesis.

${ }^{45}$ En el anexo 2 se presenta un resumen de la aportación de cada estudiante para el desarrollo de la presente investigación 
Tabla 17. Resultados del grupo de trabajo 2 a partir de la dirección de tesis de licenciatura Estudiante $\quad$ Tesis $1 \quad$ Tesis $2 \quad$ Tesis 3

\begin{tabular}{|c|c|c|c|}
\hline Estudiante & $\frac{\text { lesis } 1}{\text { David Soto Ríos }}$ & Ramsés Salazar Mora & Omar Gómez González \\
\hline Producto final & Numeritos & Ármalo & Entivo \\
\hline Número de niños & 9 & 9 & 6 \\
\hline Diversidad funcional & Neurotípicos & $\begin{array}{l}\text { Grupo 1. Neurotípicos } 4 \\
\text { Grupo 2. Síndrome de down y } 1 \text { con } \\
\text { déficit intelectual. Grupo 3. TEA }\end{array}$ & $\begin{array}{l}\text { Grupo 1: Neurotípicos } 4 \\
\text { Grupo 2: Neurotípicos } 7 \\
\text { Grupo 3: TEA } 6\end{array}$ \\
\hline Rango de edad & 3-6 años & $\begin{array}{l}\text { 3-5 años (neurotípicos) } \\
\text { 6-7 años (con diversidad funcional) }\end{array}$ & $\begin{array}{l}\text { Grupo 1: 3-5 años } \\
\text { Grupo 2: 6-7 años } \\
\text { Grupo 3: 6-11 años } \\
\end{array}$ \\
\hline Grado escolar & $\begin{array}{l}3 \text { de cada grado de } \\
\text { preescolar }\end{array}$ & $\begin{array}{l}4 \text { de preescolar } \\
5 \text { de educación especial }\end{array}$ & Primaria \\
\hline Saben leer & No & No & $\mathrm{Si}$ \\
\hline $\begin{array}{l}\text { Modalidad sensorial } \\
\text { para recibir } \\
\text { Instrucciones }\end{array}$ & Auditiva & Auditiva y visual & Auditiva y visual \\
\hline Control visomotor & $\mathrm{Si}$ & $\mathrm{Si}$ & $\mathrm{Si}$ \\
\hline $\begin{array}{l}\text { Presentan interés } \\
\text { por recibir } \\
\text { reforzamientos } \\
\text { positivos }\end{array}$ & Si & $\mathrm{Si}$ & Si \\
\hline $\begin{array}{l}\text { Estímulos } \\
\text { empleados para } \\
\text { reforzar } \\
\text { positivamente }\end{array}$ & $\begin{array}{l}\text { Monedas en la } \\
\text { pantalla del juego }\end{array}$ & $\begin{array}{l}\text { Recompensa verbal "Muy bien", "Lo } \\
\text { lograste" }\end{array}$ & $\begin{array}{l}\text { Recompensa verbal "Lo has } \\
\text { logrado", "Muy bien", "Has } \\
\text { encontrado el tesoro" }\end{array}$ \\
\hline $\begin{array}{l}\text { Modalidad sensorial } \\
\text { para reforzamientos } \\
\text { positivos }\end{array}$ & Auditivo y visual & Auditivo y visual & Auditiva \\
\hline
\end{tabular}

\begin{tabular}{|c|c|c|c|}
\hline Le gusta el juego & $\mathrm{Si}$ & $\mathrm{Si}$ & $\mathrm{Si}$ \\
\hline $\begin{array}{l}\text { Modalidad sensorial } \\
\text { preferida por grupo }\end{array}$ & Visual & $\begin{array}{l}\text { Grupo 1. Visual } \\
\text { Grupo 2. Visual } \\
\text { Grupo 3. Visual }\end{array}$ & $\begin{array}{l}\text { Grupo 1. Visual y auditiva } \\
\text { Grupo 2. Visual y auditiva } \\
\text { Grupo 3. Visual y auditiva }\end{array}$ \\
\hline $\begin{array}{l}\text { Dominio de campos } \\
\text { semánticos o } \\
\text { habilidad }\end{array}$ & $\begin{array}{l}\text { Números básicos, } \\
\text { colores básicos y } \\
\text { animales }\end{array}$ & Colores, formas y tamaños & Colores y lateralidad \\
\hline Actividad realizada & $\begin{array}{l}\text { Crear una cuenta para } \\
\text { iniciar un juego en PC } \\
\text { Realizar una prueba } \\
\text { inicial } \\
\text { Seleccionar un juego } \\
\text { y jugar }\end{array}$ & $\begin{array}{l}\text { Armar un rompecabezas que contiene } \\
\text { colores, formas y tamaños variables }\end{array}$ & $\begin{array}{l}\text { Identificación de colores y } \\
\text { clasificación de fichas de color }\end{array}$ \\
\hline $\begin{array}{l}\text { Eficacia lograda en } \\
\text { la actividad }\end{array}$ & $85.7 \%$ de aciertos & $\begin{array}{l}\text { Grupo 1: } 98.14 \% \text { aciertos } \\
\text { Grupo 2: } 90.09 \% \text { aciertos } \\
\text { Grupo 3: } 100 \% \text { aciertos }\end{array}$ & $\begin{array}{l}\text { Grupo 1: } 70 \% \\
\text { Grupo 2: } 100 \% \\
\text { Grupo 3: } 100 \%\end{array}$ \\
\hline
\end{tabular}

Reconocimiento de colores
Si
$\mathrm{Si}$
$\mathrm{Si}$

Continúa... 
Tabla 17. (Continuación...)

\begin{tabular}{llll} 
Estudiante & Tesis 1 & Tesis 2 & Tesis 3 \\
\cline { 2 - 4 } & David Soto Ríos & Ramsés Salazar Mora & Omar Gómez González \\
\hline $\begin{array}{l}\text { Reconocimiento } \\
\text { de tamaño }\end{array}$ & $\mathrm{Si}$ & $\mathrm{Si}$ & $\mathrm{Si}$ \\
\hline $\begin{array}{l}\text { Reconocimiento } \\
\text { de formas }\end{array}$ & $\mathrm{Si}$ & $\mathrm{Si}$ & No aplica \\
\hline FE involucradas & $\begin{array}{l}\text { Planificación, } \\
\text { categorización } \\
\text { Memoria de trabajo }\end{array}$ & $\begin{array}{l}\text { Categorización } \\
\text { Memoria de trabajo }\end{array}$ & $\begin{array}{l}\text { Planificación, inhibición, } \\
\text { Flexibilidad cognitiva }\end{array}$ \\
\hline $\begin{array}{l}\text { Particularidad } \\
\text { identificada }\end{array}$ & $\begin{array}{l}\text { Les gusta recibir trofeos } \\
\text { o premios cuando hacen } \\
\text { bien algo. }\end{array}$ & $\begin{array}{l}\text { El estudiante refiere que cuando las } \\
\text { actividades incluían al mismo tiempo, el color, } \\
\text { la forma y el tamaño del objeto presentaban } \\
\text { confusión, pero no cuando estaban por } \\
\text { separado }\end{array}$ & $\begin{array}{l}\text { En otras tareas más } \\
\text { complejas medidas con los } \\
\text { niños con la práctica } \\
\text { mejoraban su ejecución }\end{array}$
\end{tabular}

Fuente: elaboración propia

Las observaciones y conclusiones analizadas en las tesis (ver anexo 2) definieron las recomendaciones específicas para el desarrollo de los materiales de trabajo que se emplearían en las interacciones humano-humano. En la Tabla 18 se presentan las conclusiones y su aplicación para el diseño de los materiales a emplear.

Tabla 18. Guía para la aplicación de resultados

\begin{tabular}{|c|c|c|}
\hline Descripciones generales & $\begin{array}{l}\text { Diversidad } \\
\text { funcional }\end{array}$ & Aplicación \\
\hline \multicolumn{3}{|l|}{ Instrucciones } \\
\hline $\begin{array}{l}\text { Si los niños aún no saben leer, las instrucciones deben ser } \\
\text { auditivas. }\end{array}$ & Neurotípicos & \multirow{3}{*}{$\begin{array}{l}\text { Dar instrucciones claras, repetir instrucciones } \\
\text { si es necesario. Esto ya se había comprobado } \\
\text { con las interacciones niño-robot en repertorios } \\
\text { básicos. Se corroboró con estos resultados. }\end{array}$} \\
\hline $\begin{array}{l}\text { Entiende las indicaciones cuando son cortas, claras y se } \\
\text { dicen con seguridad. A veces es necesario repetir las } \\
\text { órdenes. }\end{array}$ & TEA & \\
\hline $\begin{array}{l}\text { Su conciencia no es predictiva, se deben dar instrucciones } \\
\text { claras y directas. }\end{array}$ & TEA & \\
\hline \multicolumn{3}{|l|}{ Dificultad de las tareas } \\
\hline $\begin{array}{l}\text { Tarda un poco en comprender alguna dinámica, pero cuando } \\
\text { lo hace se regula y puede entender las actividades que tiene } \\
\text { que realizar. }\end{array}$ & TEA & \multirow{4}{*}{$\begin{array}{l}\text { Las tareas deben ser cortas, sencillas, de } \\
\text { interés general, que no impliquen un gran } \\
\text { esfuerzo mental, pero que sí tengan un grado } \\
\text { de dificultad creciente. Esto ayuda a que todos } \\
\text { los niños trabajen desde un nivel básico hasta } \\
\text { el nivel de complejidad que les permitan sus } \\
\text { habilidades }\end{array}$} \\
\hline $\begin{array}{l}\text { Comprensión literal de lo que oyen o leen, no entienden los } \\
\text { dobles sentidos, metáforas, ironías o chistes). }\end{array}$ & TEA & \\
\hline $\begin{array}{l}\text { Dificultad para identificar la secuenciación de tareas, prestar } \\
\text { atención, inhibir sus impulsos, para memorizar y recordar } \\
\text { instrucciones. }\end{array}$ & TEA & \\
\hline $\begin{array}{l}\text { Presenta problemas con los conceptos de tiempo, espacio y } \\
\text { secuencia, generando una incapacidad para concentrarse en } \\
\text { tareas simultaneas. }\end{array}$ & TEA & \\
\hline
\end{tabular}


Tabla 18. (continuación...)

\begin{tabular}{|c|c|c|}
\hline Descripciones generales & $\begin{array}{l}\text { Diversidad } \\
\text { funcional }\end{array}$ & Aplicación \\
\hline \multicolumn{3}{|l|}{ Tipo de tareas } \\
\hline $\begin{array}{l}\text { Es recomendable emplear tareas académicas o pre-académicas de } \\
\text { las que los niños tengan conocimiento. }\end{array}$ & TEA, DI, Down & \multirow{3}{*}{$\begin{array}{l}\text { Empleo de tareas pre-académicas que } \\
\text { incluso sean aprendidas en casa sin } \\
\text { necesidad de ir a la escuela. Facilitando } \\
\text { que la atención a tareas complejas no sea } \\
\text { un obstáculo para la realización de éstas. }\end{array}$} \\
\hline $\begin{array}{l}\text { Aunque los niños con TEA ubican su atención principalmente en sus } \\
\text { intereses personales, si se les presentan actividades de bajo } \\
\text { contenido cognitivo se logra mantener su atención por más tiempo. }\end{array}$ & $\begin{array}{l}\text { TEA, DI, } \\
\text { Down }\end{array}$ & \\
\hline $\begin{array}{l}\text { Si las tareas son cortas, es más fácil mantener la atención de los } \\
\text { niños de edades menores a cinco años y niños con TEA de hasta } \\
9 \text { años. }\end{array}$ & $\begin{array}{l}\text { TEA, DI, } \\
\text { Down }\end{array}$ & \\
\hline \multicolumn{3}{|l|}{ Tipo de estímulos } \\
\hline $\begin{array}{l}\text { Usar códigos de comunicación básicos como los colores, figuras y } \\
\text { tamaños, ayuda a que la atención se mantenga por más tiempo. }\end{array}$ & TEA, DI, Down & \multirow{3}{*}{$\begin{array}{l}\text { Los estímulos deben ser sencillos, de } \\
\text { baja complejidad perceptiva. }\end{array}$} \\
\hline Es visual y aprende mejor a través de imágenes. & TEA & \\
\hline Orientación hacia objetos en movimiento, luces y sonidos. & TEA & \\
\hline \multicolumn{3}{|l|}{ Actividades de interés } \\
\hline $\begin{array}{l}\text { Si algo les aburre o no les atrae, buscan o se entretienen con otra } \\
\text { cosa. }\end{array}$ & Neurotípicos & \multirow{3}{*}{$\begin{array}{l}\text { Si las tareas son familiares implican un } \\
\text { reto y ofrecen la posibilidad de obtener } \\
\text { un logro, para los niños es más fácil } \\
\text { mantener su atención, aunque no se trate } \\
\text { de una actividad que incluya sus gustos } \\
\text { restringidos y repetitivos. }\end{array}$} \\
\hline $\begin{array}{l}\text { Las maestras refieren que los niños son totalmente visuales y } \\
\text { kinestésicos, siendo el juego una parte fundamental para su } \\
\text { aprendizaje. }\end{array}$ & Neurotípicos & \\
\hline $\begin{array}{l}\text { Muestra interés por los animales, robots, caricaturas y dispositivo } \\
\text { electrónicos. }\end{array}$ & TEA & \\
\hline \multicolumn{3}{|l|}{ Reforzamiento positivo } \\
\hline $\begin{array}{l}\text { A los niños les gusta más competir entre ellos para presumir que le } \\
\text { ganaron al otro. }\end{array}$ & Neurotípicos & \multirow{6}{*}{$\begin{array}{l}\text { Para todos los niños es importante recibir } \\
\text { felicitaciones y refuerzos positivos. }\end{array}$} \\
\hline $\begin{array}{l}\text { Les emocionan frases de aliento cuando van contestando bien y } \\
\text { sobre todo recibir pequeños trofeos o recompensas. }\end{array}$ & Neurotípicos & \\
\hline Ser reconocidos por lo que hicieron les motiva mucho. & Neurotípicos & \\
\hline $\begin{array}{l}\text { El uso de las estrategias de gamificación hace que las actividades } \\
\text { sean más atractivas para los niños. }\end{array}$ & TEA, DI, Down & \\
\hline La recompensa verbal es muy útil y bien apreciada por los niños. & TEA, DI, Down & \\
\hline $\begin{array}{l}\text { Le gusta las caricaturas, los videos, canciones, clasificar cosas y } \\
\text { que le digan palabras motivadoras. }\end{array}$ & TEA & \\
\hline
\end{tabular}

\section{Disposición para interactuar}

Presenta dificultades para la interacción social, especialmente con personas de su misma edad.

TEA

TEA

TEA
Solo los niños con TEA presentaron problemas de interacción, pero el uso del robot humanoide compensa su poco interés en la interacción.

quehaceres de la casa.

TEA imprevistas.

Nota: El material fue tomado de las tablas 2, 4 y 6 del anexo 2. Los datos de la segunda columna están asociados a las tesis de las que se extrajo la información: David Soto (2018) Neurotípicos, Ramsés Salazar (archivo propio) TEA, DI y Down, Omar González (2020) TEA.

Durante las pruebas que se implementaron en las tesis antes presentadas se incluyeron ejercicios pre-test para identificar las habilidades básicas y las posibilidades de respuesta que 
tenían los niños. De la primera tesis sólo se tomaron datos del comportamiento general de los niños. En la siguiente lista se mencionan algunos ejercicios que formaron parte de la evaluación pre-test de las tesis 2 y 3, y que fueron adaptados a las pruebas humano-humano de la presente investigación.

De la tesis 2 se consideró:

1. Atención, memoria

a. Reconocimiento e identificación de color.

b. Reconocimiento y uso de formas.

c. Reconocimiento de números.

d. Reconocimiento de cantidad.

2. Asociación con ayuda de guías visuales. Por ejemplo, asociar cuadro con un marco cuadrado o con la palabra escrita "cuadro".

De la tesis 3 se consideró:

1. Utilización de códigos gráficos para identificar una estrategia.
a. Reconocimiento e identificación de color.
b. Identificación de dirección y lateralización.
c. Asociación de color con dirección.

En ambas tesis se evaluó la capacidad para el seguimiento de instrucciones. En el apartado 4.2 se retoman estos ejercicios para determinar los ejercicios de pruebas humanohumano. 


\subsection{Etapa de investigación B: conceptualizar}

Como se mencionó en el capítulo 3, la conceptualización consistió en plantear los materiales que servirían para poner en práctica las FE de los niños. Se utilizaron cuatro elementos clave para su desarrollo. 1) empleo de los cinco EATR; 2) observación del comportamiento de los niños con TEA (descrito en el apartado 4.1 ; 3) recomendaciones tomadas de la dirección de tesis de licenciatura del apartado 4.1.8, y 4) sugerencias y análisis de tareas realizadas por seis expertas en educación especial. A partir de éstos, se determinaron los ejercicios que se pondrían a los niños durante las interacciones humano-humano y niño-robot humanoide. En la Figura 37, se muestra la relación de la etapa de conceptualización con el EATR 1 asociada al diagnóstico de los niños con TEA.

Figura 37. Relación de etapa de investigación A con el EATR 1
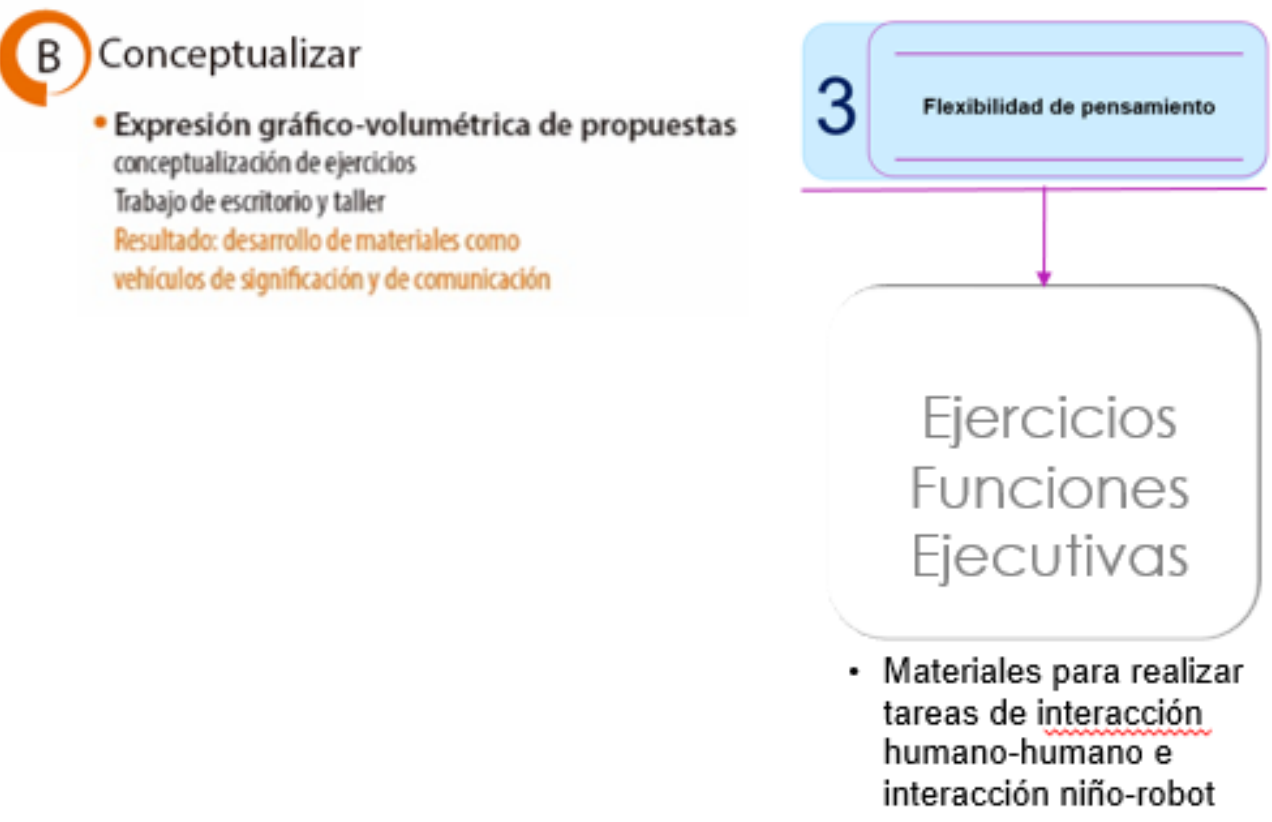

Fuente: elaboración propia.

\subsubsection{Consulta a expertas de educación especial}

Un elemento importante al que se puede recurrir para conocer un objeto de estudio proviene de la literatura y de la relación que ésta tenga con la realidad del propio objeto de estudio. En el caso de los niños con TEA, tener conocimiento del manejo que se le puede dar al interior de una familia, dentro del ámbito social o escolar puede ser la clave para entender las estrategias de acercamiento. Por tal motivo, consultar a las especialistas facilitó el encuentro con los niños. 
A través de entrevistas, se solicitó a seis especialistas en educación especial que describieran el tipo de estrategias (de acercamiento) utilizadas con los niños con TEA. En la Figura 38, se presentan lo que respondieron.

Figura 38. Estrategias de acercamiento recomendadas por especialistas en educación especial

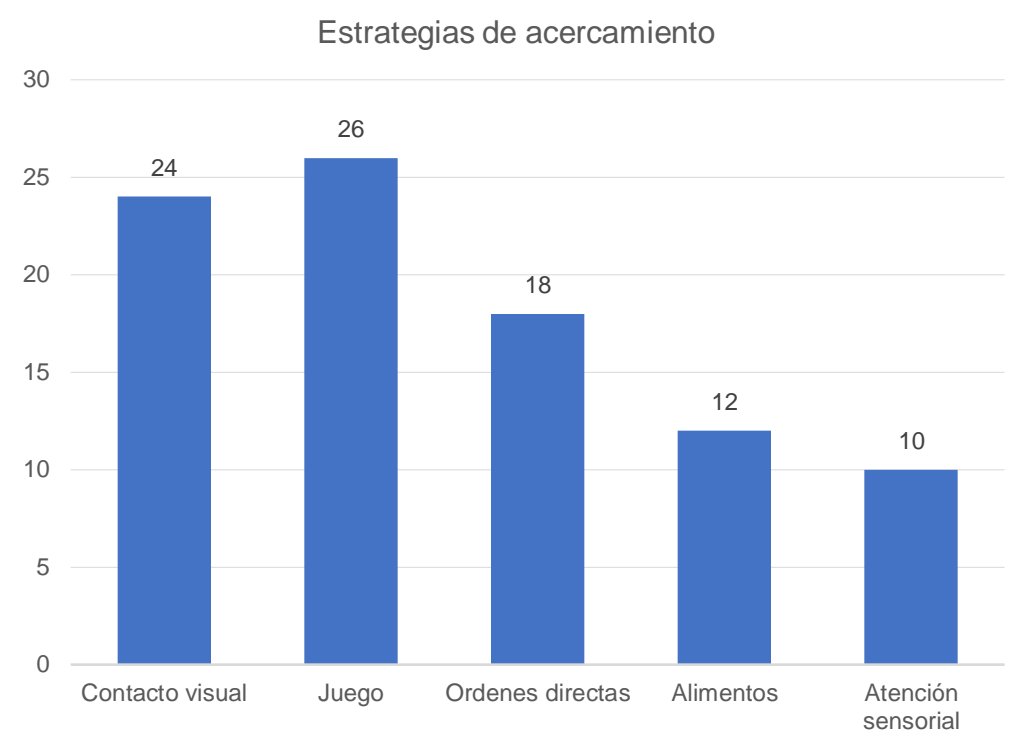

Nota. Los puntajes que se muestran sobre las barras corresponden a los puntos asignados por cada especialista a las actividades. A quienes se les pidió asignar de 1 a 5 puntos (siendo uno el de menor importancia). El puntaje máximo de cada actividad era de 30 puntos. Fuente: elaboración propia.

Los datos fueron contabilizados y jerarquizados con el fin de determinar cómo se podía iniciar las interacciones con los niños. Como se observa en la Figura 38, el primer punto fue el juego, seguido del contacto visual, las órdenes directas, los alimentos y finalmente la atención sensorial.

El resultado de las recomendaciones de las especialistas fue empleado para orientar el inicio de las interacciones con los niños durante la evaluación. En las interacciones humanohumano se siguieron esas recomendaciones, se sustituyó el juego por la empatía con el fin de no restarle seriedad ni tiempo a las interacciones con cada niño. Para las interacciones niño-robot, el juego se asumió como parte del interés que los niños establecen con el robot. El contacto visual no fue necesario controlarlo, debido a que la mayoría de los niños mantenían su atención sobre el robot; lo cual hacían con agrado, manteniendo una postura similar a la adoptada en las interacciones humano-humano.

En cuanto al control del uso de las FE, se solicitó a las especialistas asignar puntajes de 1 a 5 para determinar el orden en el que ellas notan que se desarrollan las FE en los niños con 
TEA. Se asignó un punto a las FE de menor control y cinco puntos a las de mayor control. Estos datos sirvieron para indicar el nivel de dificultad que se asignaría a las FE durante las interacciones (Figura 39).

Figura 39. Niveles de control de FE en niños con TEA

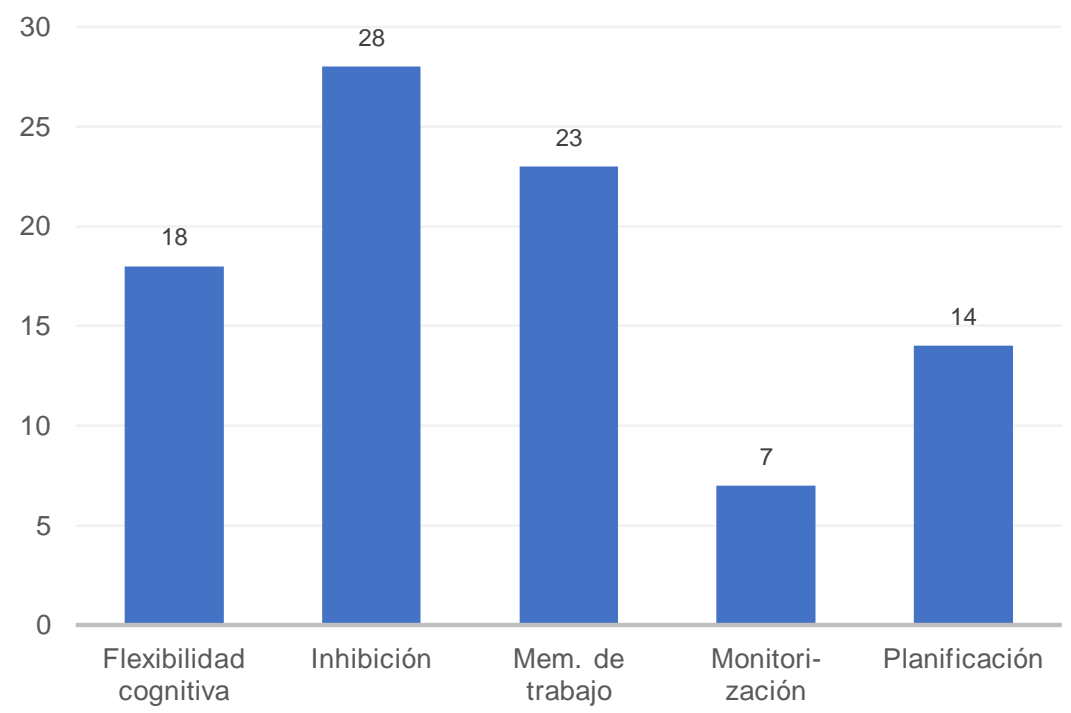

Nota. Los datos fueron obtenidos de especialistas en educación especial quienes jerarquizaron las tareas que se deben realizar con niños con TEA en un proceso de trabajo con ellos. Fuente: elaboración propia 


\subsubsection{Ejercicios para poner en práctica las FE en interacción humano-humano}

La exploración del comportamiento de los niños con TEA (neurotípicos o de alguna otra diversidad funcional) fue la base para definir los ejercicios que adaptarían para interactuar con los niños en la primera condición humano-humano. Este paso tuvo dos fines: 1) permitió especificar las tareas que se podían aplicar, y 2) se puso a prueba la tolerancia y disposición de los niños para interactuar realizando ejercicios específicos.

\subsubsection{Vehículos de significación en interacción humano-humano}

En las tesis presentadas en el apartado 4.2, los ejercicios y el producto final de cada una evaluó: eficiencia, eficacia y satisfacción. De los cuales, el parámetro de eficacia fue el más relevante para determinar si los ejercicios se podían aplicar como ejercicios de prueba para esta investigación. A pesar de que las tareas incluidas en las tesis presentadas en la Tabla 16, tenían propósitos distintos, lo relevante para esta tesis era conocer, cualitativamente, si en los rangos de edad mencionados los niños podían identificar los códigos gráficos $\mathrm{y}$, a partir de ellos, siguiendo instrucciones sencillas, realizar ejercicios que implicaran: atención, orden, parear códigos por similitudes, identificación de dirección y seguimiento de instrucciones dobles. En la Figura 40 se presentan los códigos considerados como los vehículos de significación para los ejercicios de interacción humano-humano.

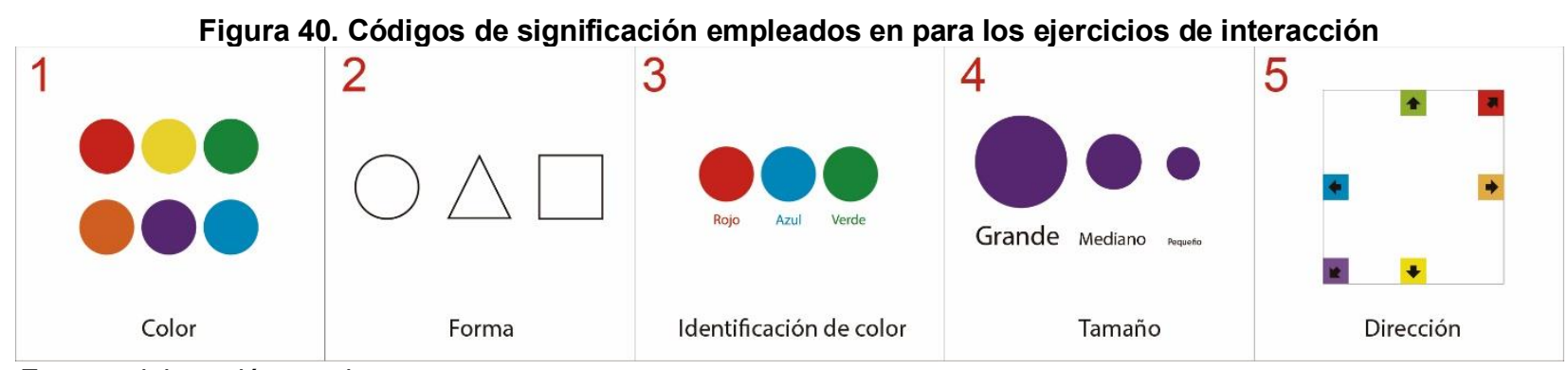

Fuente: elaboración propia. 


\subsubsection{Vehículos de comunicación en interacción niño-robot}

A partir de los resultados hasta aquí expuestos, se definió que las tareas tenían que facilitar la interacción con los niños, empezar con baja complejidad perceptiva.

La interacción se realizó explorando el uso de las FE que los niños ponen en práctica por medio de vehículos de comunicación. Cabe señalar que éstos fueron desarrollados como una variante de los vehículos de significación expuestos en el apartado anterior. En la Figura 41 se presentan estos códigos empleados para los ejercicios de interacción niño-robot.

Figura 41. Códigos gráficos empleados durante los ejercicios de interacción

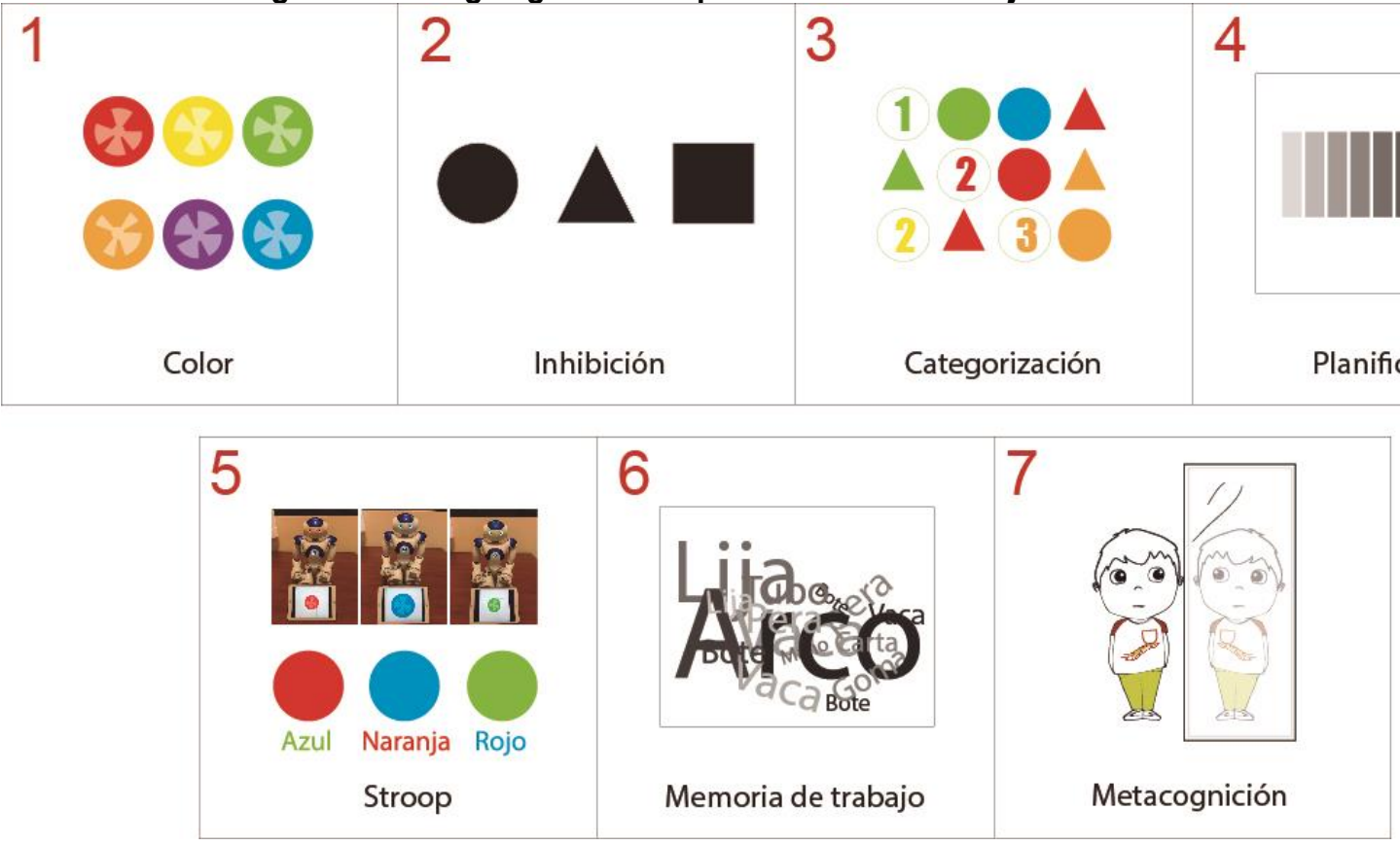

Fuente: elaboración propia

\subsubsection{Tareas para poner en práctica las FE de niños con TEA}

La implementación de los códigos de comunicación fue definida a la par de las tareas para ejercitar las FE en los niños con TEA. Además, como se ha mencionado previamente, había que considerar ciertas características básicas para su desarrollo.

De esta manera, se consideraron tareas que tenían que ser fáciles de hacer para el niño y fáciles de implementar en el robot; se propusieron seis ejercicios para las FE definidas previamente: inhibición, categorización, planificación, metacognición y memoria de trabajo; los cuales se evaluaron a partir de criterios de factibilidad que consideran criterios negativos y criterios positivos. 
Los negativos se enfocaron en factores relacionados con la dificultad para implementar la tarea, en el robot y los positivos se consideraron factores que dependían de la complejidad de la tarea para los. En la Tabla 19, se presenta un ejemplo de cómo se aplicaron los puntajes.

Tabla 19. Ejemplo de asignación de puntajes de factibilidad de tareas para FE

Planeación de actividades

Factibilidad

\begin{tabular}{|c|c|c|c|c|c|c|c|c|c|}
\hline \multirow{2}{*}{\multicolumn{3}{|c|}{ Planeación de actividades }} & \\
\hline & & & \multicolumn{3}{|c|}{$\begin{array}{c}\text { Puntajes } \\
\text { negativos, de } \\
0 \text { a }-3\end{array}$} & \multicolumn{3}{|c|}{$\begin{array}{l}\text { Puntajes } \\
\text { positivos } \\
\text { de } 0 \text { a } 3\end{array}$} & \multirow[b]{2}{*}{ 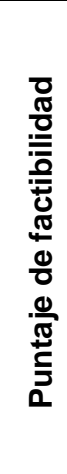 } \\
\hline $\begin{array}{l}\text { Función } \\
\text { ejecutiva }\end{array}$ & $\begin{array}{l}\text { Nombre de } \\
\text { actividad }\end{array}$ & Descripción & 응 & 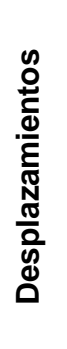 & 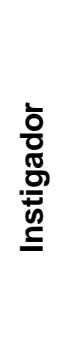 & 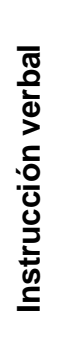 & 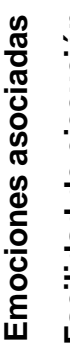 & 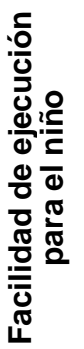 & \\
\hline Inhibición & $\begin{array}{l}\text { Selección } \\
\text { del color } \\
\text { adecuado }\end{array}$ & $\begin{array}{l}\text { Se presentan figuras de colores en el } \\
\text { piso. El niño debe seleccionar cada uno } \\
\text { de acuerdo con las instrucciones. }\end{array}$ & 0 & 0 & 0 & 1 & 1 & 3 & 5 \\
\hline
\end{tabular}

Nota. La tabla incluye las actividades que se emplearon durante la interacción. El puntaje de factibilidad indican que estas tareas son las que obtuvieron el puntaje más alto, y por lo tanto, mayor factibilidad. Fuente: elaboración propia.

En cuanto al ideal de aplicación se consideró que, dado que el uso del robot sólo cumplía una función de vehículo de interacción asistida y no se pondría a prueba su programación, en la valoración de las tareas se consideraron aquellas que cumplieran la puntuación ideal de aplicación, con menor número de movimientos del robot, menor intervención del instigador y tareas de baja complejidad para los niños.

En la Tabla 20 se presentan las tareas desarrolladas para cada FE. Los ejercicios 1 y 2 fueron incluidos como una condición básica para identificar si los niños estaban en estado de alerta, y si tenían disposición de realizar los ejercicios, incluyendo uno básico como la identificación de colores. 
Tabla 20. Tareas para ejercitar FE usando códigos básicos de comunicación

\begin{tabular}{|c|c|c|c|}
\hline FE & Ejercicio & Descripción & $\begin{array}{l}\text { Vehículos de } \\
\text { comunicación }\end{array}$ \\
\hline Atención & $\begin{array}{l}\text { Estímulo de } \\
\text { alerta }\end{array}$ & $\begin{array}{c}\text { El único requisito que debe cumplir es que se } \\
\text { trate de un estímulo (cualquiera que sea) que } \\
\text { atraiga instantáneamente la atención de los } \\
\text { niños. }\end{array}$ & Atención / Alerta \\
\hline Identificación & $\begin{array}{l}\text { Identificar } \\
\text { colores }\end{array}$ & $\begin{array}{c}\text { Este paso es necesario para identificar si el niño } \\
\text { está en la disposición de realizar o no los } \\
\text { ejercicios. }\end{array}$ & Color \\
\hline Inhibición & $\begin{array}{l}\text { Selección } \\
\text { de figuras }\end{array}$ & $\begin{array}{l}\text { Se presentan figuras. El niño debe seleccionar } \\
\text { cada una de acuerdo con las instrucciones } \\
\text { dadas. }\end{array}$ & Inhibición \\
\hline Categorización & $\begin{array}{l}\text { Selección } \\
\text { de tarjetas }\end{array}$ & $\begin{array}{l}\text { Se pide a los niños que elijan tarjetas de } \\
\text { acuerdo a un orden determinado. }\end{array}$ & 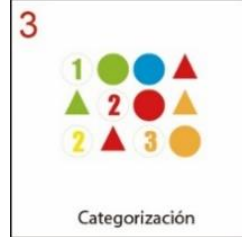 \\
\hline Planificación & $\begin{array}{l}\text { Orden de } \\
\text { barras. }\end{array}$ & $\begin{array}{l}\text { Se presenta una serie de barras de colores, se } \\
\text { pide a los niños que las ordene siguiendo } \\
\text { algunas reglas. }\end{array}$ & Planificación \\
\hline Memoria de trabajo & $\begin{array}{l}\text { Recordando } \\
\text { palabras }\end{array}$ & $\begin{array}{l}\text { Memorizar una lista de nueve palabras y } \\
\text { repetirlas. Este ejercicio se extrajo de la prueba } \\
\text { de BANFE-2. }\end{array}$ & 6 \\
\hline Metacognición & $\begin{array}{l}\text { Autoevaluación } \\
\text { del desempeño }\end{array}$ & $\begin{array}{l}\text { Se hacen algunas preguntas al niño para } \\
\text { detectar su autoevaluación. }\end{array}$ & 7 \\
\hline
\end{tabular}

Fuente: elaboración propia. 


\subsection{Etapa de investigación C: aplicar}

Durante esta fase se trabajó con el Grupo de trabajo 3 perteneciente a la Clínica de Autismo de Santa María Huatulco, Oaxaca, se solicitaron los permisos adecuados y se contactó a los responsables de los niños para identificar las características generales de éstos.

\subsubsection{Actividades de la interacción humano-humano}

La observación, durante esta etapa, también fue el elemento de mayor importancia para la descripción y categorización de las pautas de comportamiento de los niños con TEA. La interacción humano-humano tuvo el fin de comprobar si los ejercicios seleccionados - a partir de la viabilidad y pertinencia educativa, la dificultad para el niño y la dificultad para el robot-, eran adecuados. Los ejercicios sirvieron como base para la implementación de la interacción con el robot. En la Figura 42 se presenta la relación de la etapa de investigación C con el EATR1.

Figura 42. Relación de etapa de investigación C con el EATR 1
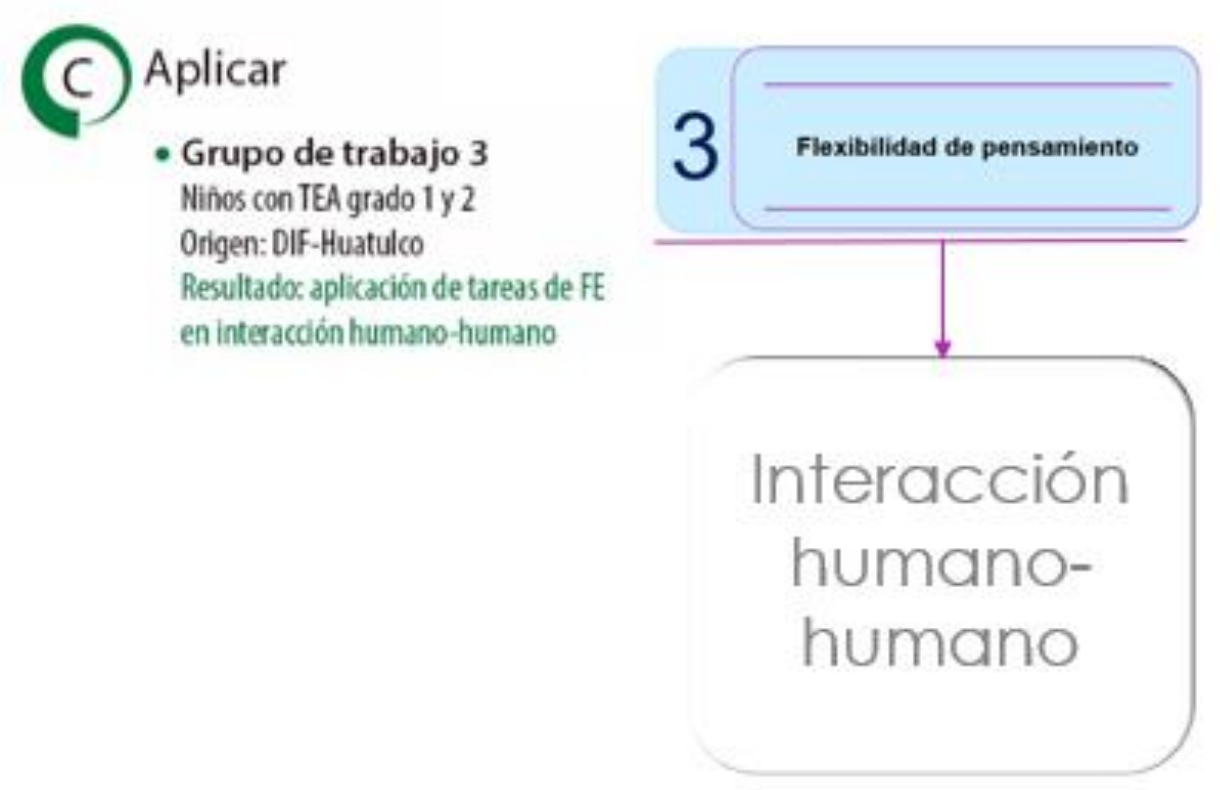

Fuente: elaboración propia.

Se realizaron tres actividades: 1) sesión de grupo con todos los participantes para explicar los objetivos del estudio; 2) una entrevista grupal, cumplimentación de formato con las características generales de los participantes y firma de autorización de participación, y 3) aplicación de la prueba de SCQ para corroborar el grado de TEA de los participantes. 


\subsubsection{Grado de TEA del grupo 3}

De acuerdo con la evaluación de las especialistas de la clínica de autismo del DIF, todos los participantes de este grupo fueron diagnosticados con TEA. Sin embargo, para corroborarlo y agruparlos por nivel de gravedad, se aplicó la prueba SCQ. Como se mencionó en el capítulo 3 y en el apartado 4.1.4., el SCQ es una prueba rápida diseñada para identificar problemas de interacción social, dificultades de comunicación y conductas restringidas, repetitivas y estereotipadas.

Los puntajes de la prueba indican que las personas regulares obtienen menos de 5.2 puntos, mientras que las personas con TEA pueden ser detectadas a partir de 15 puntos (Rutter et al., 2005, p. 10). Los puntajes mínimos y máximos para ubicar a los participantes en grado de TEA fueron: grado 1, de 15 a 23 puntos; grado 2, de 24 a 29 puntos; grado 3, de 30 a 39 puntos.

Se descartaron dos participantes (sombreados en la tabla 21). El primero fue por ser menor a cuatro años, el segundo porque tuvo un puntaje menor de 15 en la prueba SCQ.

\begin{tabular}{|c|c|c|c|c|c|}
\hline Grado & Núm. & Responsable & Edad & Género & $\mathrm{SCQ}$ \\
\hline \multirow{8}{*}{ TEA 1} & 1 & Madre & 8 & $\mathrm{H}$ & 15 \\
\hline & 2 & Madre & 6 & $\mathrm{H}$ & 17 \\
\hline & 3 & Madre & 4 & $\mathrm{H}$ & 17 \\
\hline & 4 & Madre & 6 & M & 20 \\
\hline & 5 & Madre & 11 & $\mathrm{H}$ & 20 \\
\hline & 6 & Madre & 6 & $\mathrm{H}$ & 22 \\
\hline & 7 & Madre & 6 & $\mathrm{H}$ & 23 \\
\hline & 8 & Abuelita & 5 & $M$ & 13 \\
\hline \multirow{6}{*}{ TEA 2} & 1 & Madre & 6 & $\mathrm{H}$ & 26 \\
\hline & 2 & Madre & 9 & $\mathrm{H}$ & 28 \\
\hline & 3 & Madre & 8 & $\mathrm{H}$ & 28 \\
\hline & 4 & Madre & 6 & $\mathrm{H}$ & 28 \\
\hline & 5 & Madre & 9 & $\mathrm{H}$ & 29 \\
\hline & 6 & Madre & 3 & $\mathrm{H}$ & 28 \\
\hline \multirow{3}{*}{ TEA 3} & 1 & Hermana & 23 & $\mathrm{H}$ & 30 \\
\hline & 2 & Madre & 11 & $\mathrm{H}$ & 30 \\
\hline & 3 & Madre & 17 & $\mathrm{H}$ & 33 \\
\hline
\end{tabular}

Fuente: elaboración propia 


\subsubsection{Resultados de interacción humano-humano}

En la Figura 43, se presentan los resultados obtenidos por grupo en la ejecución de las tareas de interacción humano-humano. Para ello, se utilizaron los códigos gráficos mostrados en la Figura 41. Se muestran los puntajes obtenidos por cada grupo en relación con su grado de TEA.

Con estas pruebas lo importante era determinar si a través del uso de estos códigos básicos los niños de los tres niveles de TEA podían responder favorablemente. Lo esperado por el nivel de habilitación era que el grado 1 tuviera un alto porcentaje de logro, el grado dos tuviera un mediano porcentaje de logro, y el tres un menor o nulo porcentaje de logro. Tal como se muestra en la Figura 43.

Figura 43. Porcentaje del logro de tareas de niños con TEA

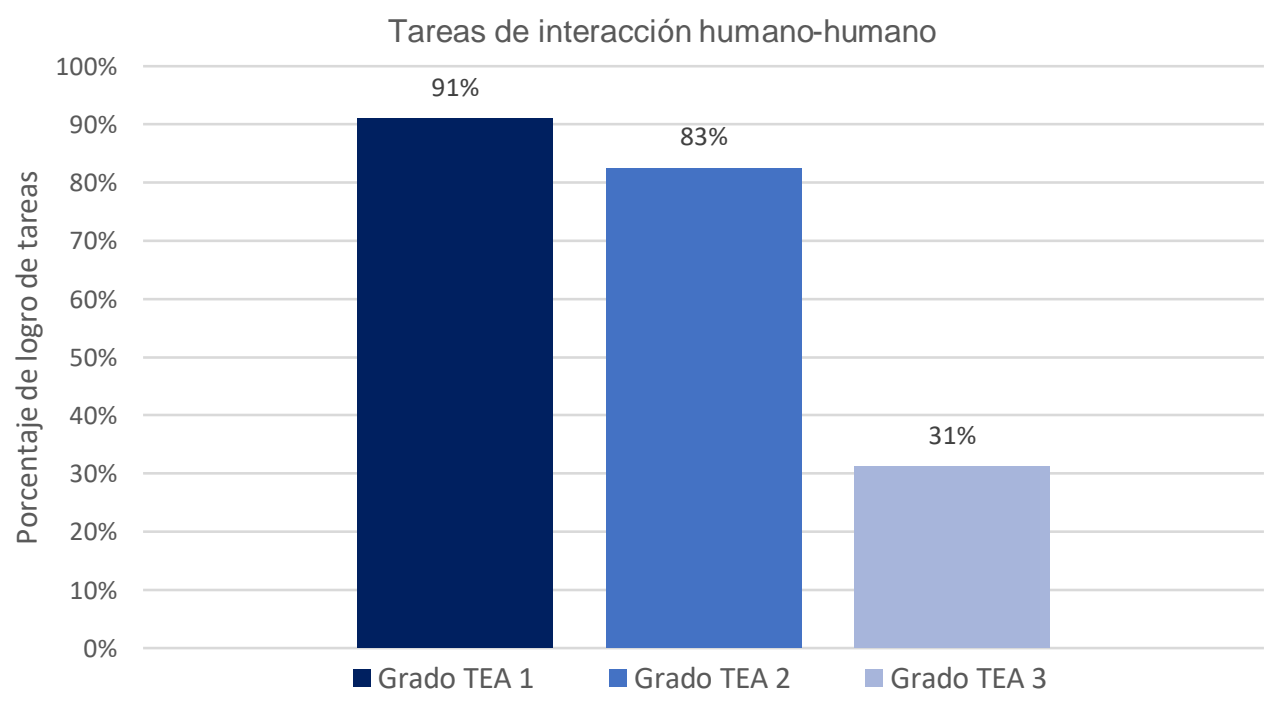

Nota: La gráfica muestra el porcentaje de aciertos que tuvieron los 17 niños en las tareas que se les proporcionaron durante la interacción con otra persona. Las tareas emplearon los códigos gráficos mostrados en la Figura 42. Las barras representan el porcentaje de logro de todas las tareas por grupo asociado a su grado de TEA.

Fuente: elaboración propia.

A partir de estos resultados se desarrollaron ejercicios básicos para poner en práctica las FE de los niños con TEA. La conceptualización consistió, como se ha mencionado, en identificar las tareas y los elementos de significación para los niños de acuerdo con las pruebas de (Soto, 2018, Salazar, 2019, González 2020). 


\subsection{Aplicación de axiomas de consciencia a las tareas de FE}

En el Capítulo 2 se explica la relación que existe entre la consciencia y la identificación que tiene un individuo de la información interna o externa que percibe del mundo o de sí mismo. Se menciona que la consciencia y las FE forman una estructura jerárquica que se activa en su forma más compleja a medida que se incrementan los niveles de atención y del estado de alerta de una persona.

Entre los factores involucrados en la dificultad que presentan las personas con TEA para imaginar y diferenciar sus pensamientos y emociones de lo que piensan o sienten otras personas, están las alteraciones perceptivas y de atención. Ambas funcionan como filtros que se enlazan a aquellas cosas que son realmente significativas para que una persona logre (involuntariamente) atravesar la barrera del acceso consciente (Dehaene, 2015).

Como se mencionó en el planteamiento en el capítulo 1, la atención y la autoconciencia o autoanálisis son los aspectos básicos para poner en práctica las FE. A través de éstos la persona valora sus experiencias subjetivas para emplearlas en la resolución de problemas y guiar la toma de decisiones de su presente (Stuss y Benson en Tirapu-Ustárroz et al., 2005).

A continuación, se retoma el esquema de aplicación de los axiomas de Igor Aleksander presentado en la Tabla 9, pero esta vez enfatizando su condición de aplicación. Posteriormente, se muestra la relación de los axiomas con las FE evaluadas en los niños mientras interactúan con el robot-humanoide.

Aplicación de axiomas de Igor Aleksander (Aleksander, 2005, 2009)

\section{Mecanismo neuronal 1. Presencia}

- Axioma 1. "Siento que estoy centrado en un mundo exterior".

- Condición de uso. El "mundo exterior" debe representarse fenomenalmente como no afectado por las acciones. Es decir, el mundo tiene existencia propia y es independiente al de la persona o del agente. Lo cual implica tener la habilidad de interiorizar el mundo exterior a través del reconocimiento de sí mismo y del entorno.

- Condición de aplicación. Se deben emplear estímulos externos que activen el estado de alerta del usuario. 


\section{Mecanismo neuronal 2. Imaginación}

- Axioma 2. "No sólo puedo recordar la experiencia pasada, sino también la imaginación ficticia".

- Condición de uso. Las estructuras que representan la experiencia pueden perdurar sin información sensorial como resultado de las propiedades generalizadoras.

- Condición de aplicación. Se pueden emplear estímulos que recurran a la comprobación de la percepción de los usuarios.

\section{Mecanismo neuronal 3. Atención}

- Axioma 3. "Sólo soy consciente de lo que atiendo".

- Condición de uso. Se considera un tipo de atención distinta al estado de alerta. Es decir, que no sólo impliquen un tiempo de reacción o una activación de tipo si-no. La atención debe ser evaluada a través de la capacidad de aplicar un filtro de selección focalizado.

- Condición de aplicación. Se deben planear tareas que impliquen la selección de estímulos.

\section{Mecanismo neuronal 4. Volición}

- Axioma 4. "Puedo seleccionar lo que quiero y puedo actuar para obtenerlo"

- Condición de uso. Se refiere a la voluntad de hacer algo. Se establece un sistema de control que es dirigido por esquemas de control internos o externos.

- Condición de aplicación. Se deben emplear instrucciones que requieran que los usuarios quieran realizar las tareas dadas.

\section{Mecanismo neuronal 5. Emociones}

- Axioma 5. "Puedo evaluar los resultados de planificar diferentes acciones de acuerdo con la experiencia previa".

- Condición de uso. La emoción junto con la volición son dos aspectos que dirigen la conducta a partir de lo que se desea y de lo que se siente.

- Condición de aplicación. Se deben emplear ejercicios que estimulen la activación afectivo-emotiva de los usuarios. 


\subsection{Condiciones primarias para las FE en interacción niño-robot}

Las tareas para ejercitar las FE fueron propuestas a partir de tres resultados: 1) la conducta que los niños con TEA tuvieron en un contexto natural (ver sección 4.1);2) los resultados de las pruebas realizadas por las investigaciones de las tesis de licenciatura, y 3) las bases del procesamiento sensorial perceptivo descritas en el apartado 2.3.1.3 (ver tabla 7 y Tabla 22) y los axiomas de consciencia de Igor Aleksander.

Tabla 22. Características de los objetos que influyen en la percepción

\begin{tabular}{|c|c|c|}
\hline $\begin{array}{l}\text { Modalidad } \\
\text { sensorial }\end{array}$ & $\begin{array}{l}\text { Aspectos percibidos o alterados por las } \\
\text { personas con TEA }\end{array}$ & $\begin{array}{l}\text { Consideraciones para diseñar las } \\
\text { tareas de FE }\end{array}$ \\
\hline Visual & $\begin{array}{l}\text { Se han identificado tres niveles en los patrones } \\
\text { de observación: } 1^{\circ} \text { Tienden a centrarse en } \\
\text { detalles como el color, el contraste y la } \\
\text { orientación. } 2^{\circ} \text { Después perciben el tamaño, la } \\
\text { densidad o la complejidad del contorno. } 3^{\circ} \text { Se } \\
\text { centran en características de contenido } \\
\text { semántico como el texto, o identificación de } \\
\text { caras. }\end{array}$ & $\begin{array}{l}\text { 1․ Colores básicos y complementarios } \\
2^{\circ} \text { Tamaño } \\
\text { 3ํㅡㄴ Contornos de objetos bien definidos }\end{array}$ \\
\hline Percepción táctil & $\begin{array}{l}\text { Se han identificado alteraciones en las } \\
\text { características temporales del procesamiento } \\
\text { sensorial. }\end{array}$ & Objetos fácilmente reconocibles. \\
\hline $\begin{array}{l}\text { Percepción } \\
\text { auditiva }\end{array}$ & $\begin{array}{l}\text { Se ha detectado retraso en las latencias de las } \\
\text { respuestas auditivas sobre todo en estímulos } \\
\text { sociales complejos como los sonidos del habla, } \\
\text { lo cual podría tener implicaciones de orden } \\
\text { superior en la comunicación. }\end{array}$ & Se hicieron pruebas de voz. \\
\hline $\begin{array}{l}\text { Integración } \\
\text { multisensorial }\end{array}$ & $\begin{array}{l}\text { Presentan problemas en relación con el tiempo } \\
\text { para discernir entre un estímulo y otro, entre los } \\
\text { eventos sincrónicos con los asincrónicos. Esto } \\
\text { se ha detectado sobre todo cuando se ha } \\
\text { explorado con mecanismos audiovisuales, se } \\
\text { considera que es debido a la integración de } \\
\text { estímulos provenientes de varias vías } \\
\text { sensoriales. }\end{array}$ & $\begin{array}{l}\text { Se dejó un tiempo determinado entre la } \\
\text { presentación de un estímulo y otro. }\end{array}$ \\
\hline
\end{tabular}

$\begin{array}{ll} & \text { Han reflejado problemas asociados a varias } \\ \text { modalidades sensoriales. Particularmente, se ha } \\ \text { Procesamiento } & \text { observado en respuestas evocadas retrasadas } \\ \text { en el dominio auditivo y en la integración de } \\ \text { múltiples estímulos locales. }\end{array}$

Sólo en una prueba se usaron dos canales sensoriales.

Nota. En las dos primeras columnas se presentan datos de Robertson y Baron-Cohen (2017) relacionadas con la modalidad sensorial y su descripción. La tercera columna describe la aplicación que se da a la información para el desarrollo de los objetos empleados en la evaluación de las FE que se explican más adelante. 


\subsubsection{Bases para la interacción niño-robot, repertorios básicos}

El uso de los repertorios básicos fue un elemento que se obtuvo de la propuesta realizada para la creación red temática de colaboración académica "Tecnologías interactivas para atender necesidades educativas especiales (UTM-UPPue-IMSS)" (Anexo 3). En ella el primer planteamiento que se hizo fue ¿de qué manera se puede integrar multidisciplinariamente la tecnología robótica con las necesidades de la educación especial? Por lo que, aprovechando el acceso que se tenía para utilizar un robot como elemento auxiliar, se decidió utilizarlo.

Los repertorios básicos son condiciones mínimas que se deben tener si se quiere hacer alguna intervención conductual con los niños, por lo que se implementaron como parte de la interacción.

\subsubsection{Resultados de interacción niño-robot y repertorios básicos}

La etapa de interacción humano-robot se desarrolló a partir de la adecuación de las tareas de interacción básicas. En la Figura 46, se muestra un ejemplo de las tareas que se realizaron con los niños en interacción con una persona y una adecuación que se hizo para la interacción niñorobot. En la parte superior de la Figura 46, de izquierda a derecha, se muestra al primer niño acomodando las fichas por color; el segundo las acomoda de manera desordenada, y el tercero invade la zona de trabajo sin atender las instrucciones. En la parte inferior se muestra al niño detrás de los colores atendiendo la instrucción; el segundo está delante de los colores, y el tercero dirige la mirada hacia distintos lugares sin poner atención al robot. En cuanto a la ejecución de los niños; el primero logró desarrollar las actividades que se le indicaron; el segundo lo hizo con dificultad, y al tercero le costaba trabajo estar en interacción con el robot, por lo que no alcanzó a realizar la mayoría de las actividades. 
Figura 44. Ejemplo de interacción humano-humano y niño-robot

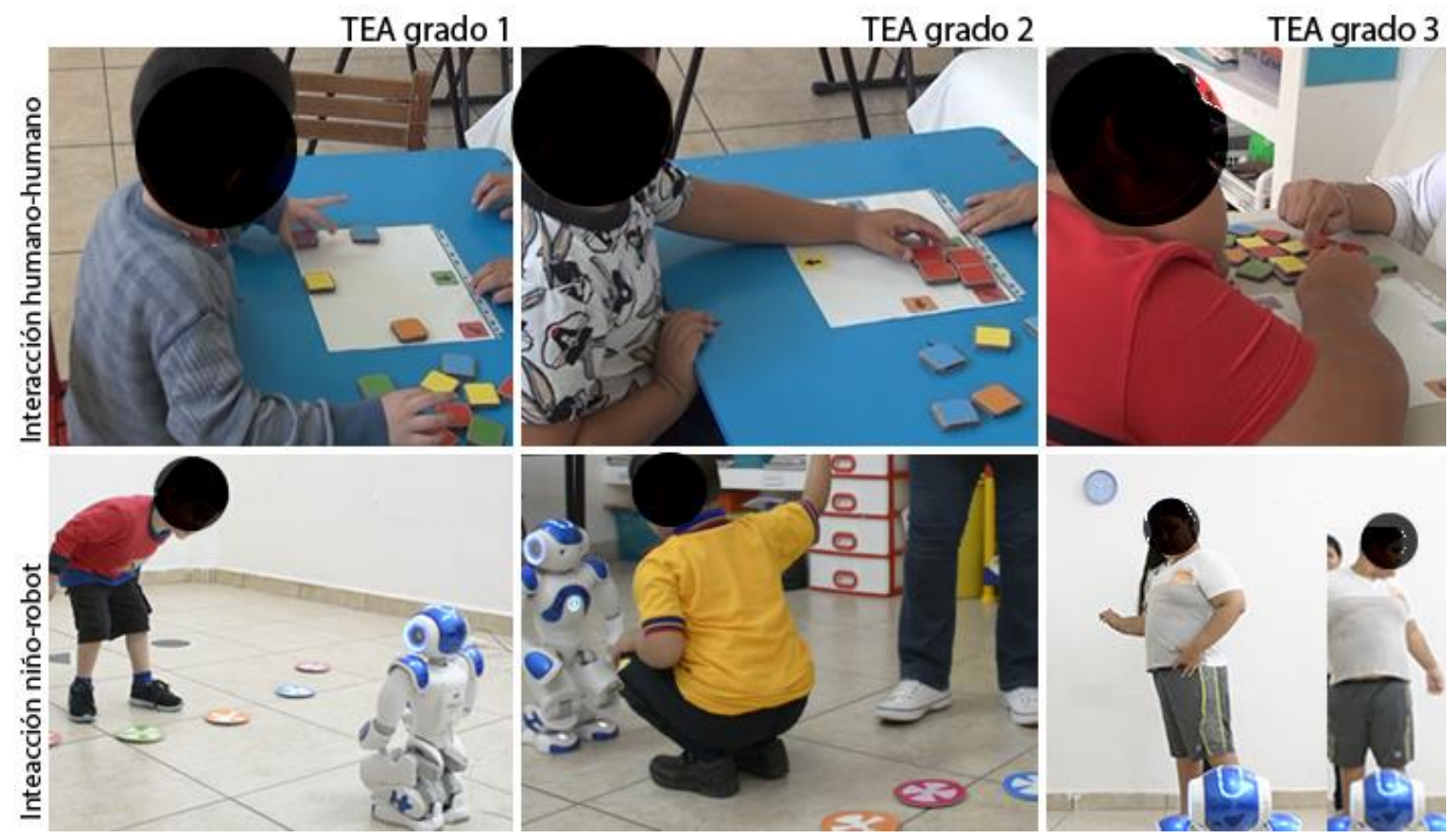

Nota. Las fichas de la parte superior se adaptaron de un ejercicio de Gómez (2020). Fuente: elaboración propia.

\subsubsection{Análisis del comportamiento durante interacción niño-robot}

La interacción niño robot se dividió en dos partes. La primera parte enfocada en la evaluación de habilidades pre-académicas (como la identificación de colores) y en la segunda se evaluaron las actividades de RB (atención, imitación y seguimiento de instrucciones).

A partir de las interacciones se desarrolló un esquema observacional de comportamiento dividido en cuatro partes: 1) saludo al iniciar la interacción, 2) RB de atención e imitación, 3) RB de seguimiento de instrucciones, 4) habilidades cognitivas de dificultad creciente (aplicada con el grupo 4). En cada ejercicio se les daban tres oportunidades para ejecutar la acción; suspendiendo la prueba si fracasaban en el tercer intento. La reacción ante los ejercicios fue positiva, el $87 \%$ las aceptó sin problemas (Figura 45), aunque cada niño realizó las actividades de acuerdo con el alcance de sus habilidades. De este grupo, un participante se rehusó a trabajar, manifestando su desagrado con llanto por entrar al salón en el que realizaría las pruebas con el robot. Otro de los niños inició las actividades, pero le rebasó la ansiedad y se negó a continuar, prefiriendo quedarse con su mamá. Después sólo disfrutó ver cómo trabajaba su compañero con el robot. 
Figura 45. Participantes en interacción con robot humanoide

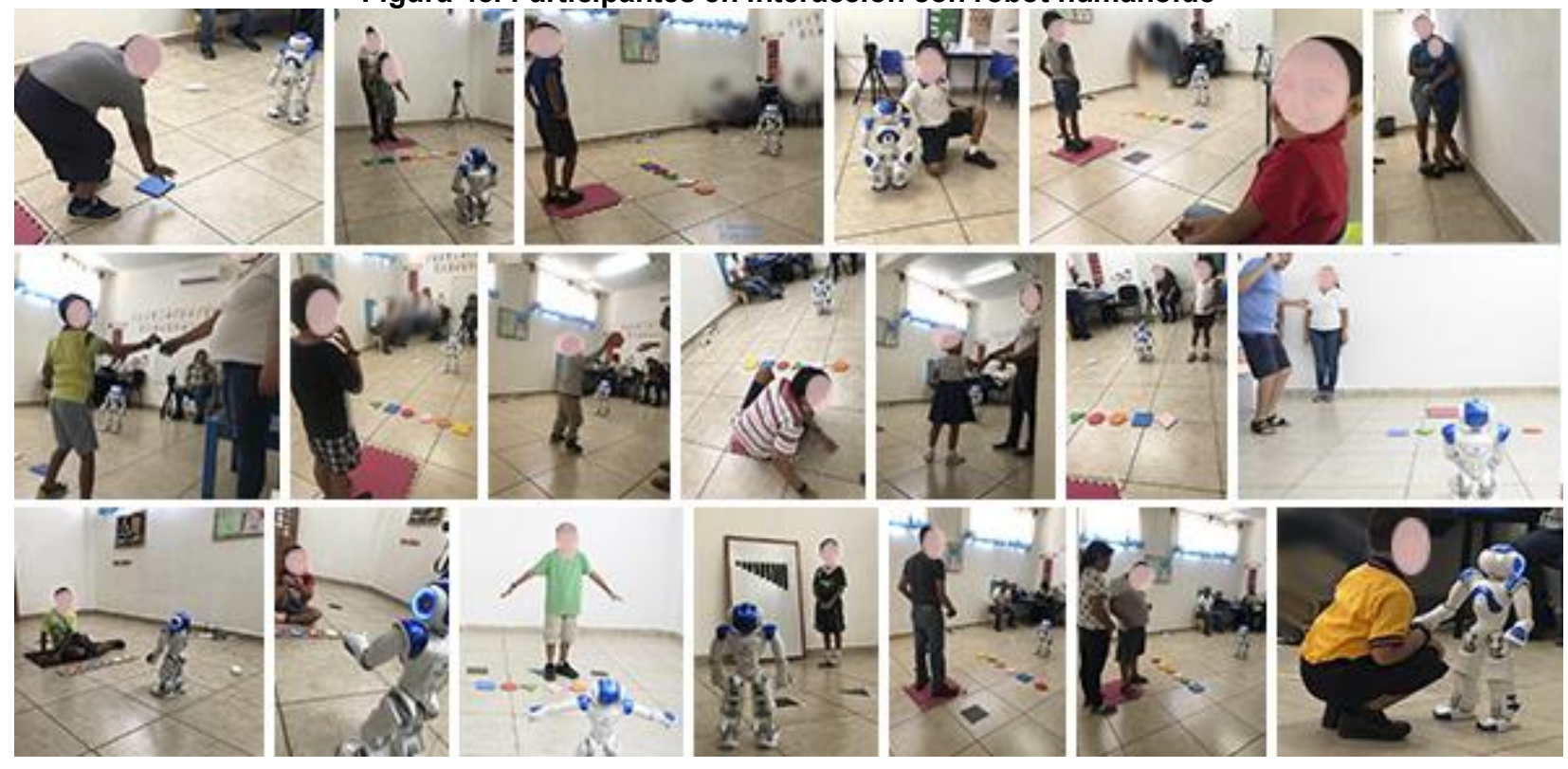

Fuente: elaboración propia.

4.5.4 Análisis del desempeño en pruebas de interacción humano-humano y niño-robot A partir de las observaciones realizadas en las interacciones humano-humano y niño-robot se identificaron algunas características generales ubicadas en un antes, durante o después de la interacción. En la Tabla 23 se presenta un resumen de dichas observaciones. Éstas, junto con la definición de las tareas descritas en el apartado 4.2, determinaron los niveles de interacción.

En la tabla se presentan en color las tareas de interacción enfocada:

Antes

Durante

Después 
Tabla 23. Comportamiento de los niños antes, durante y después de las interacciones

\begin{tabular}{|c|c|c|}
\hline Obs. & Definición & Descripción \\
\hline 1 & Impronta tecnológica & $\begin{array}{l}\text { Considerada en términos de Spalding (1873) como sello de la experiencia, pero } \\
\text { trasladada al ámbito tecnológico. }\end{array}$ \\
\hline 2 & Proto-interacción & Periodo en el que se evalúa el agrado o desagrado de los usuarios para interactuar. \\
\hline 3 & Interacción libre & $\begin{array}{l}\text { Periodo de prueba en el que sólo se observa la conducta de aceptación o rechazo de } \\
\text { los usuarios para interactuar. }\end{array}$ \\
\hline 4 & $\begin{array}{l}\text { Adopción de turnos e } \\
\text { intercambio mutuo con } \\
\text { el otro }\end{array}$ & $\begin{array}{l}\text { Condición inicial para que los usuarios puedan interactuar e intercambiar acciones con } \\
\text { otro, ya sea persona o robot. }\end{array}$ \\
\hline 5 & Rapport tecnológico & $\begin{array}{l}\text { Centrado en el sello de la experiencia y el uso de las posibilidades de uso } \\
\text { (Gibson,1873; Norman, 1988; y C. Breazilian, 2019). }\end{array}$ \\
\hline 6 & Atención & Condición básica para establecer un intercambio comunicacional. \\
\hline 7 & $\begin{array}{l}\text { Atención visual y } \\
\text { auditiva }\end{array}$ & $\begin{array}{l}\text { Son los dos tipos de atención que se requieren para establecer una interacción con el } \\
\text { robot. }\end{array}$ \\
\hline 8 & Imitación & $\begin{array}{l}\text { Está dentro de las condiciones básicas para establecer una relación de intercambio } \\
\text { comunicacional. }\end{array}$ \\
\hline 9 & $\begin{array}{l}\text { Seguimiento de } \\
\text { instrucciones }\end{array}$ & $\begin{array}{l}\text { Está dentro de las condiciones básicas para establecer una relación de intercambio } \\
\text { comunicacional. }\end{array}$ \\
\hline 10 & Códigos de interacción & Facilitan el intercambio comunicacional con el otro durante la interacción. \\
\hline 11 & $\begin{array}{l}\text { Códigos de interacción } \\
\text { más útil }\end{array}$ & $\begin{array}{l}\text { El más útil fue el código de color para facilitar el intercambio comunicacional con el } \\
\text { otro durante la interacción }\end{array}$ \\
\hline 12 & Complejidad de la tarea & $\begin{array}{l}\text { Es recomendable iniciar la interacción a través de tareas de menor a mayor } \\
\text { complejidad. }\end{array}$ \\
\hline 13 & Reflejo simple positivo & Técnica psicoterapéutica empleada para lograr establecer empatía con el usuario. \\
\hline 14 & Fluidez de interacción & $\begin{array}{l}\text { Es recomendable mantener fluida la interacción por lo que se sugiere tener } \\
\text { preparados los escenarios de trabajo para los usuarios. }\end{array}$ \\
\hline 15 & Tiempo de reacción & $\begin{array}{l}\text { Es preferible medir los tiempos de ejecución que la latencia de las tareas que debe } \\
\text { realizar el usuario, además de la capacidad de logro. }\end{array}$ \\
\hline 16 & Tareas combinadas & $\begin{array}{l}\text { Se pueden emplear tareas combinadas durante las sesiones para no saturar la } \\
\text { disposición de los niños. Es decir, se puede prescindir de la iteración en las tareas } \\
\text { cuando no haya disposición para hacerlo de parte de los usuarios. }\end{array}$ \\
\hline 17 & Movimiento corporal & $\begin{array}{l}\text { Es recomendable incluir tareas que impliquen el movimiento o la acción de los } \\
\text { usuarios. }\end{array}$ \\
\hline 18 & Prueba previa de tareas & $\begin{array}{l}\text { Las tareas diseñadas para ejecutarse durante las interacciones deben ser probadas } \\
\text { previamente. Una alternativa es probarlas con usuarios neurotípicos de igual o menor } \\
\text { edad cronológica que la de los usuarios finales. }\end{array}$ \\
\hline 19 & Permanencia emotiva & $\begin{array}{l}\text { La emoción manifestada en los usuarios durante las sesiones con el robot permanece } \\
\text { aun después de varias sesiones. }\end{array}$ \\
\hline 20 & Traslación de tareas & $\begin{array}{l}\text { Es posible trasladar una tarea que se realizó en interacción humano-humano a una } \\
\text { interacción niño-robot. }\end{array}$ \\
\hline 21 & $\begin{array}{l}\text { Responsabilidad } \\
\text { emotiva }\end{array}$ & Es primordial cuidar de la emoción de los usuarios durante las etapas de interacción. \\
\hline 22 & Códigos de cierre & $\begin{array}{l}\text { Es útil manejar códigos de cierre que indiquen a los usuarios que ha finalizado una } \\
\text { sesión. }\end{array}$ \\
\hline
\end{tabular}

Fuente: elaboración propia

La descripción de estas anotaciones, y el uso de las tareas que se tenían programadas para las sesiones de interacción, facilitaron el establecimiento de las etapas y niveles jerárquicos del modelo de interacción descrito en el siguiente capítulo. 


\section{Modelo de interacción cognitiva}

En este apartado se presenta la propuesta del modelo cognitivo, como una aportación al diseño de interacción cognitiva inteligente. Corresponde a la línea de investigación en la que se inscribe esta tesis. Parte de la visualización de un proceso para identificar los elementos clave de la interacción de niños con TEA para ejercitar sus FE.

El modelo facilita la interacción de un robot humanoide empleado como vehículo de interacción asistido ${ }^{46}$ para trabajar FE asociadas a un nivel de consciencia de niños con TEA. Su representación se basa en el uso de diagramas de flujo y de pseudocódigos que integran el modelo estructural de interacción cognitiva, articulado por módulos jerárquicos de complejidad creciente.

Para establecer el modelo de interacción se definieron los parámetros que abastecieron su integración. En primer lugar, se definieron las variables y sus características presentadas en el Capítulo 2 con los EATR. En segundo lugar, se consideraron tres aspectos básicos:

1. Los usuarios, (definidos en el capítulo tres del marco metodológico, y en el que se consideraron los tres niveles de TEA).

2. Las tareas que desarrollarían los usuarios (definidas en el capítulo cuatro). Especificadas para la interacción humano-humano y posteriormente para la interacción niño-robot.

3. El contexto de uso (también definido en el capítulo cuatro). El contexto de uso son los escenarios de interacción de niños con TEA y un robot humanoide.

Para integrar el modelo cognitivo se consideraron cinco etapas descritas en el Capítulo 4: 1) observación y descripción naturalista; 2) evaluación psicométrica de SCQ (Rutter et al., 2005); 3) evaluación de tareas de desempeño ejecutivo en interacción humano-humano; 4) evaluación de interacción niño-robot humanoide en repertorios básicos, y 5) propuesta para evaluar las FE asociadas a los niveles de consciencia de Igor Aleksander (2005). A este conjunto se añade la base teórico-práctica del modelo que define los parámetros para ejercitar las FE de los niños con

\footnotetext{
${ }^{46}$ La implicación de que el robot sea considerado como un vehículo de interacción asistido es que la programación de sus acciones no está automatizada. Sin embargo, a través de un mago de oz sus acciones siguen el orden dado por el modelo cognitivo. Esta característica dota de credibilidad al robot y se acerca de manera más empática a los niños, tanto neurotípicos como con TEA.
} 
TEA mientras interactúan con un robot humanoide. El modelo se basó en la descripción de los niveles de interacción definidos a partir del proceso de significación revisado en el EATR1, como se describe a continuación.

\subsection{Propuesta de niveles de interacción basados en el proceso de significación}

La importancia de identificar los proceso de significación en personas con TEA —asociados con la capacidad de percibir el entorno y a sí mismos (Handel, 2019; Noel et al., 2019)_ radica en que el entendimiento que adquieren del mundo suele depender del apoyo externo que reciban para interpretar todo aquello que ven antes de poder emplearlo socialmente.

Los sistemas de significación se determinan a partir de la experiencia de las personas. Por lo que a medida que tienen mayor conocimiento de los signos, mejores serán las posibilidades de usarlos en su expresión, recepción y comunicación.

A partir de las observaciones y análisis del comportamiento de los niños en interacción humano-humano y niño-robot, descritos en la Tabla 23, se proponen diversos rangos de interacción que incluyen la clasificación de las acciones que los niños realizaban antes, durante o después de la interacción. De acuerdo con la información obtenida se desarrolló un esquema de cuatro categorías (Tabla 24).

Tabla 24. Niveles de interacción del robot asociado a niveles de TEA

\begin{tabular}{clcl} 
Nivel & Tipo de interacción & $\begin{array}{c}\text { Grado de } \\
\text { TEA }\end{array}$ & \multicolumn{1}{c}{ Tareas asociadas a la interacción } \\
\hline 1 & Interacción por impronta & 1,2 y 3 & Saludo previo al inicio de la interacción \\
\cline { 2 - 4 } 2 & $\begin{array}{l}\text { Interacción por } \\
\text { significación }\end{array}$ & 1,2 y 3 & Repertorio básico de atención e imitación \\
\hline 3 & $\begin{array}{l}\text { Interacción por } \\
\text { comunicación }\end{array}$ & 1 y 2 & $\begin{array}{l}\text { FE de primer orden: memoria, uso de fichas de color para } \\
\text { inhibición y atención }\end{array}$ \\
\hline 4 & $\begin{array}{l}\text { Interacción } \\
\text { cognitiva }\end{array}$ & 1 & $\begin{array}{l}\text { FE de segundo orden: para evaluar flexibilidad cognitiva con } \\
\text { tareas de planificación y para metacognición }\end{array}$ \\
\hline
\end{tabular}

Fuente. Elaboración propia.

Se espera que alguien que no tiene habilidad para desarrollar un bagaje de información, y propiamente de signos, podrá dar una interpretación de lo que le rodea (proceso de significación), aunque es altamente probable que tenga menor posibilidad de intercambio comunicacional, tal como parece sucederles a las personas con TEA. 


\subsubsection{Niveles de interacción}

El objetivo de diseñar un modelo de interacción por niveles surgió, primordialmente, a partir de las observaciones y análisis del desempeño de los usuarios durante las pruebas de interacción humano-humano y niño-robot explicados en el capítulo 4. Éstas interacciones asumieron el rol de entrenamiento que validó los parámetros a seguir en cada etapa (ver Tabla 23 del capítulo 4). En las siguientes secciones se detalla el modelo:

\subsubsection{Nivel 0. Interacción por impronta}

En primer lugar, se determinó que el modelo requería tener cuatro niveles para conducir adecuadamente el desempeño de los usuarios. Atendiendo las observaciones 1, 2, 3 y 5 de la Tabla 23 Se estableció un primer nivel en estado "cero" que consiste en la

Extracto 1 de Tabla 23

\begin{tabular}{cl}
\hline Obs. & \multicolumn{1}{c}{ Definición } \\
\hline 1 & Impronta tecnológica \\
\hline 2 & Proto-interacción \\
\hline 3 & Interacción libre \\
\hline 5 & Rapport tecnológico \\
\hline
\end{tabular}
presentación del robot con el niño. La principal característica de este nivel es la ausencia de acciones requeridas y dirigidas del usuario. Es una etapa de prueba "libre" en la que se determina si el usuario desea de manera "improntada" interactuar o no con el robot, por lo que a este nivel se le llamó interacción por impronta (InIm). Este rango se caracteriza por ser de presentación, y porque en él se da la oportunidad de iniciar un rapport tecnológico.

\subsubsection{Nivel 1. Interacción por significación}

\begin{tabular}{cl}
\hline \multicolumn{2}{c}{ Extracto 2 de Tabla 23 } \\
\hline Obs. & \multicolumn{1}{c}{ Definición } \\
\hline 4 & $\begin{array}{l}\text { Adopción de turnos e } \\
\text { intercambio mutuo con el } \\
\text { otro }\end{array}$ \\
\hline 6 & Atención \\
\hline 7 & Atención visual y auditiva \\
\hline 8 & Imitación \\
\hline 9 & $\begin{array}{l}\text { Seguimiento de } \\
\text { instrucciones }\end{array}$ \\
\hline
\end{tabular}

En este primer nivel se consideraron las observaciones 6, 7, 8 y 9 de la Tabla 23. En dicha categoría se emplearon los repertorios básicos como una condición inicial indispensable para el moldeamiento de una conducta. Esta condición fue básica para implementar tareas de mayor complejidad que implicaban el uso de las FE. El nombre Interacción por significación se le asignó debido a que se observó que durante el primer momento de interacción entre el robot y los niños, no se establece una interacción recíproca. El robot sólo da instrucciones verbales y no verbales en las que el niño únicamente debe responder con una acción corporal. Las tareas que se emplearon en este rango implican los códigos aplicados en los vehículos de significación dirección, tamaño, forma y la atención.

Otra de las conductas esperadas de los niños es la de adopción de turnos y la capacidad del intercambio mutuo con el otro, como se menciona en la observación 4 de la Tabla 23. Actividad 
que se lleva a cabo mediante las pruebas de imitación y seguimiento de instrucciones, en las que, tampoco se podría considerar que se establece una interacción recíproca entre niño-robot.

\subsubsection{Nivel 2. Interacción por comunicación}

El siguiente rango de interacción fue estructurado a partir de las observaciones 10,11, 17 y 22 de la Tabla 23, en ellas se plantea el uso de códigos para facilitar la comunicación con los usuarios a través de signos que sean reconocidos fácilmente por ellos. A este nivel se le dio el nombre de interacción por comunicación debido a

\begin{tabular}{cl}
\hline \multicolumn{2}{c}{ Extracto 3 de Tabla 23 } \\
\hline Obs. & \multicolumn{1}{c}{ Definición } \\
\hline 10 & $\begin{array}{l}\text { Códigos de } \\
\text { interacción }\end{array}$ \\
\hline 11 & $\begin{array}{l}\text { Códigos de } \\
\text { interacción más útil }\end{array}$ \\
\hline 17 & Movimiento corporal \\
\hline 22 & Códigos de cierre \\
\hline
\end{tabular}
que, en esta interacción, a diferencia de la interacción por significación, sí se involucran acciones en las que se comparte un código de comunicación dirigido hacia la ejecución de una tarea específica. Como se menciona en el punto 11, el código de comunicación más útil durante las evaluaciones fue el color. Por lo que se empleó en varios de los submódulos de la planeación de tareas. Estos códigos fueron descritos en el capítulo cuatro (ver Tabla 20).

\subsubsection{Nivel 3. Interacción cognitiva en tareas de FE}

El cuarto grupo de interacción se organizó a partir de las observaciones $12,15,16$ y 20. En este aspecto lo más importante no fue la estructura de la interacción, sino las tareas en sí mismas enfocadas en ejercicios de FE encaminadas a la activación de Extracto 4 de Tabla 23

\begin{tabular}{cl}
\hline Obs. & \multicolumn{1}{c}{ Definición } \\
\hline 12 & $\begin{array}{l}\text { Complejidad de la } \\
\text { tarea }\end{array}$ \\
\hline 15 & Tiempo de reacción \\
\hline 16 & Tareas combinadas \\
\hline 20 & Traslación de tareas \\
\hline
\end{tabular}
habilidades mentales de los usuarios o personas con TEA.

Como se puede notar en el extracto 4 de la Tabla 23, las observaciones están más encaminadas en el orden de las tareas y en la evaluación de su ejecución. Esto es debido a que las tareas se basaron en las prioridades de ejecución de acuerdo con la literatura, y considerando las recomendaciones de las especialistas.

A este cuarto nivel se le denominó Interacción cognitiva en tareas de FE. El nombre es un reflejo de lo que se realizó finalmente en el modelo de interacción. Un aspecto importante de mencionar es que las tareas propuestas fueron probadas previamente con niños regulares $y$, después, con niños con TEA, por lo que cada tarea pasó por varios filtros de depuración; una vez establecidas se desarrolló el modelo estructural de interacción. 


\subsection{Propuesta de un modelo de interacción}

La propuesta que se presenta atiende a la estructura cognitiva determinada por los niveles de interacción antes descritos. Cada rango de interacción arrojó resultados preliminares a partir de los cuales se definieron los componentes del modelo: módulos, submódulos, tareas y subtareas o ejercicios, definidos como sigue:

1. Un módulo corresponde a un nivel de complejidad de la interacción.

2. Un submódulo corresponde a una o varias tareas de interacción. Por ejemplo, de la tarea de atención podría dividirse en atención selectiva, focalizada, alternante o sostenida.

3. Una tarea es una actividad que implica el uso de repertorios básicos o de FE, puede estar integrada por diferentes actividades especializadas en ese tipo de tarea. Por ejemplo, la tarea del repertorio básico de atención podría incluir ejercicios con estímulos visuales, auditivos, kinestésicos, etc.

4. Las subtareas o ejercicios son variantes de las tareas, entendidas como actividades específicas para ejercitar alguna habilidad. Cada tarea incluye varios ejercicios o subtareas. Por ejemplo, un ejercicio visual podría incluir el uso de papeles de colores, varitas de jacaranda, botes de leche con la vaquita Pili, una flor, una mariposa, etc. Es decir, los ejercicios podrían estar adaptados a los intereses restringidos y repetitivos de los niños con TEA o niños neurotípicos. En el caso de esta tesis, las subtareas estuvieron compuestas de códigos básicos para ser entendidos por los tres niveles de TEA. Sin embargo, como no hubo variantes se consideraron como tareas.

La Figura 46 muestra los componentes enlazados por relaciones modulares e intramodulares, lo cual favorece que las tareas puedan desarrollarse de acuerdo con una distribución jerarquizada de las tareas por nivel de complejidad. 
Figura 46. Elementos que integran el modelo general de interacción

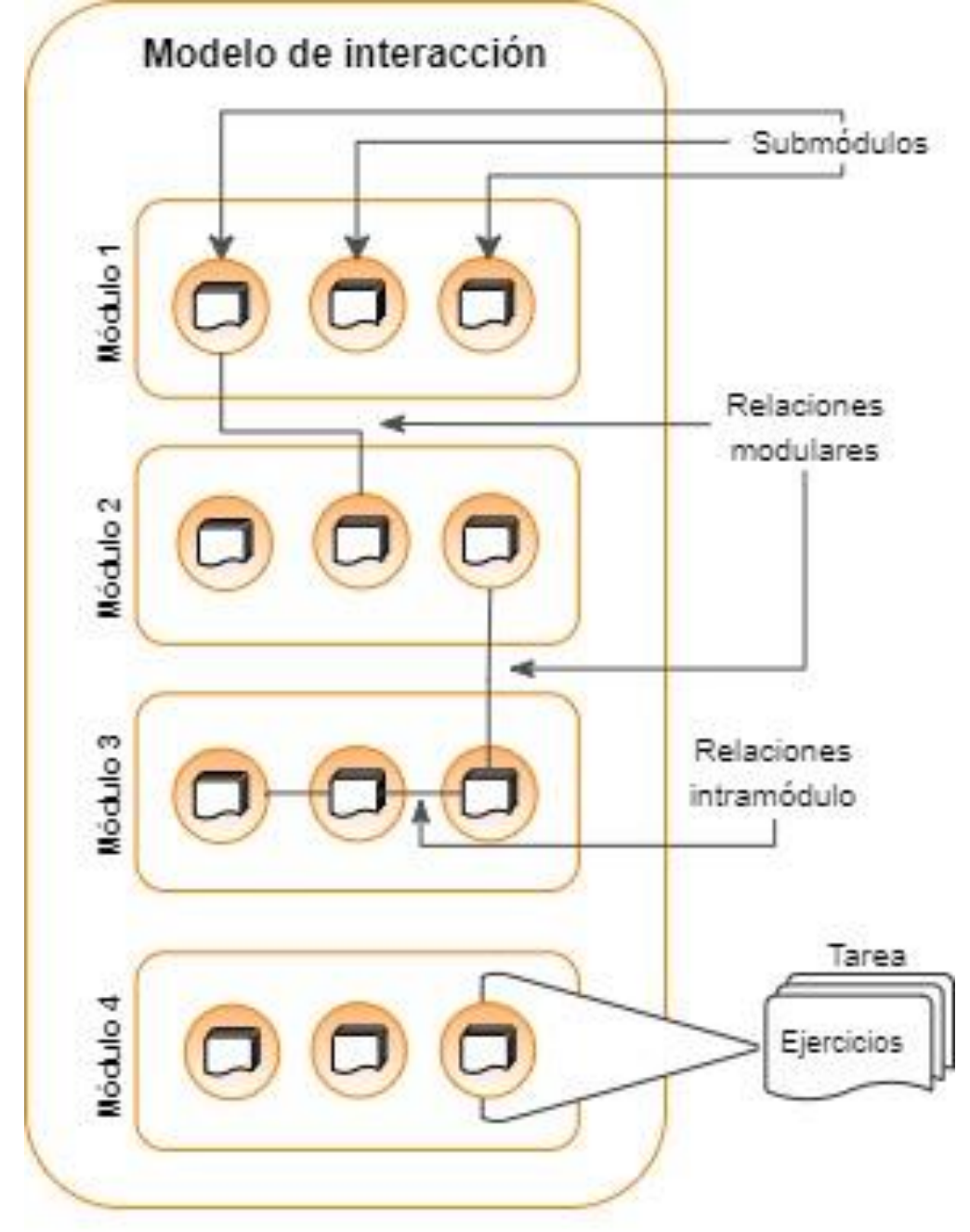

Fuente: elaboración propia

El modelo de interacción tuvo como fin la determinación de qué y cómo se interpretaría la conducta de los usuarios mientras estuvieran interactuando con el robot. A partir de ello y considerando la propuesta de los niveles de interacción propuestos en el capítulo 4, apartado 4.5.5, se definen los niveles en los que se ejecutarán las tareas de interacción durante las interacciones niño-robot.

Es importante mencionar que a pesar de que el robot fungió como un vehículo de interacción asistida, contar con un modelo de interacción ayudó a visualizar el alcance de desarrollo que puede tener un niño de acuerdo con su nivel de TEA, de acuerdo con su capacidad o disposición para ejercitar sus FE. 


\subsubsection{Variables del modelo de interacción}

Para representar las acciones y pasos a seguir durante la programación de las tareas de interacción se emplearon algunas herramientas de programación, como diagramas de flujo, pseudocódigo o diagramas de Nassi-Shneiderman (Pinales et al., 2014) ${ }^{47}$. Con ellas se definieron los escenarios y ejecuciones que debía seguir el robot ante las acciones del usuario. Para su representación se consideraron dos aspectos: el porcentaje de aciertos (PA) en el desempeño de una tarea dada, y la intención ${ }^{48}$ de continuar en interacción (Int.). En esta etapa los diagramas de flujo también se emplearon para representar el modelo estructural de interacción. En cuanto a la utilidad de los pseudocódigos, su implementación favoreció la representación del modelo de la conducta, acciones y posibles respuestas de los usuarios.

Para diseñar algoritmos es necesario contar con identificadores que pueden asumir valores que cambian o que son constantes ${ }^{49}$. En esta investigación sólo se emplearon variables que pueden cambiar su valor durante el proceso de la solución del problema, llamadas:

1. Variable de tipo entero. Son aquellas que almacenan un número sin decimales (v.g. personas o edad).

2. Variables reales. Son aquellas que pueden adquirir un valor con decimales (v.g. son los porcentajes, peso o costo de algo).

3. Variable de cadena o string. Pueden ser designadas a través de caracteres como letras, número u otros signos asignados arbitrariamente (v.g. a, b, c).

4. Variables booleanas. Almacenan valores enteros 0 y 1 interpretados como falso (0) o verdadero (1).

47 Los pseudocódigos y los diagramas de flujo son herramientas empleadas en programación para representar los algoritmos que facilitan la interpretación de las secuencias de instrucciones que se deben seguir para programar los sistemas informáticos o computacionales. Un algoritmo es una serie de pasos para resolver un problema. Se representan considerando tres condiciones: 1) son descritos de manera precisa (indican un orden); 2) estar bien definidos (implica que, bajo las mismas condiciones de un problema, el resultado siempre debe ser el mismo), y 3) deben ser finitos (siempre tiene un fin). Su uso facilita la transcripción a un lenguaje de programación.

${ }^{48} \mathrm{Se}$ ha comentado que la intención se basa en la voluntad de una persona para decidir algo en torno a un fin. En el modelo propuesto el usuario puede salir, continuar o iterar dentro de una misma actividad.

49 Es importante comentar que, para los expertos en programación, esta información puede ser muy básica e irrelevante. Sin embargo, si se considera que la tesis apunta a una propuesta transdisciplinaria la definición de estos términos es importante para ampliar el rango de lectores no especializados. 


\subsubsection{Descripción de unidades de interacción básica}

El modelo de interacción puede ser dividido en módulos, submódulos, tareas y subtareas o ejercicios. Cada uno de ellos puede ser considerado como una unidad de interacción siempre y cuando sea el último eslabón de la cadena. Es decir, si en el modelo sólo hay módulos y submódulos, el submódulo adquiere la categoría de unidad de interacción. Pero si en un modelo existen módulos, submódulos, tareas y subtareas, entonces la subtarea es la que se considera como la unidad de interacción. Esta definición permite que el modelo sea grande o pequeño pero que la toma de decisiones sea dada por los mismos parámetros de la medida.

En el caso de esta tesis, considerando las siete tareas descritas en la Tabla 20, cada una ocupa un submódulo porque no tienen variantes ni otras tareas asociadas. Por lo que no es necesario hacer la diferencia entre submódulo y tarea. En ese caso, una unidad de interacción se aplica a las tareas que pueden ser definidas de acuerdo con las variables de la Tabla 25.

Tabla 25. Variables empleadas para la representación de la unidad de interaccón

\begin{tabular}{clc}
$\begin{array}{c}\text { Nomen- } \\
\text { clatura }\end{array}$ & \multicolumn{1}{c}{ Descripción } & Tipo \\
\hline II & Iniciar interacción. Se refiere a la disposición de interactuar. & Booleano \\
\hline DCI & Deseo de continuar en interacción. Facilita el ingreso a otra tarea. & Booleano \\
\hline Int & $\begin{array}{l}\text { Intención cuya resultante puede ser iterar, salir o continuar la interacción. Esta } \\
\text { opción está presente en cada unidad de interacción. }\end{array}$ & Booleano \\
\hline IT & $\begin{array}{l}\text { Iniciar actividad en la unidad de interacción. Se refiere a la participación de una } \\
\text { tarea en específico }\end{array}$ & Booleano \\
\hline RTA & $\begin{array}{l}\text { Si se tiene un PA menor a } 59 \% \text { no se puede avanzar a la siguiente tarea, pero } \\
\text { si se puede regresar a la unidad de interacción anterior. }\end{array}$ & Numérico/Real \\
\hline AT & $\begin{array}{l}\text { Si se alcanza un PA menor a } 59 \% \text { se puede abandonar la unidad de } \\
\text { interacción. }\end{array}$ & Numérico/Real \\
\hline Ite & Si se cubre un PA entre 60 y $89 \%$, usa la alternativa de iterar. & Numérico/Real \\
\hline ST & Si se tiene un PA mayor a $90 \%$ se supera la unidad de interacción. & Numérico/Real \\
\hline ScDI & $\begin{array}{l}\text { Si se alcanza un PA mayor a } 90 \% \text { y se tiene intención o deseos de continuar } \\
\text { interacción, se puede superar unidad de interacción }\end{array}$ & Numérico/Real \\
\hline AsDI & $\begin{array}{l}\text { Si se alcanza un PA mayor a } 90 \% \text { pero se tiene nula Intención o deseo de } \\
\text { continuar interacción se puede abandonar la unidad de interacción. }\end{array}$ & Numérico/Real \\
\hline LT & Logra completar la unidad de interacción & Booleano \\
\hline MIA & $\begin{array}{l}\text { Mantenerse en interacción anterior } \\
\text { Iniciar nueva unidad de interacción si existe Int. o deseo de continuar }\end{array}$ & Booleano \\
\hline interacción
\end{tabular}

Nota. PA corresponde al porcentaje de aciertos obtenidos en la unidad de interacción. Fuente: elaboración propia 
Los valores presentados en la Tabla 25 son la base para proponer la dinámica que se puede llevar a cabo en la unidad de interacción, como se observa en la Figura 47. Se incluyen cuatro posibilidades: iniciar tarea (IT), lograr tarea (LT), abandonar tarea (AT) e iterar (Ite). Las tres primeras determinadas por el porcentaje de aciertos (PA) del usuario en la actividad dada y por su intención (Int) ${ }^{50}$ o deseo de continuar en interacción (DCI) con el robot, determinado con un SI o un NO. En el caso de la iteración (Ite), depende del PA que logre el usuario en la ejecución de la actividad en turno.

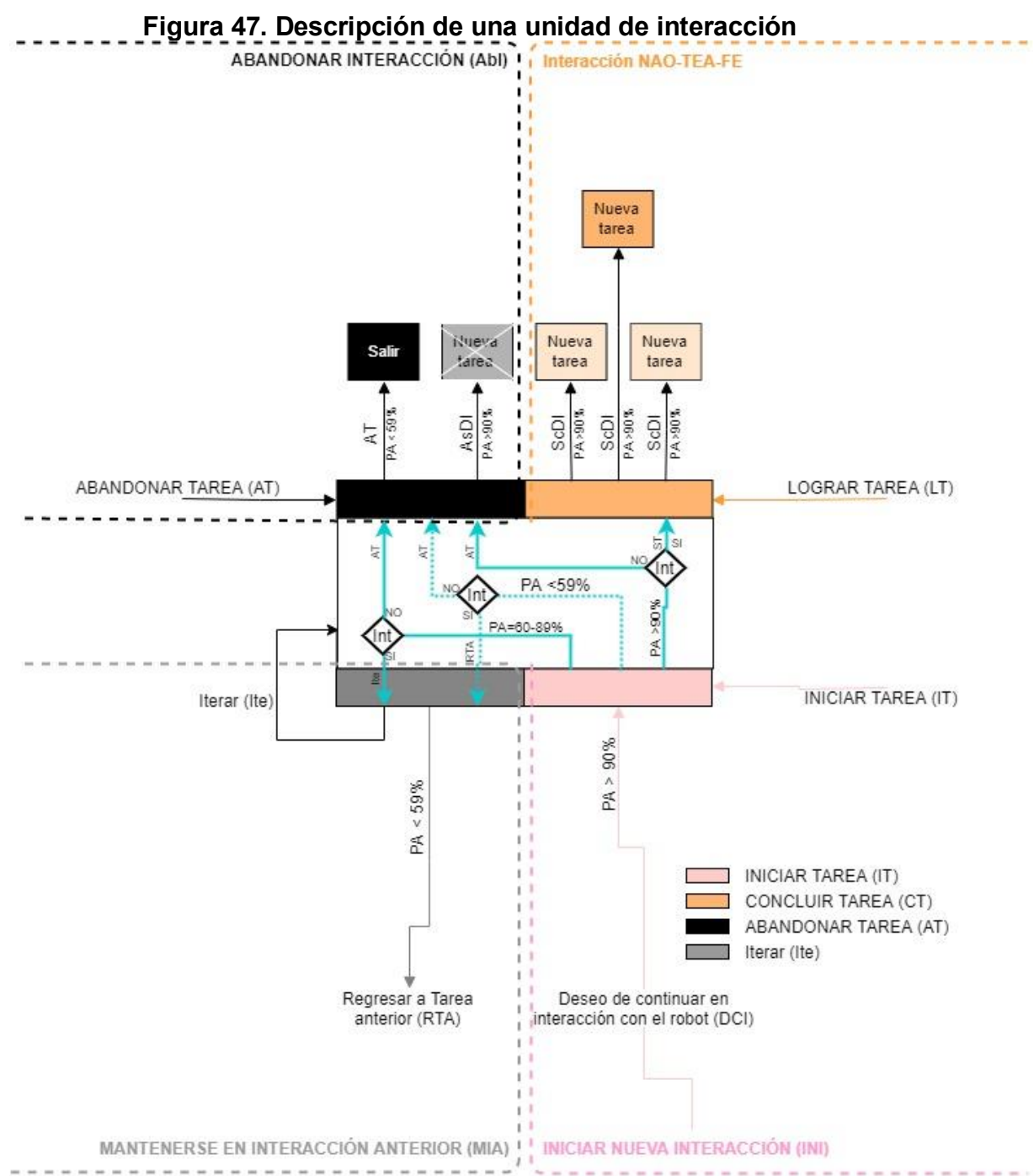

Fuente: elaboración propia.

50 Se ha descrito que la intención puede adquirir la forma de salir, continuar o iterar dentro de la misma actividad de interacción. Mientras que el Deseo de continuar la interacción (DCl) se aplica para una nueva actividad. 
El análisis de una unidad de interacción, cuando un niño está frente al desarrollo de una tarea, presenta cuatro posibles respuestas:

1. Iniciar interacción (II).

2. Mantenerse en la interacción anterior (MIA) en caso de que hubiera un ejercicio previo o no hacer nada.

3. Iniciar nueva interacción (INI); es decir, iniciar el ejercicio que se le asigne, o

4. abandonar interacción (Al).

Una vez resueltos los parámetros de una unidad de interacción se diseñaron las pruebas que conformarían el modelo propuesto. En el siguiente apartado se describen los niveles jerárquicos del modelo, denominados niveles de interacción, que retoman el proceso de significación descrito en el EATR 1. Dicho proceso está relacionado con la semiótica y concretado en la propuesta de niveles de interacción en el apartado 5.1.

\subsubsection{Definición de variables del modelo de interacción}

\begin{tabular}{|c|c|c|}
\hline \multirow{7}{*}{$\begin{array}{l}\text { Finalmente, considerando las observaciones del } \\
\text { extracto } 5 \text { de la Tabla 23, se siguieron algunas } \\
\text { recomendaciones generales que permearon en todos } \\
\text { los niveles }\end{array}$} & \multicolumn{2}{|r|}{ Extracto 5 de Tabla 23} \\
\hline & Obs. & Definición \\
\hline & 13 & Reflejo simple positivo \\
\hline & 14 & Fluidez de interacción \\
\hline & 18 & Probar previamente las tareas \\
\hline & 19 & Permanencia emotiva \\
\hline & 20 & Traslación de tareas \\
\hline
\end{tabular}

1. Se debe mantener una actitud responsiva.

2. Hacer fluida la interacción.

3. Hay que considerar que la permanencia de la emoción

4. Se debe valorar la viabilidad de las tareas.

Con los elementos antes descritos se pudieron concretar los parámetros del modelo de interacción que definiría la interacción niño-robot. La Tabla 26 define las variables de la interacción niño-robot. 
Tabla 26. Variables de identificación de cada módulo de interacción

\begin{tabular}{cclc} 
Núm. & Nomenclatura & Descripción & Tipo \\
\hline 1 & Inlm & Interacción por impronta & String/cadena \\
\hline 2 & IS & Interacción por significación & String/cadena \\
\hline 3 & IC & Interacción por comunicación & String/cadena \\
\hline 4 & ICA & Interacción cognitiva en tareas de FE & String/cadena \\
\hline 5 & Int. 1, 2 y 3 & $\begin{array}{l}\text { Intención de interacción entendida como la determinación de la } \\
\text { voluntad en orden a un fin (1, 2 o 3) }\end{array}$ & Booleano \\
\hline 6 & PA & Porcentaje de aciertos & Entero
\end{tabular}

Los diagramas de flujo ayudan a entender la dinámica de los niveles de interacción descritos en este mismo apartado: nivel 0, interacción por impronta (Inlm); nivel 1, interacción por significación (IS); nivel 2, interacción por comunicación (IC), y nivel 3, interacción cognitiva con FE (ICA). Los niveles jerárquicos fueron definidos por el grado de acercamiento que tuvieron los niños con el robot. En el diagrama de flujo de la Figura 48 se muestra la relación de los cuatro módulos de interacción.

Figura 48. Diagrama de flujo de la interacción general niño-robot

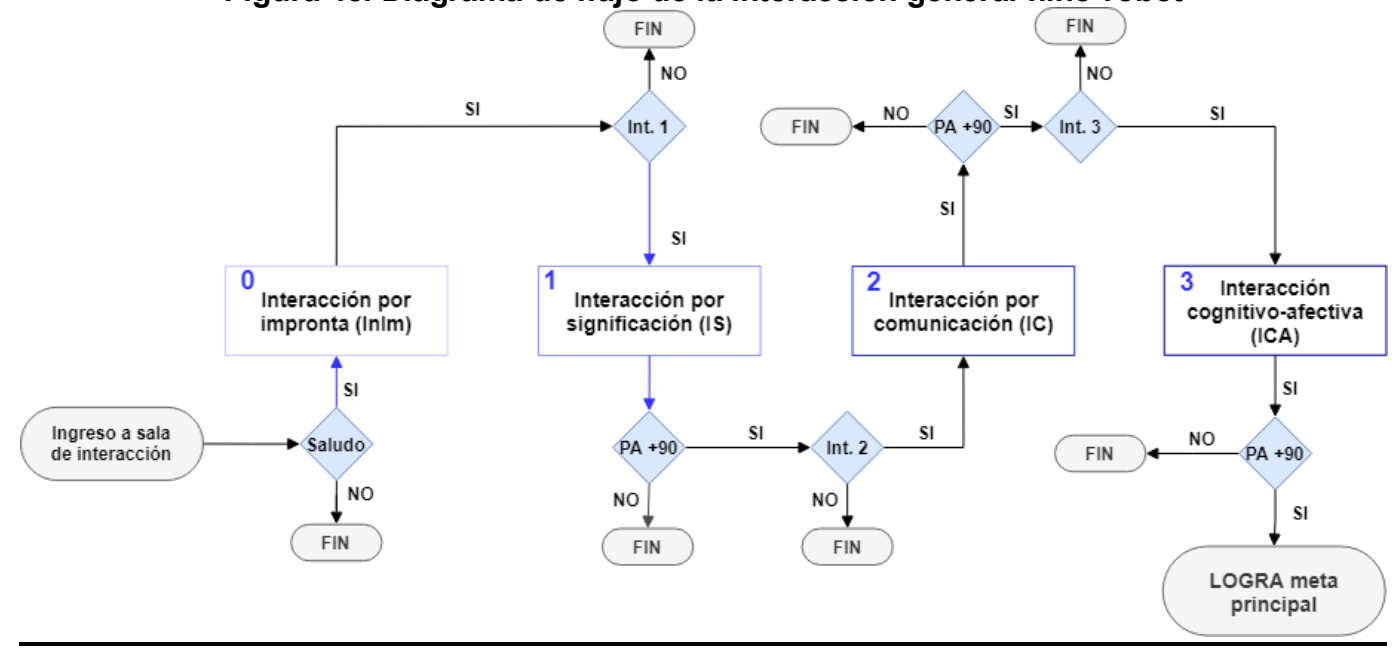

Fuente: elaboración propia

La Figura 49 muestra la herramienta de pseudocódigo representando el diagrama descrito en la Figura 48. A partir de la descripción del submódulo de interacción, de la definición de los niveles de interacción, y del desarrollo del pseudocódigo respectivo, se integraron los submódulos en el modelo estructural de interacción. Mismo que para facilitar su lectura se presentan por separado en las siguientes páginas. 
Figura 49. Pseudocódigo del modelo mental general de la interacción niño-robot humanoide

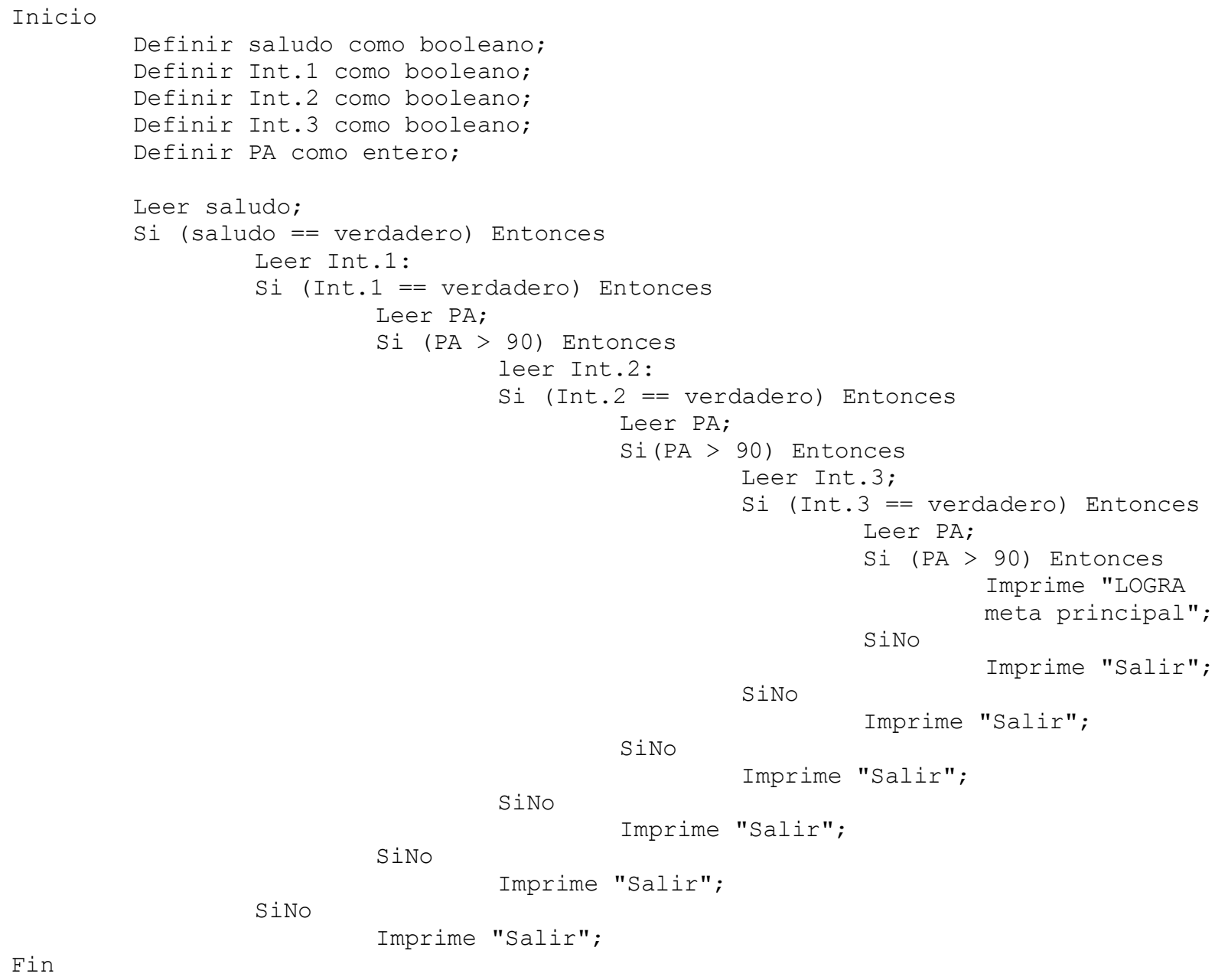




\subsubsection{Modelo de interacción jerárquico-estructural cognitiva}

El diseño del modelo de interacción-jerárquico estructural cognitiva tuvo como fin, articular todas las tareas programadas para que el usuario las ejecutara. Considerando la experiencia adquirida durante las interacciones de entrenamiento (descrita en la etapa anterior) se definieron los parámetros que servirían como base para realizar el modelo de interacción. La incorporación de la consciencia en este prototipo se asocia al uso de las FE cuya base de desarrollo es la autoconsciencia, descrita en el capítulo 4.

Para definir y especificar los parámetros que intervendrían en el se consideraron las observaciones recabadas durante las pruebas de interacción. Integrando las posibilidades y alternativas que se tenían para iniciar, mantener, iterar o abandonar la interacción.

En la figura 47 se presentaron las características de la unidad de interacción. A partir de éstas se integró un arquetipo general que explicara la relación entre los niveles de interacción y las tareas que tenían que realizar los niños durante las interacciones (Figura 50). El modelo de interacción general señala las vías para avanzar, mantener, regresar al módulo anterior o salir de la interacción, dependiendo del desempeño del usuario (PA e Int.). 
Figura 50. Modelo de interacción por niveles niño-robot

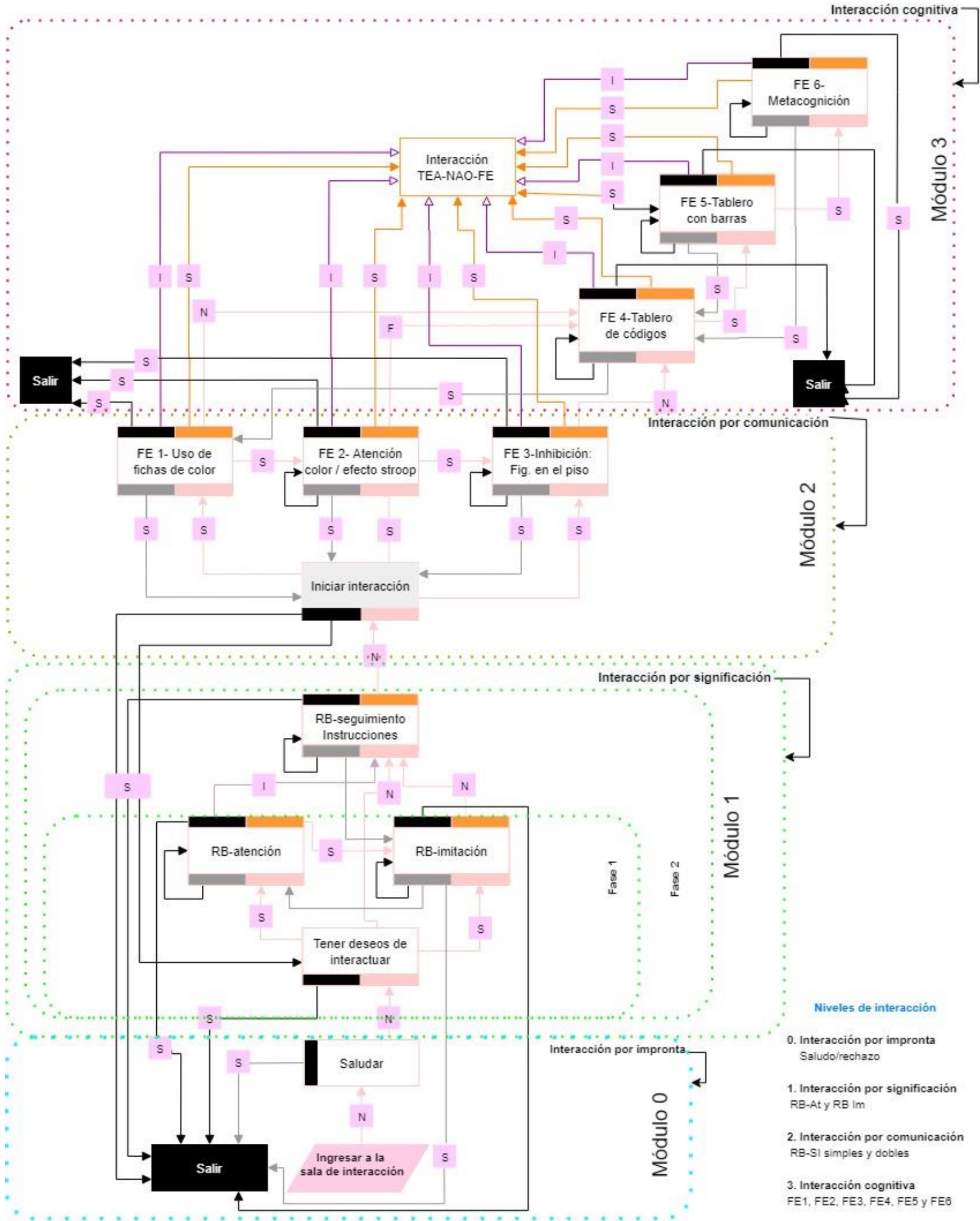

Fuente: elaboración propia. 


\subsubsection{Definición de las tareas del modelo}

Retomando la Figura 50, en este apartado se integra la definición de las tareas y ejercicios que componen el modelo y que fueron explicadas en la etapa $\mathrm{C}$. Aquí se presentan asociadas a un nivel jerárquico, se explican a través del diseño de una macroestructura y de diagramas de flujo.

\subsubsection{Módulo de interacción, nivel 0}

El nivel 0 es la primera interacción, no se requiere ninguna acción específica. Pero la atracción o rechazo que muestra el usuario define si inicia la interacción con el robot o si la abandona (Tabla 27, Figuras 51-53).

Tabla 27. Características del modelo de interacción nivel 0.

\begin{tabular}{cc} 
Características & Descripción \\
\hline Módulo & 0 \\
\hline Tipo de interacción & Por impronta \\
\hline Grado de TEA asociado & 1,2 y 3 \\
\hline Nivel de consciencia & 1 \\
\hline Tarea & Interacción libre \\
\hline Ejercicios & Saludar
\end{tabular}

Figura 51. Módulo 0 del modelo de interacción

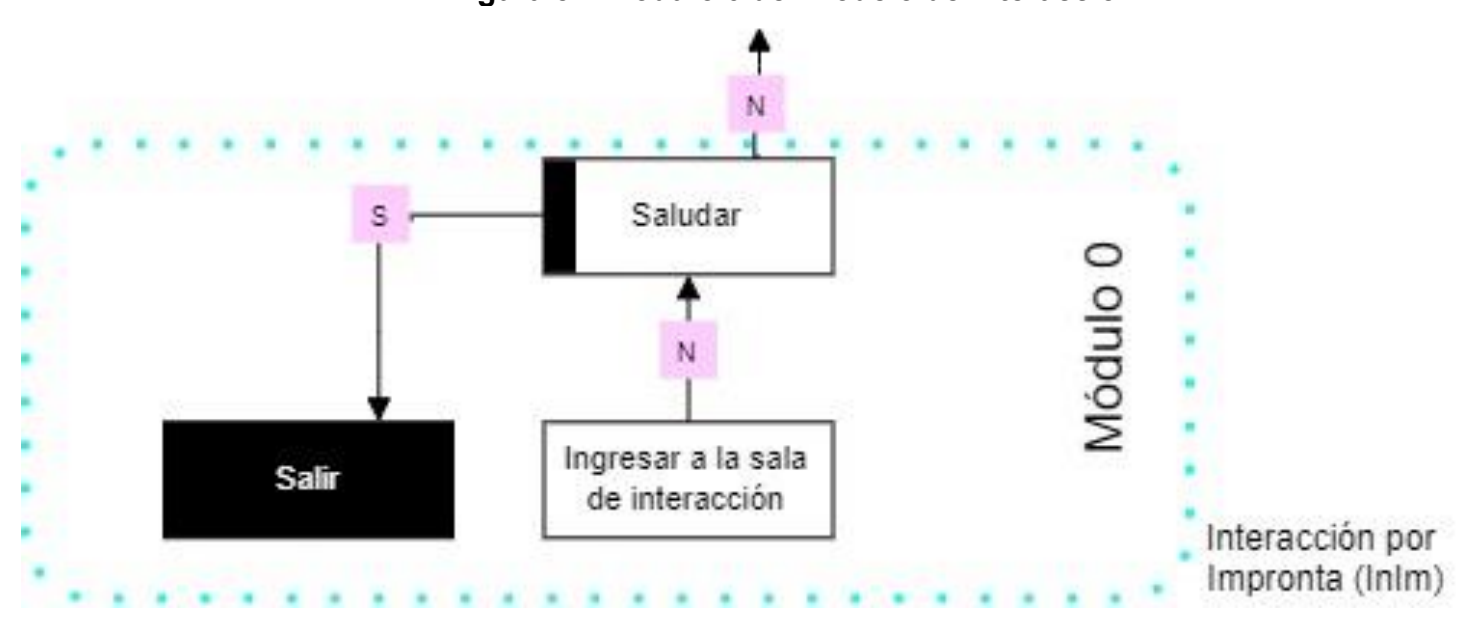


Figura 52. Diagrama de flujo del módulo 0 del modelo de interacción Módulo 0

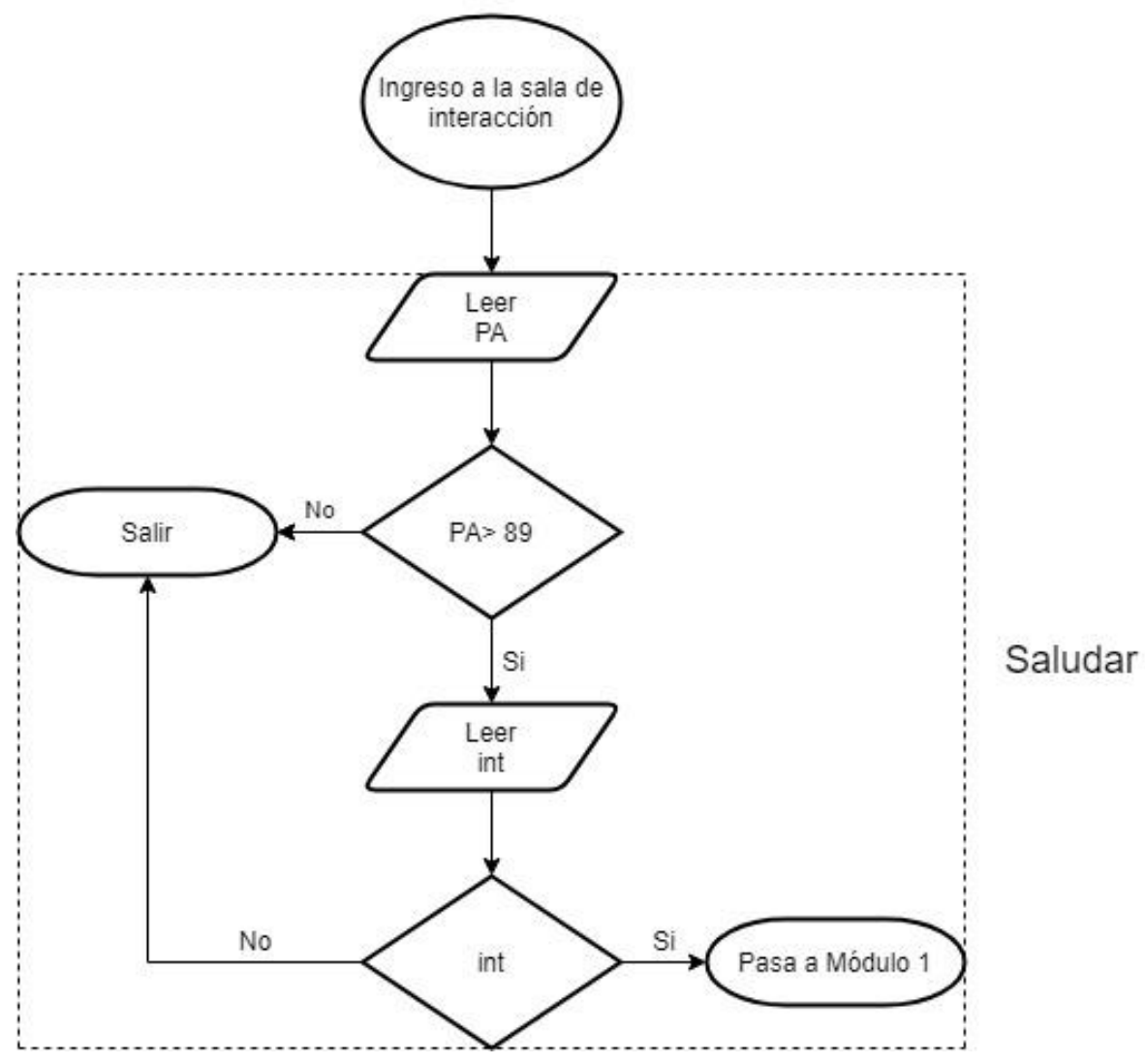

Figura 53. Pseudocódigo del módulo 0 del modelo de interacción

Inicio Módulo 0

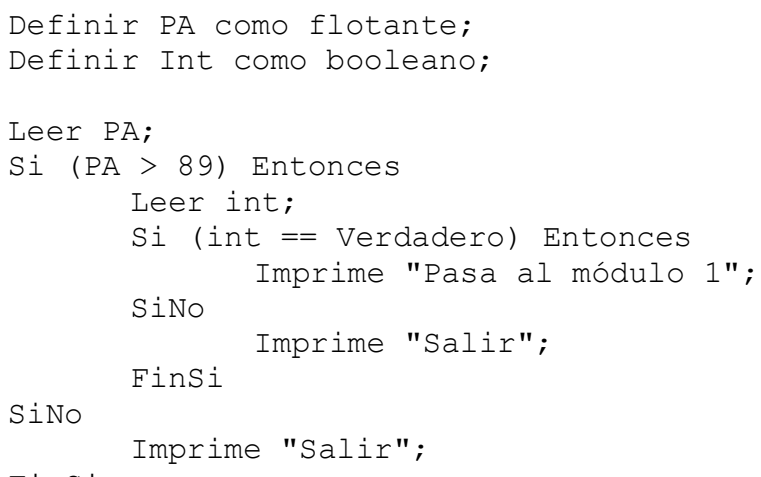

Fin Módulo 0 
En este módulo sólo se esperaba que se realizara una tarea y un ejercicio: el saludo. La interacción fue libre para permitir que hubiera un reconocimiento natural de gusto o de rechazo hacia el robot (ver definición de tareas en el capítulo cuatro).

\subsubsection{Módulo de interacción, nivel 1}

En esta etapa no se requiere que el usuario tenga un reconocimiento claro de lo que el robot le solicite que haga, lo único que necesita es interpretar los gestos y movimientos que el robot realiza para evaluar si en ese momento hay atención, y si es capaz de hacer un seguimiento de las acciones por imitación y por instrucción verbal.

Aunque los tres repertorios básicos fueron integrados en el mismo nivel, de manera operativa puede dividirse en dos fases: 1) atención e imitación, y 2) seguimiento de instrucciones (Tabla 28, y Figura 54 y 55). Dividirlos de esta manera permite trabajar en este nivel con usuarios TEA grado 3 (en la fase uno), y TEA grado 1 y 2 (en la fase dos). De acuerdo con la experiencia que se tuvo con los usuarios grado 3 se identificó que era posible trabajar iterativamente, en las dos fases del módulo 1. Por lo que en este modelo se ha considerado que es posible trabajar con iteraciones constantes en el repertorio básico $(\mathrm{RB})$ de atención y de imitación, y, pasar a la fase dos cuando se cumplan las condiciones de PA $>90$.

Tabla 28. Características del modelo de interacción nivel 1

\begin{tabular}{ll}
\multicolumn{1}{c}{ Característica } & \multicolumn{1}{c}{ Descripción } \\
\hline Módulo & Por significación \\
\hline Tipo de interacción & 1, 2 para las fases 1 y 2 \\
\hline Grado de TEA asociado & 3 para la fase 1 \\
\hline Nivel de consciencia & 1 y 2 \\
\hline Tarea & Repertorios básicos \\
\hline Ejercicios & $\begin{array}{l}\text { Atención e imitación (fase uno) y seguimiento } \\
\text { de instrucciones (fase dos) }\end{array}$
\end{tabular}


Figura 54. Módulo 1 del modelo de interacción

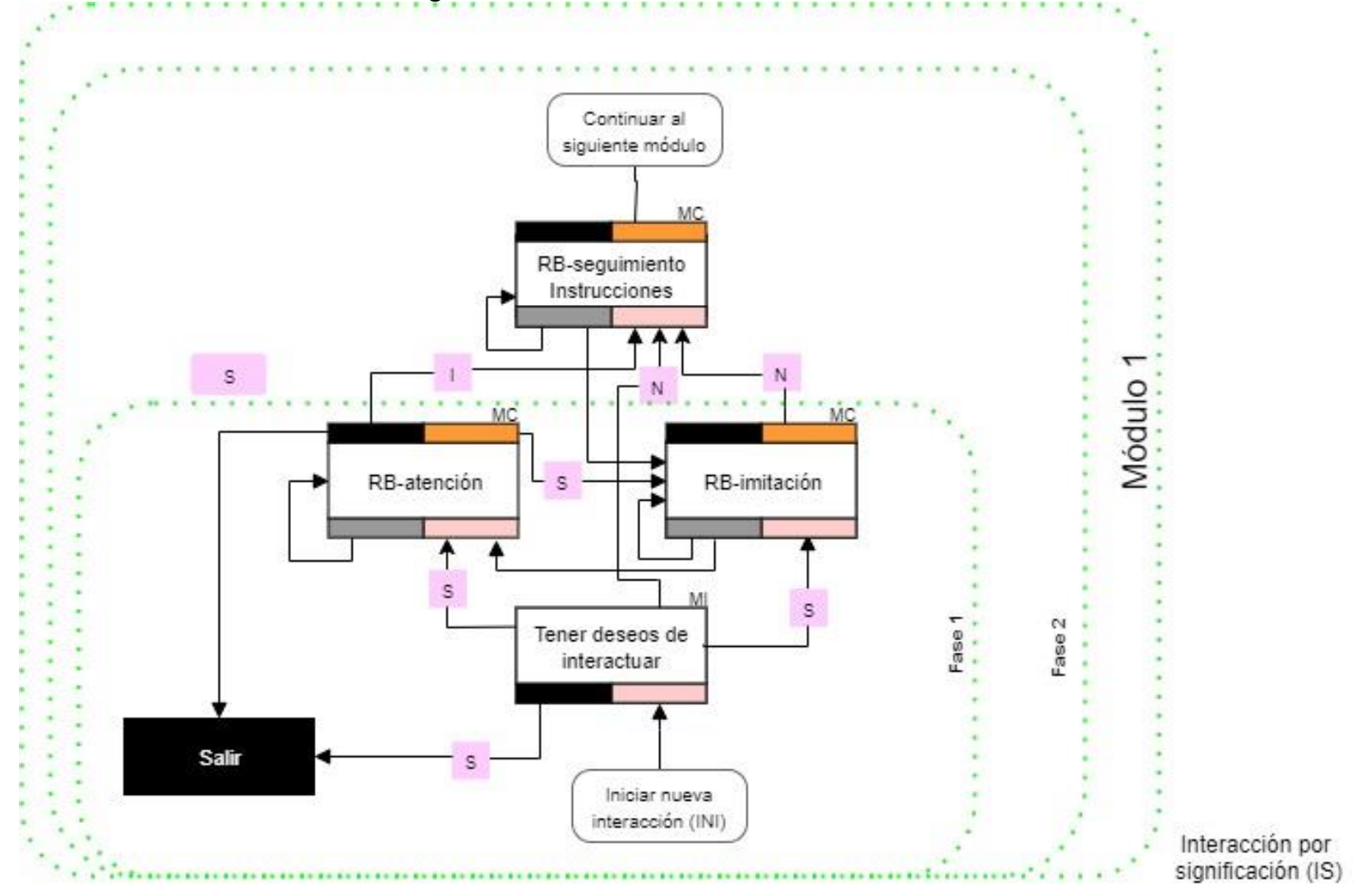

En el Anexo 4 se presenta el diagrama de flujo seccionado para poder ver los detalles del módulo 1 del modelo de interacción y el pseudocódigo correspondiente. 
Figura 55. Diagrama de flujo del módulo 1 del modelo de interacción Módulo 1

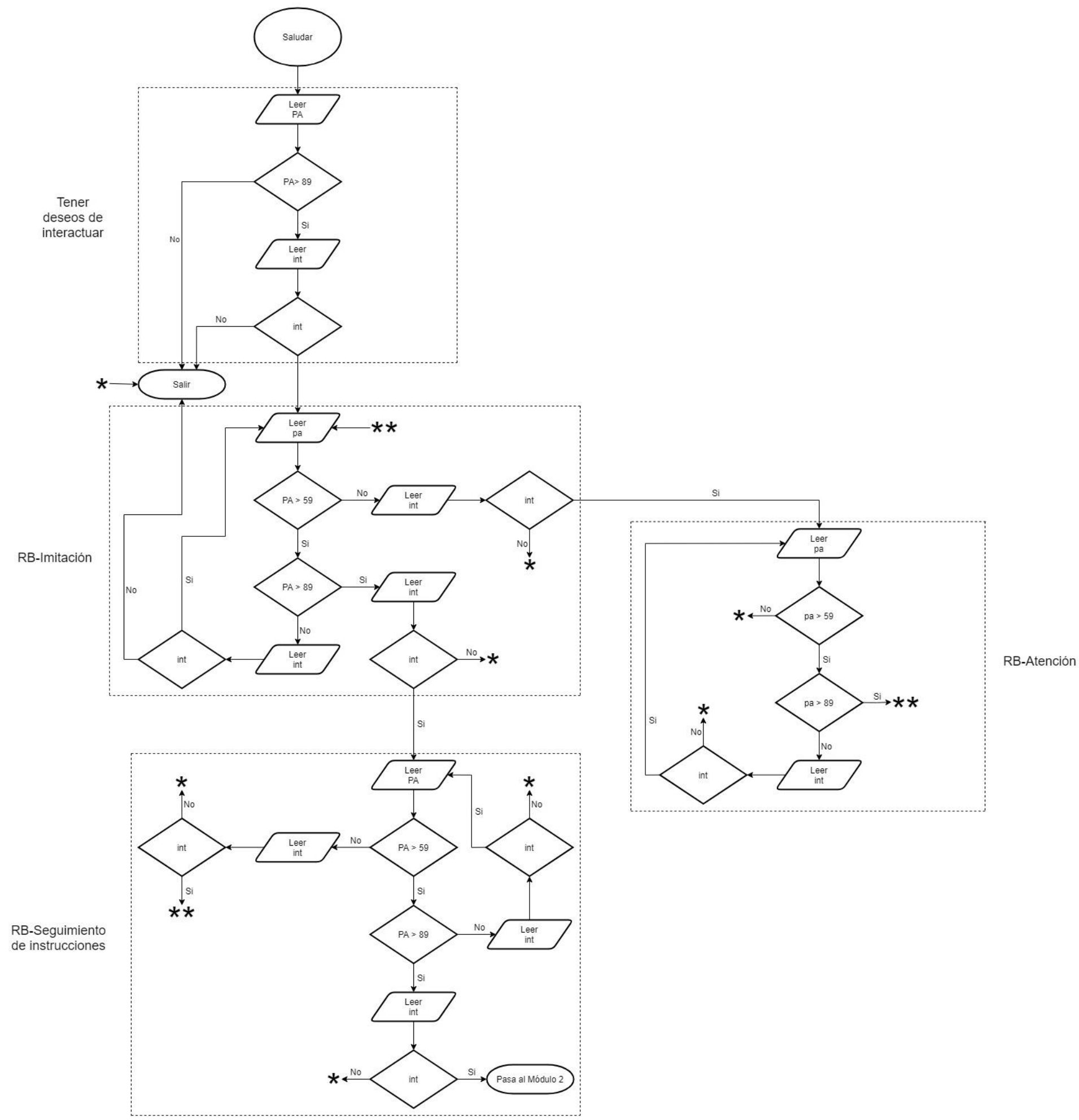




\subsubsection{Módulo de interacción, nivel 2}

En este nivel de interacción se ponen a prueba tres ejercicios básicos que evalúan si hay o no facilidades de parte del usuario para realizar los ejercicios de un nivel superior. Los ejercicios se basaron en el uso de las FE de primer orden en el que se explora el uso de fichas de color, de inhibición y de atención (Tabla 29 y Figura 56 y 57). Las tareas fueron explicadas en el capítulo cuatro.

Tabla 29. Características del modelo de interacción nivel 2 Característica Descripción

\begin{tabular}{ll}
\hline Módulo & 1 \\
\hline Tipo de interacción & Por comunicación \\
\hline Grado de TEA asociado & 1 y 2 \\
\hline Nivel de consciencia & 1 y 2 \\
\hline Tarea & FE de primer orden \\
\hline Ejercicios & FE-1, FE-2, FE-3
\end{tabular}

Figura 56. Módulo 2 del modelo de interacción

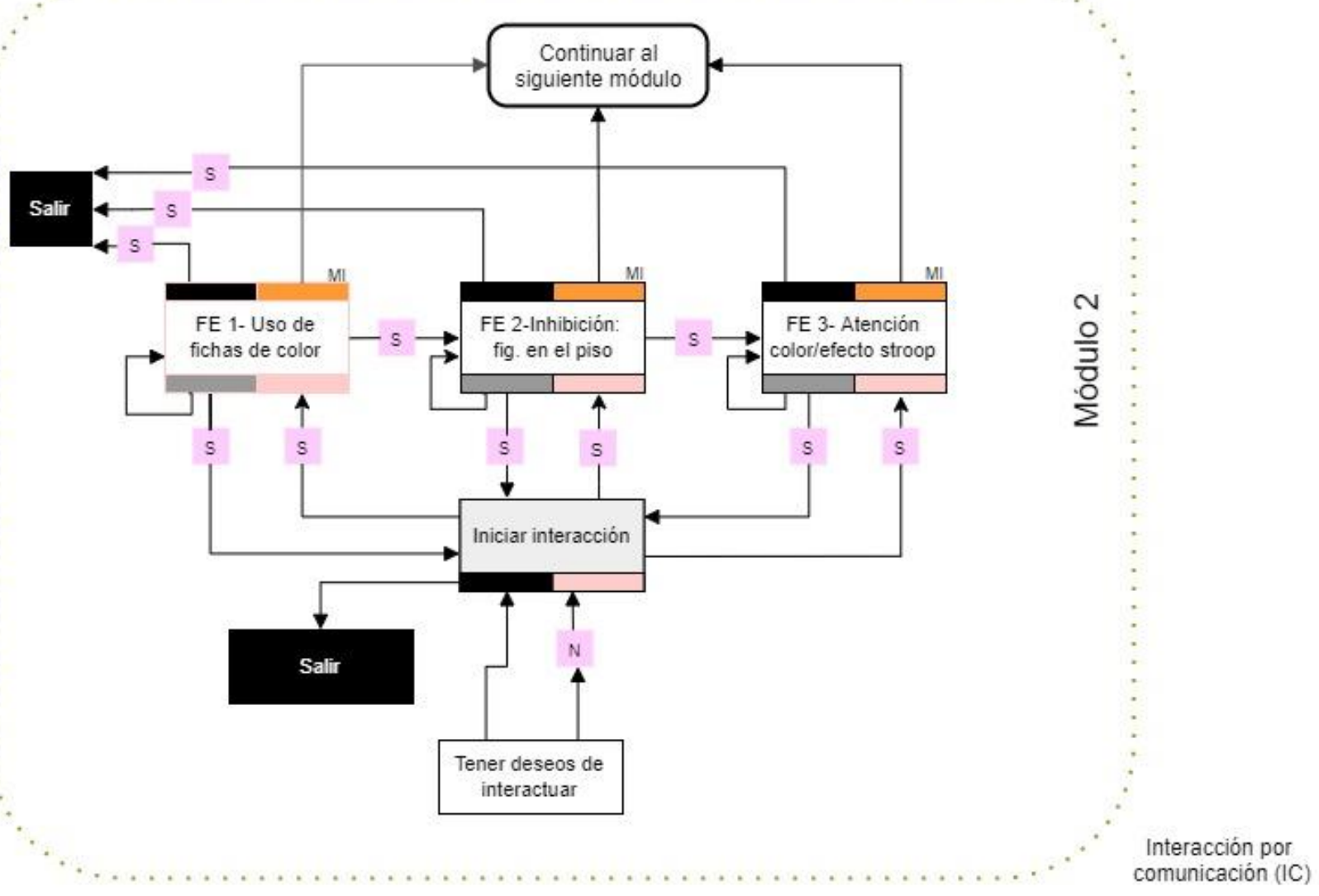

En el Anexo 5 se presenta el diagrama de flujo seccionado para poder ver los detalles del módulo 2 del modelo de interacción y el pseudocódigo correspondiente. 
Figura 57. Diagrama de flujo del módulo 2 del modelo de interacción Módulo 2

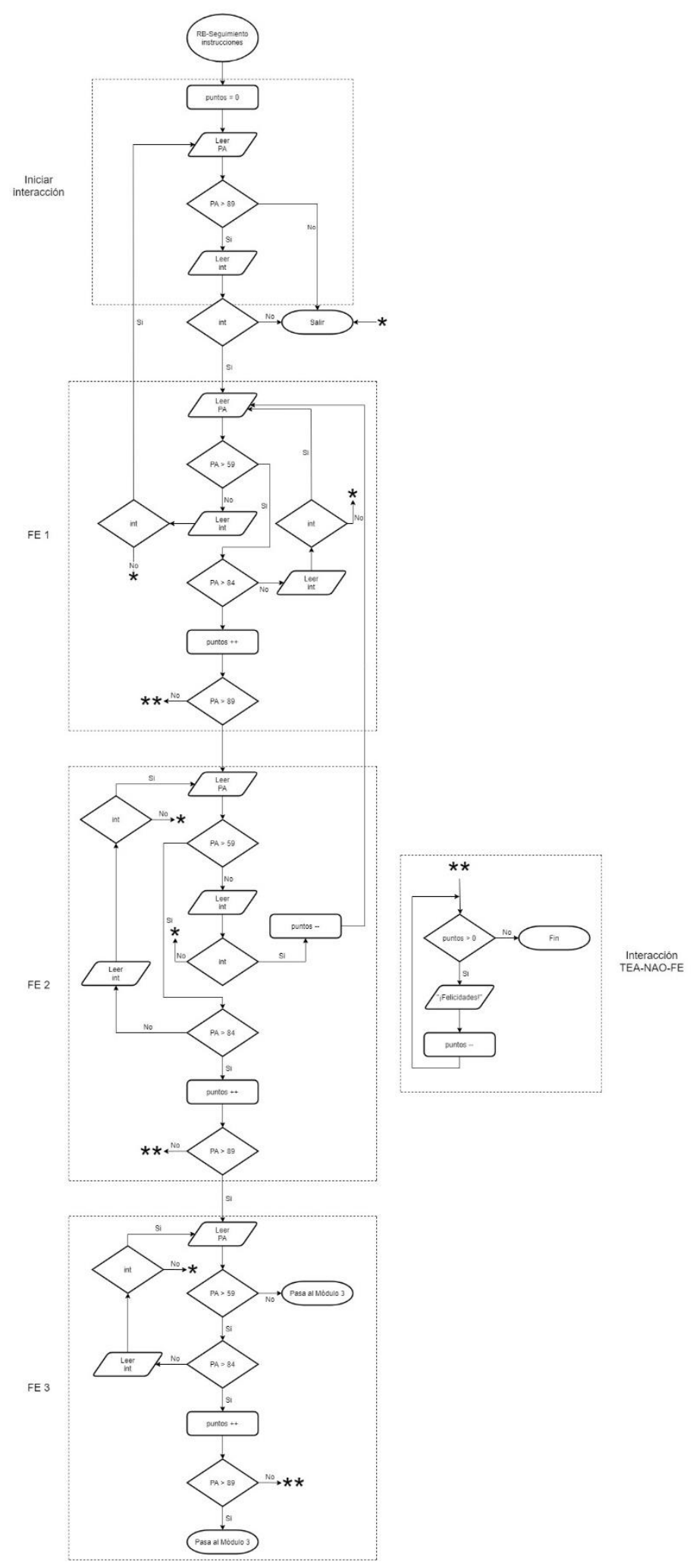




\subsubsection{Módulo de interacción, nivel 3}

El cuarto nivel se caracteriza por la ejecución de tareas de FE de segundo orden. Una particularidad es que estas tareas son escalonadas, por lo que el usuario no puede avanzar si no ha concluido la tarea previa con un PA $>90$. Los ejercicios propuestos se basan en la función ejecutiva 4,5 y 6 (Tabla 30 y Figura 58 y 59). Las tareas explicadas en el capítulo cuatro.

Tabla 30. Características del modelo de interacción nivel 3

\begin{tabular}{|c|c|}
\hline Característica & Descripción \\
\hline Módulo & 4 \\
\hline Tipo de interacción & Por interacciones cognitivo-afectivas con FE \\
\hline Grado de TEA asociado & 1 \\
\hline Nivel de consciencia & 3,4 y 5 \\
\hline Tarea & FE de segundo orden \\
\hline Ejercicios & FE-4, FE-5, FE-6 \\
\hline
\end{tabular}

En el Anexo 6 se presenta el diagrama de flujo seccionado para poder ver los detalles del módulo 3 del modelo de interacción y el pseudocódigo correspondiente. 
Figura 58. Módulo 3 del modelo de interacción

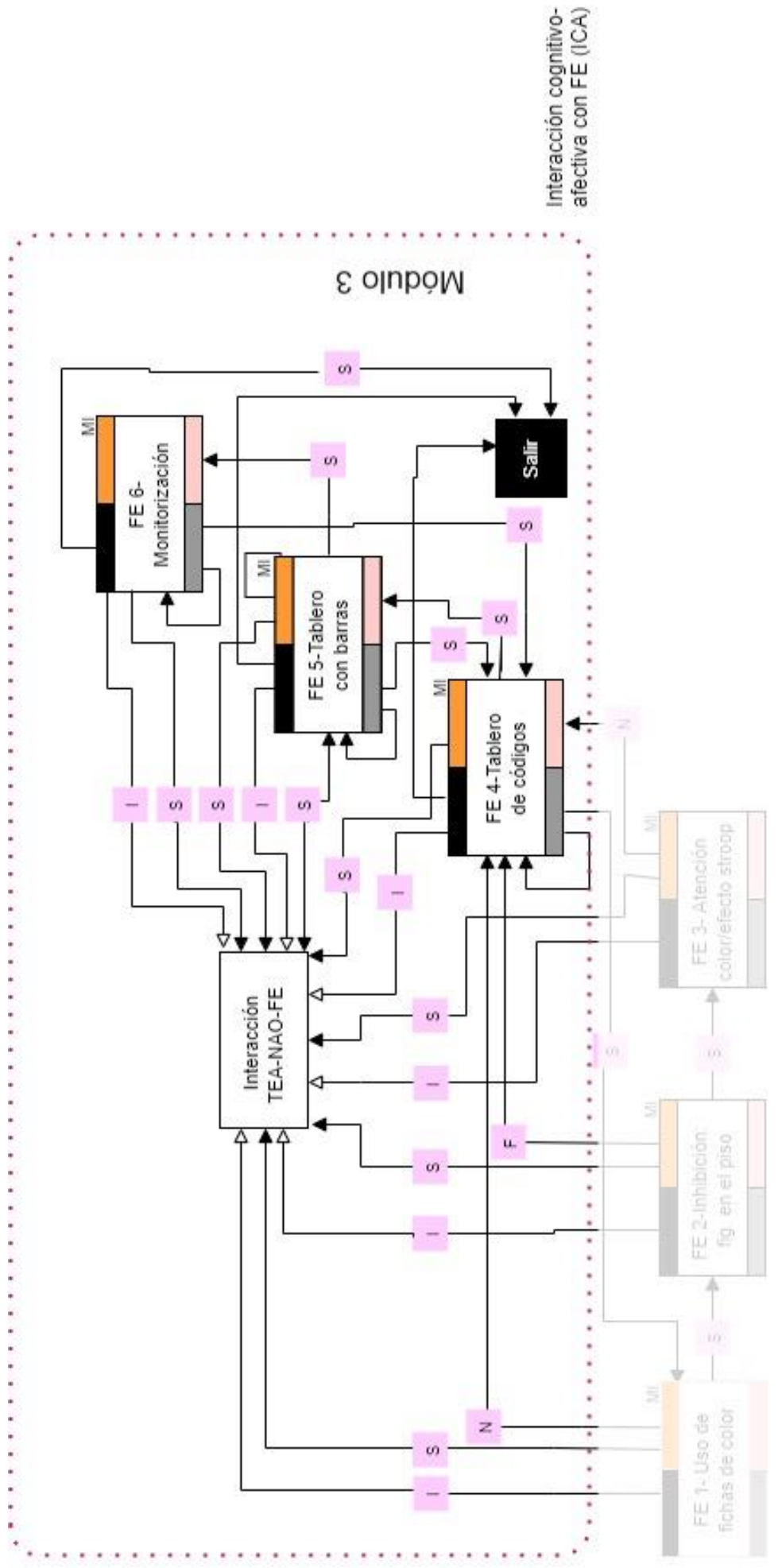


Figura 59. Diagrama de flujo del módulo 3 del modelo de interacción Módulo 3

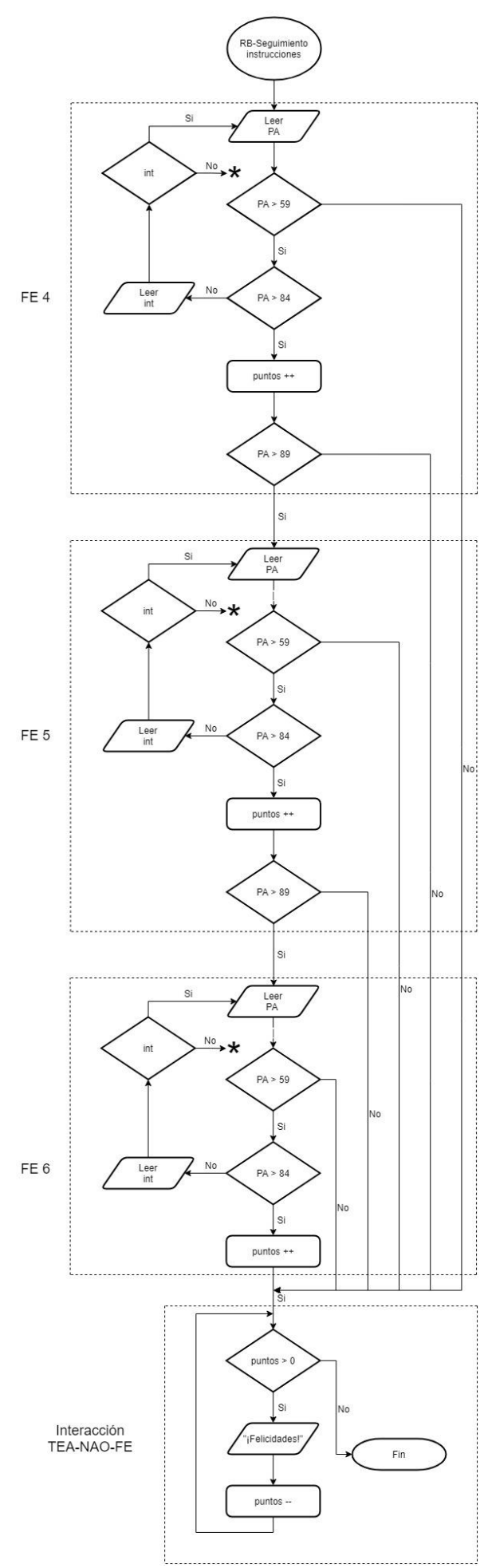




\section{Aplicación del modelo en interacción de niños con TEA y el robot humanoide}

Durante esta fase también se trabajó con el grupo 4. Los niños participantes fueron del Centro de Atención para niños y niñas con Autismo (CANNA) del DIF-Oaxaca. La aproximación a las familias y a los niños se realizó a través de la directora y de la encargada del CANNA. Se solicitaron los permisos adecuados y se contactó a los responsables/familias para identificar las características generales de los niños

\subsection{Etapa de investigación D: comprobar}

De acuerdo con la evaluación de las especialistas de la clínica de autismo del DIF, todos los involucrados fueron diagnosticados con TEA. Sin embargo, para corroborarlo y agruparlos por nivel de gravedad se aplicó la prueba SCQ. Es una prueba rápida diseñada para confirmar problemas de interacción social, dificultades de comunicación y conductas restringidas, repetitivas y estereotipadas (Figura 60).

Figura 60. Relación de etapa de investigación D con el EATR 1

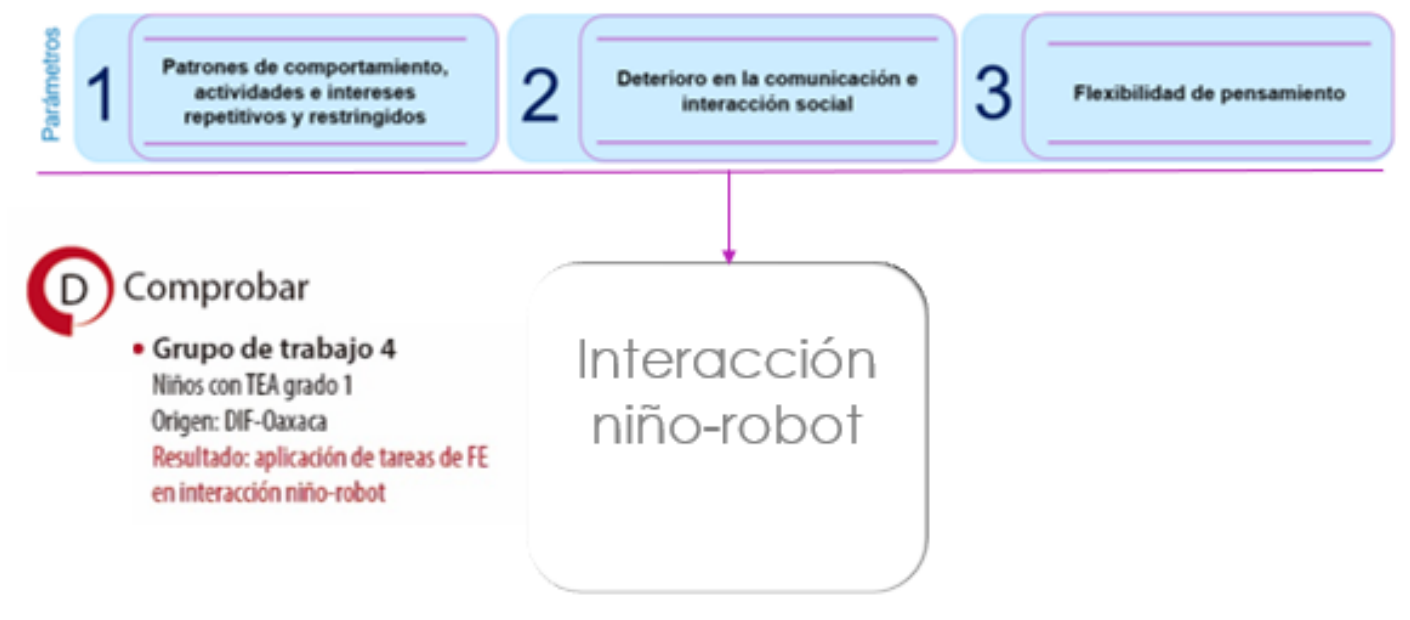

Fuente: elaboración propia

Con este grupo de trabajo se realizaron cinco actividades:

1) Sesión de grupo con todos los participantes para explicarles los objetivos del estudio.

2) Entrevista grupal, cumplimentación del formato con las características generales de los participantes y firma de autorización de participación, 
3) Aplicación de la prueba de SCQ para reafirmar el grado de TEA de los participantes.

4) Evaluación de interacción de los niños con TEA y del robot humanoide. Se evaluaron RB (considerando la misma rutina del grupo 3).

5) Evaluación de interacción de los niños con el robot humanoide, a través de tareas de dificultad creciente de FE asociadas a un esquema de consciencia artificial.

\subsubsection{Análisis de interacción semiótica de niños con TEA y un robot humanoide}

Los niños con TEA rara vez tienen intereses externos que les motiven a seleccionar, organizar e interpretar un estímulo. No obstante, se ha detectado que los robots humanoides son una forma atractiva, interesante y novedosa de llamar su atención (Breazeal, 2003; Hong et al., 2016; Liu et al., 2015; Yun et al., 2016). En la experiencia que se ha tenido de la interacción del robot humanoide con niños con TEA (ver Figura 5 ) se ha detectado que para los niños resulta muy novedoso trabajar con el artefacto. En algunas pruebas se identificó que por su naturaleza el robot es un estímulo atractivo, lo que favorece su papel como guía y como estímulo a imitar. En la Figura 61 se presenta la reacción de dos hermanos gemelos al momento de conocer al robot.
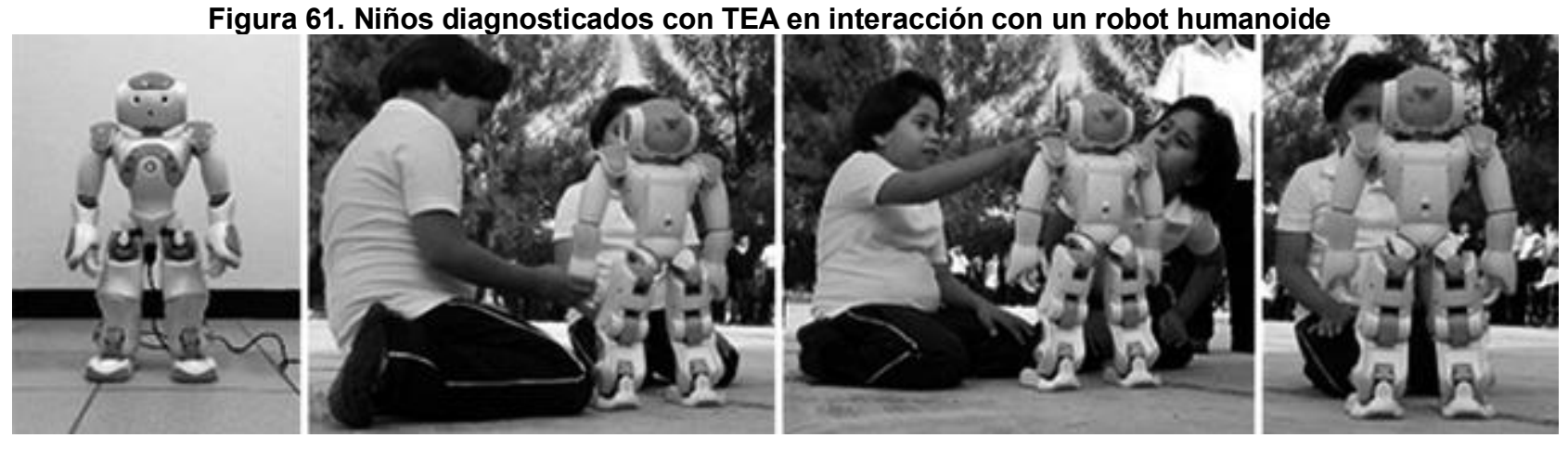

Fuente: Palacios-Villavicencio, 2020.

La sencillez del diseño del robot, las limitaciones de sus gestos y movimientos, no representó un distractor para que los niños se perdieran "perceptualmente" en sus formas, colores o aspecto externo; por el contrario, los niños lograron interactuar y seguir las instrucciones del artefacto (Arias-Aguilar, 2017). Dicha situación colocó al robot como una primera opción para interactuar con los niños. 


\section{Discusión}

Tú y yo somos reales, ¿verdad, Teddy? Los ojos del oso contemplaron al niño sin pestañear.

-Tú y yo somos reales, David.

Estaba especializado en dar consuelo.

Brian Aldiss

El epígrafe anterior corresponde a un fragmento del cuento "Los superjuguetes duran todo el verano", de Brian Aldiss; en él nuestro pequeño protagonista y su oso felpudo son dos androides que hablan, juegan, piensan y sienten. Ambos comparten la soledad humana, ambos se consuelan e ignoran su terrible condición de ser máquinas vivientes. En este cuento, como en la novela ¿Sueñan los androides con ovejas eléctricas?, de Philip K. Dick; la delgada línea entre el mundo artificial y lo natural se vuelve casi invisible.

Al respecto varios pensadores han reflexionado acerca de las relaciones o semejanzas que se puede llegar a tener con un artefacto o máquina. René Descartes en su Tratado del hombre (1633), dice "Hay un alma que razona en esta máquina...". En el texto el filósofo describe la relación dual de la mente y el cuerpo (lo inmaterial y lo material respectivamente). Si bien no fue el primero en definirlo de tal manera, sí fue el primero en asociar su presencia a la dinámica del sistema nervioso. Su propuesta, visto como algo erróneo o acertado, abrió la posibilidad para que la ciencia planteara los compontes de la mente y del cuerpo. Tres siglos después la integración de mente y cuerpo se emplean para recrear objetos inanimados tan sofisticados como los sistemas robóticos de los geminoides.

Una segunda reflexión, “¿pueden pensar las máquinas?”, fue planteada por Alan Turing (1950), con lo cual inició una de las épocas más prolíficas de los avances tecnológicos que había podido crear el ser humano hasta entonces. El planteamiento de Turing dio cabida, entre otras cosas, a la posibilidad de incluir inteligencia a las máquinas. Originalmente era limitada, pero con el tiempo fue incrementado el rango de sus posibilidades de aplicación y alcance, y, sobre todo, gestó la pauta para la creación de dos grandes paradigmas: la inteligencia artificial (FernándezCaballero et al., 2006) y, tres meses más tarde, la ciencia cognitiva (Varela et al., 1997).

Una tercera reflexión, “¿pueden sentir las máquinas?”, fue planteada por Rosalind Picard en su libro Affective computing (Picard, 1997). La investigadora plantea por primera vez la posibilidad de que una máquina - además de pensar - incorpore la información que subyace a las emociones como parte de su proceso de toma de decisiones. 
Estas tres ideas reflexivas son enfatizadas debido a que se relacionan con las bases de los elementos desarrollados en esta tesis que involucra cuatro áreas de la conducta: 1) cognición, 2) emociones, 3) consciencia, y 4) la interacción. Todas ellas enfocadas en el comportamiento de niños con trastorno del espectro autista (TEA) en el uso de sus FE suscitadas a partir de interacciones con un robot humanoide. En este último apartado de discusión y conclusiones se inicia con la integración de los elementos de anclaje teóricos referenciales. Estos se presentan como los nodos centrales de la tesis expuesta a lo largo de estas 200 páginas, y que son el soporte teórico de la investigación que se presenta articulada a partir de los cinco EATR.

Se inicia con la especificación de la caracterización diagnóstica. Como se mencionó en el EATR 1, actualmente el diagnóstico de las personas con TEA incluye tres niveles de gravedad que son definidos por el nivel de apoyo que requieren las personas para ser independientes en el ámbito social, y en los comportamientos restringidos y repetitivos (ver Tabla 2). El nivel de menor afectación es el nivel 1, está determinado porque en este nivel, en el ámbito de la comunicación y la socialización, las personas solo "requieren ayuda". El segundo nivel tiene gravedad media. Se determina porque las personas "requieren ayuda notable. Y el tercero, el de mayor afectación, se determina porque necesitan ayuda muy notable (Asociación Americana de Psiquiatría, 2014, p. 125).

Como se presentó en la investigación, se trabajó con los tres niveles con el fin de tener un panorama amplio del comportamiento que tenían cada uno con las tareas que se les asignaban. No obstante, solo los niños del nivel 1 fueron considerados para la última etapa, debido a las habilidades de éstos para realizar las actividades de las FE más complejas. Los criterios que se emplearon para obtener la muestra y para determinar el nivel en el que se encuentran se describe en el capítulo tres de la metodología.

Considerando que cada nivel tiene limitantes específicas, fue importante determinar criterios del diseño universal e inclusivo (ver 3.1.1) para el diseño de tareas, ejercicios y materiales que se emplearían durante las interacciones. Sobre todo, en el aspecto de la flexibilidad adecuada a las habilidades individuales de los niños. Por lo que se considera que los materiales deben ser simples, intuitivos, fáciles de entender, de percibir y de manipular por los niños de cualquiera de los tres niveles de TEA. Se determinó además que los instrumentos requirieran un mínimo esfuerzo físico, emplear tamaños adecuados, uso cómodo y eficiente.

En el aspecto teórico, y como parte de la delimitación semántica, se consideraron tres de las teorías expuestas para sustentar la investigación (3.1.3.4): 1) Teoría de la Mente (ToM) (3.1.3.5), enfocada en la capacidad de las personas de atribuir estados mentales a sí mismos o 
a otros; 2) Teoría de la empatización-sistematización (3.1.3.6), centrada en la capacidad de identificarse con alguien y compartir sus sentimientos, y 3) teoría de la disfunción ejecutiva (3.1.3.7) (Ahmed \& Stephen Miller, 2011; Ozonoff et al., 1991), asociada a la "capacidad de mantener un conjunto apropiado de resolución de problemas para alcanzar una meta futura" (Ozonoff et al., 1991, p. 1083).

De la primera se consideró el nivel cognitivo-social basado en la comprensión conceptual de la mente como sistema de representación, y el nivel social-perceptual o empático, éste último relacionado al sistema afectivo que integra el juicio rápido del estado mental de otro a partir de sus expresiones faciales, gestos, tono de voz, movimientos y acciones (Pedreño et al., 2017, p. 2402).

La segunda se usó como un complemento de la ToM, debido a que es importante responder emotiva y congruentemente ante lo que se observa del otro de una manera empática (Gross, 2012, p. 479). De esta teoría se consideraron sus componentes cognitivo y afectivo (Warrier \& Baron-Cohen, 2018). Primero hay un reconocimiento visual del estado mental de otra persona y, después, una respuesta al estado mental del otro. Esta teoría se basa en estudios de neuropsicología cognitiva y fue la base de la descripción de las FE retomadas en el EATR 3.

En el EATR 2 se exploraron las posibilidades de interpretar y construir la totalidad de la realidad circundante de las personas con TEA dentro del proceso de comunicación. Para ello se propuso un análisis del uso de los signos, involucrado en el encadenamiento de las ideas a partir de la significación del mundo asociado a dos líneas de aplicación: 1) el desarrollo de la propuesta semiótica de Charles Sanders Peirce $(1974,1987,1998)$, como base explicativa del proceso de significación, y 2) la división más elemental de los signos propuesta por Umberto Eco (1989): impronta o huella, indicio y síntoma (3.2.2).

Los elementos constituyentes de la propuesta de Peirce $(1974,1987,1998)$ parten de una triple relación: consigo mismo, con el objeto al cual alude y con el interpretante (Zecchetto, 2005). Al respecto McNabb (2018), basándose en Peirce, menciona que todo lo que hay alrededor nuestro son signos que "representan algo y significan algo. Lo que representan es el objeto y lo que significan es el interpretante". Cuando ese interpretante es compartido se genera el intercambio comunicacional, por lo que se emplea dicha teoría para explicar cómo se lleva a cabo el intercambio de comunicación de los niños con TEA.

Como se revisó en el capítulo 4, tanto la aportación de Peirce como la de Umberto Eco fueron utilizadas para clasificar los niveles de interacción de los niños con TEA con el robot humanoide. Con base en la semiótica de Peirce $(1974,1987,1998)$, la división de los signos en 
tricotomías se desgloso para explicar cómo se lleva a cabo el proceso de significación. Así, a mayor conocimiento de los signos, mayor posibilidad de uso en la recepción, expresión y comunicación. Estos parámetros se asociaron a los niveles de gravedad de los niños con TEA, y a la división más elemental de los signos propuesta por Umberto Eco (Eco, 1989), como se explicó en el EATR 2.

En el EATR 3 se enfatizó la coparticipación de la cognición, los niveles de consciencia y las FE. Los tres, junto con las emociones, forman parte de un proceso que inicia con la percepción, y la atención, para facilitar la toma de consciencia del sí mismo y del ámbito circundante (Grondin, 2016). En ese proceso, la filtración de la información relevante, la capacidad para sostenerla, y manipularla, son la base para iniciar, primero, con la toma de consciencia, después, con la activación de un proceso cognitivo que dé pauta al uso de las FE en diferentes niveles y, finalmente, guiar las decisiones pertinentes (Stuss y Benson en TirapuUstárroz et al., 2005).

De acuerdo con las modalidades sensoriales se expusieron las características de los objetos. Éstos influyen en la percepción con el fin de fijar las directrices del diseño de los materiales que se emplearían en la interacción de los niños con el robot humanoide (3.3.1.3).

En otro orden de ideas, pero en el mismo EATR, se definieron operacionalmente las FE (3.3.2.1) usadas durante las pruebas de interacción. Las FE son entendidas como el "conjunto de procesos responsables de dirigir, guiar y controlar las funciones cognitivas, emocionales y conductuales" (Gioia et al., 2015). El parámetro para evaluarlas operativamente fue a partir de las pruebas de evaluación conductual de la función ejecutiva con BRIEF-2 (Gioia et al., 2015), y de la batería neuropsicológica de FE y lóbulos frontales BANFE-2 (Flores et al., 2014). Una de las grandes implicaciones de las FE es su relación con la consciencia, permitiendo inferir el grado de ésta en niños con TEA, y el uso o su facilidad para aplicar las FE.

A su vez, los rangos de consciencia parten de los datos ofrecidos por la neurología; la cual señala las siguientes categorías: inconsciencia, consciencia residual y consciencia, dividida en sueño y vigilia (3.3.3). Estos tres son explicados, primordialmente, a partir del modelo del espacio de trabajo neuronal global (3.6.1.1) que se relacionan, además, con los modelos de consciencia artificial.

De la consciencia artificial, se consideraron dos aportaciones: 1) Marvin Minsky (2006) (ver Figura 14), y 2) e Igor Aleksander (2005, 2009). Ambas se basan en el análisis de la consciencia humana para aplicarla a la consciencia artificial. Sin embargo, en esta investigación no se propone la implementación a nivel artificial, sólo se consideraron para analizar la conducta 
de los niños en interacción. M. Minsky (2006) describe seis niveles de conducta que explican el reflejo de la consciencia que va de un sistema de comportamiento instintivo-emotivo hasta un sistema de valoración social cognitivo-afectivo.

En cuanto a Aleksander (2005, 2009), se retomó la definición operativa de los axiomas que describen cinco elementos de la consciencia traducidos como mecanismos neuronales que indican: "presencia, imaginación, atención, volición y emoción" (2009, p. 25). A partir de estos se define la condición de uso, la condición de aplicación, la aplicación práctica, los módulos de interacción asociados a las FE y el mecanismo requerido para comprobar que el axioma se pone en práctica durante la interacción de los niños con el robot humanoide.

Examinando los elementos expuestos en el EATR 4, se representan los paradigmas de la interacción humano-robot que explican los modelos mentales que subyacen de la percepción de las personas cuando interactúan con un robot. Partiendo de que el robot humanoide es definido como un robot sociable (debido a sus características antropomórficas). En este mismo EATR se exponen algunos robots que se han empleado para la interacción de niños con TEA y se definen algunas características del robot humanoide NAO, mismas que se amplían en la parte metodológica e instrumentos de evaluación. Hasta este punto, todo el marco teórico referencial sirve para establecer un modelo de interacción cognitiva; sin embargo, con el fin de complementar la explicación de la interacción, en el EATR 5 se presentan las bases para una posible interacción cognitivo-afectiva, a futuro.

En este último elemento teórico referencial se establece la relación de las emociones en el contexto de la cognición desde sus aspectos neurológicos, fisiológicos y psicológicos (Damasio, 1999; Gross, 2012; Halty et al., 2011; Jain \& Asawa, 2019). También se consideró el de la inteligencia artificial, particularmente desde la computación afectiva (3.6.1) en donde se clasifican como emociones categóricas, componenciales y dimensionales (Ekman, 1992; Ekman \& Oster, 1981; Lisetti \& Hudlicka, 2015; Moerland et al., 2018; Mora-Torres, 2015; Mora-Torres et al., 2011; Scherer, 2018) relacionadas a la conducta y a las reacciones observables.

De las emociones categóricas, se retoma la propuesta de Paul Eckman $(1992 ; 1981)$ cuya propuesta considera que existen emociones básicas asociadas a expresiones faciales como miedo, alegría, temor, enojo, sorpresa y asco.

Como base de aplicación, que se deja como un trabajo futuro, desde el enfoque de las emociones componenciales, se queda el modelo cognitivo OCC de Ortony, Clore y Collins (Jain \& Asawa, 2019; Laureano-Cruces et al., 2018; Lisetti \& Hudlicka, 2015; Mora-Torres, 2015; Ortony et al., 1996; Ramírez-Laureano et al., 2018) que podría ser aplicado a la interacción. 


\subsection{Integración gráfica de conceptos clave}

A manera de resumen dirigido hacia las conclusiones, en la Figura 64 se hace una recapitulación de los cuatro elementos de anclaje teórico referenciales planteados hasta este momento. Se trata de una ampliación de la Figura $12^{51}$ en la que se muestra gráficamente la relación de los estados de consciencia asociados a los conceptos clave de la tesis que se sustenta:

1. Alcance de los elementos de anclaje teórico referenciales

a. IIT y P: Teoría de la información integrada (aportación neurológica) y teoría semiótica de Peirce (aportación semiótica)

b. TENG: Teoría del espacio neuronal global (aportación neurológica)

c. MM y E: Propuestas de Marvin Minsky (aportación de Inteligencia artificial) y Umberto Eco (aportación semiótica)

d. IA: Igor Aleksander (aportación de Inteligencia artificial)

e. ToM, E-S y OCC: teoría de la mente, teoría de la empatización-sistematización (aportación de las teorías del TEA) y teoría de Ortony, Clore y Colins (aportación de Inteligencia artificial)

2. Activación del despertar de la consciencia en vigilia

3. Niveles de conducta a partir de las reacciones instintivas, FE y metacognición

a. Comportamiento instintivo-emotivo

b. Índice conductual

c. Índice de control emocional

d. Índice cognitivo

e. Valoración social cognitivo-afectivo

f. Metacognición

4. Niveles de interacción niño-robot

51 La ubicación de los estados de consciencia de Laurey consideraron una aproximación del nivel de alerta, sin embargo, el equipo del Instituto de Stanford para neuroinnovación y neurociencia (2020) los reubicó con ligeras modificaciones a partir de los correlatos neurológicos detectados por medio del registro encefalográfico. Considerando esa base, la ubicación de los elementos de la activación del despertar de la consciencia en vigilia, del alcance de los elementos de anclaje teórico referenciales y de las funciones ejecutivas, las determiné sólo de manera jerárquica de acuerdo con lo que refieren las teorías y literatura consultada. En el caso de los niveles de interacción niño-robot, éstos fueron determinados a partir de la literatura, y fueron complementados por la observación que hice de las conductas de éstos durante las interacciones humano-humano y niño-robot. Este último aspecto se explica ampliamente en los capítulos cuatro y cinco. 


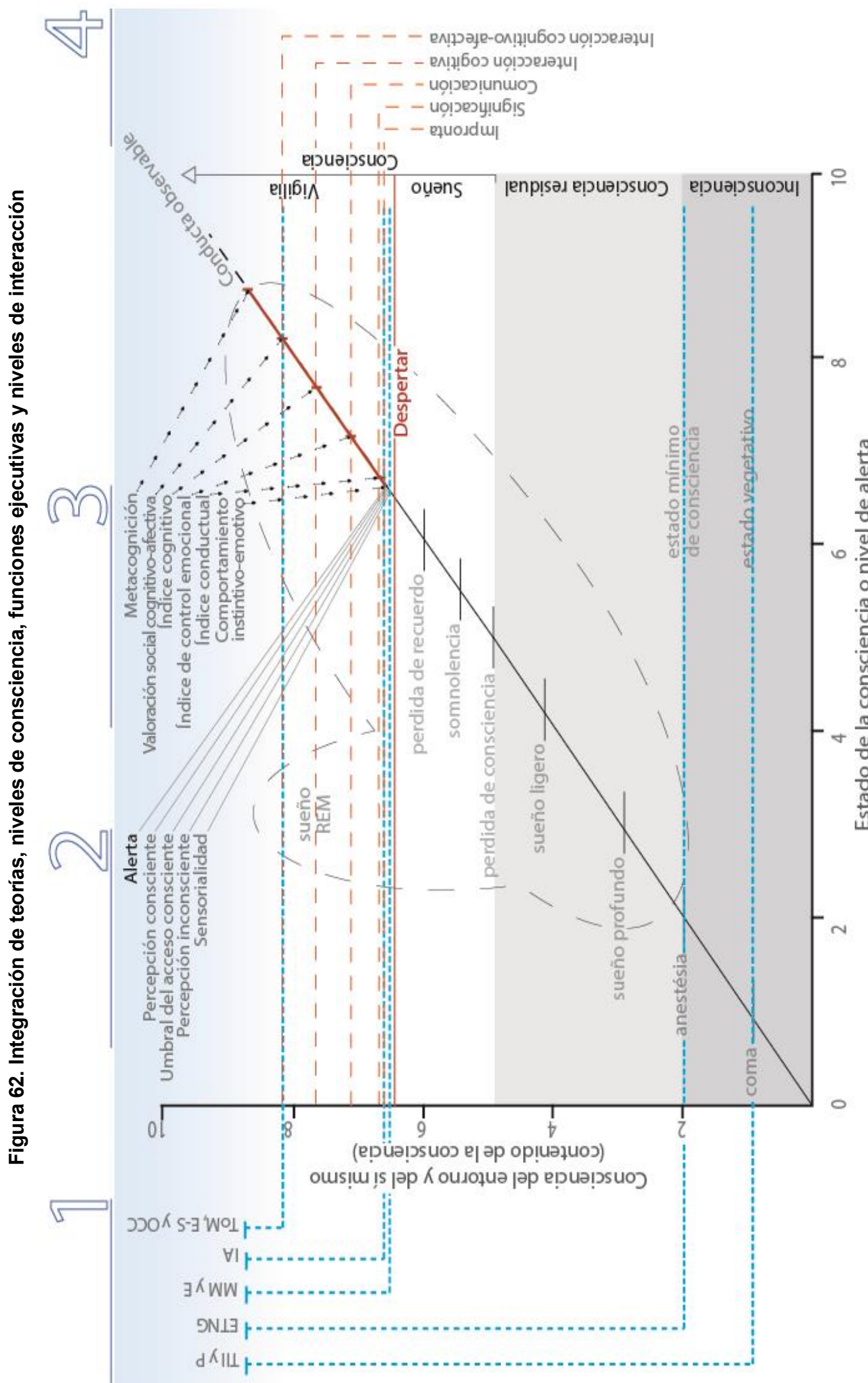

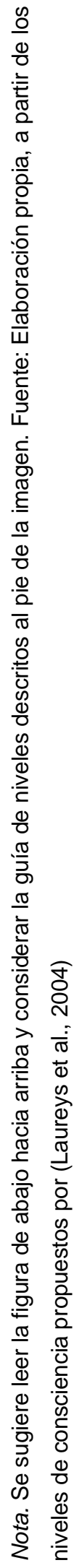




\subsection{Alcance de los elementos de anclaje teórico referenciales}

Como parte del alcance de los elementos de anclaje teórico referenciales se presentan las teorías más relevantes para analizar los niveles de interacción entre los niños y el robot humanoide. Dichos postulados fueron explicados en distintos EATR; en la Figura 64 se integran para mostrar el alcance que tiene cada una de acuerdo con los datos revisados de las propias teorías ${ }^{52}$. La nomenclatura para identificar las teorías en la ilustración es:

1. IIT y P: Teoría de la información integrada (aportación neurológica) y teoría semiótica de Peirce (aportación semiótica)

2. TENG: Teoría del espacio neuronal global (aportación neurológica)

3. MM y E: Propuestas de Marvin Minsky (aportación de Inteligencia artificial) y Umberto Eco (aportación semiótica)

4. IA: Igor Aleksander (aportación de Inteligencia artificial)

5. OCC, ToM y E-S: Teoría de Ortony, Clore y Colins (aportación de Inteligencia artificial), Teoría de la Mente y empatización-sistematización (ambas teorías del TEA)

Una de las teorías de mayor alcance para analizar el nivel de consciencia de una persona (no necesariamente con TEA), es la teoría de la información integrada (IIT), propuesta por Guilo Tononi (Koch, 2018; Oizumi et al., 2014; Tononi, 2015). Como se explicó previamente (EATR 3) la exploración de la consciencia se lleva a cabo a partir de la estimulación masiva provocada por un pulso de energía magnética aplicada sobre el cráneo que arroja datos mapeados de acuerdo con las zonas estimuladas. La técnica ha permitido comparar la respuesta de personas despiertas con plena consciencia, en estado vegetativo, en personas catalogadas con estado mínimo de consciencia e, incluso, con personas que están conscientes, pero no pueden comunicarse con los demás (Koch, 2018).

La teoría IIT podría ser de gran utilidad si se mapeara el nivel de consciencia de las personas con TEA mientras están presentes ante estimulaciones sensoriales externas, pero no responden a menos que encuentren algo verdaderamente interesante para ellos. Por ejemplo, en una de las exploraciones de activación sensorial táctil que se realizaron con niños con diversas

\footnotetext{
52 Es importante mencionar que no todas las teorías se han integrado directamente en la investigación. Sin embargo, las he incluido debido a que a través de ellas se podría llegar a explicar de mejor manera la conducta que subyace en las personas con TEA mientras realizan tareas específicas o cuando sus sentidos son estimulados y éstos no responden, como ocurre con muchos niños pequeños con TEA del nivel tres.
} 
discapacidades en 2011 (Palacios-Villavicencio \& Olivos Contreras, 2011), una de las niñas con TEA (grado 3) no respondió en absoluto a ninguna de las estimulaciones táctiles a las que se sometió. Ante todos los estímulos su respuesta fue nula, sin movimiento voluntario alguno. Sin embargo, uno de los materiales (harina de fécula de maíz) le produjo tanta alegría que aprendió a identificar en dónde estaba colocado el material para ir en su búsqueda. Dicho material, le atrajo tanto que lograba promover una conducta con intención y estrategia para ponerse en contacto nuevamente con el material cuando estaba fuera de su alcance. En casos como éste, la técnica descrita por la teoría IIT podría ser de gran utilidad porque no requiere que el individuo en estudio tenga una participación voluntaria para determinar su nivel de consciencia.

La segunda teoría, incluida al mismo nivel de la IIT, es la teoría semiótica de Peirce (1894, 1987, 2003) descrita en el EATR 2. De acuerdo con ella, el mundo circundante toma sentido y por lo tanto es significativo para alguien cuando algún estímulo externo o interno logra ser interpretado como signo de algo y, a su vez, significa "algo" para ese "alguien". Desde la triada explicada por Peirce, los signos pueden adquirir características básicas desde la percepción de una cualidad, un hecho en bruto o leyes que surgen de las dos primeras.

De acuerdo con la teoría de Peirce (Peirce, 1987), en el momento en el que alguien responde a una cualidad de lo que percibe externa o internamente podría estar ante un ejemplo de consciencia. En el caso de las personas que están en coma, o que tienen estado mínimo de consciencia, la consciencia (valga la redundancia) podría ser medida a partir de las cualidades percibidas. En las personas con TEA, cuando parecen quedarse con los pensamientos suspendidos ante una crisis epiléptica de ausencia $^{53}$ la detección de su percepción de las cualidades o los hechos en bruto que perciban podrían ser útiles para determinar qué tan conscientes son de lo que perciben mientras están en ese estado. Estas dos teorías, las de IIT y la de Peirce, son identificadas en la Figura 64 como "IIT y P".

La teoría ETNG propuesta por Dehaene $(2011,2017)$ se fundamenta en evidencias neurológicas (Baars, 1988; Barttfelda et al., 2015; Dehaene \& Changeux, 2011) para explicar que la consciencia es el proceso global en el que, de manera masiva y ordenada, el cerebro comparte información entre sus áreas asociativas: de percepción, motoras, de atención, de memoria y de valoración (Figura 13). A través de éstas se accede al espacio de trabajo global. De acuerdo con su sustento teórico, por medio de las conexiones sinápticas se almacena la información que

${ }^{53}$ Este tipo de crisis suele ser recurrente en las personas con TEA, principalmente niños. Y se presenta como una suspensión súbita de la actividad quedando como si se estuvieran ausentes (Muñoz Yunta et al., 2006). 
guardan las bases de la intuición (2015, p. 243). Siendo esta condición una particularidad de las personas con TEA a quienes frecuentemente les cuesta trabajo intuir y anticiparse a lo relacionado con otras personas. Otro aspecto relevante de esta teoría es que los procesos cognitivos que requieren consciencia se asocian a representaciones mentales en la memoria de trabajo, activación de un procesamiento estratégico y presencia de comportamiento espontáneo intencional Rohaut y Naccache (2017). Aspectos que también pueden ser considerados como una carencia en algunas personas con TEA ante determinadas tareas de complejidad mayor. En la Figura 64, el alcance de la teoría del ETNG inicia con la estimulación sensorial cuando la percepción es inconsciente.

El siguiente nivel de profundidad marcado en la Figura 64 (línea punteada verde), determina la descripción de la consciencia de acuerdo con la propuesta de Marvin Minsky (Minsky, 2006) que, como se describió en el apartado 3.3.3.4, parte de los impulsos instintivos e innatos al que se le denomina sistema de comportamiento instintivo-emotivo hasta el sistema de valoración social cognitivo-afectivo. Su aplicación se consideró debido a que, si bien describe el comportamiento ordinario de las personas regulares, estos niveles podrían estar asociados a los grados descritos de los TEA en el DSM-5. Así, los niños con TEA grado 3 se encontrarían predominantemente en el sistema de comportamiento instintivo-emotivo. A medida que van madurando atraviesan por los otros niveles descritos por Minsky (ver Figura 14), hasta llegar al nivel de sistema de valoración social cognitivo-afectivo (grado 3 de TEA) en el que se conjugan los aspectos aprendidos e introyectados socialmente con el uso de las FE frías o cognitivas descritas en la sección 2.3.

En la Figura 64 se incluye la propuesta de Umberto Eco $(1976,1989)$, quien desde la semiótica expone tres tipos de signos elementales: la impronta, los indicios y los síntomas. De los cuales, la impronta (el más elemental de ellos) se basa en el procesamiento automático de una expresión-tipo (de algo que se percibe) que es relacionado con una posible causa física. Determinando que la interpretación de eso que se observa dependerá de la experiencia de las personas para aceptar o rechazar de manera automática algo que perciben, considerando el criterio de que les atrae o que les disgusta, como ocurre con las personas con TEA cuando aún al no haber entrado en contacto con ciertas cosas de manera casi instantánea lo aceptan o lo repelen.

El siguiente nivel de profundidad de la Figura 64 se determina a partir del método axiomático / introspectivo de Igor Aleksander (2005, 2009) que descompone el concepto de ser consciente en "elementos que tienen transiciones razonablemente claras en arquitecturas 
neuronales" (Aleksander, 2009, p. 22), y que indican: "presencia, imaginación, atención, volición y emoción" (2009, p. 25). Estos axiomas inician con el estado de alerta marcado en la Figura 64, y se presentan por niveles jerárquicos de aplicación a la conducta de niños con TEA como se presenta en el apartado 3.3.3.5.

El último nivel de profundidad asociado a las teorías que se presentan en la Figura 64 corresponde a las teorías desarrolladas para explicar el Trastorno del Espectro Autista: ToM o teoría de la mente y E-S empatización-sistematización explicadas en el apartado 3.1.3.4 (ver Figura 5). La otra teoría considerada en este nivel es la OCC descrita por Ortony, Clore y Colins (Ortony et al., 1996), la cual ha sido desarrollada como un modelo cognitivo-afectivo por LaurenoCruces (Laureano-Cruces et al., 2013, 2015, 2018, 2019) y Mora-Torres (Mora-Torres, 2015; Mora-Torres et al., 2011, 2014). Rosalind Picard (1988) comenta que el enfoque de OCC se ha considerado en sí mismo un modelo de apreciación cognitiva, en el que se representan las emociones a partir de la agrupación de éstas, de acuerdo con las condiciones cognitivas que las generan. Es posible emplear dicho modelo debido a que en las personas con TEA se pueden relacionar con las $\mathrm{FE}$ cognitivas o frías que se presentan en situaciones en las que las personas son capaces de relacionar los acontecimientos, agentes y objetos (Mora-Torres et al., 2014, p. 18) con sus posibles consecuencias (ver Tabla 12).

\subsection{Activación del despertar de la consciencia en vigilia ${ }^{54}$}

Como se mencionó en el EATR 3, la consciencia es un proceso continuo. A partir de datos neurológicos (Gosseries et al., 2014; Laureys et al., 2004, 2007), se ha detectado en personas que están en estado de coma y en personas que llegan a un nivel alterado de consciencia en donde hay una expansión de la mente. A partir de la propuesta de Laureys (2004) en la que se representa el estado de la consciencia (nivel de alerta) y el contenido de la consciencia (consciencia del entorno y del sí mismo), esbozo la adaptación de los parámetros que se emplean de los EATR para desarrollar los niveles de interacción de niños con TEA con un robot humanoide mientras ponen en práctica sus FE.

Con base a la literatura (Dehaene et al., 2011; Tononi, 2015) se determinó que la activación del despertar de la consciencia en vigilia es el primer elemento que se considera clave para la interacción, esto se debe a que es a partir del estado de alerta que las personas están en

\footnotetext{
${ }^{54}$ El despertar de la consciencia también puede presentarse durante el sueño (Laureys et al., 2007) y es considerado como un estado alterado o especial.
} 
un estado óptimo para poner atención a los estímulos circundantes. Como se explica en el capítulo cinco, para poder iniciar una interacción con un niño con TEA lo primero que se debe revisar es que su nivel de alerta esté activo y sea suficiente en ese momento de poner atención. Este primer paso aplica para los tres niveles de gravedad del TEA.

La activación del despertar de la consciencia es una transición entre el sueño y la vigilia. Se presenta después de que hay una estimulación sensorial interna o externa que, a su vez, activa el sistema de percepción inconsciente, en el que, si la estimulación es suficientemente relevante para el organismo se llega al umbral de acceso consciente activando la percepción consciente y llegando al estado de alerta. En las personas con TEA, el estar despierto no necesariamente los pone en un estado de alerta. Algunos de ellos, sobre todo del nivel de gravedad tres, si la estimulación circundante o la de sí mismos no es suficientemente relevante, ellos pueden estar despiertos, pero sin activar su estado de alerta.

\subsection{Niveles de conducta a partir de las reacciones instintivas, FE y metacognición} El tercer concepto clave de la tesis representado en la Figura 54, son las FE. Éstas fueron delimitadas operacionalemente con las pruebas BRIEF-2, evaluación conductual de la función ejecutiva (Gioia et al., 2015) y BANFE-2, batería neuropsicológica de FE y lóbulos frontales (Flores et al., 2014).

Como se mencionó en el apartado 3.3.2.1, las FE son definidas como "un conjunto de procesos responsables de dirigir, guiar y controlar las funciones cognitivas, emocionales y conductuales" (Gioia et al., 2015). Se dividen en frias (incluyen las conductuales o cognitivas), y calientes (relacionadas con las emotivas). En ellas se involucran habilidades como la atención, la memoria y las habilidades motoras (González Osornio, 2015) que son la base de las FE, sin ellas no se podrían desarrollar. En el apartado 3.3.2.2 se explican las diez FE a evaluar, son agrupadas en cuatro categorías: conductuales, cognitivas, emocionales y de metacognición (ver Tabla 8).

No existen parámetros claros que determinen los límites de cada FE, incluso, no hay parámetros para definirlas de manera consensada (E. A. Demetriou et al., 2018; Martos Pérez \& Paula Pérez, 2011; Tirapu-Ustárroz \& Luna-Lario, 2011). No obstante, el grado de complejidad sí puede ser previsto considerando el grado de desarrollo o involucramiento mental que requiere cada una de ellas. A partir de ello, en la figura 64, se presentan las tres categorías que surgen de los puntajes de los índices que mide la prueba BRIEF-2 (Gioia et al., 2015), que se complementan 
con tres categorías más que provienen de la propuesta de Minsky $(2006)$ y Eco $(1976,1989)$, de OCC (Ortony et al., 1996) y de BANFE-2 (Flores et al., 2014).

Teniendo como resultado seis niveles jerárquicos de las habilidades relacionadas con las FE, de mayor a menor complejidad se consideraron los siguientes niveles:
1. Metacognición
- $\quad$ BANFE-2
2. Valoración social cognitivo-afectivo Minsky, ToM, E-S y OCC
3. Índice cognitivo - BRIEFF-2
4. Índice de control emocional - BRIEFF-2
5. Índice conductual - BRIEFF-2
6. Comportamiento instintivo-emotivo Minsky y U. Eco

Ahora, leyéndolas de abajo hacia arriba, el comportamiento instintivo proviene del modelo de Marvin Minsky (Figura 14) en el que explica los niveles de consciencia, iniciando con los impulsos instintivos e innatos agrupados en el sistema de comportamiento instintivo-emotivo. En este mismo rango se ubica la impronta de Umberto Eco, quien propone la división más elemental de los signos, de los cuales, la impronta es la más básica (ver apartado 3.2.3.4).

En cuanto a los índices detectados por la prueba BRIEF-2, se considera primero el conductual (por ser el más básico), la inhibición y supervisión de sí mismo. En segundo lugar el índice de control emocional, que no necesariamente se refiere al sistema emotivo básico instintivo, sino más bien a la capacidad de controlar los impulsos y a la flexibilidad mental (Gioia et al., 2015). El tercero es el índice cognitivo, en el que se involucran tareas de mayor complejidad para la resolución de problemas de manera eficaz.

El siguiente nivel asociado a la consciencia se asocia a la valoración social cognitivoafectivo, en el que convergen cuatro teorías: 1) Minsky (2006); 2) teoría de la mente (ToM), (Baron-Cohen et al., 1985; Bottema-Beutel et al., 2019; Frith \& Baron-Cohen, 1987; Jones et al., 2018; O’Nions et al., 2014); 3) teoría de empatización-sistematización (E-S) (Baron-Cohen, 2009, 2012; Groen et al., 2015; Javed \& Park, 2019), y 4) modelo OCC (Laureano-Cruces et al., 2013, 2015, 2018, 2019) y Mora-Torres (Mora-Torres, 2015; Mora-Torres et al., 2011, 2014).

En este nivel se explica un sistema en el que intervienen aspectos aprendidos socialmente, asociados a la experiencia y a la capacidad de internalizar el mundo propio y dar cabida al de los otros. En él convergen directamente dos de las teorías del TEA descritas en el apartado 3.1.3.4 con el modelo OCC revisado en el apartado 3.5. 
El último aspecto de las FE es la metacognición, considerada como el aspecto más desarrollado de las FE, en el que interviene la capacidad de controlar y regular los procesos cognitivos propios. Como se mencionó previamente, se ha valorado como una función ejecutiva supervisora de la conducta propia (Tirapu-Ustárroz \& Luna-Lario, 2011), asociada con la edad y la conducta social (Torske et al., 2018). Además de asociarse con la capacidad para desarrollar estrategias de memoria, por medio de un control metacognitivo y la capacidad para predecir el desempeño propio (Flores et al., 2014).

\subsection{Niveles de interacción niño-robot}

El último aspecto relacionado con la Figura 64 se centra en los niveles de interacción que se pueden establecer entre los niños con TEA y el robot humanoide. Aunque su descripción se proporciona de manera amplia en el Capítulo 5 y 6 , de manera general se dividen en cinco niveles:

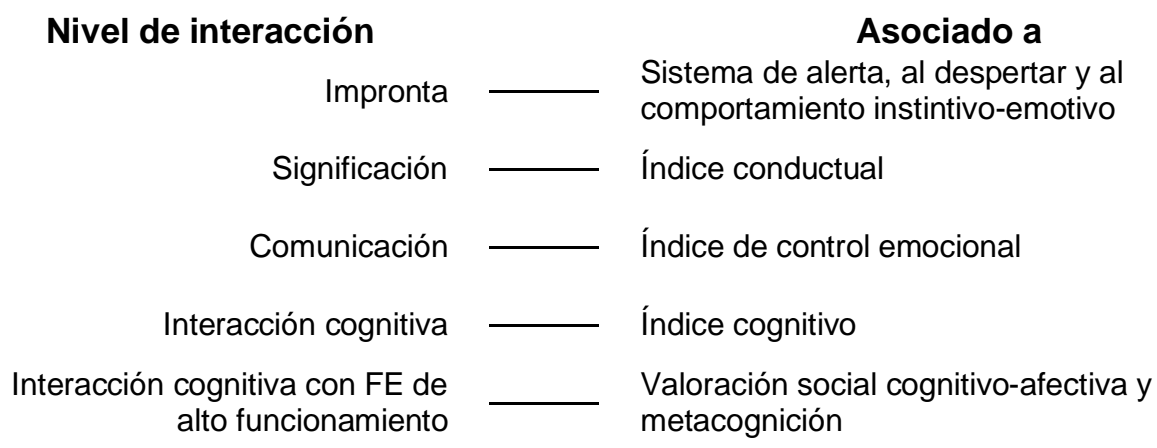

Éstos a su vez, dan pauta de desarrollo a los niveles de interacción niño-robot:

1. Interacción por impronta: requiere que se relacione lo que se conoce con lo que se ve, aunque esa relación tácita o sobreentendida por la persona no sea compartida con otras personas.

2. Interacción por significación: las relaciones dadas entre un signo y su interpretación dependen exclusivamente de la percepción inicial de la persona. En el caso de los niños con TEA pueden asociar un signo con una posible causa física, sin que haya una relación real entre ellos.

3. Interacción por comunicación: los sistemas de significación se determinan a partir de la experiencia de las personas. A medida que tienen mayor conocimiento y control del uso de los signos mayor serán sus posibilidades de expresión, recepción y comunicación. En esa línea se espera que alguien que no tienen habilidad para desarrollar un bagaje de 
información y propiamente de signos podrá dar una interpretación de lo que le rodea (proceso de significación), pero es altamente probable que tenga menor posibilidad de intercambio comunicacional, tal como parece sucederles a las personas con TEA.

4. Interacción cognitiva: la relación que se establece surge a partir de la interacción reflexiva o analítica, pero la conducta no se guía por los afectos.

5. Interacción cognitivo-afectiva: hay un involucramiento de las emociones que pasan por el filtro de los afectos modulados a partir de las experiencias sociales y afectivas que se hayan experimentado previamente o que se sea capaz de experimentar.

Finalmente, la delimitación semántica y teórica, mostradas en la Figura 64, surge a partir de los aspectos teórico-referenciales presentados en los cinco EATR. El enlace de aplicación práctica se aplica con los niveles de interacción de los niños con TEA con el robot humanoide como se describió a lo largo de los capítulos. 


\section{Conclusiones}

\section{Entendimiento transdisciplinar}

El recurso más eficiente que se empleó para entender el problema provino de un eje teórico y uno empírico. El primer eje se obtuvo a partir del desarrollo de los elementos de anclaje teórico referenciales (EATR) descritos en el capítulo dos. Mientras que el segundo eje se desarrolló considerando los cuatro procesos descritos en el apartado 3.2.1:

- Observación y descripción naturalista

- Evaluación psicométrica

- Evaluación de tareas de desempeño ejecutivo considerando interacción humanohumano

- Evaluación de interacción niño-robot considerando repertorios básicos e interacción niño-robot humanoide en FE

Las creencias hipotético-deductivas que definieron las fases y etapas de la investigación se aplicaron a los elementos de anclaje teórico referenciales contenidos en esta primera fase. Como se describe a continuación.

- Se consideró la teoría semiótica de Peirce (ver Figura 9, del capítulo dos) para identificar los tipos de significación que se desarrollan en los niños con TEA, a partir de la observación naturalista y de las relaciones de interacción humano-humano y niño-robot. Del enfoque semiótico se retomaron los conceptos para definir los niveles de interacción niño-robot.

- La teoría del espacio neuronal global (TENG) se empleó para ubicar los rangos de interacción con los niños, determinando que es a partir del estado de alerta que debe ser activada por medio de estímulos visuales y auditivos.

- La propuesta de M. Minsky se empleó para caracterizar la conducta como cognitivaafectiva más que como instintiva-emotiva, ésta fue aplicada para definir las categorías conductuales de los usuarios.

- Del área de la inteligencia artificial, se retomaron los cinco axiomas de la propuesta de Igor Aleksander para identificar los niveles de consciencia interpretados como mecanismos neuronales que indican: "presencia, imaginación, atención, volición y emoción" (2009, p. 25). 
- De las teorías que explican el TEA se consideraron los conceptos básicos de la teoría de la mente (ToM) y la empatización-sistematización (E-S) para ser explorados durante los dos enfoques cualitativo y cuantitativo. En el cualitativo se valoró la conducta como parte de la observación, y en el cuantitativo se consideran los últimos niveles de las FE evaluadas.

- Las reacciones instintivas, las FE y la metacognición, fueron evaluadas a partir de seis niveles jerárquicos de conducta basados en las pruebas BANFE-2 y BRIEF-2 (apartado 2.3).

- La última aplicación conceptual, que sirvió para completar la primera fase del procedimiento retomado de los EATR, son los niveles de interacción niño-robot, definidos como: interacción por significación, interacción por comunicación e interacción cognitiva.

En el apartado 2.4.4, se expuso que lo más importante del entendimiento es la identificación del problema, por lo que se dio mayor relevancia a su definición partiendo de las necesidades y adecuaciones para los usuarios en estudio con el fin de identificar la viabilidad de la investigación. Con el marco teórico-semántico expuesto en esta primera etapa se sustentaron los alcances del estudio, las bases para su futura aplicación y, sobre todo, para abordar la segunda etapa del procedimiento.

Por otro lado, a través del desarrollo de la tesis, se plantearon múltiples preguntas que fueron teniendo respuesta a medida que se avanzaba en el trabajo. Dado que la metodología estuvo guiada por el constante seguimiento de la UCDe y de la UX, las reflexiones finales subyacen a partir de las recomendaciones de Peter Morville de incluir en el diseño: utilidad, usabilidad, deseabilidad, accesibilidad, credibilidad y valor.

Utilidad. La primera pregunta que se trató de mantener durante toda la investigación fue ¿qué tan útil serán los resultados que se obtendrán con el desarrollo de esta investigación? La respuesta que se afirmar ahora, es que definitivamente la herramienta no es lo más importante para dar utilidad posterior a esta investigación. Como ha de imaginar el lector, en la región mixteca, con la población oaxaqueña en general, y en particular con los usuarios del DIF difícilmente se podría dar acceso libre al uso de un robot humanoide para trabajar las FE con sus niños con TEA. Por lo que, se puede afirmar que la riqueza del estudio no radica en la herramienta sino en el proceso. 
En cuanto a la utilidad del estudio, se afirma que el estudio sí aportó beneficios para el conocimiento de los niños con TEA en sus tres niveles de gravedad. Esos conocimientos, posteriormente fueron aplicados al modelo de interacción que recoge las observaciones, necesidades y limitantes del estudio y de los niños a partir de la profundidad de su diagnóstico.

A partir de la detección de esas necesidades, se desarrollaron varios prototipos de apoyo para los distintos rangos de edad y grado de TEA. Además de proponer un modelo que puede adecuarse a la atención de niños con TEA en sus tres niveles, considerando o no el uso del robot como herramienta de trabajo. Es decir, el resultado en última instancia priorizo el proceso de atención y no tanto la herramienta empleada. Claro está, que para lograr el objetivo de la tesis sí se empleó al robot para poder evaluar el I impacto de la interacción con los niños.

Además de ello, puedo afirmar que el modelo se pude aplicar incluso con poblaciones que tienen pocos recursos como la población oaxaqueña o mixteca.

Usabilidad. La opción para cumplir con el criterio de usabilidad no era trabajar solo un producto ni trabajar con un solo niño. La clave fue hacer un modelo que proporcionará la facilidad de que el modelo pudiera aplicarse a varios niños, considerando distintos niveles de uso.

En cuanto a los intereses, actividades, repetitivas y estereotipadas se logró atravesar la barrera de tener una gran diversidad de conductas, utilizando dos recomendaciones, una del diseño universal, y otra de la UX (ver capítulo 2). Del diseño universal se consideró emplear elementos que fueran fácilmente perceptibles por los usuarios a nivel pictórico, verbal o táctil. $Y$ de la UX se buscaron estrategias para que su uso fuera flexible y adecuado a las habilidades individuales. Por otro lado, se emplearon elementos gráficos que fueran fácilmente adaptados a diversos entornos lingüísticos y culturales, como recomienda la UXPA, por lo que los elementos de diseño empleados para la elaboración de los vehículos de interacción se basaron en cuatro códigos: color, tamaño, posición y forma (capítulo tres y cuatro)

Los materiales y las tareas propuestos para la interacción surgieron de las observaciones con los niños neurotípicos y con TEA de distintas edades de niveles de gravedad en su diagnóstico. Posteriormente cada tarea fue probada en interacción humano-humano y finalmente se adaptaron a las interacciones robóticas. En cada etapa se evaluaron los criterios de usabilidad.

Este procedimiento, ayudo a asegurar que tanto los materiales como las tareas funcionan con todos los usuarios propuestos.

Deseabilidad. Este aspecto, planteado por Peter Morville (2016), impulsó e incentivo el uso del robot humanoide como vehículo de interacción, debido al alto grado de atracción que los 
niños con TEA mostraron al ver al robot humanoide durante algunas pruebas previas al inicio de esta investigación.

Ante esos primeros resultados, la respuesta a la deseabilidad se cumplía perfectamente. Cabe mencionar que el "casi", se debió a que durante las evaluaciones de interacción se encontraron resultados totalmente opuestos. Es decir, hubo niños que no querían ni ver al robot porque les despertaba una reacción identificada como miedo. Sin embargo, el rechazo solo se presentó en algunos niños.

Accesibilidad. Considerando que las FE son parte del desarrollo cognitivo y maduración de las personas, entonces el modelo debería servir para cualquier persona que quiera o requiera poner en práctica sus FE. Por lo que la accesibilidad del modelo de interacción cognitiva que se presentó depende de las capacidades de los niños que lo usen, cuyo perfil va más allá de ser etiquetado o no como alguien con discapacidad. El hecho de que el modelo de interacción cognitiva se pueda trabajar por niveles, es un factor importante para favorecer la accesibilidad a distintos tipos de usuarios, con o sin discapacidad y con o sin el robot humanoide.

El tener desarrolladas varias tareas para ejercitar las FE con posibilidades de ser replicadas, ampliadas utilizadas de manera independiente al uso del robot humanoide, también es un factor que facilita que el estudio sea accesible a una mayor cantidad de usuarios. Lo que correspondería hacer, es tal vez buscar la forma en la que esos materiales estén disponibles para las personas que trabajan con niños con son TEA que requieran poner en práctica sus FE.

Finalmente, se afirma que el modelo de interacción cognitiva es un modelo que puede seguir creciendo bajo la lógica de que se trata de integrar a los niños a un proceso de desarrollo guiado. Los ejercicios que se propusieron en esta investigación son solo algunos de los múltiples ejercicios que se podrían integrar para que un niño con TEA pueda poner en práctica sus FE. La clave de todo será adecuar las tareas a tres condiciones: 1) que faciliten el contacto y la comunicación con los niños, 2) que los objetos o materiales sean de baja complejidad perceptiva, y 3 ) que las tareas sean de complejidad creciente. 


\section{Bibliografía}

[SEDESOL], S. de D. S. (2015a). Informe anual sobre la situación de pobrea y rezago social. Heroica Ciudad de Huajuapan de León, Oaxaca (Número 20039). http://diariooficial.gob.mx/SEDESOL/2017/Oaxaca_039.pdf

[SEDESOL], S. de D. S. (2015b). Informe anual sobre la situación de pobrea y rezago social. Oaxaca de Juárez, Oaxaca (Número 20067). http://diariooficial.gob.mx/SEDESOL/2017/Oaxaca_039.pdf

[SEDESOL], S. de D. S. (2015c). Informe anual sobre la situación de pobrea y rezago social. Santa María Huatulco, Oaxaca (Número 20413). http://diariooficial.gob.mx/SEDESOL/2017/Oaxaca_413.pdf

[UXPA], A. U. E. P. (2003). ¿Qué es la usabilidad? Definición: http://usabilitybok.org. www.usabilitybok.org/print/whatis-usability

[UXPA], A. U. E. P. (2018). International supports people who research, design, and evaluate the user experience (UX) of products and services. UXPA International. https://uxpa.org/about-uxpa-international/

Ackovska, N., Kirandziska, V., Tanevska, A., Bozinovska, L., \& Bozinovski, A. (2017). Robot - Assisted therapy for autistic children. Conference Proceedings - IEEE SOUTHEASTCON. https://doi.org/10.1109/SECON.2017.7925401

AESDU, C. E. P. D. (2019). Welcome to the ASDEU newsletter: our final issue. November $2018,1-8$. http://asdeu.eu/wp-content/uploads/2015/05/Newsletter-ASDEU-Nov-2018.pdf

Agostini, A., Torras, C., \& Wörgötter, F. (2017). Efficient interactive decision-making framework for robotic applications. Artificial Intelligence, 247, 187-212. https://doi.org/10.1016/j.artint.2015.04.004

Aguayo W. Pablo. (2011). La teoría de la abducción de peirce: lógica, metodología e instinto. Ideas y Valores, 60(145), 33-53. https://revistas.unal.edu.co/index.php/idval/article/view/36688/38639

Ahmed, F. S., \& Stephen Miller, L. (2011). Executive function mechanisms of theory of mind. Journal of Autism and Developmental Disorders, 41(5), 667-678. https://doi.org/10.1007/s10803-010-1087-7

Alanwood, G., \& Beare, P. (2015). Diseño de experiencias de usuario (2a.). Parramón arts \& design.

Aleksander, I. (2005). The World in my Mind, My Mind in the World. Imprint Academic.

Aleksander, I. (2009). Designing conscious systems. Cognitive Computation, 1(1), $22-28$. https://doi.org/10.1007/s12559-009-9008-9

Aliseda-Llera, A. (1997). Seeking Explanations: Abduction in Logic, Philosophy of Science and Artificial Intelligence.

Alsaedi, R. H., Carrington, S., \& Watters, J. J. (2020). Behavioral and neuropsychological evaluation of executive functions in children with autism spectrum disorder in the gulf region. Brain Sciences, 10(2). https://doi.org/10.3390/brainsci10020120

Anzalone, S. M., Boucenna, S., Ivaldi, S., \& Chetouani, M. (2015). Evaluating the Engagement with Social Robots. International Journal of Social Robotics, 7(4), 465-478. https://doi.org/10.1007/s12369-015-0298-7

Ardila, A. (2012). GUIA PARA EL DIAGNÓSTICO NEUROPSICOLÓGICO.

Arias-Aguilar, J. A., Palacios-Villavicencio, M. L., Bretado-Gallegos, R., Medina-Nieto, M. A., Ruiz Benitez, A., Rodríguez-López, V., \& Estrada-Bautista, J. (2017). Analysis of children-humanoid robot interaction to support social skills development. XVIII International Conference on Human Computer Interaction, 17, Article 10, 1-4. https://doi.org/DOI:https://doi.org/10.1145/3123818.3123837

Artigas, J., \& Paula, I. (2012). El autismo 70 años después de Leo Kanner y Hans Asperger. Revista de la Asociación Española de Neuropsiquiatría, 32(115), 567-587. https://doi.org/10.4321/s0211-57352012000300008

Asociación Americana de Psiquiatría, A. (2014). Manual diagnóstico y estadístico de los trastornos mentales (DSM-5) (p. 947). Editorial médica panamericana.

Ayres, J. (2012). La integración sensorial y el niño. Trillas.

Baars, B. J. (1988). A Cognitive Theory of Consciousness (1a ed.). Cambridge University Press. https://www.sscnet.ucla.edu/comm/steen/cogweb/Abstracts/Baars_88.html\#13

Baars, B. J. (2005). Global workspace theory of consciousness: Toward a cognitive neuroscience of human experience. Progress in Brain Research, 150, 45-53. https://doi.org/10.1016/S0079-6123(05)50004-9

Baron-Cohen, S. (2002). The extreme male brain theory of autism. Trends in Cognitive Sciences, 6(6), $248-254$. https://doi.org/10.1016 / s1364-6613 (02) 01904-6

Baron-Cohen, S. (2009). Autism: The empathizing-systemizing (E-S) theory. Annals of the New York Academy of Sciences, 1156, 68-80. https://doi.org/10.1111/j.1749-6632.2009.04467.x

Baron-Cohen, S. (2012). Empatia cero. Nueva teoría de la crueldad (1a ed.). Alianza editorial.

Baron-Cohen, S., Leslie, A. M., \& Frith, U. (1985). Does the autistic child have a "theory of mind" ? Cognition, 21(1), 37-46. https://doi.org/10.1016/0010-0277(85)90022-8

Baron-Cohen, S., Lombardo, M. V., Auyeung, B., Ashwin, E., Chakrabarti, B., \& Knickmeyer, R. (2011). Why are Autism Spectrum conditions more prevalent in Males? PLoS Biology, 9(6). https://doi.org/10.1371/journal.pbio.1001081 
Baron-Cohen, S., \& Wheelwright, S. (2004). The Empathy Quotient: An Investigation of Adults with Asperger Syndrome or High Functioning Autism, and Normal Sex Differences Simon. 34(2), 163-175. https://doi.org/10.1023 / b: jadd.0000022607.19833.00

Barrio, V. del. (2009). Raíces y evolución del DSM. Revista de Historia de la Psicología, 30(2-3), 81-90. http://www.revistahistoriapsicologia.es/app/download/5838398111/9+DEL+BARRIO.pdf?t=1362393478

Barttfelda, P., Uhriga, L., Sitta, J. D., Sigmane, M., Jarrayaa, B., \& Dehaene, S. (2015). Signature of consciousness in the dynamics of resting-state brain activity. Proceedings of the National Academy of Sciences of the United States of America, 112(3), 887-892. https://doi.org/10.1073/pnas.1418031112

Bock, O., Haeger, M., \& Voelcker-Rehage, C. (2019). Structure of executive functions in young and in older persons. PLoS ONE, 14(5), 1-20. https://doi.org/10.1371/journal.pone.0216149

Boren, M., \& Liles, K. R. (2016). A Case Study with Children Diagnosed with Autism. Human-Robot Interaction, 419420.

Bottema-Beutel, K., Kim, S. Y., \& Crowley, S. (2019). A systematic review and meta-regression analysis of social functioning correlates in autism and typical development. Autism Research, 12(2), 152-175. https://doi.org/10.1002/aur.2055

Breazeal, C. (2003a). Emotion and sociable humanoid robots. International Journal of Human Computer Studies, 59(12), 119-155. https://doi.org/10.1016/S1071-5819(03)00018-1

Breazeal, C. (2003b). Toward sociable robots. Robotics and Autonomous Systems, 42(3-4), 167-175. https://doi.org/10.1016/S0921-8890(02)00373-1

Breazeal, C. (2004). Social interactions in HRI: The robot view. IEEE Transactions on Systems, Man and Cybernetics Part C: Applications and Reviews, 34(2), 181-186. https://doi.org/10.1109/TSMCC.2004.826268

Breazeal, C., \& Scassellati, B. (1999). How to build robots that make friends and influence people. IEEE International Conference on Intelligent Robots and Systems, 2, 858-863. https://doi.org/10.1109/iros.1999.812787

Breazeal, C., Takanishi, A., \& Kobayashi, T. (2008). Social Robots. En K. O. (eds) Siciliano B. (Ed.), Springer Handbook of Robotics (1a ed., pp. 1349-1369). Springer Handbook of Robotics. Springer, Berlín, Heidelberg. https://doi.org/https://doi.org/10.1007/978-3-540-30301-5_59

Call, J., \& Tomasello, M. (2008). Does the chimpanzee have a theory of mind? 30 years later. Trends in Cognitive Sciences, 12(5), 187-192. https://doi.org/10.1016/j.tics.2008.02.010

Calle Sandoval, D. A. (2017). Filogenia y desarrollo de funciones ejecutivas/ Phylogeny and executive functions development. Psicogente, 20(38), 368-381. https://doi.org/10.17081/psico.20.38.2557

Casacuberta, D., \& Valleverdu, J. (2010). Emociones sintéticas. Páginas de Filosofía, 11(13), 116-144. http://www.ub.edu/imarte/investigacions/estudis-teorics/david-casacuberta/emociones-sinteticas/

Cervantes Martínez, J. C., Hernández Ledesma, G., Ortiz Olivera, Á., Palacios Villavicencio, M. L., \& Cruz Barbosa, R. (2017). Hacia un sistema de reconocimiento de posturas para personas con trastorno del espectro autista. En M. de L. Sánchez Guerrero, A. García Gaona, \& F. Álvarez Rodríguez (Eds.), Tecnologías emergentes para un mundo inteligente. El profesional de TIC y la transdisciplina (1a ed., pp. 37-42). ALFA-OMEGA.

Chandler, D. (1998). Semiótica para principiantes (1a.). Abya-Yala Editing. Serie pluriminor.

Charman, T., Baron-Cohen, S., Swettenham, J., Baird, G., Cox, A., \& Drew, A. (2000). Testing joint attention, imitation, and play as infancy precursors to language and theory of mind. Cognitive Development, 15(4), 481-498. https://doi.org/10.1016/S0885-2014(01)00037-5

Chen, C. P., Gau, S. S. F., \& Lee, C. C. (2019). Toward differential diagnosis of autism spectrum disorder using multimodal behavior descriptors and executive functions. Computer Speech and Language, 56, 17-35. https://doi.org/10.1016/j.csl.2018.12.003

Chevalier, P., Raiola, G., Martin, J. C., Isableu, B., Bazile, C., \& Tapus, A. (2017). Do Sensory Preferences of Children with Autism Impact an Imitation Task with a Robot? ACM/IEEE International Conference on Human-Robot Interaction, Part F1271, 177-186. https://doi.org/10.1145/2909824.3020234

Chrisley, R., Aleksander, I., Bringsjord, S., Clowes, R., Parthemore, J., Stuart, S., Torrance, S., \& Ziemke, T. (2008). Assessing artificial consciousness: A collective review article. Journal of Consciousness Studies, 15(7), 95-110.

Christensen, D. L., Maenner, M. J., Bilder, D., Constantino, J. N., Daniels, J., Durkin, M. S., Fitzgerald, R. T., KurziusSpencer, M., Pettygrove, S. D., Robinson, C., Shenouda, J., White, T., Zahorodny, W., Pazol, K., \& Dietz, P. (2019). Prevalence and Characteristics of Autism Spectrum Disorder Among Children Aged 4 Years - Early Autism and Developmental Disabilities Monitoring Network, Seven Sites, United States, 2010, 2012, and 2014. Morbidity and mortality weekly report. Surveillance summaries (Washington, D.C.: 2002), 68(2), 1-19. https://doi.org/10.15585/mmwr.ss6802a1

Clarkson, J. P., \& Coleman, R. (2015). History of inclusive design in the UK. Applied Ergonomics, 46(PB), 235-247. https://doi.org/10.1016/j.apergo.2013.03.002

Programa Nacional para el Desarrollo y la Inclusión de las Personas con Discapacidad 2014-2018, 1 (2014). 
https://www.gob.mx/conadis/documentos/programa-nacional-para-el-desarrollo-y-la-inclusion-de-las-personascon-discapacidad-2014-2018

Connell, B. R., Jones, M., Mace, R., Mueller, J., Mullick, A., Ostroff, E., Sanford, J., Steinfeld, E., Story, M., \& Vanderheiden, G. (1997). Los principios del diseño universal. EL CENTRO PARA EL DISEÑO UNIVERSAL N.C. State University, 2-3. https://bit.ly/2ekUiqN

Costa, J. (2003). Diseñar para los ojos (2a.). Grupo Editorial Design.

Crow, D. (2008). No te creas una palabra. Una introduccion a la semiótica (1a ed.). Promopress.

Dağlarlı, E., Dağlarlı, S. F., Günel, G. Ö., \& Köse, H. (2017). Improving human-robot interaction based on joint attention. Applied Intelligence, 47(1), 62-82. https://doi.org/10.1007/s10489-016-0876-x

Damasio, A. (1999). El error de Descartes. La razón de las emociones (3ª). Editorial Andrés Bello.

Damásio, H., Grabowski, T., Frank, R., Galaburda, A. M., \& Damásio, A. R. (1994). The return of phineas gage: Clues about the brain from the skull of a famous patient. Science, 264(5162), 1102-1105. https://doi.org/10.1126/science.8178168

Dehaene, S. (2014). Consciousness and the Brain (Penguin (ed.)).

Dehaene, S. (2015). La conciencia en el cerebro. Descifrando el enigma de cómo nuestro cerebro elabora nuestros pensamientos $\left(1^{\mathrm{a}}\right)$. S.XXI editores.

Dehaene, S., Changeux, J.-P., \& Naccache, L. (2011). The Global Neuronal Workspace Model of Conscious Access: From Neuronal Architectures to Clinical Applications. En S. Dehaene \& Y. Christen (Eds.), Characterizing consciousness: From cognition to the clinic? (pp. 55-84). Springer. https://doi.org/10.1007/978-3-642-18015-6

Dehaene, S., \& Changeux, J. P. (2011). Experimental and Theoretical Approaches to Conscious Processing. Neuron, 70(2), 200-227. https://doi.org/10.1016/j.neuron.2011.03.018

Dehaene, S., Lau, H., \& Kouider, S. (2017). What is consciousness, and could machines have it? Special section challenges in neuroscience, 358(27 October), 486-492. https://doi.org/10.1126/science.aan8871

Dehaene, S., \& Naccache, L. (2001). Towards a cognitive neuroscience of consciousness: Basic evidence and a workspace framework. Cognition, 79(1-2), 1-37. https://doi.org/10.1016/S0010-0277(00)00123-2

Demetriou, E. A., Lampit, A., Quintana, D. S., Naismith, S. L., Song, Y. J. C., Pye, J. E., Hickie, I., \& Guastella, A. J. (2018). Autism spectrum disorders: A meta-analysis of executive function. Molecular Psychiatry, 23(5), 11981204. https://doi.org/10.1038/mp.2017.75

Demetriou, Eleni A., DeMayo, M. M., \& Guastella, A. J. (2019). Executive Function in Autism Spectrum Disorder: History, Theoretical Models, Empirical Findings, and Potential as an Endophenotype. Frontiers in Psychiatry, 10(November), 1-17. https://doi.org/10.3389/fpsyt.2019.00753

Echeburúa, E., Salaberría, K., \& Cruz-Sáez, M. (2014). Aportaciones y Limitaciones del DSM-5 desde la Psicología Clínica. Terapia psicológica, 32(1), 65-74. https://doi.org/10.4067/S0718-48082014000100007

Eco, U. (1976). Signo (2a ed.). Editorial Labor S.A. http://www.catedranaranja.com.ar/taller2/notas_T2/Libro_Signo_Umberto_Eco.pdf

Eco, U. (1989). Cuernos, cascos, zapatos: algunas hipótesis sobre tres tipos de abducción. En U. Eco \& T. Sebeok (Eds.), El signo de los tres. Dupin, Holmes, Pierce (Primera, pp. 265-294). LUMEN.

Eco, U. (1993). Lector in fabula. La cooperación interpretativa en el texto narrativo (3a.). Lumen. https://monoskop.org/images/6/6e/Eco_Umberto_Lector_in_Fabula_3rd_ed_1993.pdf

Eco, U. (2000). Tratado de semiótica general (5a.). Lumen. http://mastor.cl/blog/wp-content/uploads/2015/08/ECOTratado-de-Semiótica-General.pdf

Eco, U., \& Sebeok, T. A. (1989). El signo de los tres. Dupin, Holmes, Peirce.

Eicher, L. D., Kuert, W., Maréchal, R., Grey, V., Frontard, R., Sturen, O., Thor, A., \& Barchietto, R. (1997). Recollections from ISO 's first fifty years. http://www.iso.org/iso/home/about/the_iso_story.htm

Ekman, P. (1992). Facial Expressions of Emotion: New Findings, New Questions. Psychological Science, 3(1), 34-38. https://doi.org/10.1111/j.1467-9280.1992.tb00253.x

Ekman, P., \& Oster, H. (1981). Expresiones faciales de la emoción. Annual Review of Psychology, 7, $116-144$.

Elsabbagh, M., Divan, G., Koh, Y. J., Kim, Y. S., Kauchali, S., Marcín, C., Montiel-Nava, C., Patel, V., Paula, C. S., Wang, C., Yasamy, M. T., \& Fombonne, E. (2012). Global Prevalence of Autism and Other Pervasive Developmental Disorders. Autism Research, 5(3), 160-179. https://doi.org/10.1002/aur.239

Farisco, M. (2018). Filosofía de las neurociencias (1ed Salta). Universidad Católica de Salta. https://books.google.com.mx/books?id=mJy6DwAAQBAJ\&pg=PA5\&hl=es\&source=gbs_selected_pages\&cad=2 $\# \mathrm{v}=$ onepage\& $q \& \mathrm{f}=\mathrm{false}$

Feng-Hsiung, H. (1999). IBM's Deep Chess grandmaster chips. IEEE Micro, 19 (2 marzo/abril), 70-81. https://doi.org/10.1109 / 40.755469

Fernández-Caballero, A., Manzano Arjona, M. G., Alonso González, E., \& Tomé, S. M. (2006). Una perspectiva de la inteligencia artificial en su 50 aniversario (1a ed.). Universidad de Castilla-La Macha. 
Flores-Lázaro, J. C., \& Ostrosky-Shejet, F. (2012). Desarrollo neuropsicológico de lóbulos frontales y funciones ejecutivas. Manual Moderno.

Flores, J. C., Ostrosky, F., \& Lozano, A. (2014). BANFE 2 - Batería de Funciones ejecutivas y lóbulos frontales (Manual Moderno (ed.); 2a.).

Fombonne, E., Marcin, C., Manero, A. C., Bruno, R., Diaz, C., Villalobos, M., Ramsay, K., \& Nealy, B. (2016). Prevalence of Autism Spectrum Disorders in Guanajuato, Mexico: The Leon survey. Journal of Autism and Developmental Disorders, 46(5), 1669-1685. https://doi.org/10.1007/s10803-016-2696-6

Frith, U., \& Baron-Cohen. (1987). Perception in autistic children. En Handbook of autism and pervasive developmental disorders (pp. 85-102).

Frith, U., \& Happé, F. (1994). Autism: beyond "theory of mind". Cognition, 50(1-3), 115-132. https://doi.org/10.1016/0010-0277(94)90024-8

Galindo, E., Galguera, I., Taracena, E., \& Hinojosa, G. (2009). Modificación de conducta en la educación especial (3a.). Trillas.

García Rodríguez, R. E., \& Gonzalez Ramírez, V. (2014). Las funciones psíquicas superiores, la corteza cerebral y la cultura. Reflexiones a partir del pensamiento de A. R. Luria. En-claves del Pensamiento, VII(15), 39-62. http://www.redalyc.org/articulo.oa?id=141131696002

Gardiner, E., Hutchison, S. M., Müller, U., Kerns, K. A., \& larocci, G. (2017). Assessment of executive function in young children with and without ASD using parent ratings and computerized tasks of executive function. Clinical Neuropsychologist, 31(8), 1283-1305. https://doi.org/10.1080/13854046.2017.1290139

Garibay Rubio, C. R. (2017). Las inferencias abductivas y su relación con la generación, mantenimiento y convicción de creencias inadecuadas en pacientes con trastornos mentales [Posgrado interuniversitario: Universidad de Salamanca, España]. https://gredos.usal.es/bitstream/handle/10366/136274/DFLFC_GaribayRubioCR_InferenciasAbductivas.pdf?se quence $=1$ \&isAllowed $=y$

Giacino, J. T. (2005). The minimally conscious state: Defining the borders of consciousness. Progress in Brain Research, 150, 381-395. https://doi.org/10.1016/S0079-6123(05)50027-X

Ginnerup, S. (2010). Hacia la plena participación mediante el diseño universal. 106. http://www.ceapat.es/InterPresent1/groups/imserso/documents/binario/21019participacionmediantedise.pdf

Gioia, G. A., Espy, K. A., \& Isquith, P. (2015). BRIEF®-2. Evaluación Conductual de la Función Ejecutiva-2 (P. A. R. PAR (ed.)). tea-editiones.

Girardot, A. M., De Martino, S., Rey, V., \& Poinso, F. (2009). Étude des relations entre l'imitation, l'interaction sociale et l'attention conjointe chez les enfants autistes. Neuropsychiatrie de l'Enfance et de l'Adolescence, 57(4), 267274. https://doi.org/10.1016/j.neurenf.2008.09.009

Giullian, N., Ricks, D., Atherton, A., Colton, M., Goodrich, M., \& Brinton, B. (2010). Detailed requirements for robots in autism therapy. Conference Proceedings - IEEE International Conference on Systems, Man and Cybernetics, 2595-2602. https://doi.org/10.1109/ICSMC.2010.5641908

Glannon, W. (2013). Brain, body and mind. Neuroethics with a Human Face. Oxford Scholarship. https://doi.org/10.1093/acprof:oso/9780199734092.001.0001

Glenne Øie, M., Andersen, P. N., Hovik, K. T., Skogli, E. W., \& Rund, B. R. (2020). Similar impairments shown on a neuropsychological test battery in adolescents with high-functioning autism and early onset schizophrenia: a twoyear follow-up study. Cognitive Neuropsychiatry, 25(3), 163-178. https://doi.org/10.1080/13546805.2020.1713736

Goldfine, A. M., \& Schiff, N. D. (2011). Consciousness: Its Neurobiology and the Major Classes of Impairment. Neurology Clinic, 29(4), 723-737. https://doi.org/10.1016/j.ncl.2011.08.001

Goldstein, B. (2011). Sensacion y percepcion (8a ed.). Cengage Learning.

Gómez González, O. (2020). Entivo, dispositivo interactivo para ejercitar las funciones ejecutivas en niños con trastorno del espectro autista (TEA) grado 1. [Tesis de licenciatura inédita] Universidad Tecnológica de la Mixteca.

González Osornio, M. G. (2015). Desarrollo neuropsicológico de las funciones ejecutivas en preescolar (1a ed.). Manual Moderno.

Gosseries, O., Di, H., Laureys, S., \& Boly, M. (2014). Measuring Consciousness in Severely Damaged Brains. Annual Review of Neuroscience, 37(1), 457-478. https://doi.org/10.1146/annurev-neuro-062012-170339

Grandgeorge, M., Bourreau, Y., Alavi, Z., Lemonnier, E., Tordjman, S., Deleau, M., \& Hausberger, M. (2014). Interest towards human, animal and object in children with autism spectrum disorders: an ethological approach at home. European Child and Adolescent Psychiatry, 24(1), 83-93. https://doi.org/10.1007/s00787-014-0528-9

Gray, D. (2017). Empathy Map Canvas. Xplane.Com, July, 2017. http://canadianentrepreneurtraining.com/wpcontent/uploads/2019/03/empathy-map.png

Griffiths, P. E. (2008). History of ethology comes of age. Biology \& Philosophy, 23(1), 129-134. 
https://doi.org/10.1007/s10539-007-9075-9

Grisdale, E., Lind, S. E., Eacott, M. J., \& Williams, D. M. (2014). Self-referential memory in autism spectrum disorder and typical development: Exploring the ownership effect. Consciousness and Cognition, 30, $133-141$. https://doi.org/10.1016/j.concog.2014.08.023

Groen, Y., Fuermaier, A. B. M., Den Heijer, A. E., Tucha, O., \& Althaus, M. (2015). The Empathy and Systemizing Quotient: The Psychometric Properties of the Dutch Version and a Review of the Cross-Cultural Stability. Journal of Autism and Developmental Disorders, 45(9), 2848-2864. https://doi.org/10.1007/s10803-015-2448-z

Grondin, S. (2016). Psychology of percepcion (1a ed.). Springer Nature Switzerland AG. https://doi.org/10.1007/978-3319-31791-5

Gross, R. (2012). Psicología. La ciencia de la mente y la conducta (M. Moderno (ed.); 5a).

Grupo MU. (1993). Tratado del Signo Visual, para una retorica de la imagen. Catedra. Singo e imagen.

Haegele, M. (2017). Double-Digit Growth Highlights a Boom in Robotics. IEEE robotics \& magazine, 24(1), 12-14. www.ieee-ras.org/publications/ram

Halty, L., Martínez, A., Requena, C., Santos, J. M., \& Ortiz, T. (2011). Aportaciones desde la psicología. En Rev Neurol (Vol. 52). www.neurologia.com

Handel, S. (2019). Perceptual organization. An Integrated Multisensory Approach (1a ed.). Springer Nature Switzerland AG. https://doi.org/10.1007/978-3-319-96337-2

Harper, R., Rodden, T., Rogers, Y., \& Sellen, A. (2008). Being Human: Human-Computer Interaction in the year 2020. England: Microsoft Research Ltd.

Hasegawa, C., Kikuchi, M., Yoshimura, Y., Hiraishi, H., Munesue, T., Takesaki, N., Higashida, H., Oi, M., Minabe, Y., \& Asada, M. (2015). Changes in autistic trait indicators in parents and their children with ASD: A preliminary longitudinal study. Psychiatry Research, 228(3), 956-957. https://doi.org/10.1016/j.psychres.2015.05.048

Hedger, N., Haffey, A., McSorley, E., \& Chakrabarti, B. (2018). Empathy modulates the temporal structure of social attention. Proceedings of the Royal Society B: Biological Sciences, 285(1893). https://doi.org/10.1098/rspb.2018.1716

Hernández Sampieri, R., Fernández Collado, C., \& Baptista Lucio, P. (2014). Metodología de la investigación (6a ed.). Mc Graw Hill education.

Hobson, R. P. (1993). The emotional origins of social understanding. Philosophical Psychology, 6(3), $227-249$. https://doi.org/10.1080/09515089308573090

Hong, T. S., Mohamaddan, S., Shazali, S. T. S., Mohtadzar, N. A. A., \& Bakar, R. A. (2016). A review on assistive tools for autistic patients. IECBES 2016 - IEEE-EMBS Conference on Biomedical Engineering and Sciences, 51-56. https://doi.org/10.1109/IECBES.2016.7843413

Huang, A. X., Hughes, T. L., Sutton, L. R., Lawrence, M., Chen, X., Ji, Z., \& Zeleke, W. (2017). Understanding the self in individuals with Autism Spectrum Disorders (ASD): A review of literature. Frontiers in Psychology, 8(AUG), 18. https://doi.org/10.3389/fpsyg.2017.01422

Huijnen, C. A. G. J., Lexis, M. A. S., Jansens, R., \& de Witte, L. P. (2017). How to Implement Robots in Interventions for Children with Autism? A Co-creation Study Involving People with Autism, Parents and Professionals. Journal of Autism and Developmental Disorders, 47(10), 3079-3096. https://doi.org/10.1007/s10803-017-3235-9

Hull, L., Mandy, W., \& Petrides, K. V. (2017). Behavioural and cognitive sex/gender differences in autism spectrum condition and typically developing males and females. Autism, 21(6), 706-727. https://doi.org/10.1177/1362361316669087

Hutchinson, B. T. (2019). Toward a theory of consciousness: A review of the neural correlates of inattentional blindness. Neuroscience and Biobehavioral Reviews, 104(March), 87-99. https://doi.org/10.1016/j.neubiorev.2019.06.003

IEEE, I. of E. and E. E. (2020). ROBOTS: Your Guide to the World of Robotics. https://robots.ieee.org/robots/?t=sort

IFR, I. F. of robotics. (2020). Timeline History, Robot. https://ifr.org/robot-history

INEGI, I. nacional de estadistica y geografía. (2014). La discapacidad en México, datos al 2014. Inegi, 368.

Infoabe. (2018). "Adiós a Asimo ": el grupo Honda puso fin al desarrollo de un robot pionero. https://www.infobae.com/america/tecno/2018/06/28/adios-a-asimo-el-grupo-honda-puso-fin-al-desarrollo-de-unrobot-pionero/

ISO, I. O. for S. (2019). Iso 9241-210: 2019. Ergonomía de la interacción humano-sistema. Parte 210: Diseño centrado en el ser humano para sistemas interactivos. https://www.iso.org/standard/77520.html

Jain, S., \& Asawa, K. (2019). Modeling of emotion elicitation conditions for a cognitive-emotive architecture. Cognitive Systems Research, 55, 60-76. https://doi.org/10.1016/j.cogsys.2018.12.012

Javed, H., \& Park, C. H. (2019). Interactions with an Empathetic Agent: Regulating Emotions and Improving Engagement in Autism. En IEEE Robotics and Automation Magazine (Vol. 26, Número 2, pp. 40-48). Institute of Electrical and Electronics Engineers Inc. https://doi.org/10.1109/MRA.2019.2904638

Jaynes, J. (1969). The historical origins of "Ethology" and "Comparative psychology". Animal Behaviour, 17(4), 601- 
606. https://doi.org/10.1016/S0003-3472(69)80001-1

Jones, C. R. G., Simonoff, E., Baird, G., Pickles, A., Marsden, A. J. S., Tregay, J., Happé, F., \& Charman, T. (2018). The association between theory of mind, executive function, and the symptoms of autism spectrum disorder. Autism Research, 11(1), 95-109. https://doi.org/10.1002/aur.1873

Jyoti, V., \& Lahiri, U. (2020). Human-Computer Interaction based Joint Attention cues: Implications on functional and physiological measures for children with autism spectrum disorder. Computers in Human Behavior, 104(June 2019), 106163. https://doi.org/10.1016/j.chb.2019.106163

Kasari, C., Gulsrud, A., Paparella, T., Helleman, G., \& Berry, K. (2015). Randomized comparative efficacy study of parent-mediated interventions for ...: EBSCOhost. Journal of Consulting and Clinical Psychology, 83(3), 554-563. http://web.b.ebscohost.com.turing.library.northwestern.edu/ehost/pdfviewer/pdfviewer?vid=12\&sid=8c4bc84a3fd2-40f4-bea5-39ef367825cc\%40sessionmgr103

Kerlinger, F. N., \& Lee, H. B. (2013). Investigación del comportamiento (4a).

Kilroy, E., Aziz-Zadeh, L., \& Cermak, S. (2019). Ayres theories of autism and sensory integration revisited: What contemporary neuroscience has to say. Brain Sciences, 9(3). https://doi.org/10.3390/brainsci9030068

Kingstone, A., Laidlaw, K. E. W., Nasiopoulos, E., \& Risko, E. F. (2017). Cognitive Ethology and Social Attention. En On Human Nature: Biology, Psychology, Ethics, Politics, and Religion. Elsevier Inc. https://doi.org/10.1016/B9780-12-420190-3.00022-3

Király, I., Csibra, G., \& Gergely, G. (2013). Beyond rational imitation: Learning arbitrary means actions from communicative demonstrations. Journal of Experimental Child Psychology, 116(2), 471-486. https://doi.org/10.1016/j.jecp.2012.12.003

Koch, C. (2018). What is Consciousness? Nature, 557, S8-S12. https://doi.org/10.4324/9781315123554-5

Kory-Westlund, J. M., \& Breazeal, C. (2019). Exploring the Effects of a Social Robot's Speech Entrainment and Backstory on Young Children's Emotion, Rapport, Relationship, and Learning. Frontiers in Robotics and Al, 6(54), 1-24. https://doi.org/10.3389/frobt.2019.00054

Kouklari, E. C., Tsermentseli, S., \& Monks, C. P. (2019). Developmental trends of hot and cool executive function in school-aged children with and without autism spectrum disorder: Links with theory of mind. Development and Psychopathology, 31(2), 541-556. https://doi.org/10.1017/S0954579418000081

Kozima, H., Nakagawa, C., \& Yasuda, Y. (2007). Children-robot interaction: a pilot study in autism therapy. En Progress in Brain Research (Vol. 164, pp. 385-400). https://doi.org/10.1016/S0079-6123(07)64021-7

Kumazaki, H., Muramatsu, T., Yoshikawa, Y., Yoshimura, Y., Ikeda, T., Hasegawa, C., Saito, D. N., Shimaya, J., Ishiguro, H., Mimura, M., \& Kikuchi, M. (2019). Brief Report: A Novel System to Evaluate Autism Spectrum Disorders Using Two Humanoid Robots. Journal of Autism and Developmental Disorders, 49(4), 1709-1716. https://doi.org/10.1007/s10803-018-3848-7

Laureano-Cruces, A. L., Guadarrama-Ponce, C., \& Ramírez-Rodríguez, J. (2019). Motives and Personality: the case of Sr. and Jr. Trader. 6(4), 125-142.

Laureano-Cruces, A. L., Miranda-Rochin, E., Ramírez-Rodríguez, J., Mora-Torres, M., \& Sánchez-Guerrero, L. (2018). Emotions, Implicit Information that Allows the Conscious Phenomenon. IJISET-International Journal of Innovative Science, Engineering \& Technology, 5(10), 55-77. www.ijiset.com

Laureano-Cruces, A. L., Mora-Torres, M., Sánchez-Guerrero, L., Ramírez-Rodríguez, J., Montiel-Bernal, I. I., \& AllierPavia, E. B. (2015). Dynamic Interaction through a Reactive Interface in Patients with Dementia, by Means of Cognitive Stimulation. E-Health Telecommunication Systems and Networks, 04(04), 57-67. https://doi.org/10.4236/etsn.2015.44006

Laureano-Cruces, A. L., Ramírez Rodríguez, J., Mora-Torres, M., \& Sánchez-Guerrero, L. (2016). Artificial Self Awareness for Emergent Behavior. 5(1), 1-15. http://www.academicpub.org/fpbs/lssue.aspx? Volume=5\&Number=1\&Abstr=false

Laureano-Cruces, A. L., Sosa-Ortíz, A. L., Mora-Torres, M., Rodríguez-García, A., \& Ramírez-Rodríguez, J. (2013). La cosciencia como interfaz entre el mundo interno y externo. En Universidad Autónoma Metropolitana (Ed.), Avances de las mujeres en las ciencias las humanidades y todas las disciplinas: Vol. I (pp. 246-258). http://mujeresenlasciencias.azc.uam.mx/

Laureys, S., Owen, A. M., \& Schiff, N. D. (2004). Brain function in coma, vegetative state, and related disorders. Lancet Neurology, 3(9), 537-546. https://doi.org/10.1016/S1474-4422(04)00852-X

Laureys, S., Perrin, F., \& Brédart, S. (2007). Self-consciousness in non-communicative patients. Consciousness and Cognition, 16(3), 722-741. https://doi.org/10.1016/j.concog.2007.04.004

Lemaignan, S., Warnier, M., Sisbot, E. A., Clodic, A., \& Alami, R. (2017). Artificial cognition for social human-robot interaction: An implementation. Artificial Intelligence, 247, 45-69. https://doi.org/10.1016/j.artint.2016.07.002

Lewis, P. R., Chandra, A., Faniyi, F., Glette, K., Chen, T., Bahsoon, R., Torresen, J., \& Yao, X. (2015). Architectural aspects of self-Aware and self-expressive computing systems: From psychology to engineering. Computer, 48(8), 
62-70. https://doi.org/10.1109/MC.2015.235

Lisetti, C., \& Hudlicka, E. (2015). Why and How to Build Emotion-Based Agent Architectures. En R. Calvo, S. D'Mello, J. Gratch, A. Kappas, C. Lisetti, \& E. Hudlicka (Eds.), The Oxford Handbook of Affective Computing (pp. 94-109). https://doi.org/10.1093/oxfordhb/9780199942237.013.019

Liu, X., Liu, C., Zhou, X., Zhou, X., \& Jiang, A. (2015). Movement imitation underlying coaching platform for children with ASD. IEEE International Conference on Consumer Electronics-Taiwan, ICCE-TW, 57-58. https://doi.org/10.1109/ICCE-TW.2015.7217029

López, B., \& Leekam, S. R. (2007). Teoría de la coherencia central: Una revisión de los supuestos teóricos. Infancia y Aprendizaje, 30(3), 439-457. https://doi.org/10.1174/021037007781787462

Ley General de Educación para hacerla inclusiva, (2016).

http://comunicacion.senado.gob.mx/index.php/informacion/boletines/27889-se-modifica-ley-general-deeducacion-para-hacerla-inclusiva.html

Magariños de Morentin, J. A. (2008). La semiótica de los bordes: apuntes de metodologia semiotica. Fondo de Cultura Económica. http://www.magarinos.com.ar/Impresion.html

Málaga, I., Lago, R. B., Hedrera-Fernández, A., Álvarez-Álvarez, N., Oreña-Ansonera, V. A., \& Baeza-Velasco, M. (2019). Prevalence of autism spectrum disorders in USA, Europe and Spain: Coincidences and discrepancies. Medicina, 79(1), 4-9.

Marino, F., Chilà, P., Sfrazzetto, S. T., Carrozza, C., Crimi, I., Failla, C., Busà, M., Bernava, G., Tartarisco, G., Vagni, D., Ruta, L., \& Pioggia, G. (2019). Outcomes of a Robot-Assisted Social-Emotional Understanding Intervention for Young Children with Autism Spectrum Disorders. Journal of Autism and Developmental Disorders. https://doi.org/10.1007/s10803-019-03953-x

Martin, G. A. (2015). For the Love of Robots: Posthumanism in Latin American Science Fiction Between 1960-1999. Theses and Dissertations--Hispanic Studies University, 21, 287. https://search.proquest.com/docview/1923063080?accountid=50217

Martos Pérez, J., \& Paula Pérez, I. (2011). Una aproximación a las funciones ejecutivas en el trastorno del espectro autista. Revista de Neurología, 52(S01), S147. https://doi.org/10.33588/rn.52s01.2010816

Maurice, D. (1996). Las grandes etapas del progreso técnico (1a edición). Fondo de Cultura Económica.

Mavadati, S. M., Feng, H., Salvador, M., Silver, S., Gutierrez, A., \& Mahoor, M. H. (2016). Robot-based therapeutic protocol for training children with Autism. 25th IEEE International Symposium on Robot and Human Interactive Communication, RO-MAN 2016, 855-860. https://doi.org/10.1109/ROMAN.2016.7745219

McNabb, D. (2018). Hombre, signo y cosmos (1a.). Fondo de Cultura Económica.

Medavarapu, S., Marella, L. L., Sangem, A., \& Kairam, R. (2019). Where is the Evidence? A Narrative Literature Review of the Treatment Modalities for Autism Spectrum Disorders. Cureus, 11(1). https://doi.org/10.7759/cureus.3901

Meirelles, I. (2013). Design for Information: An Introduction to the Histories, Theories, and Best Practices Behind Effective Information (1a ed.). Rockport.

Melo Florián, A. (2011). Cerebro, mente y conciencia. Un enfoque multidisciplinario. Internal Medical Publishing.

Minsky, M. (2006). The emotion machine. Commonsense thinking, artificial intelligence, and the future of the human mind (1a ed.). Simon \& Schuster.

Moerland, T. M., Broekens, J., \& Jonker, C. M. (2018). Emotion in reinforcement learning agents and robots: a survey. En Machine Learning (Vol. 107, Número 2). Springer US. https://doi.org/10.1007/s10994-017-5666-0

Moore, P. (2017). Do we understand the relationship between affective computing, emotion and context-awareness? Machines, 5(3), 7-9. https://doi.org/10.3390/machines5030016

Mora-Torres, M. (2015). La representación cognoscitiva de las emociones como elemento que potencia la eficacia en la toma de decisiones de un agente pedagógico [UNAM]. https://repositorio.unam.mx/contenidos?c=Bd006G\&q=martha_._mora_.torres\&t=search_0\&as=0\&d=false\&a= $2 \& v=1$

Mora-Torres, M., Laureano-Cruces, A. L., Gamboa-Rodríguez, F., Ramírez-Rodríguez, J., \& Sánchez-Guerrero, L. (2014). An Affective-Motivational Interface for a Pedagogical Agent. International Journal of Intelligence Science, 04(01), 17-23. https://doi.org/10.4236/ijis.2014.41003

Mora-Torres, M., Laureano-Cruces, A. L., \& Velasco-Santos, P. (2011). Estructura de las emociones dentro de un proceso de enseñanza-aprendizaje1. Perfiles Educativos, 33(131), 64-79. https://doi.org/10.22201/iisue.24486167e.2011.131.24224

Morin, A. (2006). Levels of consciousness and self-awareness: A comparison and integration of various neurocognitive views. Consciousness and Cognition, 15(2), 358-371. https://doi.org/10.1016/j.concog.2005.09.006

Morin, A. (2011). Self-recognition, theory-of-mind, and self-awareness: What side are you on? Laterality, 16(3), 367383. https://doi.org/10.1080/13576501003702648

Morville, P. (2016). User Experience Honeycomb. (c) 2020 Semantic Studios . Diseño y desarrollo por Q LTD. 
https://intertwingled.org/user-experience-honeycomb/

Moya Albiol, L., Herrero Sebastián, N., \& Bernal Santacreu, M. C. (2019). Bases neuronales de la empatía. Revista de Neurología, 50(02), 89. https://doi.org/10.33588/rn.5002.2009111

Mrachko, A. A., \& Kaczmarek, L. A. (2017). Examining Paraprofessional Interventions to Increase Social Communication for Young Children With ASD. Topics in Early Childhood Special Education, 37(1), 4-15. https://doi.org/10.1177/0271121416662870

Mulas, F., Ros-Cervera, G., Millá, M. G., Etchepareborda, M. C., Abad-Mas, L., \& Téllez de Meneses, M. (2010). Modelos de intervención en niños con autismo. Revista de Neurologia, 50(Supl. 3: S77-S84). https://doi.org/DOI: https://doi.org/10.33588/rn.50S03.2009767

Muñoz Arteaga, J., González Calleros, C., \& Sánchez Huitón, A. (2015). la interaccion humano-computadora en mexico.pdf (Z. A. M. Elena (ed.)). Pearson education.

Muñoz Yunta, J. A., Montserrat, P. B., Salvadó Salvadó, B., \& Valls Santasusana, A. (2006). Autismo y epilepsia. Acta neurol. colomb, 112-117.

Myers, S. M., Johnson, C. P., Lipkin, P. H., Cartwright, J. D., Desch, L. W., Duby, J. C., Elias, E. R., Levey, E. B., Liptak, G. S., Murphy, N. A., Tilton, A. H., Lollar, D., Macias, M., McPherson, M., Olson, D. G., Strickland, B., Skipper, S. M., Ackermann, J., Del Monte, M., ... Yeargin-Allsopp, M. (2007). Management of children with autism spectrum disorders. Pediatrics, 120(5), 1162-1182. https://doi.org/10.1542/peds.2007-2362

Nicolescu, B. (2002). Manifesto of transdisciplinarity. Briefings in bioinformatics, 169. http://redcicue.org/attachments/article/138/2.2 TRANSDISCIPLINARIEDAD MANIFIESTO BASARAB NICOLESCU.pdf

Nishio, S., Ishiguro, H., \& Hagita, N. (2007). Geminoid: Teleoperated Android of an Existing Person. En A. C. de Pina Filho (Ed.), Intechopen: Vol. iJune (Número tourism, p. 13). https://doi.org/10.1016/j.colsurfa.2011.12.014

Noel, J. P., Faivre, N., Magosso, E., Blanke, O., Alais, D., \& Wallace, M. (2019). Multisensory perceptual awareness: Categorical or graded? Cortex, 120, 169-180. https://doi.org/10.1016/j.cortex.2019.05.018

Norman, D. A. (1988). La psicología de los objetos cotidianos (4a ed.). Nerea.

O’Nions, E., Sebastian, C. L., McCrory, E., Chantiluke, K., Happé, F., \& Viding, E. (2014). Neural bases of Theory of Mind in children with autism spectrum disorders and children with conduct problems and callous-unemotional traits. En Developmental science (Vol. 17, Número 5, pp. 786-796). https://doi.org/10.1111/desc.12167

Ochoa-Guaraca, M., Pulla-Sánchez, D., Robles-Bykbaev, V., López-Nores, M., Carpio-Moreta, M., \& García-Duque, J. (2017). A hybrid system based on robotic assistants and mobile applications to support in speech therapy for children with disabilities and communication disorders, Un sistema híbrido basado en asistentes robóticos y aplicaciones móviles para brindar soporte en la. Campus Virtuales, April. http://www.scopus.com/inward/record.url?eid=2-s2.0-85048288596\&partnerID=MN8TOARS

Oizumi, M., Albantakis, L., \& Tononi, G. (2014). From the Phenomenology to the Mechanisms of Consciousness: Integrated Information Theory 3.0. PLoS Computational Biology, 10(5). https://doi.org/10.1371/journal.pcbi.1003588

OMS, O. M. de la salud. (2019). Autism spectrum disorders. https://www.who.int/news-room/fact-sheets/detail/autismspectrum-disorders

Organización Mundial de la Salud, O. (2019). Trastornos del espectro autista Datos y cifras. OMS, Nota descriptiva. https://www.who.int/es/news-room/fact-sheets/detail/autism-spectrum-disorders

Organización Mundial de la Salud, \& Organización Panamericana de la Salud. (2001). Clasificación Internacional del Funcionamiento, de la Discapacidad y de la Salud. En Revista Española de Salud Pública (Vol. 76, Número 4). https://doi.org/10.1097/01.pep.0000245823.21888.71

Ortega, B. (2014). Tecnologías de la información y la comunicación para la innovación educativa. En Perfiles Educativos: Vol. XXXVI (144.

Ortony, A., Clore, G. L., \& Collins, A. (1996). La estructura cognitiva de las emociones. http://books.google.com/books?id=s-bruVe5ilUC\&pgis=1

Osborne-Crowley, K. (2020). Social Cognition in the Real World: Reconnecting the Study of Social Cognition With Social Reality. Review of General Psychology, 24(2), 144-158. https://doi.org/10.1177/1089268020906483

Ozonoff, S., Pennington, B. F., \& Rogers^, S. J. (1991). Executive Function Deficits in High-Functioning Autistic Individuals: Relationship to Theory of Mind. J. ChildPsychol. Psychiat, 32(7), 1081-1105.

Palacios-Villavicencio, M. L., Laureano-cruces, A. L., \& Arias-aguilar, J. A. (2020). Interaction between children of the autism spectrum and a humanoid robot modulated by levels of consciousness. International Journal of Innovative Science, Engineering \& Technology, 7(11), 121-133.ISSN (Online) 2348- 7968

Palacios-Villavicencio, M. L., Arias Aguilar, J. A., Auxilio Medina Nieto, M., \& Castillo Diego, T. I. (2015). Propuesta metodológica para el desarrollo de recursos didácticos con tecnologías interactivas para niños con Necesidades Educativas Especiales (NEE): redes multidisciplinarias. Academia Journals en Tecnologías, 1125-1130. 
http://www.academiajournals.com/publicaciones-colima

Palacios-Villavicencio, M. L., \& Olivos Contreras, R. (2011). Análisis de respuesta a estimulación sensorial táctil de niños con multidiscapacidad para el desarrollo de material didáctico como apoyo a la superación de actividades curriculares. $13^{\circ}$ Foro estatal de investigación científica y tecnológica, 261-264.

Palacios-Villavicencio, M. L., Pérez Humara, D. M., Olivos Contreras, M. R., Acosta Romero, A., Cortés Camacho, E., \& Vázquez Sánchez, J. (2012). Sensory space focused on elementary school children with disabilities in the Mixteca region, Oaxaca, Mexico. INTED2012 Proceedings, 1333-1341. https://library.iated.org/view/PALACIOSVILLAVICENCIO2012SEN

Papadopoulos, I., Koulouglioti, C., Lazzarino, R., \& Ali, S. (2020). Enablers and barriers to the implementation of socially assistive humanoid robots in health and social care: A systematic review. BMJ Open, 10(1), 1-13. https://doi.org/10.1136/bmjopen-2019-033096

Papazian, O., Alfonso, I., \& Luzondo, R. J. (2006). Trastornos de las funciones ejecutivas. REV NEUROL, 42 (Supl 3 , S45-S50.

Pastor-Cerezuela, G., Fernández-Andrés, M. I., Sanz-Cervera, P., \& Marín-Suelves, D. (2020). The impact of sensory processing on executive and cognitive functions in children with autism spectrum disorder in the school context. Research in Developmental Disabilities, 96(November 2019), 103540. https://doi.org/10.1016/j.ridd.2019.103540

Pedreño, C., Pousa, E., Navarro, J. B., Pàmias, M., \& Obiols, J. E. (2017). Exploring the Components of Advanced Theory of Mind in Autism Spectrum Disorder. Journal of Autism and Developmental Disorders, 47(8), $2401-2409$. https://doi.org/10.1007/s10803-017-3156-7

Pegoraro, L. F. L., Setz, E. Z. F., \& Dalgalarrondo, P. (2014). Ethological approach to autism spectrum disorders. Evolutionary psychology: an international journal of evolutionary approaches to psychology and behavior, 12(1), 223-244. https://doi.org/10.1177/147470491401200116

Peirce, C. S. (1894). ¿Qué es un signo? Obra Filosófica Reunida. Tomo II (1893-1913), 1894, 53-60.

Peirce, C. S. (1974). La ciencia de la semiótica. Ediciones nueva visión. Colección de semiología y epistemología. http://mastor.cl/blog/wp-content/uploads/2015/08/PEIRCE-CH.-S.-La-Ciencia-de-La-Semiótica.pdf

Peirce, C. S. (1987). Obra lógico semiótica (Armando Se). Taurus comunicación.

Peirce, C. S. (1998). The essential Peirce. Proyecto Peirce Edition 1998. https://peirce.sitehost.iu.edu/ep/ep2/ep2.htm

Peirce, C. S. (2003). LOS SIGNOS Y SUS OBJETOS (tomado de " Meaning ", 1910). 1910, 21-22.

Perinat Maceres, A. (1979). Socialización. Un enfoque comparativo y pluridisciplinar. Quaderns de Psicología, O(No. 1 (Época II)), 47-70. https://doi.org/10.5565/rev/qpsicologia.366

Perinat Maceres, A. (1980). Contribuciones de la Etología al Estudio del Desarrollo Humano y Socialización. El Basilisco, 11(Noviembre-Diciembre), 27-34. www.fgbueno.es

Perinat Maceres, A. (1982). Por un enfoque psicobiológico del desarrollo humano. Quaderns de Psicología, 6(1), 2-38. https://doi.org/10.5565/rev/qpsicologia.417

Peters-Scheffer, N., Didden, R., Korzilius, H., \& Sturmey, P. (2011). A meta-analytic study on the effectiveness of comprehensive ABA-based early intervention programs for children with Autism Spectrum Disorders. Research in Autism Spectrum Disorders, 5(1), 60-69. https://doi.org/10.1016/j.rasd.2010.03.011

Peterson, C. C., Slaughter, V., \& Brownell, C. (2015). Children with autism spectrum disorder are skilled at reading emotion body language. Journal of Experimental Child Psychology, 139, 35-50. https://doi.org/10.1016/j.jecp.2015.04.012

Picard, R. W. (1988). K-bits ¿ordenadores con emociones? (1a ed.). Arial.

Picard, R. W. (1997). Affective Computing. Massachusetts Institute of Technology.

Pinales, F. J., César, D., \& Amador, E. V. (2014). Algoritmos resueltos con diagramas problemario de flujo y pseudocódigo. https://www.uaa.mx/direcciones/dgdv/editorial/docs/algoritmos.pdf

Posada-de la Paz, M., Ferrari-Arroyo, M. J., Touriño, E., \& Boada, L. (2005). Investigación epidemiológica en el autismo: una visión integradora. Revista de Neurología, 40((Supl 1)), S191-S198.

Premack, D., \& Woodruff, G. (1978). Premack and Woodruff: Chimpanzee theory of mind. Behavioral and Brain Sciences, 4(1978), 515-526.

Ramírez-Laureano, E., Laureano-cruces, A. L., Ledo-mezquita, Y., \& Flores-mendoza, C. (2018). Conscious interfaces : a shared responsibility. IJISET - International Journal of Innovative Science, Engineering \& Technology, 5(1).

Rebollo, M. A., \& Montiel, S. (2006). Atención y funciones ejecutivas.

Redfield, R. R., Kent, C. K., Leahy, M. A., Martinroe, J. C., Spriggs, S. R., Yang, T., Doan, Q. M., King, P. H., Maitland, P. D., Starr, T. M., Yang, M., Jones, T. F., Boulton, M. L., Caine, V. A., Daniel, K. L., Fielding, J. E., Fleming, D. W., Halperin, W. E., Holmes, K. K., ... Schaffner, W. (2014). Morbidity and Mortality Weekly Report Prevalence of Autism Spectrum Disorder Among Children Aged 8 Years-Autism and Developmental Disabilities Monitoring Network, 11 Sites, United States, 2014 Centers for Disease Control and Prevention MMWR Editorial and. MMWR Surveill Summ., 67(6), 2. https://www.cdc.gov/mmwr/volumes/67/ss/pdfs/ss6706a1-H.pdf 
Rivière, A. (1997). Desarrollo normal y Autismo (1/2). Curso de Desarrollo Normal y Autismo, celebrado los días 24, 25, 26 y 27 de septiembre de 1997 en el Casino Taoro, Puerto de la Cruz, Santa Cruz de Tenerife (España), 39. https://personal.us.es/cvm/docs/Desarrollo normal y Autismo_Angel Riviere_1.pdf

Rizzolatti, G., \& Sinigaglia, C. (2016). The mirror mechanism: A basic principle of brain function. Nature Reviews Neuroscience, 17(12), 757-765. https://doi.org/10.1038/nrn.2016.135

Robertson, C. E., \& Baron-Cohen, S. (2017). Sensory perception in autism. Nature Reviews Neuroscience, 18(11), 671-684. https://doi.org/10.1038/nrn.2017.112

Robins, B., Dautenhahn, K., Boekhorst, R. Te, \& Billard, A. (2005). Robotic assistants in therapy and education of children with autism: Can a small humanoid robot help encourage social interaction skills? Universal Access in the Information Society, 4(2), 105-120. https://doi.org/10.1007/s10209-005-0116-3

Rohaut, B., \& Naccache, L. (2017). Disentangling conscious from unconscious cognitive processing with event-related EEG potentials. Revue Neurologique, 173(7-8), 521-528. https://doi.org/10.1016/j.neurol.2017.08.001

Rutter, M., Bailey, A., \& Lord, C. (2005). SCQ. Cuestionario de Comunicación Social (TEA Ediciones). TEA.

Salazar Mora, R. (s/f). Material didáctico multimedia como apoyo para estimular la atención de niños con Trastorno de Espectro Autista (TEA). [Tesis de licenciatura inédita].Universidad Tecnológica de la Mixteca.

Sampedro, J. (2016, enero). Marvin Minsky, cerebro de la inteligencia artificial | Ciencia | EL PAís. 26 Enero de 2016. https://elpais.com/elpais/2016/01/26/ciencia/1453809513_840043.html

Scherer, K. R. (2018). Towards a prediction and data driven computational process model of emotion.

Schön, E. M., Thomaschewski, J., \& Escalona, M. J. (2017). Agile Requirements Engineering: A systematic literature review. Computer Standards and Interfaces, 49, 79-91. https://doi.org/10.1016/j.csi.2016.08.011

Schreibman, L., Dawson, G., Stahmer, A. C., Landa, R., Rogers, S. J., McGee, G. G., Kasari, C., Ingersoll, B., Kaiser, A. P., Bruinsma, Y., McNerney, E., Wetherby, A., \& Halladay, A. (2015). Naturalistic Developmental Behavioral Interventions: Empirically Validated Treatments for Autism Spectrum Disorder. Journal of Autism and Developmental Disorders, 45(8), 2411-2428. https://doi.org/10.1007/s10803-015-2407-8

Scolari, C. (2004). Hacer Clic. Hacia una sociosemiótica de las interacciones digitales (1a.). Gedisa editorial.

Shapiro, M. (2010). Once upon a stacked times series. En J. Steele \& I. Noah (Eds.), Beautiful visualization. Looking at data through the eyes of experts (1a ed., p. 397). O'Reilly.

Silva, C., Da Fonseca, D., Esteves, F., \& Deruelle, C. (2015). Motivational approach and avoidance in autism spectrum disorder: A comparison between real photographs and cartoons. Research in Autism Spectrum Disorders, 17, 13-24. https://doi.org/10.1016/j.rasd.2015.05.004

Smith, E. E. (2001). Cognitive Psychology: History Since. En International Encyclopedia of the Social \& Behavioral Sciences (pp. 2140-2147). Elsevier BV. https://doi.org/10.1016/b0-08-043076-7/01440-6

Soprano, A. M. (2014). Cómo evaluar la atenciòn y las funciones ejecutivas en niños y adolescentes (2a). Paidós.

Soriano Herrera, A., Arias-Aguilar, J. A., Palacios-Villavicencio, M. L., \& Bretado Gallegos, R. F. (2019). Enseñanza del jarabe mixteco a niños de educación primaria con apoyo de tecnología robótica humanoide. Cuadernos del Sur. Instituto Nacional de Antropología e Historia (INAH), 24(46), 90-109. https://doi.org/ISSN 2448-8836

Soto Rios, D. (2018). Implementación de un juego educativo utilizando estrategias de gamificación para adquirir competencias de conteo y resolución de problemas [TEsis de licenciatura, Universidad Tecnológica de la Mixteca]. Repositorio interno de la Universidad Tecnológica de la Mixteca. http://jupiter.utm.mx/ tesis_dig/13574.pdf

St. John, T., Dawson, G., \& Estes, A. (2018). Brief Report: Executive Function as a Predictor of Academic Achievement in School-Aged Children with ASD. Journal of Autism and Developmental Disorders, 48(1), 276-283. https://doi.org/10.1007/s10803-017-3296-9

Sumioka, H., Nishio, S., Minato, T., Yamazaki, R., \& Ishiguro, H. (2014). Minimal Human Design Approach for sonzaikan Media: Investigation of a Feeling of Human Presence. Cognitive Computation, 6(4), 760-774. https://doi.org/10.1007/s12559-014-9270-3

Szumski, G., Smogorzewska, J., Grygiel, P., \& Orlando, A. M. (2019). Examining the Effectiveness of Naturalistic Social Skills Training in Developing Social Skills and Theory of Mind in Preschoolers with ASD. Journal of Autism and Developmental Disorders, 49(7), 2822-2837. https://doi.org/10.1007/s10803-017-3377-9

Tentori, M., Escobedo, L., \& Balderas, G. (2015). A Smart Environment for Children with Autism. www.computer.org/pervasive

Tinbergen, N. (1975). Autism, stress, and ethology. Science, 188(4187), 405-406. https://doi.org/10.1126/science.188.4187.405

Tirapu-Ustárroz, J., \& Luna-Lario, P. (2011). Neuropsicología de las funciones ejecutivas. En J. Tirapu-Ustárroz, M. Ríos-Lago, \& F. Maestú (Eds.), Manual de neuropsicologia (2a , pp. 220-259). Viguera editores. https://www.neuropsicologueando.com/wp-content/uploads/manualNeuro2_muestra.pdf

Tirapu-Ustárroz, J., Muñoz-Céspedes, J. M., Pelegrín-Valero, C., \& Albéniz-Ferreras, A. (2005). Propuesta de un 
protocolo para la evaluación de las funciones ejecutivas. REV NEUROL, 41(3), 177-186.

Tononi, G. (2015). Integrated information theory. Scholarpedia, 10(1), 4164. https://doi.org/10.4249/scholarpedia.4164

Torske, T., Nærland, T., Øie, M. G., Stenberg, N., \& Andreassen, O. A. (2018). Metacognitive aspects of executive function are highly associated with social functioning on parent-rated measures in children with autism spectrum disorder. Frontiers in Behavioral Neuroscience, 11(January). https://doi.org/10.3389/fnbeh.2017.00258

Trujillo Suárez, M., Aguilar, J. J., \& Neira, C. (2016). Los métodos más característicos del diseño centrado en el usuario -DCU-, adaptados para el desarrollo de productos materiales. Iconofacto, 12(19), $215-236$. https://doi.org/10.18566/iconofact.v12.n19.a09

Turing, A. (1950). Computing Machinery and Intelligence. Mind, 49, 433-460.

University Waseda. (1973). Waseda robot. Humanoid Robotics Institute Waseda University, Japan, 4, 1-2. http://www.humanoid.waseda.ac.jp/booklet/kato_2.html

Varela, F., Thompson, E., \& Rosch, E. (1997). De cuerpo presente (2a ed.). Gedisa editorial.

Wainer, J., Robins, B., Amirabdollahian, F., \& Dautenhahn, K. (2014). Using the humanoid robot KASPAR to autonomously play triadic games and facilitate collaborative play among children with autism. IEEE Transactions on Autonomous Mental Development, 6(3), 183-199. https://doi.org/10.1109/TAMD.2014.2303116

Warren, Z. E., Zheng, Z., Swanson, A. R., Bekele, E., Zhang, L., Crittendon, J. A., Weitlauf, A. F., \& Sarkar, N. (2015). Can Robotic Interaction Improve Joint Attention Skills? Journal of Autism and Developmental Disorders, 45(11), 3726-3734. https://doi.org/10.1007/s10803-013-1918-4

Warrier, V., \& Baron-Cohen, S. (2018). Genetic contribution to "theory of mind" in adolescence. Scientific Reports, 8(1), 1-9. https://doi.org/10.1038/s41598-018-21737-8

Wiese, E., Metta, G., \& Wykowska, A. (2017). Robots as intentional agents: Using neuroscientific methods to make robots appear more social. Frontiers in Psychology, 8(OCT), 1-19. https://doi.org/10.3389/fpsyg.2017.01663

Wiltshire, T. J., \& Fiore, S. M. (2014). Social cognitive and affective neuroscience in human-machine systems: A roadmap for improving training, human-robot interaction, and team performance. IEEE Transactions on HumanMachine Systems, 44(6), 779-787. https://doi.org/10.1109/THMS.2014.2343996

WOH, (2018). ICD-11 (Número June). https://www.who.int/classifications/icd/en/

Yun, S. S., Kim, H., Choi, J., Park, S. K., Sang-Seok, Y., Hyuksoo, K., Jongsuk, C., \& Sung Kee, P. (2016). A robotassisted behavioral intervention system for children with autism spectrum disorders. Robotics and Autonomous Systems, 76, 58-67. https://doi.org/10.1016/j.robot.2015.11.004

Zahavi, D. (2018). Consciousness, Self-Consciousness, Selfhood: a Reply to some Critics. Review of Philosophy and Psychology, 9(3), 703-718. https://doi.org/10.1007/s13164-018-0403-6

Zecchetto, V. (2005). Seis semiólogos en busca del lector. (1a ed.). La crujia. https://www.escrituradigital.net/wiki/images/Seis-semiologos-en-busca-del-lector-zechetto-veron-eco.pdf

Zheng, Z., Zhang, L., Bekele, E., Swanson, A., Crittendon, J. A., Warren, Z., \& Sarkar, N. (2013). Impact of robotmediated interaction system on joint attention skills for children with autism. IEEE International Conference on Rehabilitation Robotics. https://doi.org/10.1109/ICORR.2013.6650408 


\section{Anexos}

\section{Anexo 1}

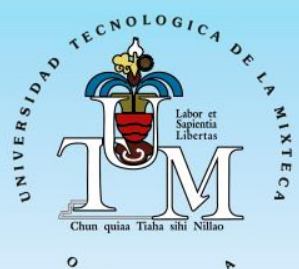

La Universidad Tecnológica de la Mixteca

a través del Cuerpo Académico

Integración Multidisciplinaria del Diseño en México

I N V I T A

a la conferencia-taller

\section{Funciones Ejecutivas en el Autismo*}

y su relación con la adaptabilidad social y funcional

Impartido por el Dr. Marcel Arvea

viernes 16 de junio de 2017

de $10: 00$ a $14: 00$ hrs

\section{y al curso}

\section{Signos gráficos de comunicación para mejorar las}

Funciones Ejecutivas de mi hijo o hija con TEA*

impartido por la Mtra. María de la Luz Palacios Villavicencio

Inicia el 19 de junio de 2017

Inscripciones

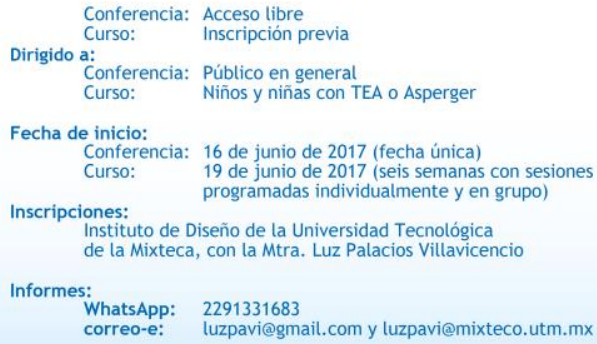

Durante el curso se realizarán interacciones con el robot NAO y los participantes

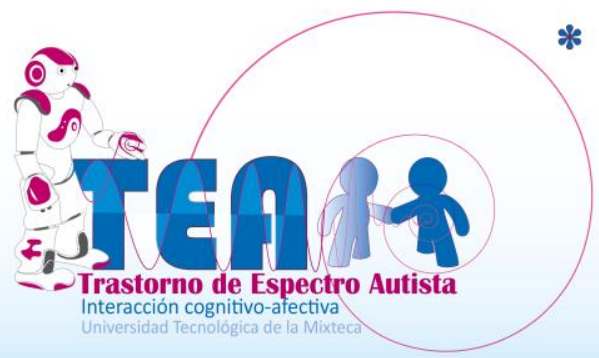




\section{Anexo 2}

Resumen de tesis 1. David Soto Ríos

Título: $\quad$ Implementación de un juego educativo utilizando estrategias de gamificación para adquirir

competencias de conteo y resolución de problemas.

Dirección: $\quad$ Directora: Lluvia Morales Reynaga

Codirectora: María de la Luz Palacios Villavicencio

Tabla 31. Resumen de aportación de tesis de Soto (2018)

\begin{tabular}{ll} 
Producto & Aplicación para computadora \\
\hline Carrera & Ing. en computación de la Universidad Tecnológica de la Mixteca \\
\hline Objetivo & $\begin{array}{l}\text { Brindar bases para adquirir competencias de aritmética básica para preescolar } \\
\text { actitud favorable hacia el aprendizaje de las competencias conteo y resolución de } \\
\text { problemas en niños de } 1^{\circ}, 2^{\circ} \text { y } 3^{\circ} \text { de preescolar. }\end{array}$ \\
\hline Aportación & $\begin{array}{l}\text { Conocimiento acerca de la forma en la que se relacionan los niños neurotípicos menores } \\
\text { de } 6 \text { años con la tecnología. Diseño de técnica persona }\end{array}$ \\
\hline Estado & $\begin{array}{l}\text { Titulado en julio } 2018 \\
\text { Fuente: elaboración propia }\end{array}$
\end{tabular}

El análisis de usuario se centró en niños de preescolar, de 3 y 6 años. Tener datos directos del comportamiento de estos niños, facilitó identificar los retos que implicaría diseñar y planear tareas para los niños con TEA. Es notable que los niños con TEA eran de un rango de mayor de edad. Sin embargo, por el nivel de maduración, la conducta detectada en los niños de preescolar fue un parámetro del comportamiento de los niños con TEA, aunque fueran mayores de edad. En la Figura 65, los niños fueron representados a través de la técnica de "persona".

Figura 63. Descripción de técnica "persona", de niños de 3 a 6 años (Soto, 2018)
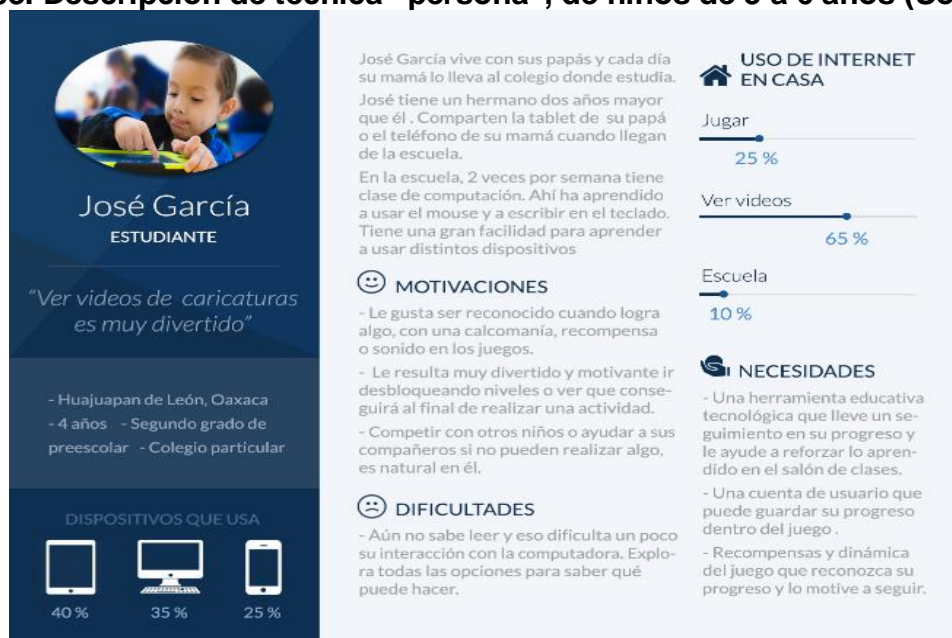

Nota. Material reproducido con autorización del autor 
Del trabajo de David se extrajo la información del estudio contextual de los niños. En la Tabla 36 y Figura 66, se describen algunos datos que se extrajeron del proceso de evaluación de los niños y que fueron pertinentes para la toma de decisiones de la presente tesis.

Tabla 32. Extracto de resultados de estudio contextual de niños de preescolar (Soto, 2018) Descripciones generales

- Si los niños aún no saben leer las instrucciones del juego deben ser auditivas. Tienen el impulso de buscar por su propia cuenta qué deben hacer. Son curiosos con la tecnología

- Son intuitivos

- $\quad$ No tienen miedo de explorar las opciones. Aprenden muy rápido

- Si algo les aburre o no les atrae, buscan o se entretiene con otra cosa

- A los niños les gusta más competir entre ellos para presumir que le ganaron al otro. Las niñas se concentran más en su juego y avanzan a su paso

- Dominan muy bien la computadora, la motricidad fina y gruesa. Tienen experiencia con la tecnología y no tienen problema en usarla

- Si algo no saben o no entienden, preguntan a sus compañeros o bien, rápidamente sus compañeros se percatan de ello y los auxilian

- Les emocionan frases de aliento cuando van contestando bien y sobre todo recibir pequeños trofeos o recompensas. Ser reconocidos por lo que hicieron les motiva mucho

- Les gustan mucho los juegos donde hay una continuidad, que tienen que ir contestando bien 0 desbloqueando pequeños contenidos para lograr un premio final

- Las maestras refieren que los niños son totalmente visuales y kinestésicos, siendo el juego una parte fundamental para su aprendizaje

Nota. El material es presentado con autorización del autor.

Material didáctico desarrollado

Figura 64. Aplicación para computadora como producto final de tesis de David Soto Ríos.
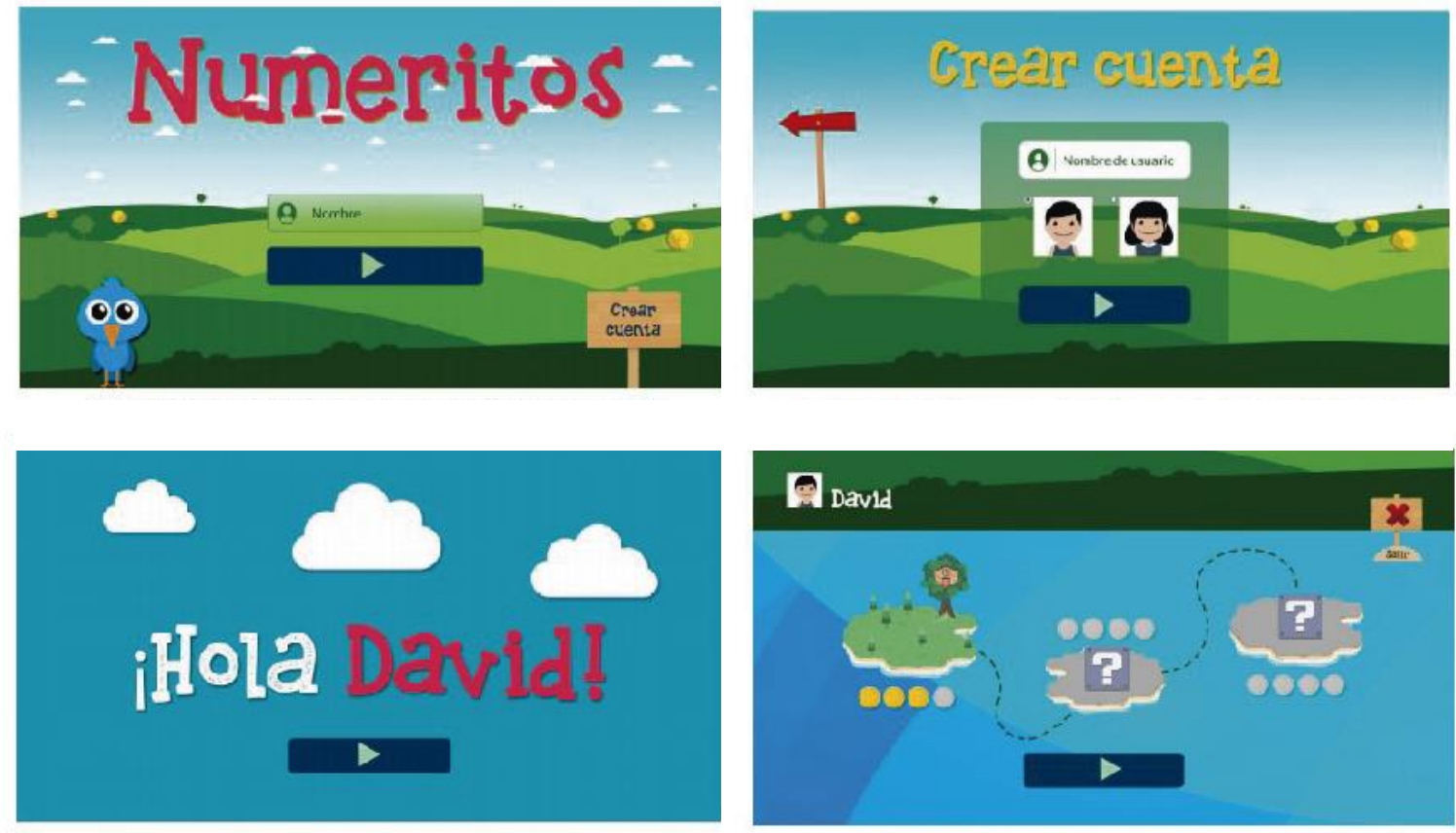

Nota. Material reproducido con autorización del autor ㄷ 
Resumen de tesis 2. Ramsés Salazar Mora

Título: $\quad$ Ármalo: material didáctico multimedia como apoyo para estimular la atención de niños con Trastorno de Espectro Autista (TEA)

Dirección: Directora: María de la Luz Palacios Villavicencio

Tabla 33. Resumen de aportación de tesis de Ramsés Salazar.

\begin{tabular}{ll} 
Producto & Aplicación para dispositivo móvil \\
\hline Carrera & Ing. en Diseño de la Universidad Tecnológica de la Mixteca \\
\hline Objetivo & $\begin{array}{l}\text { Estimular la atención visual global de niños con Estimular la atención visual global de } \\
\text { niños con Trastorno de Espectro Autista a través de una aplicación multimedia }\end{array}$ \\
\hline Aportación & $\begin{array}{l}\text { Desarrollo de fotodiario de niños con TEA grado } 3 \\
\text { Descripción posibles ejercicios básicos para lograr que los niños realicen actividades } \\
\text { dirigidas }\end{array}$ \\
\hline Estado & En proceso de finalización
\end{tabular}

Fuente: elaboración propia.

La aplicación ármalo se puso a prueba con niños de 3 a 5 años entre ellos niños con TEA grado dos. Las tareas consideraron tres elementos: colores, formas y tamaños. De los resultados se extrajo la Tabla 38 y Figura 67.

Tabla 34. Extracto de resultados de estudio contextual de niños de preescolar de la tesis de Ramsés Salazar. Descripciones generales

- Si las tareas son cortas es más fácil mantener la atención de los niños de edades menores a cinco años y niños con TEA de hasta 9 años.

- Realizar actividades con códigos de comunicación básicos como los colores, figuras y tamaños se logra que la atención no se mantenga por más tiempo sin distractores.

- $\quad$ Aunque los niños con TEA centren su atención principalmente en sus intereses personales, si se les presentan actividades de bajo contenido cognitivo se logra mantener su atención por más tiempo.

- $\quad$ Es recomendable emplear tareas académicas o pre-académicas de las que los niños tengan conocimiento.

- $\quad$ El uso de las estrategias de gamificación hace que las actividades sean más atractivas para los niños, para los niños con TEA, la gratificación verbal es muy útil y bien apreciada por los niños.

Nota: El material fue extraído con autorización del autor.. 


\section{Material didáctico desarrollado}

Figura 65. Aplicación móvil como producto final de tesis de Ramsés Salazar Mora (2020).
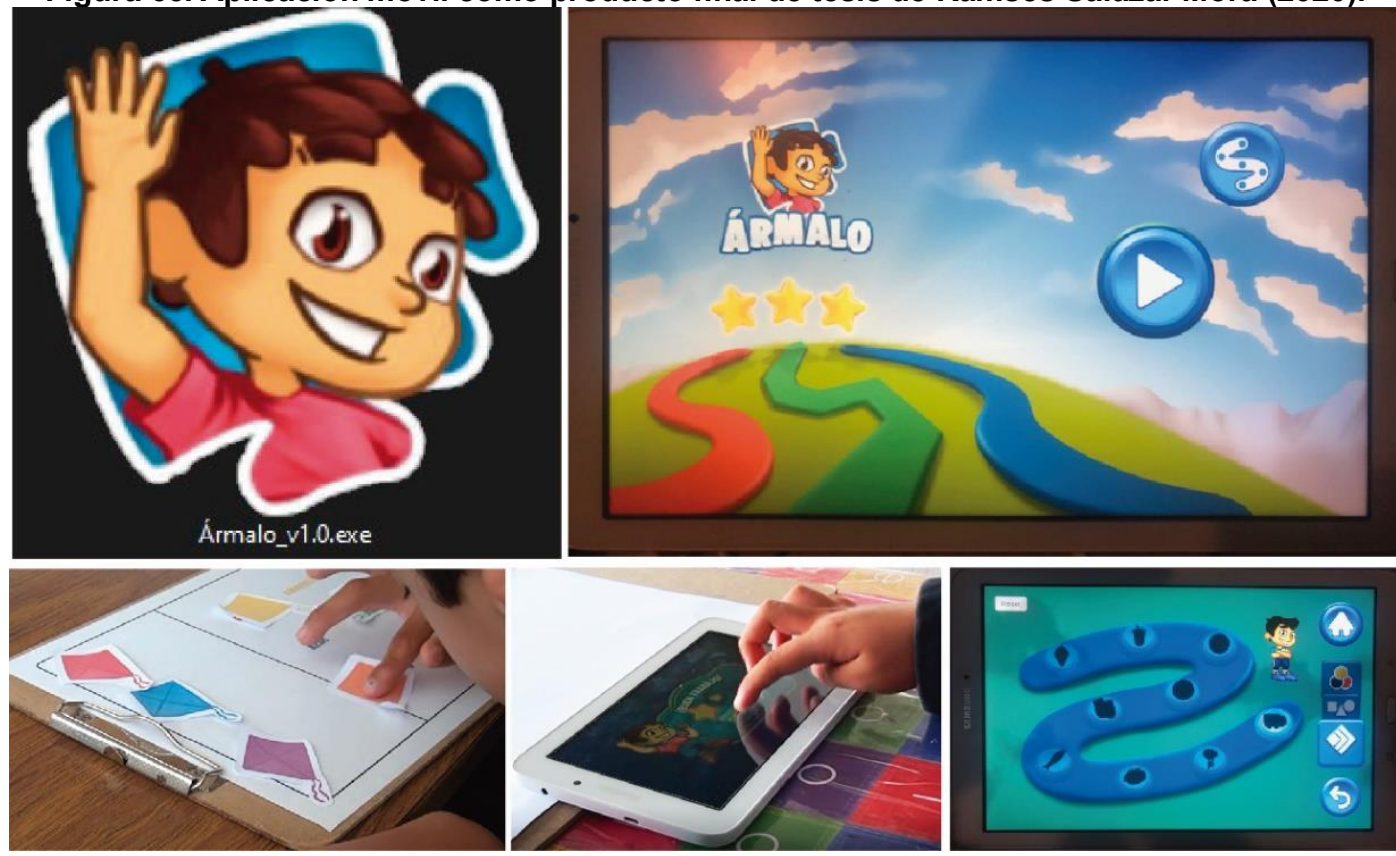

Fuente: Material reproducido con autorización del autor.

Resumen de tesis 3. Omar Gómez González

Título:

Dirección:

Entivo, dispositivo interactivo para ejercitar las funciones ejecutivas en niños con trastorno del espectro autista (TEA) grado 1

Directora: María de la Luz Palacios Villavicencio

Tabla 35. Resumen de aportación de tesis de Omar Gómez González (2020)

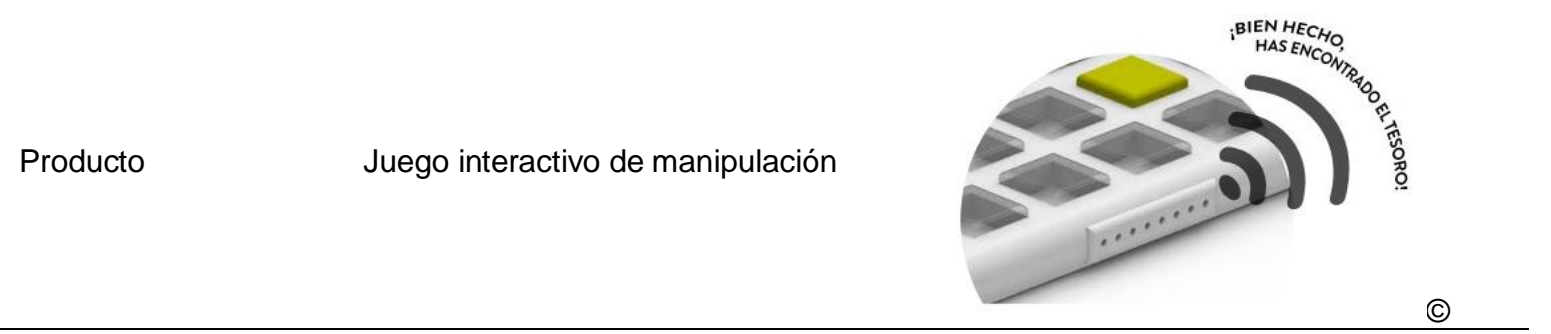

\begin{tabular}{ll}
\hline Carrera & Ing. en Diseño de la de la Universidad Tecnológica de la Mixteca \\
\hline \multirow{2}{*}{ Objetivo } & Facilitar el uso de la inhibición y la flexibilidad mental en niños con TEA \\
& Diseñar un dispositivo interactivo para ejercitar FE en niños con Trastorno del \\
& Espectro Autista (TEA) grado 1 \\
\hline Aportación & $\begin{array}{l}\text { Descripción del uso de las FE en niños con TEA descripción de posibles } \\
\text { escenarios para ser adaptados en interacciones con el robot }\end{array}$ \\
\hline Estado & Titulado en febrero 2020 \\
Fuente: elaboración propia
\end{tabular}


De la investigación de Omar Gómez, se extrajo un análisis del perfil de su usuario y se describieron las características de los niños de 6 a 11 años con TEA, quienes presentaron dificultades en algunas de sus FE como flexibilidad cognitiva, inhibición o memoria de trabajo (Tabla 40 y Figura 68). Esto motivó el desarrollo de su prototipo para poner en práctica dichas FE. Al mismo tiempo, el material sirvió para identificar el comportamiento de los niños en un contexto determinado y planear tareas de evaluación de las FE.

Tabla 36. Extracto de resultados de estudio contextual de niños de preescolar de la tesis Gómez (2020)

- Atracción por los estímulos sensoriales: luces, sonidos, imágenes

- Asiste a clases regulares, pero reciben atención complementaria en educación especial

- Presenta dificultades para la interacción social, especialmente con personas de su misma edad

- Presenta interpretación literal del lenguaje

- Presenta patrones de comportamiento

- Sus intereses son reducidos

- Dificultad para interpretar sentimientos y emociones propias y ajenas

- Graba todo lo que escucha y lo repite

- Su conciencia no es predictiva. Tarda un poco en comprender alguna dinámica, pero cuando lo hace se regula y puede entender que se va a acabar la lista de actividades.

- Parece no preocuparse de la gente o del entorno.

- Falta de interés para interactuar con las personas que los rodean

- Dificultad para identificar la secuenciación de tareas

- Dificultades para prestar atención e inhibir sus impulsos

- Dificultades para memorizar y recordar instrucciones

- Su pensamiento es lógico, sistemático, concreto, centrado e inflexible

- Puede reaccionar de manera inadecuada ante situaciones imprevistas

- Es visual y aprende mejor a través de imágenes

- Desarrolla y manifiesta una manera particular de comprender, comunicarse, pensar y actuar

- Dificultades para el uso del lenguaje con fines comunicativos (comprensión literal de lo que oyen o leen, no entienden los dobles sentidos, metáforas, ironías o chistes).

- Presenta problemas con los conceptos de tiempo, espacio y secuencia, generando una incapacidad para concentrarse en tareas simultaneas.

- Entiende las indicaciones cuando son cortas, claras y se dicen con seguridad. Si no ejecutan la orden necesitan que se las repitan una vez más

- Muestra interés por los animales, robots, caricaturas y dispositivo electrónicos.

- Le gusta las caricaturas, los videos, canciones, clasificar cosas y que le digan palabras motivadoras

- No le gusta el ruido, ir a lugares nuevos y hacer tarea ni quehaceres de la casa

- Orientación hacia objetos con movimiento, música, luces y sonidos

Nota. El material fue extraído con autorización del autor. 
Figura 66. Dispositivo de manipulación como producto final de tesis de Omar Gómez González (2020)
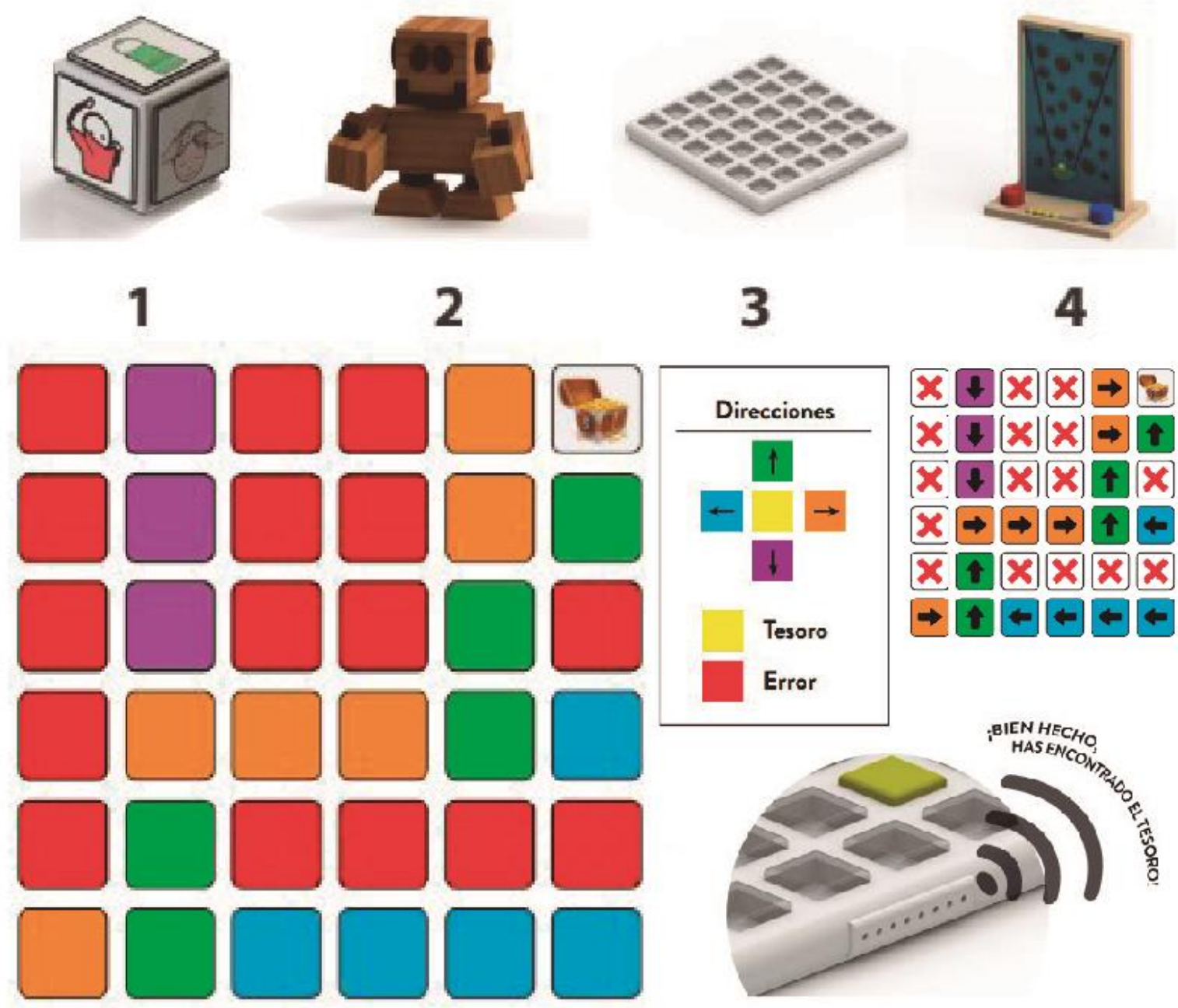

Nota. El material reproducido con autorización del autor. 


\section{Anexo 3}

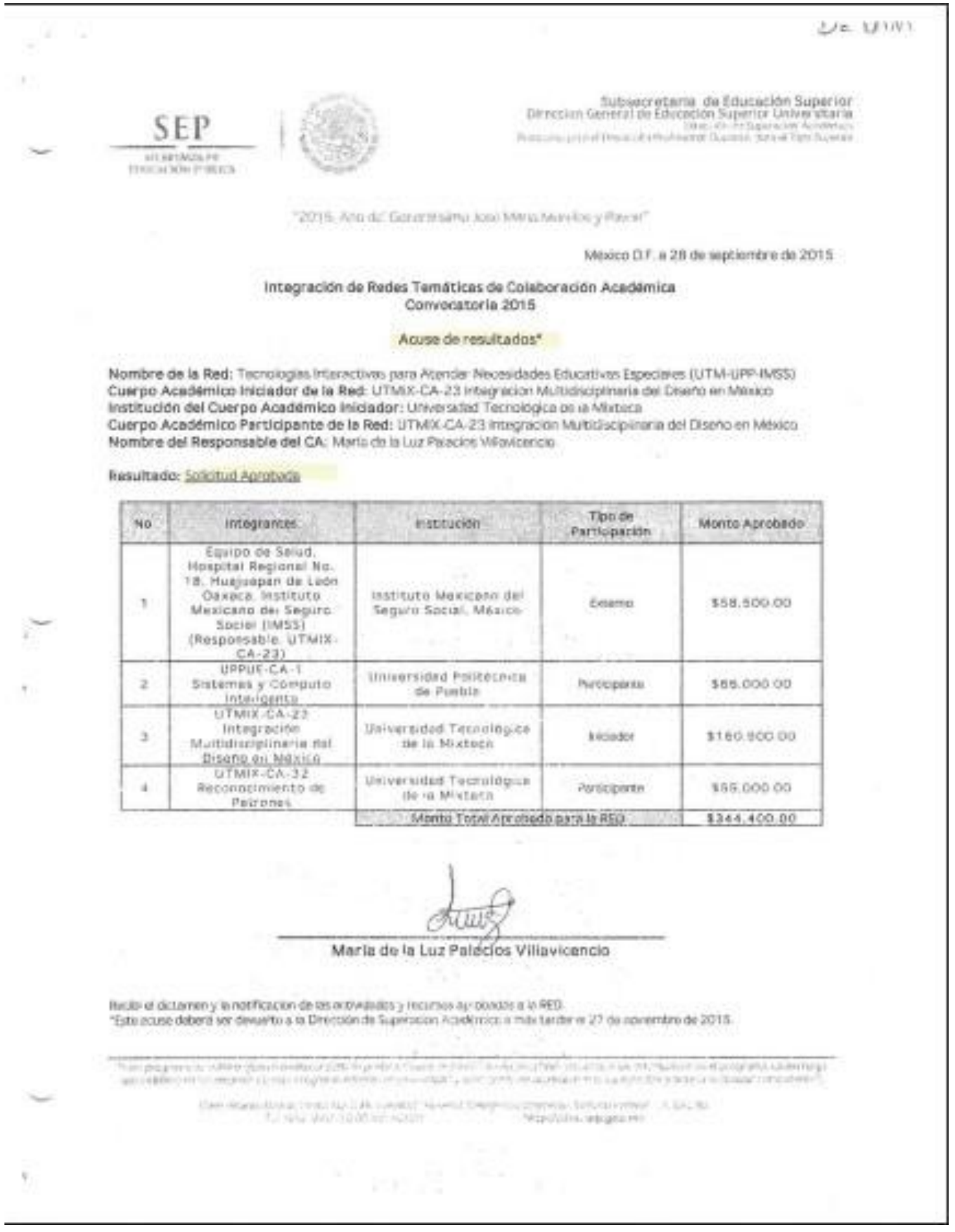


Anexo 4

\section{Detalles de la figura 54}

Diagrama de flujo del módulo 1 del modelo de interacción

Módulo 1

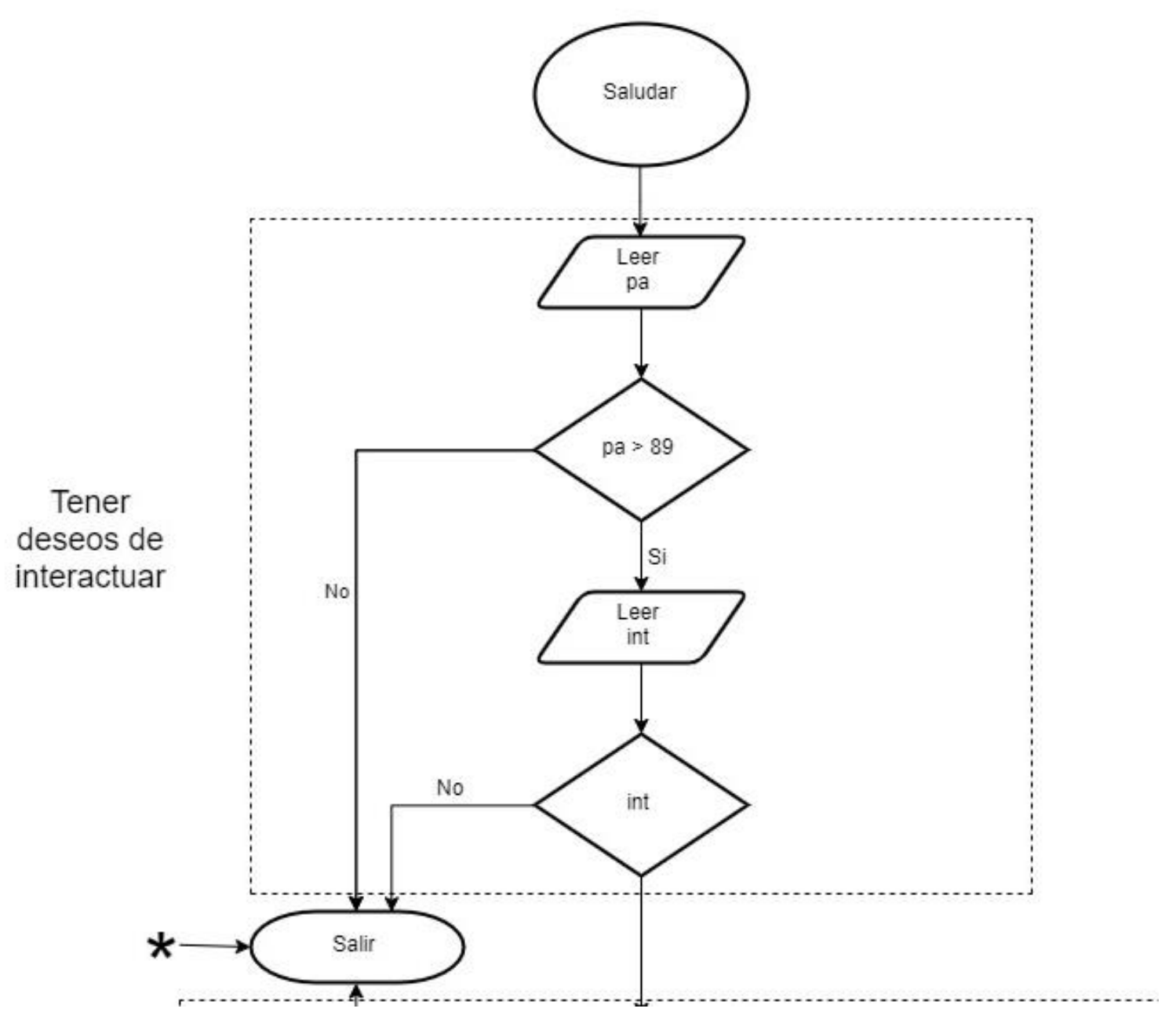




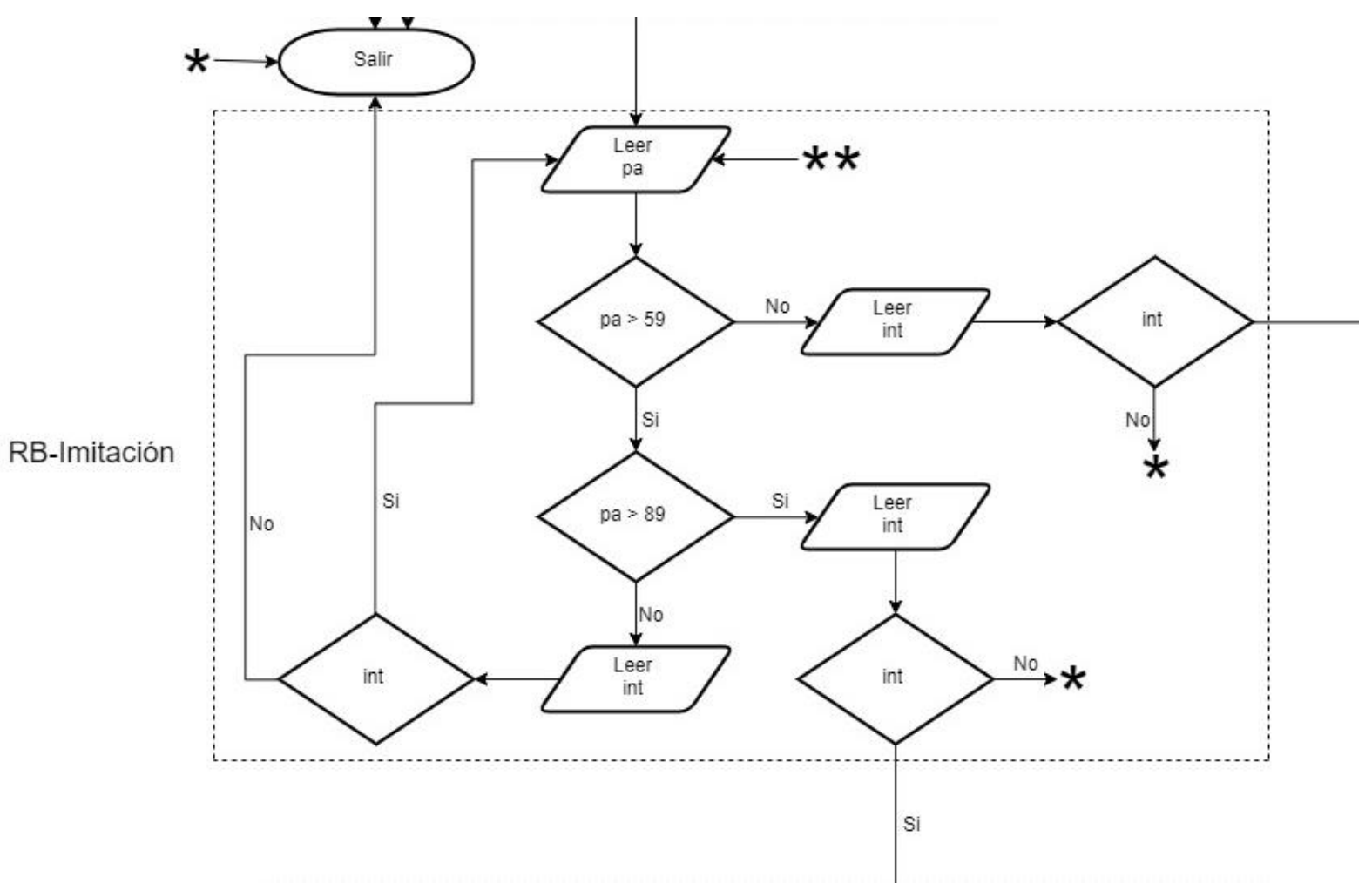

$\mathrm{Si}$

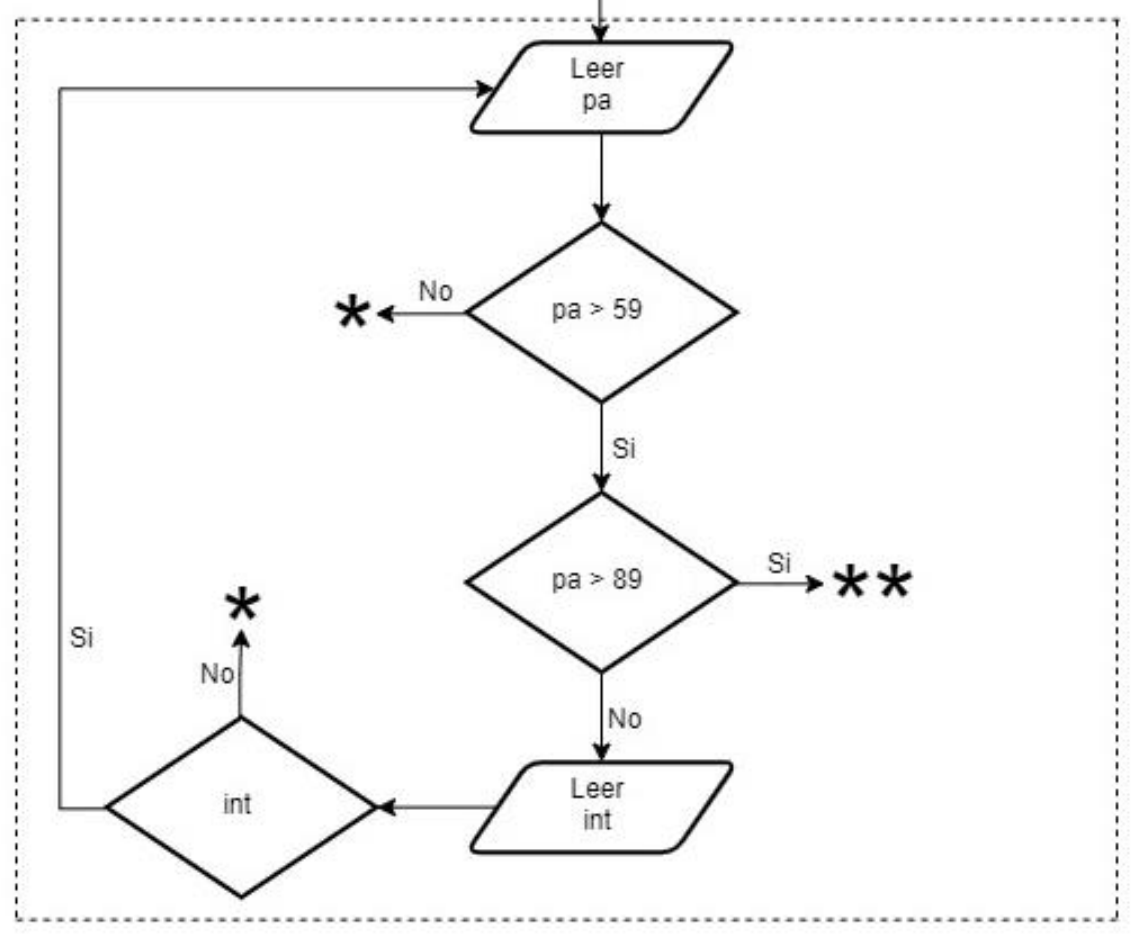

RB-Atención 


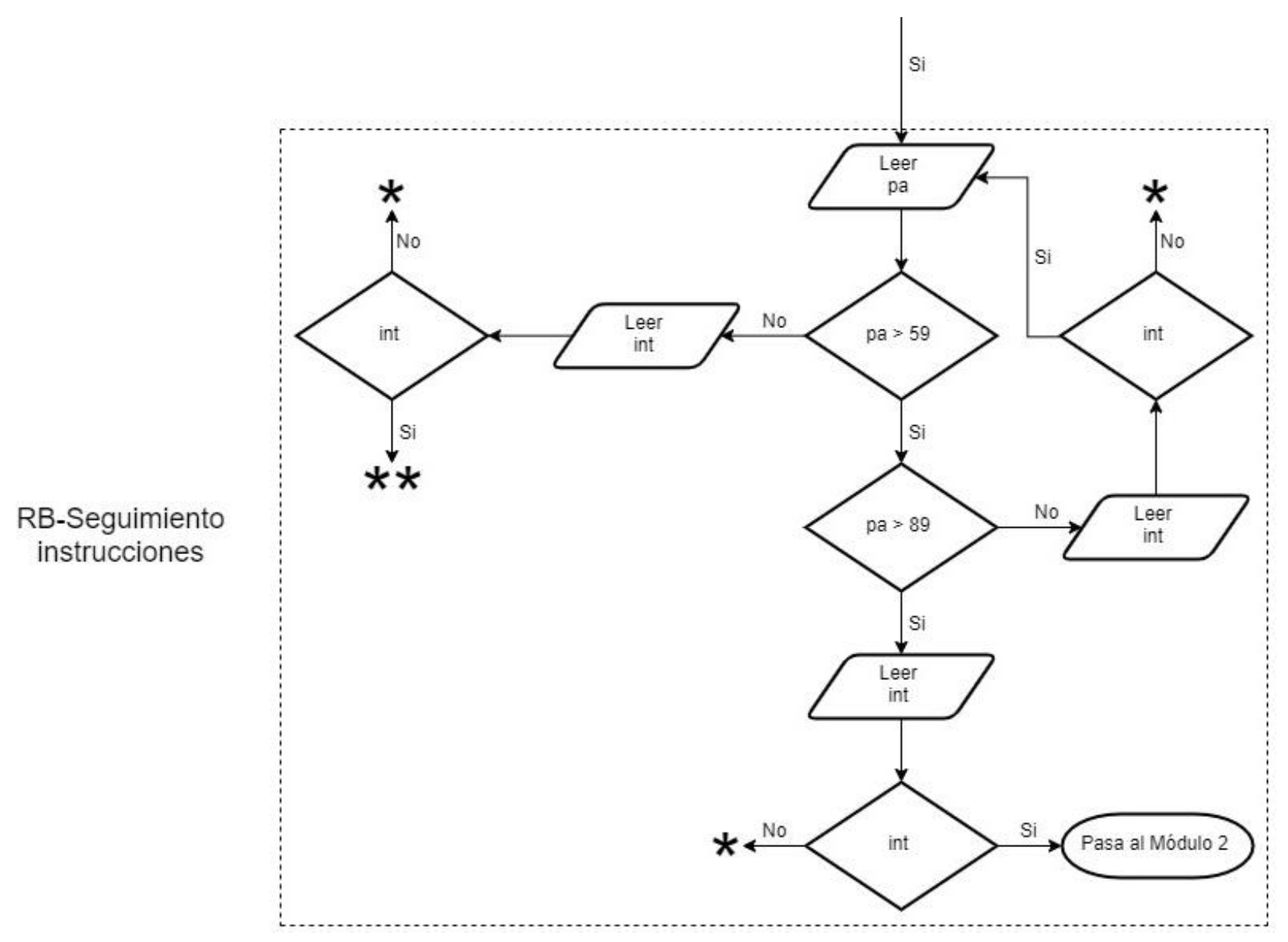




\section{Diagrama de flujo del módulo 1 del modelo estructural de interacción}

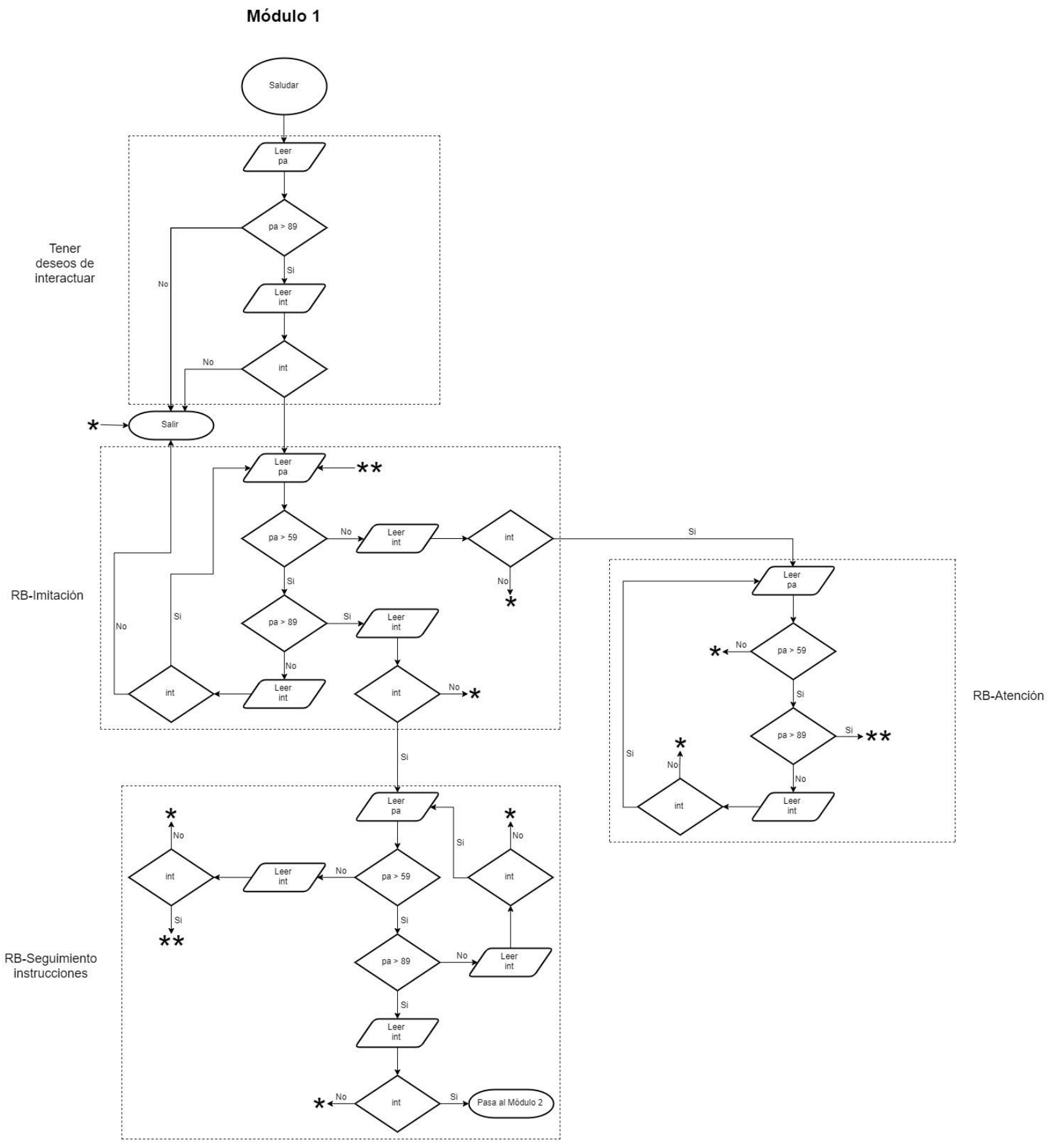




\section{Psudocódigo del módulo 1 del modelo de interacción}

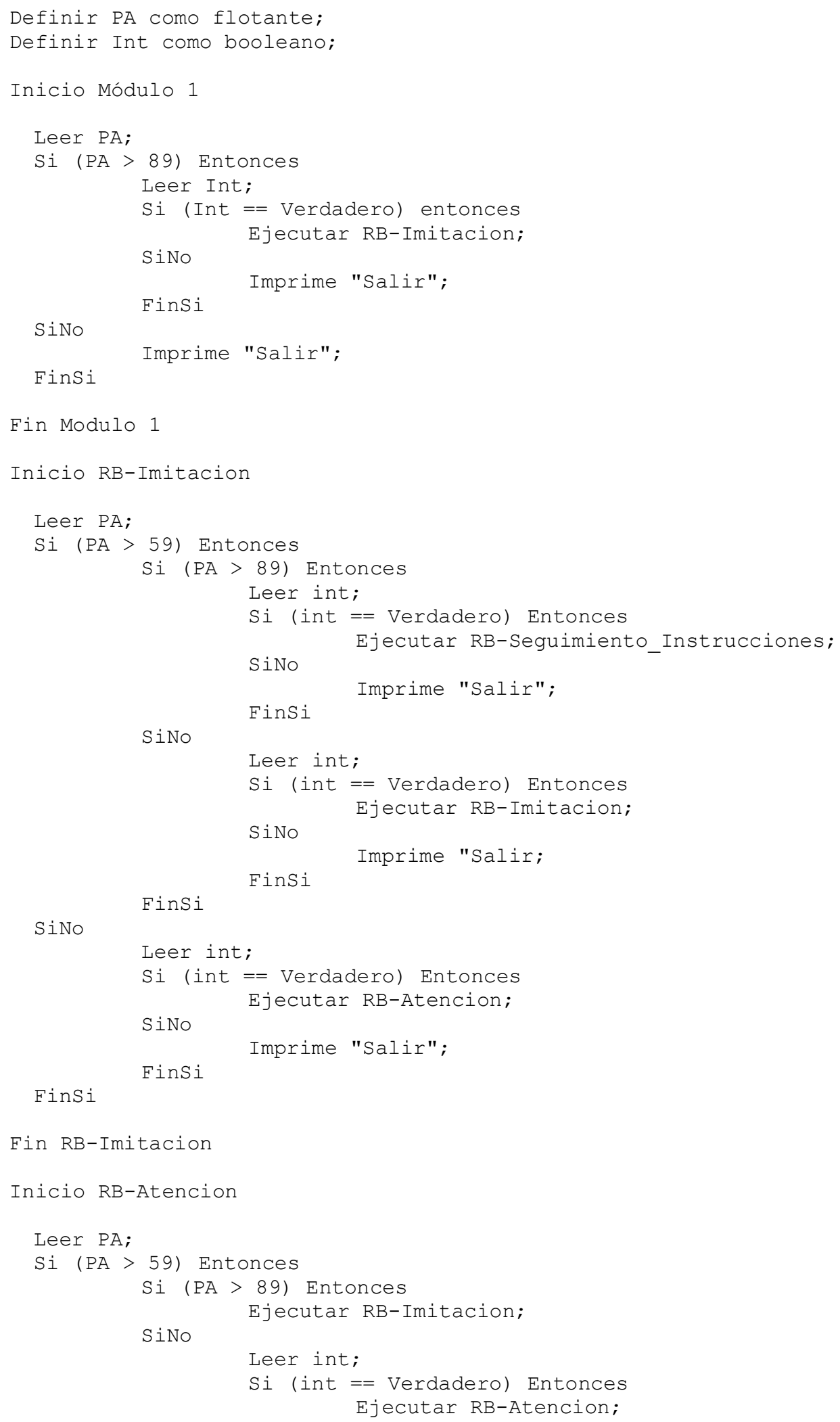




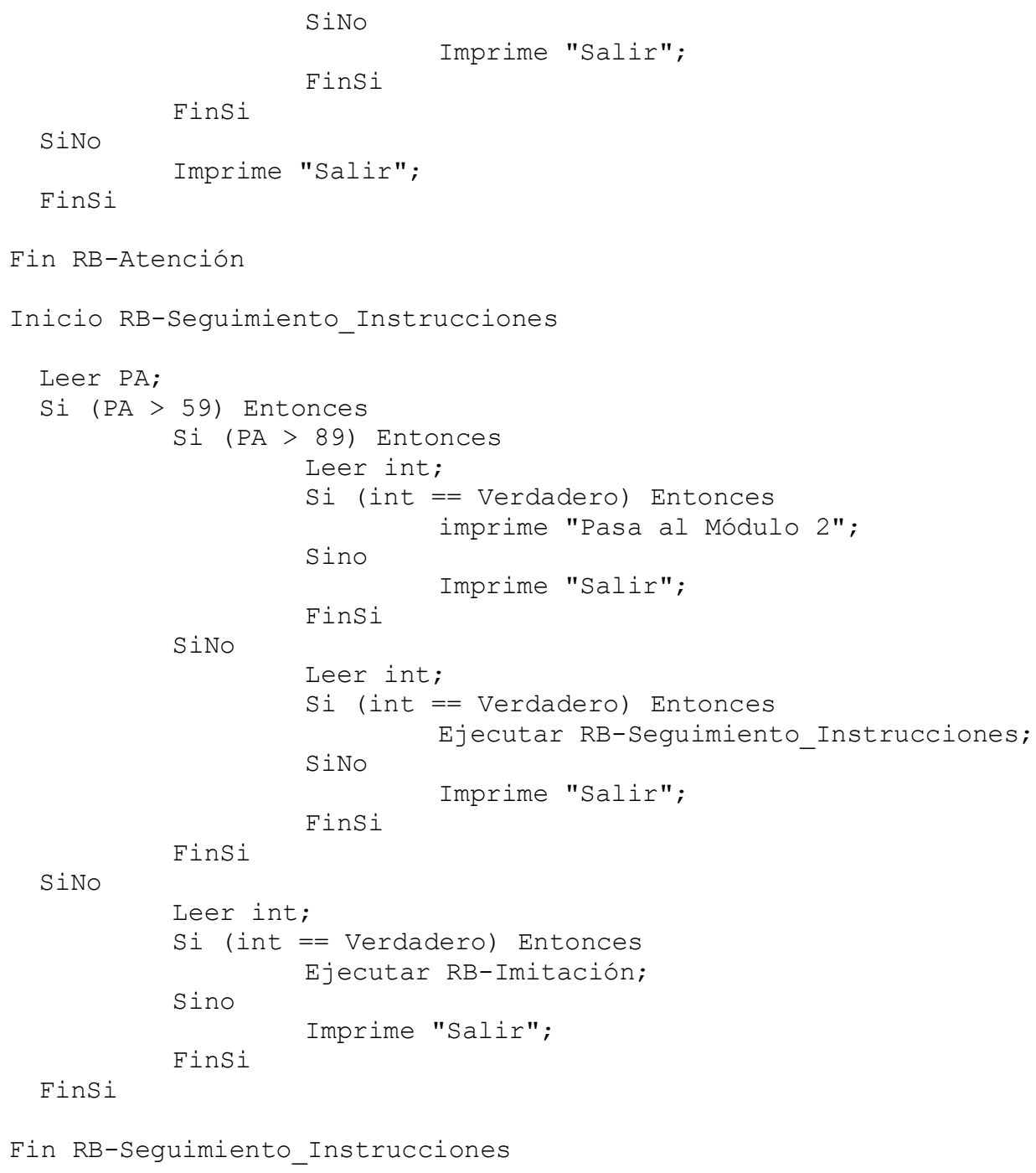




\section{Anexo 5}

\section{Detalles de la figura 56}

Diagrama de flujo del módulo 2 del modelo de interacción

Módulo 2

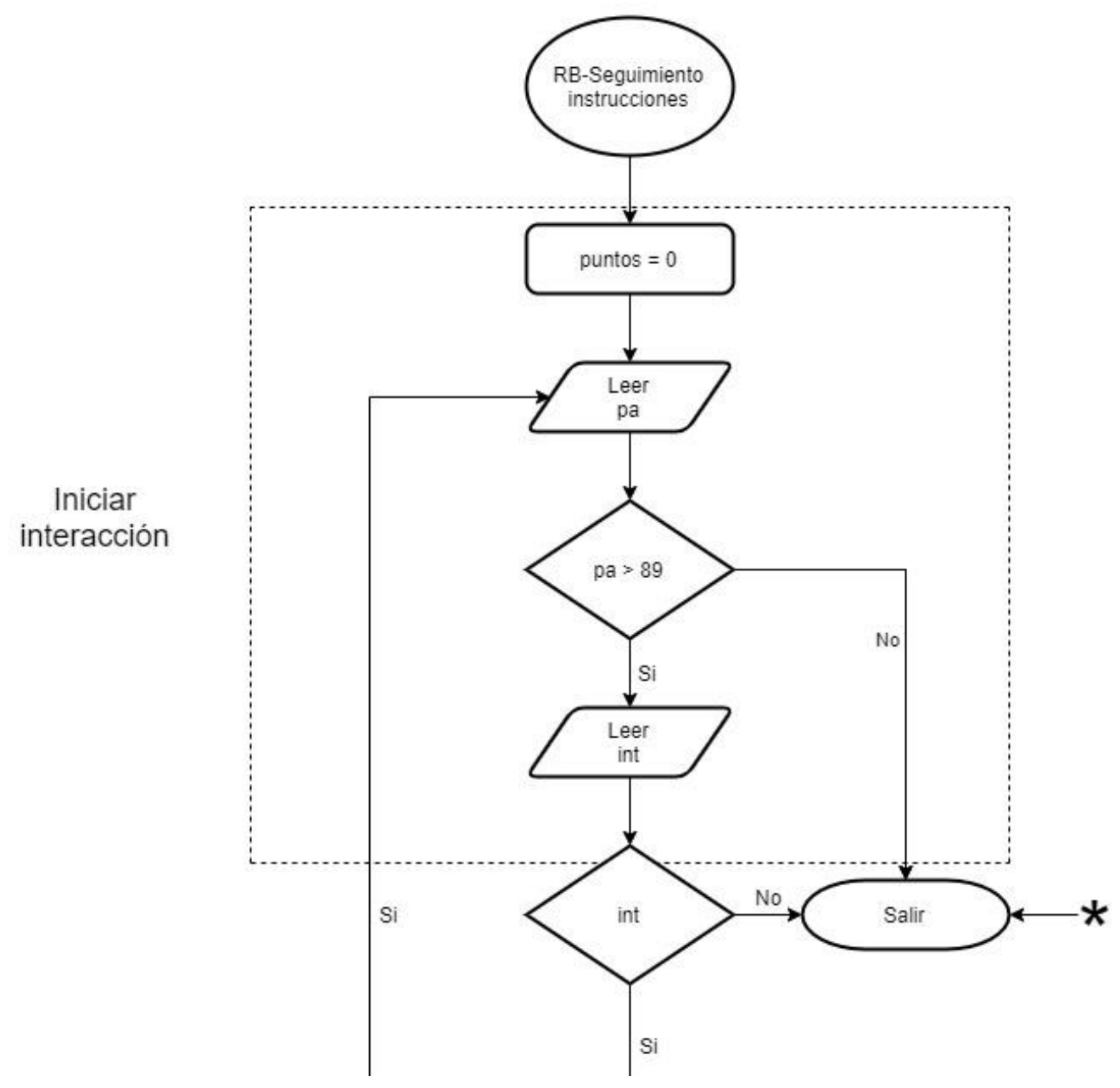




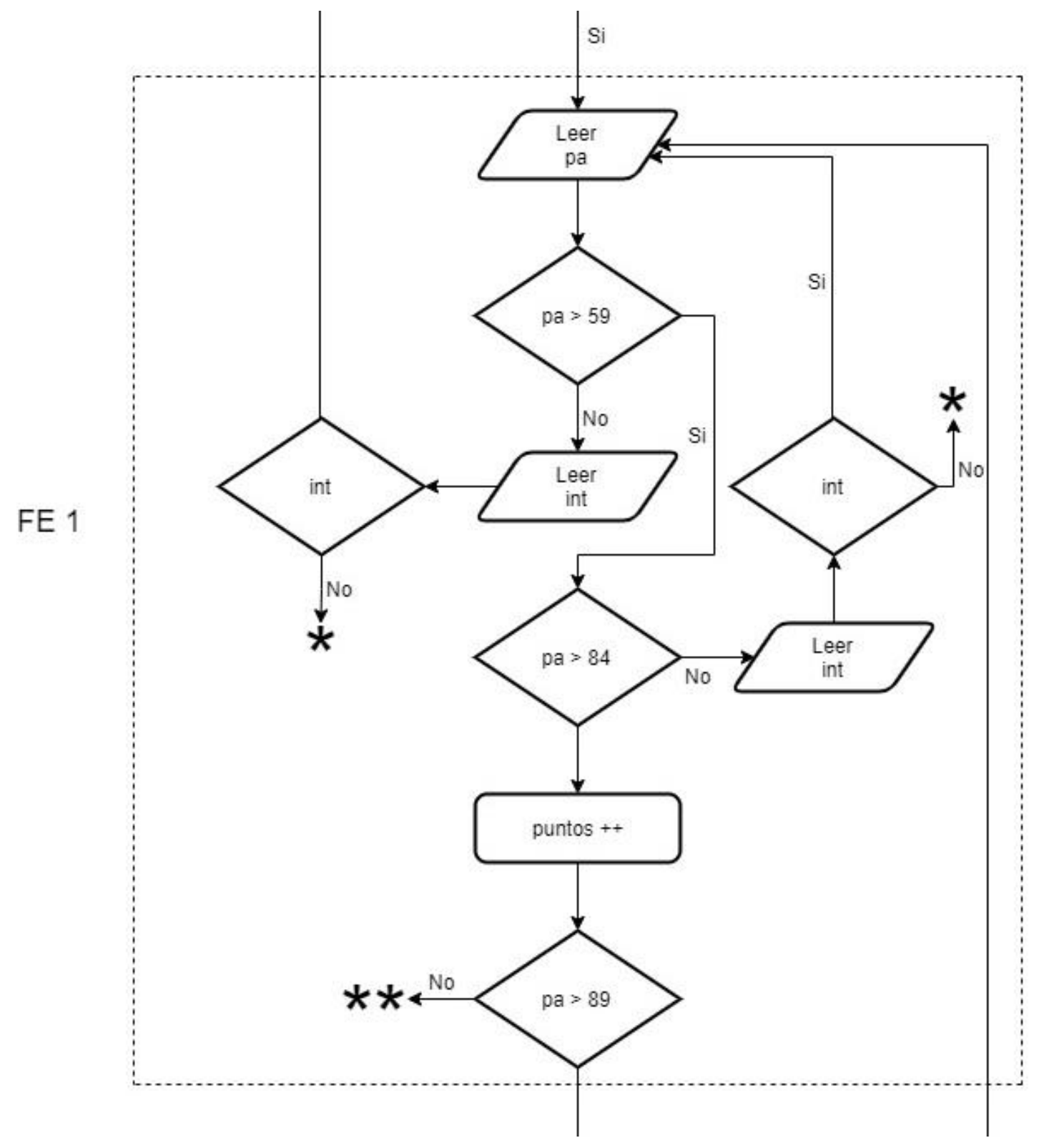




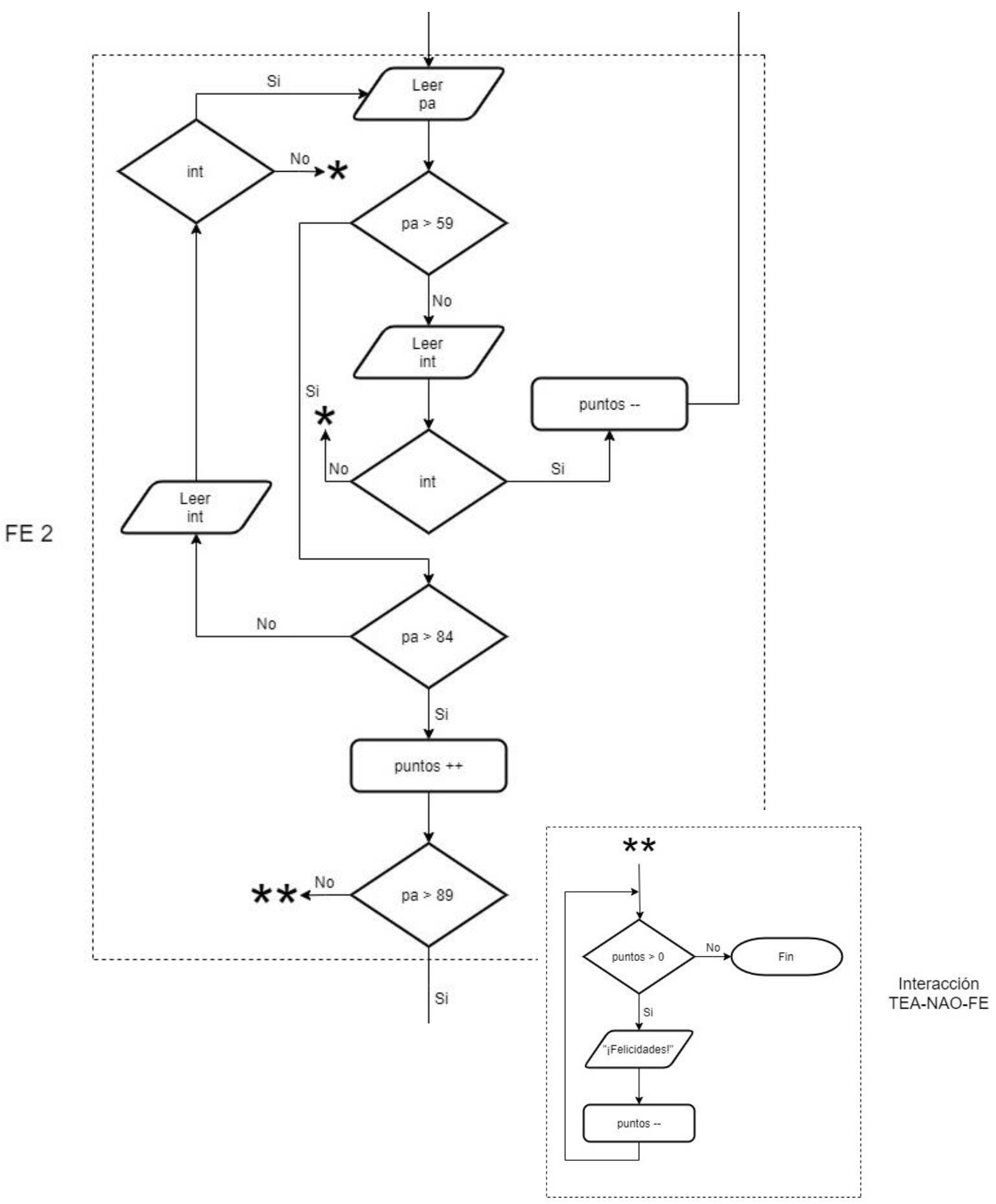




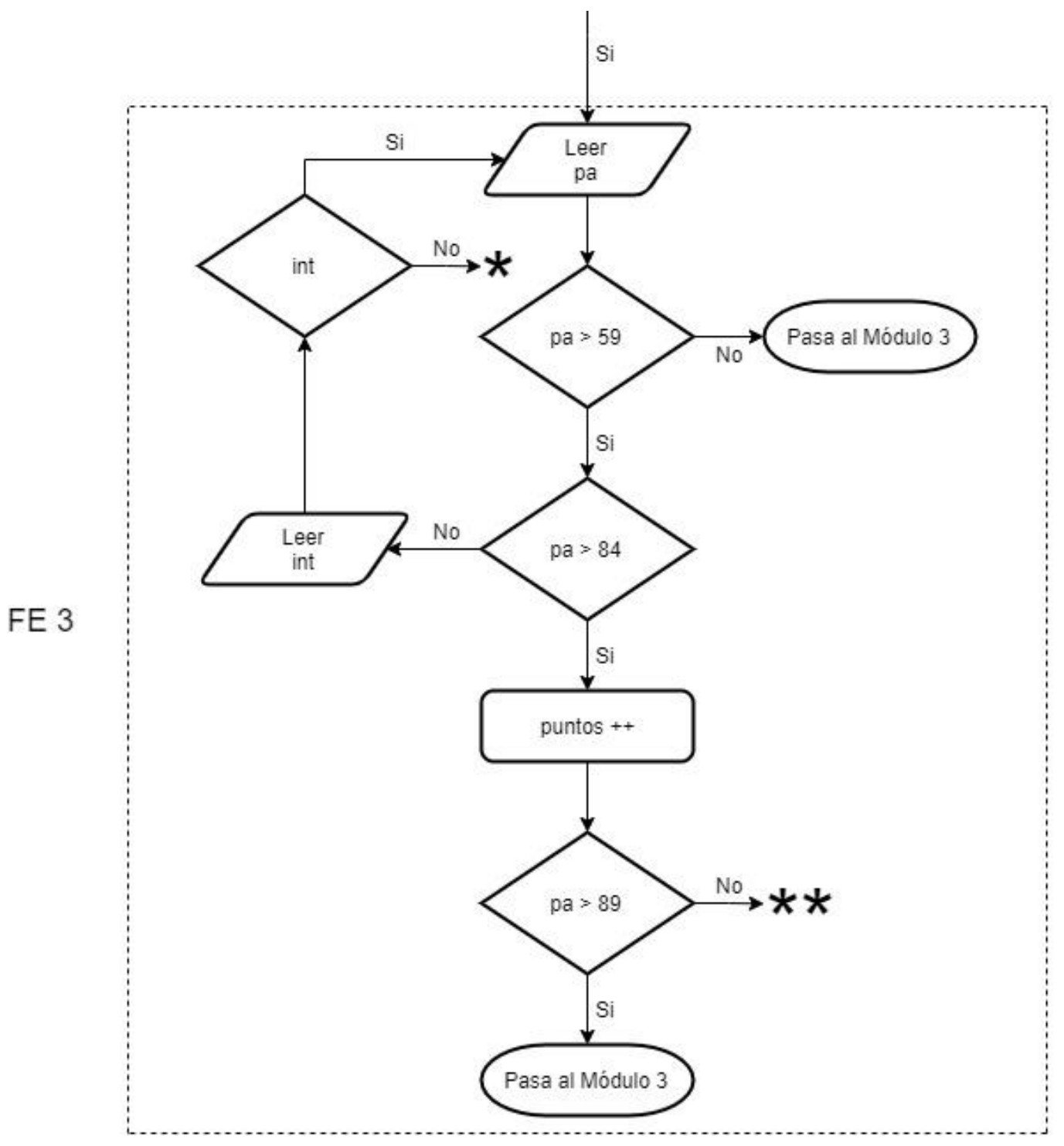


Diagrama de flujo del módulo 2 del modelo estructural de interacción (completo)

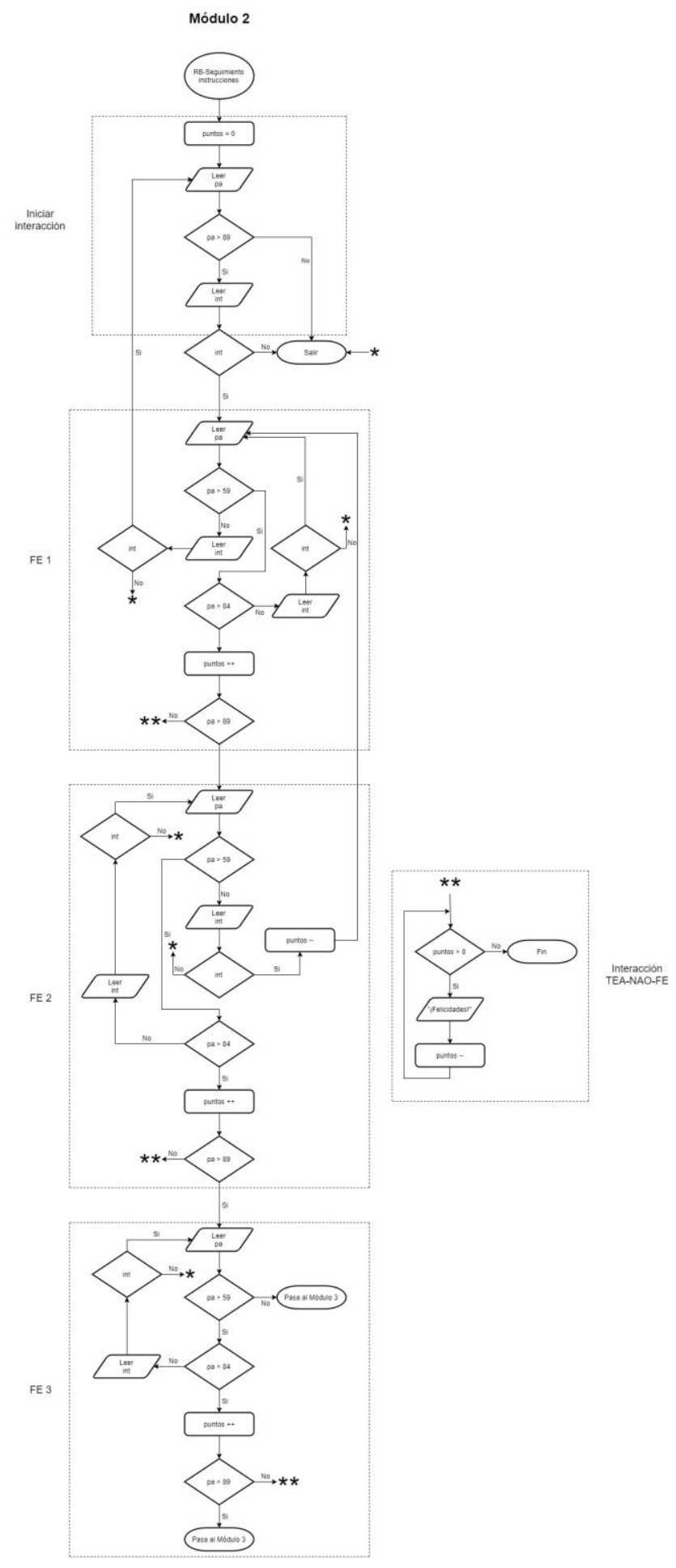




\section{Psudocódigo del módulo 2 del modelo de interacción}

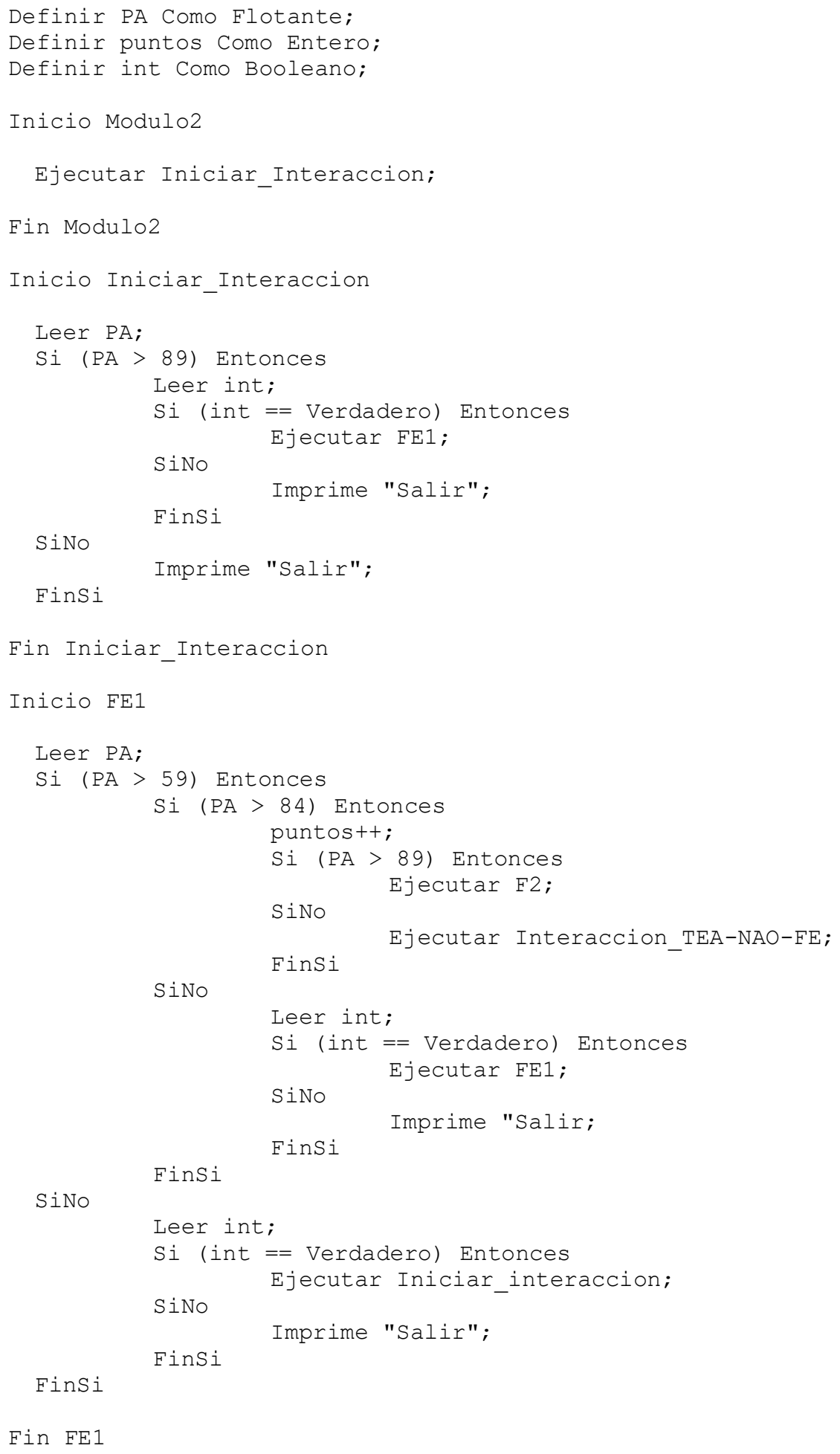




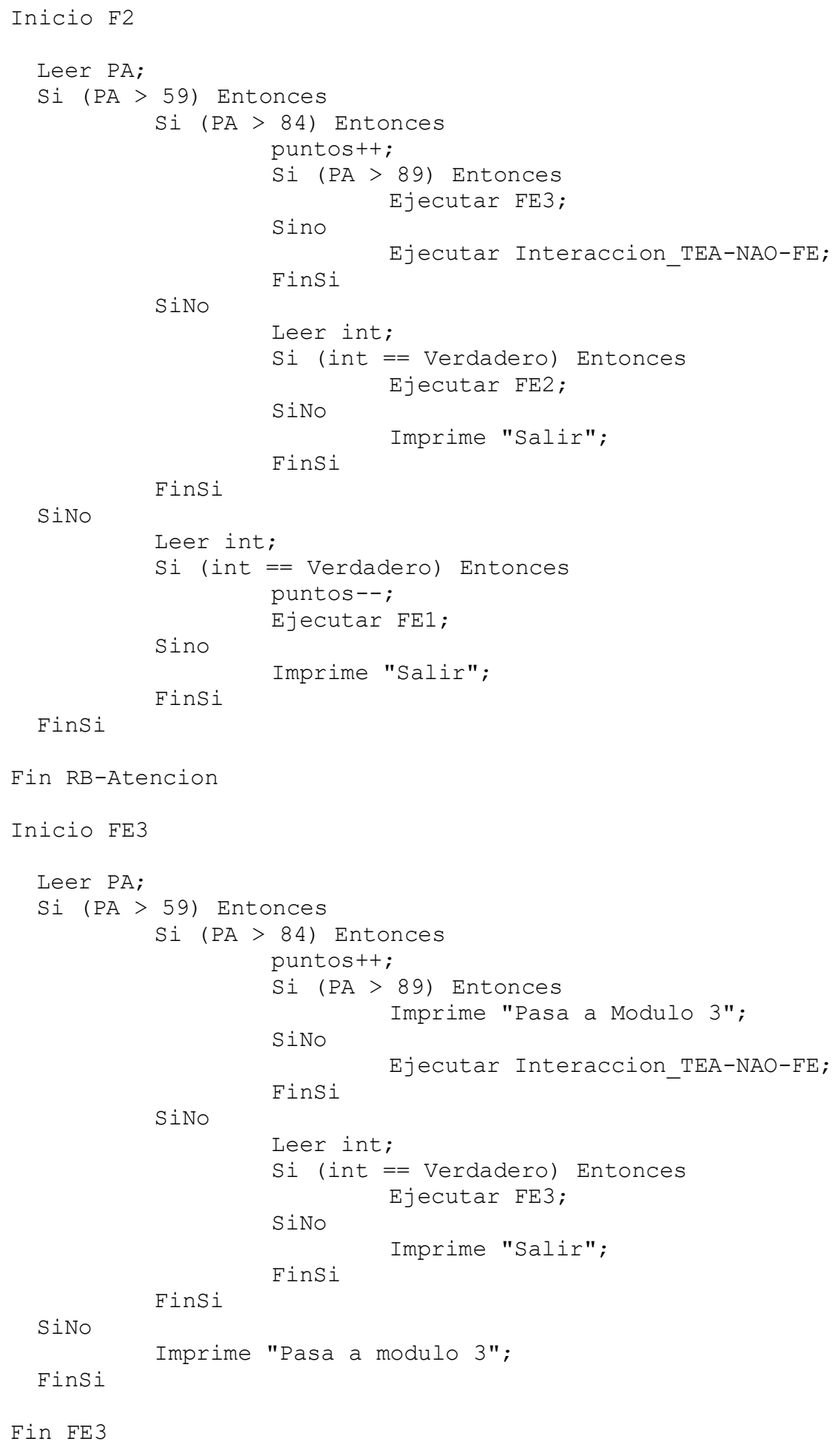




\section{Anexo 6}

\section{Detalles de la figura 58}

Diagrama de flujo del módulo 3 del modelo de interacción

Módulo 3

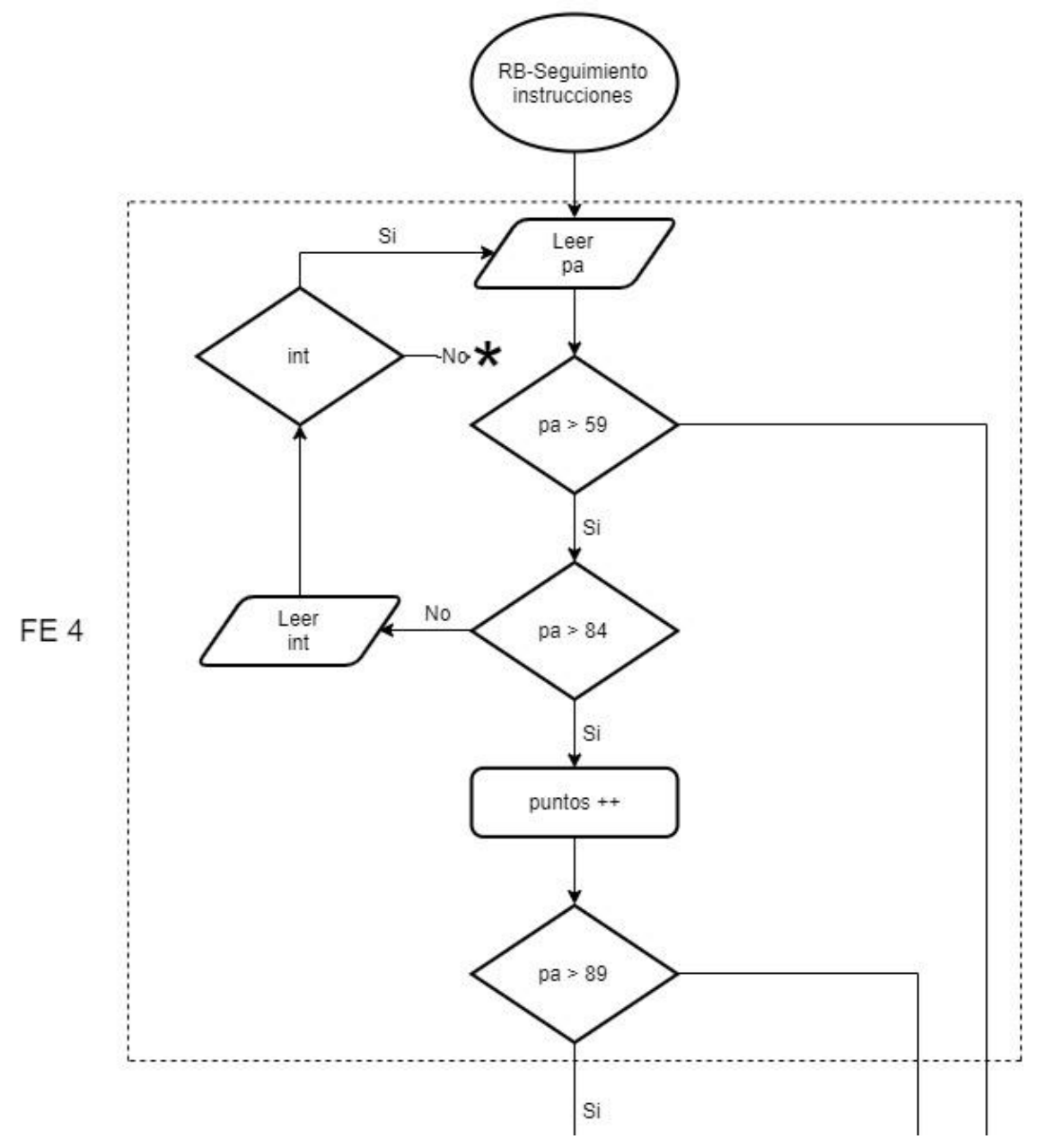




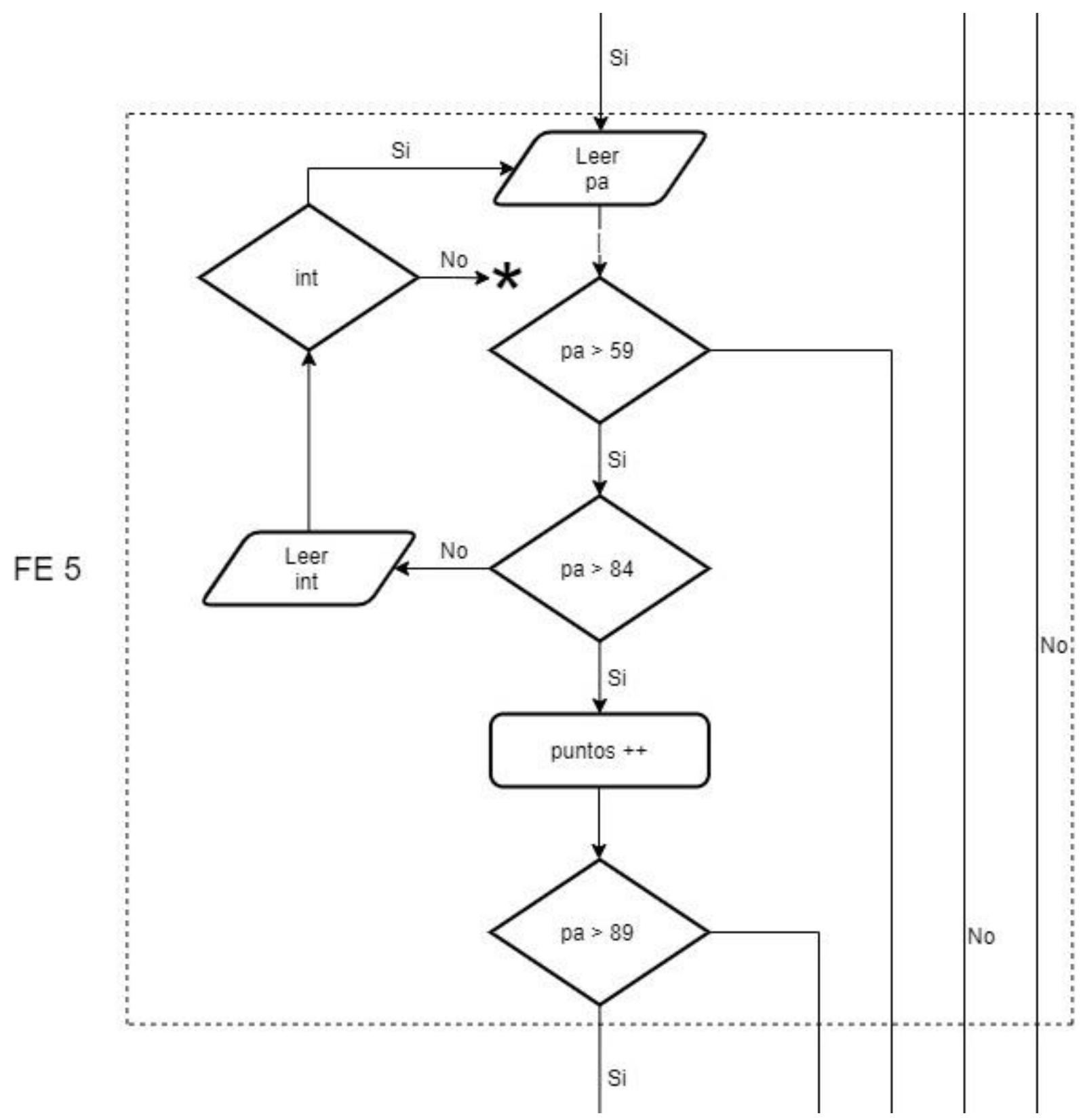




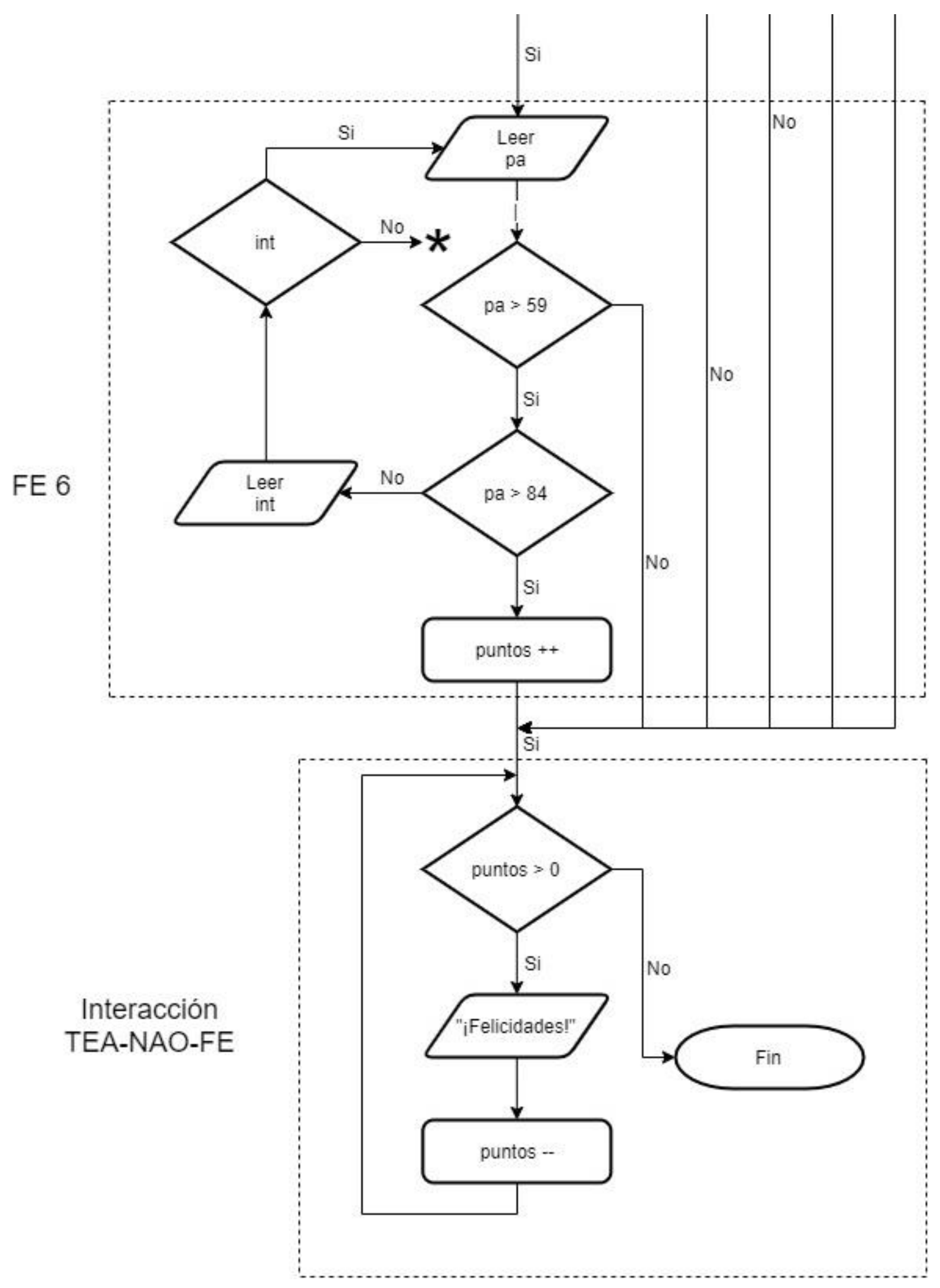


Diagrama de flujo del módulo 3 del modelo de interacción

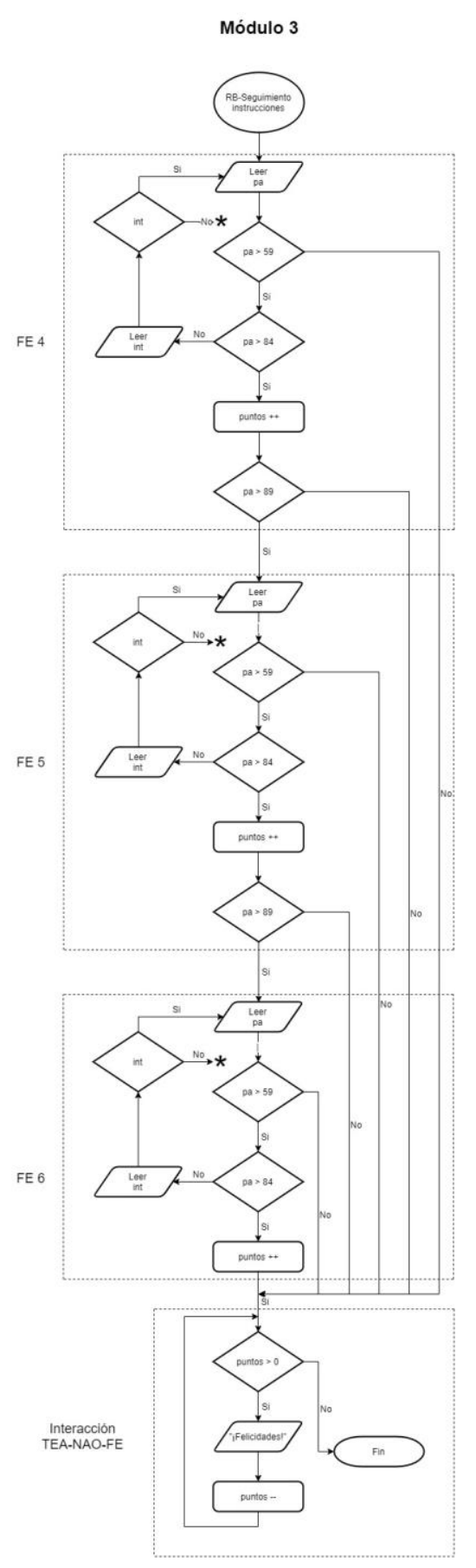




\section{Pseudocódigo del módulo 3 del modelo de interacción}

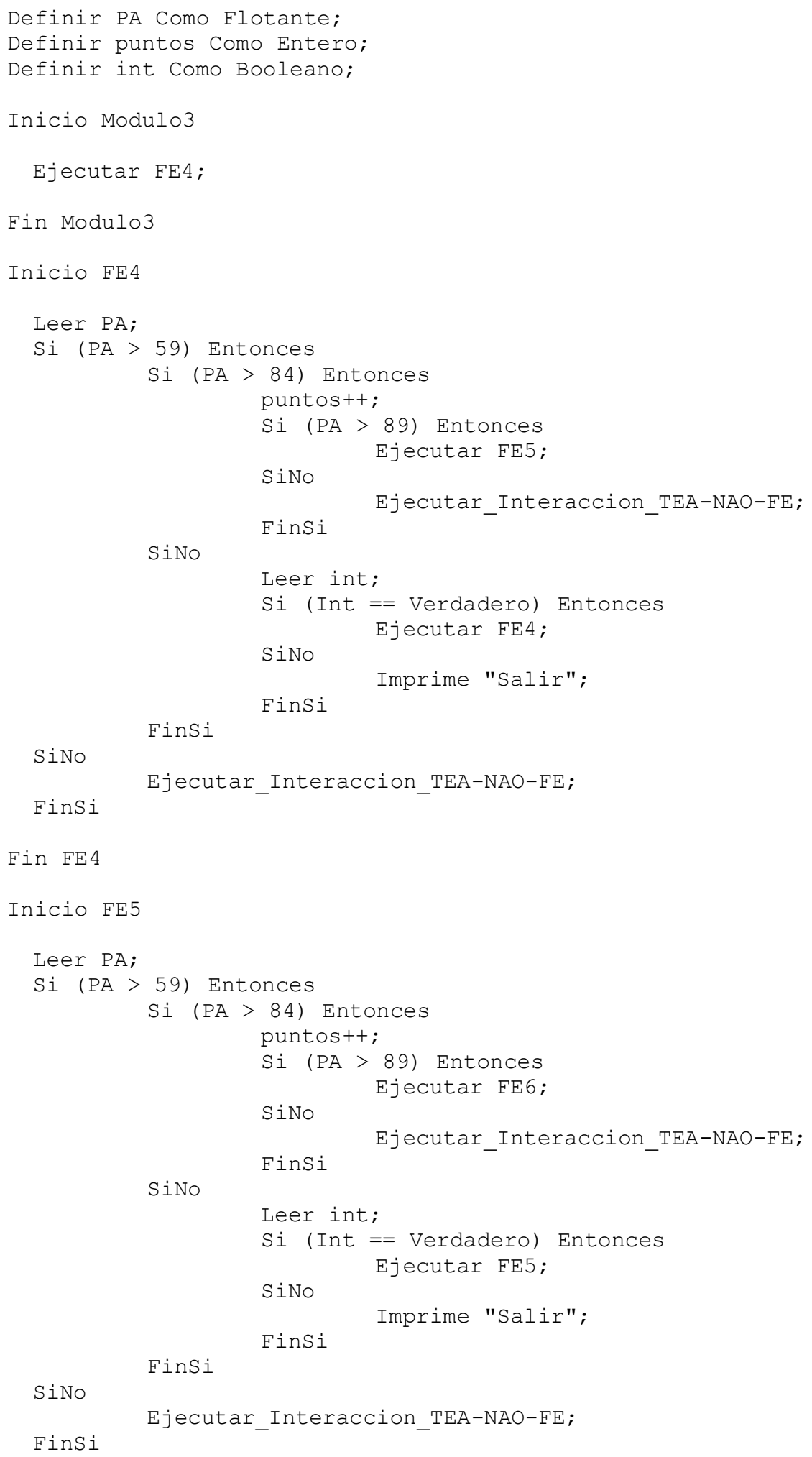




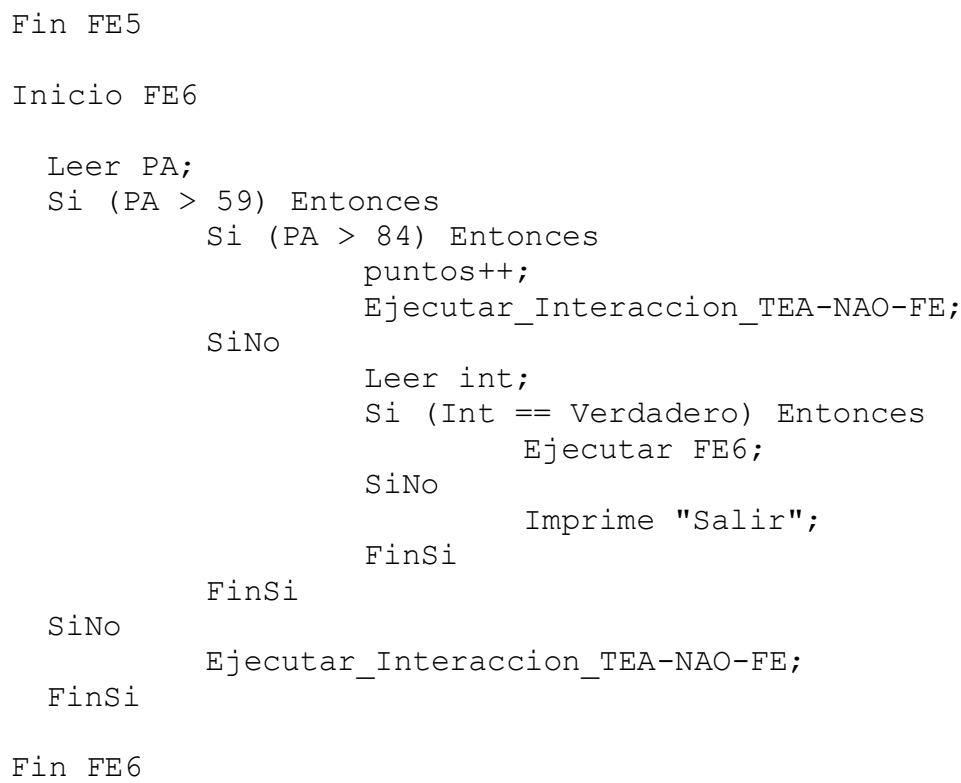




\title{
Publicaciones
}

\section{Interaction between children of the autism spectrum and a humanoid robot modulated by levels of consciousness}

\author{
Roherto FALCÓN-BRETADo
Postrado de Diseho y Visualización de la lnfonmación
Universidad Autonoma Metropolitana -Axcapotzalco
Instituto de Diseño - Universidad Tecnologica de la Mixteca - Ouxaca
'Departamento de Sistemas Universidad Autónoma Metropolitans - Azcapotzalco
${ }^{\dagger}$ División de Estudios de Poserado - Universidad
Tesnológica de la Mixteca - Oaxaca

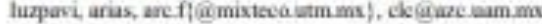

M. Laz PALACIOS-VILL.AVICENCIO ${ }^{12}$, Ana Lilia LAUREAVO-CRUCES ${ }^{13}$, José Anibal ARIAS-AGUILAR

Abstract

The lack of social and emotioeal reciprocity and the difficulty to implement executive functions (FF) are problems associaned with

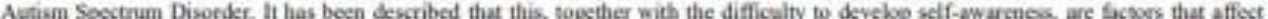
the developacest of Alexibiliny of thought add in the hierarchization of tusks to think and act efficienty. This article presents a proposal so identify five levels of comsciousness in childera with Autism Spectrum Disoeder associated with levels of cogeitive intenation with a humanoid robot. The use-cemered design methodology was implenemed. The resulhs shaw that the exe of robot expressiens associated with a children's level of consciousness can help to prograns interactions with greater possibilities of communicational interaction.

Kegweords: Autism Spectrum Disonder, Conseiowsness, Children, Ulser-Centered Design, Human-computer intenaction.

\section{Introduction}

In the last ten ycars, an increase in the prevalesce of ASD bas been detected [1] - [4], and interest in moniforing its incidence rates has increased [5] - [7]. The rise in the numbers [4]. [5] has prompted research that favors, on the one hand, the explanation of the disorder [8] and, on the other, the identification of strategies or alternatives to assist for the affected population [9] [10]. Such is the case of the use of bumanoid robots that have been used as anxiliary for the socialization of children with ASD [11] - [14].

This article starts with one of the problems associated with autistic disonder that affects the development of cognitive skills efficiently [15], [16]. A proposal is presented to identify five levels of consciousness to implement cognitive interactions between children with $\mathrm{SSD}$ and a humanoid robot.

The article is divided into four sections the second describes the theoretical elements: cognitive abilitics, autism spectrum disonder, fundamentals of perceptual sensory prosessing; understood as the basis of the cognitive system and represented by the five levels of consciousness proposed by Igor Aleksander [17], [18] and their relationship with ASD. In the thind, the methodology is presented. In the fourth, the results and the application proposal for the interactions are integrated. Finally, the comclusions are presented. 


\title{
ENSEÑANZA DEL JARABE MIXTECO A NIÑOS DE EDUCACIÓN PRIMARIA CON APOYO DE TECNOLOGIAA ROBÓTICA HUMANOIDE
}

Anabel Herrera Soriano

anabelhes@gmail.com

José Aníbal Arias Aguilar

anibal@mixteco.utm.mx

\author{
María de la Luz Palacios Villavicencio \\ luzpavi@mixteco.utm.mx
}

\author{
Roberto Falcón Bretado Gallegos \\ Universidad Tecnológica de la Mixteca \\ arc.f@mixteco.utm.mx
}

\begin{abstract}
RESUMEN
Este proyecto conjunta los avances tecnológicos desarrollados en los robots humanoides para apoyar la enseñanza de la danza conocida como Jarabe mixteco. Se programa a un robot NAO para que funcione como una herramienta didáctica para el docente de tercer grado de primaria que imparte la materia "La entidad donde vivo", en dicha asignatura se despliegan contenidos relacionados con las danzas tradicionales del estado de Oaxaca y ef docente emplea al robot para motivar y quiar a los niños en el aprendizaje de los pasos. vestimenta, música e historia del Jarabe mixteco.
\end{abstract}

PALABRAS CLAVE

ROBOT, ENSEÑANZA DISEÑO, DANZA, JARABE MIXTECO

\begin{abstract}
ABSTAACT
This project uses technological advances in humanoid robots to support the teaching of traditional ballet Jarabe Mixteco in Huajuapan de León City. We programmed a NAO robot in order to use it as a tool for teachers of 3rd grade of elementary school, teaching the course "Where do I live", particularly a lesson whose contents are traditional dances of Oaxaca State. The teacher uses Nao robot to motivate and guide children for learning dance steps, clothing, music and history of Jarabe Mixteco.
\end{abstract}

KEY WORDS

ROBOT, TEACHING, DESIGN, DANCE, JARABE MIXTECO 


\section{Analysis of children - humanoid robot interaction to support social skills development}

\author{
J. Anibal Arias-Aguilar \\ División de Estudios de Posgrado \\ Universidad Tecnológica de la Mixteca \\ Km. 2,5 Carretera a Acatlima \\ Huajuapan de León, Oaxaca C.P.69000 \\ México \\ anibal@mixteco.utm.mx
}

María Auxilio Medina-Nieto

Antonio Benitez Ruiz

Departamento de Posgrado

Universidad Politécnica de Puebla

Tercer Carril del Ejido Serrano S/N

San Mateo Cuanalá. Juan C. Bonilla Puebla, México.

maria.medina@uppue.edu.mx

antonio.benitez@uppue.edu.mx

\author{
M. Luz Palacios-Villavicencio \\ Instituto de Diseño \\ Universidad Tecnológica de la Mixteca \\ Km. 2,5 Carretera a Acatlima \\ Huajuapan de León, Oaxaca C.P.69000 \\ México \\ luzpavi@mixteco.utm.mx
}

Verónica Rodríguez-López

Instituto de Computación

Universidad Tecnológica de la Mixteca

Km. 2,5 Carretera a Acatlima

Huajuapan de León, Oaxaca C.P.69000

México

veromix@mixteco.utm.mx
Roberto Bretado-Gallegos

División de Estudios de Posgrado

Universidad Tecnológica de la Mixteca

Km. 2,5 Carretera a Acatlima

Huajuapan de León, Oaxaca C.P. 69000

México

arc.f@mixteco.utm.mx

Jaqueline Estrada-Bautista

Instituto de Diseño

Universidad Tecnológica de la Mixteca

Km. 2,5 Carretera a Acatlima

Huajuapan de León, Oaxaca C.P. 69000

México

jaesba@mixteco.utm.mx

\begin{abstract}
Children robot interaction ${ }^{1}$ has shown benefits in academic or medical applications. We started a long-term project with the goal of modifying some social behaviors on disabled children using a humanoid robot that implements tasks that a therapist does frequently; this paper reports the initial stage of our project, it focuses on the analysis, design and test of children - NAO robot interactions by taking into account a repertoire of basic social behaviors: rapport establishment, attention acquisition, imitation behavior and follow-up of instructions. Preliminary results show that interactions with regular children (aged from 5 to 12 years old) are validated and ready to be used as a promising alternative to support social skills development in disabled children.
\end{abstract}

\section{CS CONCEPTS}

- Human-centered computing $\rightarrow$ Interaction design; Robotics General Terms: Human-robot interaction, social skills, robot programming

This work was supported by the SEP-PRODEP 2015 Academic Network Founding "Interactive technologies to attend special education needs". Permission to make digital or hard copies of all or part of this work for personal or classroom use is granted without fee provided that copies are not made or distributed for profit or commercial advantage and that copies bear this notice and the full citation on the first page. Copyrights for components of this work owned by others than ACM must be honored. Abstracting wit credit is permitted. To copy otherwise, or republish, to post on servers or to permissions from Permissions@acm.org permissions from Permissions@acm.org.
Interacción '17, September 25-27, 2017, Cancun, Mexico

C 2017 Association for Computing Machinery.

ACM ISBN $978-1-4503-5229-1 / 17 / 09 \ldots \$ 15.00$

https://doi.org/10.1145/3123818.3123837

\section{KEYWORDS}

Human centered computing, social skills, robot programming.

\section{INTRODUCTION}

An efficient way of building and discovering the world is through social relationships, where effectiveness of interactions depends on personal moods and skills [1]. Children establish social relationships with other persons from an early age; although their initial communications skills are centered in crying, as stayed in [2], they begin to discriminate sounds, pitch, tone and even to differentiate human voice from the rest of sounds since the first month of life; at the fourth month, they perform different communicative responses based on their affections.

Physical contact and closeness to children's environment are important factors to maintain a comfortable social status [3] According to social learning theory, imitation and other basic behaviors are determinant to establish meaningful social relationships [4].

The use of robotic mechanisms, social robots and socially intelligent technologies to assist people is reported in the literature. From an embedded system point of view, software that models cognitive tasks in electronic devices enables the capacity to maintain dialogs between users and machines such as in a human-style conversation, that is, using social clues. From a different perspective, robots have also been used as tools to explore human social intelligence, for example, to implement interaction models in controlled scenarios or tasks as face 


\title{
Tecnologias EMERGENTES para un mundo INTELIGENTE
}

\section{Hacia un Sistema de Reconocimiento de Posturas para Personas con Trastorno de Espectro Autista}

\author{
Cervantes Martínez Julio César ${ }^{1}$, Hernández Ledesma Gil ${ }^{1}$, Ortiz Olivera Ángel ${ }^{1}$, María de la Luz Palacios \\ Villavicencio ${ }^{2}$ y Raúl Cruz Barbosa ${ }^{1}$ \\ \{ic2012020047, ic2010020210, ic2012020108\}@ndikandi.utm.mx, \{luzpavi,rcruz\}@mixteco.utm.mx \\ ${ }^{1}$ Instituto de Computación - Universidad Tecnológica de la Mixteca, \\ Carretera Huajuapan-Acatlima Km. 2.5, Huajuapan, Oaxaca, México \\ ${ }^{2}$ Instituto de Diseño - Universidad Tecnológica de la Mixteca, \\ Carretera Huajuapan-Acatlima Km. 2.5, Huajuapan, Oaxaca, México
}

\begin{abstract}
Resumen. En este artículo se presenta un sistema reconocedor de posturas para personas adultas que podrá ser adaptado como un sistema auxiliar para identificar el grado de imitación que tienen niños con Trastorno de Espectro Autista (TEA). El sistema trabaja con una base de imágenes de personas en ocho posturas distintas, con sendas siluetas, empleadas para crear un conjunto de datos de 17 características. Se utilizó un enfoque basado en clasificadores y se realizaron experimentos con el clasificador Bayesiano, Bayes ingenuo, $\mathrm{K}$-vecinos más cercanos y máquinas de soporte vectorial (SVM), estas últimas fueron las que brindaron la mejor clasificación ( $91 \%$ de exactitud utilizando un subconjunto de 9 características seleccionadas por el radio discriminante de Fisher).
\end{abstract}

Keywords: Reconocimiento de posturas, Reconocimiento de patrones, Imitación, Lateralización, TEA.

\section{Introducción}

Uno de los mecanismos de aprendizaje de mayor relevancia durante la primera infancia es la imitación. Ésta consiste en la habilidad para igualar un modelo visual o auditivo reproduciendo una acción de modo idéntico a la forma en que la ejecuta un modelo [1]. La imitación forma parte de los registros iniciales que se pueden seguir de la conducta natural de un niño, incluso, desde la lactancia [2]. Se ha descrito que a partir de los 10 años, los niños pueden imitar con mayor precisión movimientos lateralizados [3]. Sin embargo, no ocurre lo mismo con niños con problemas en el neurodesarrollo como es el caso de los niños con TEA, debido a que su desarrollo regularmente es más lento y su capacidad de lateralización también se lentifica.

La conducta imitativa ha sido asociada con la participación de las neuronas espejo $[4,5]$ encargadas de codificar movimientos dirigidos a una meta mientras registran posturas, cambios en el rostro, en las extremidades o en todo el cuerpo ejecutadas por otra persona. En ese sentido, la consciencia que una persona tiene de su cuerpo en relación a su entorno adquiere gran relevancia debido a que esta incide en sus procesos de maduración, en la activación de funciones cognitivas e incluso en la comprensión emocional de otros a través de la identificación de los movimientos corporales [4].

Contar con un sistema de reconocimiento de la postura humana para analizar acciones que impliquen imitación lateralizada puede ser de gran utilidad para identificar el nivel de maduración de una persona. En este artículo se desarrollan las bases de un sistema de reconocimiento de posturas que posteriormente será adecuado como un sistema de entrenamiento para mejorar habilidades de imitación lateralizada de personas con necesidades educativas especiales (NEE), entre ellos los niños con TEA.

El reconocimiento de la postura humana es ampliamente estudiado en el área de visión computacional, el desarrollo de métodos para clasificar posturas se basa principalmente en la forma en la que se recupera la información de una persona en el ambiente.

El sistema planteado en este artículo (Fig. 1), se compone de 7 etapas ubicados en dos fases. La fase I consta de 5 etapas: 1) selección de personas, 2) captura de imágenes, 3) pre-procesamiento de las imágenes, 4) creación de conjuntos de datos, 5) reconocimiento de posturas con un modelo analítico convencional y por el enfoque de clasificadores para después compararlos. La fase II tiene 2 etapas: 6) reconocimiento de posturas en tiempo real y 7) propuestas de actividades de interacción.

Aquí, se desarrolló la fase I con adultos, se construyó un conjunto de datos de 17 características a partir de 168 siluetas obtenidas de imágenes que contenían adultos en 8 poses distintas. A este conjunto de datos se le aplicó 
Congresos, cursos y conferencias

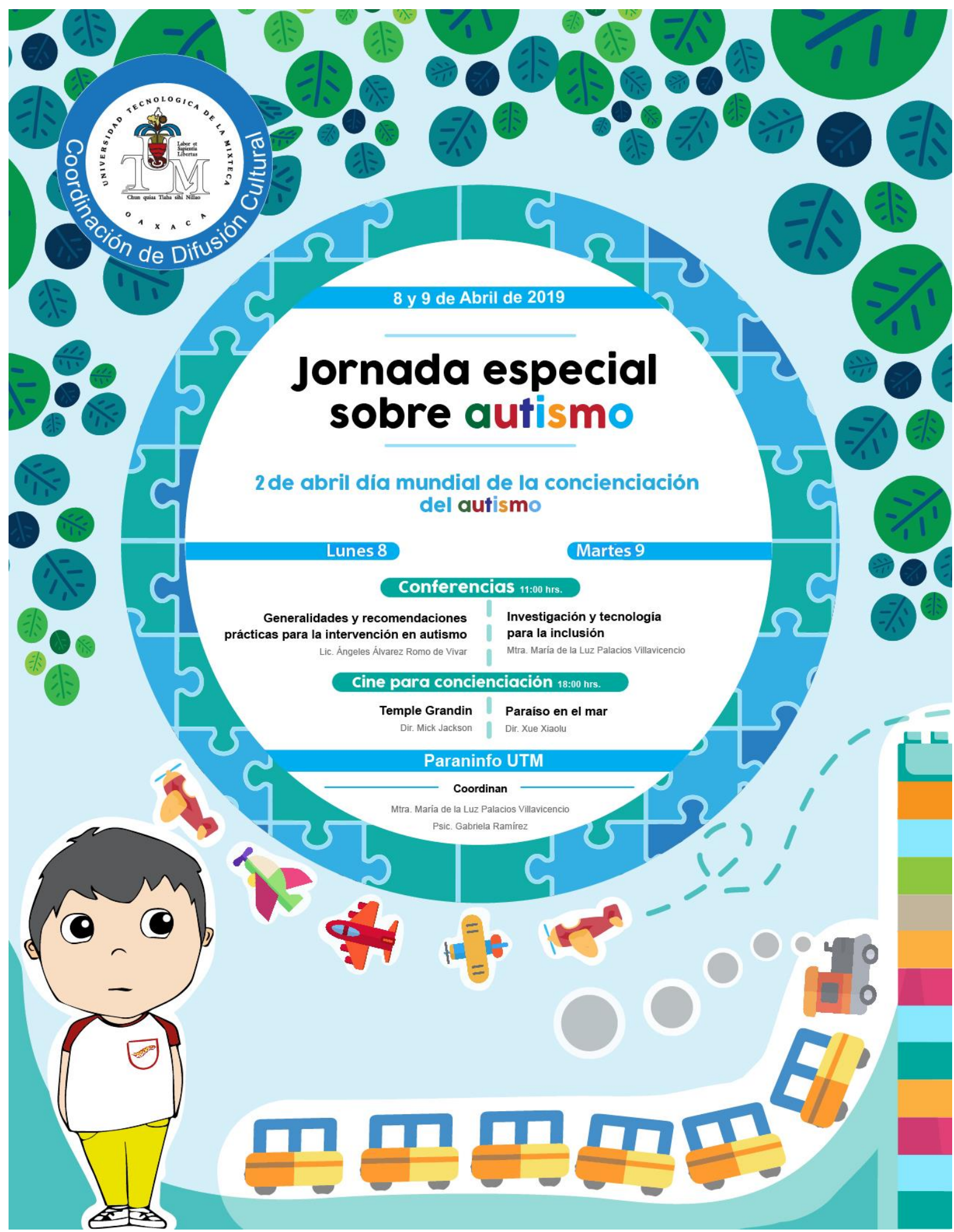



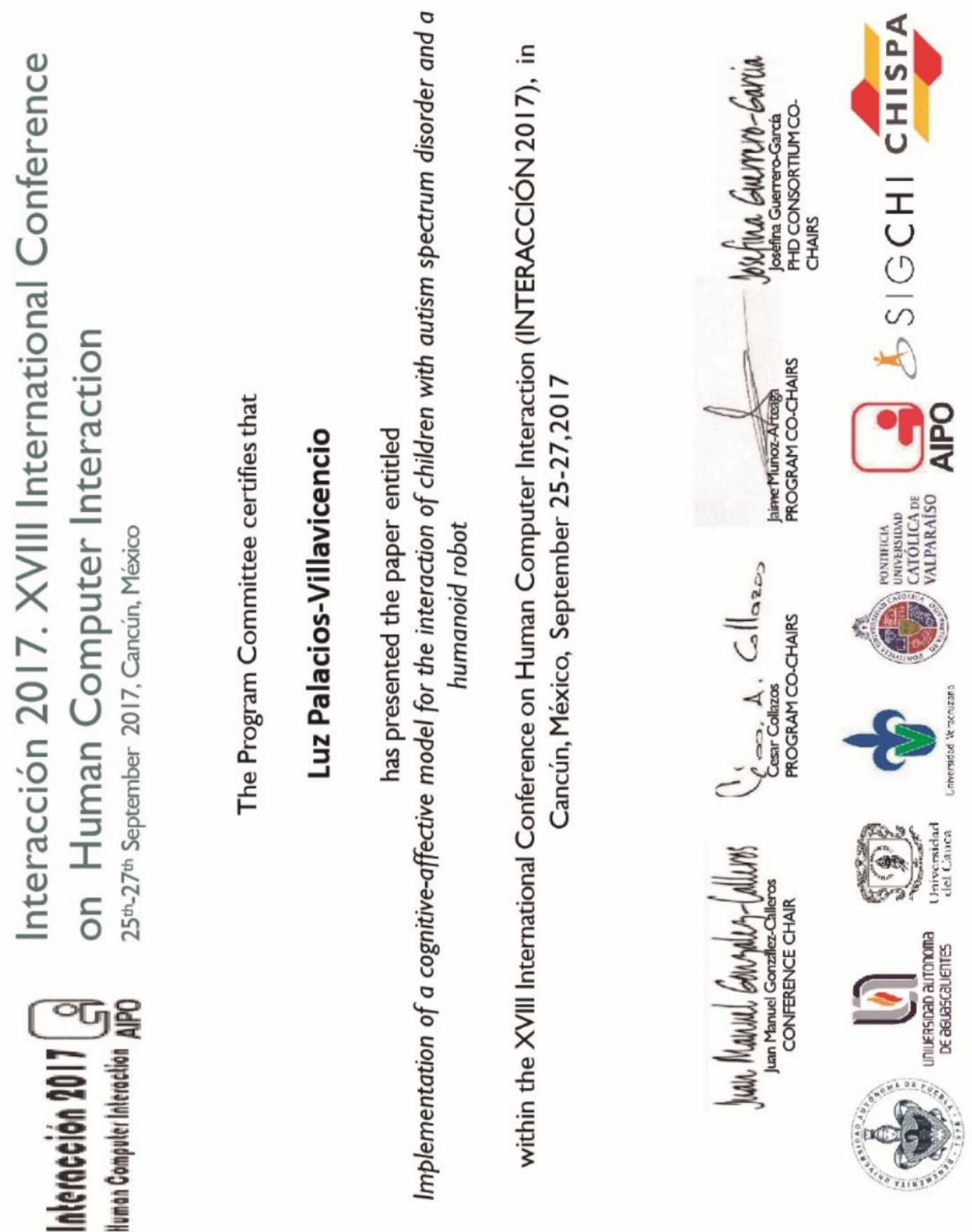

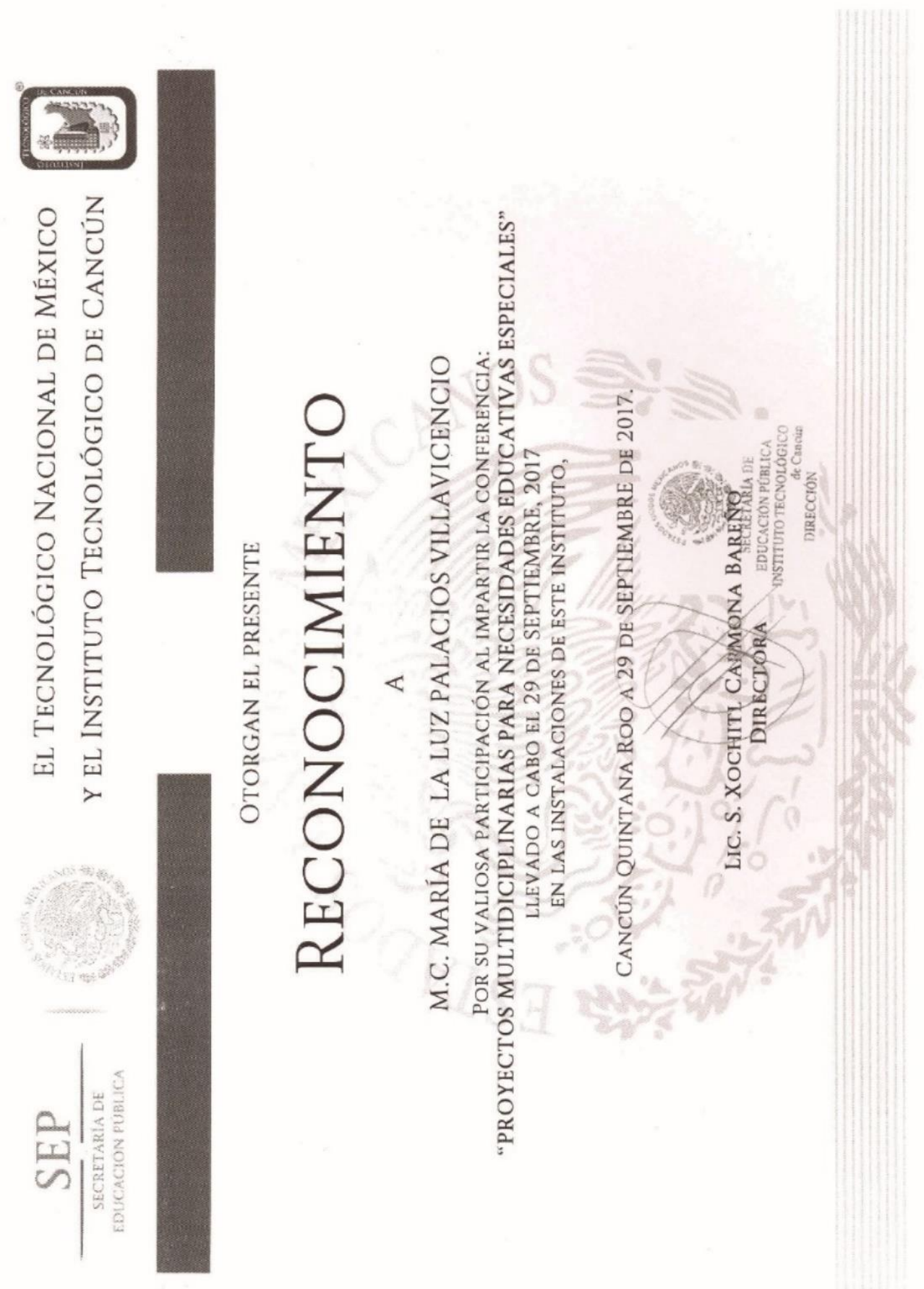

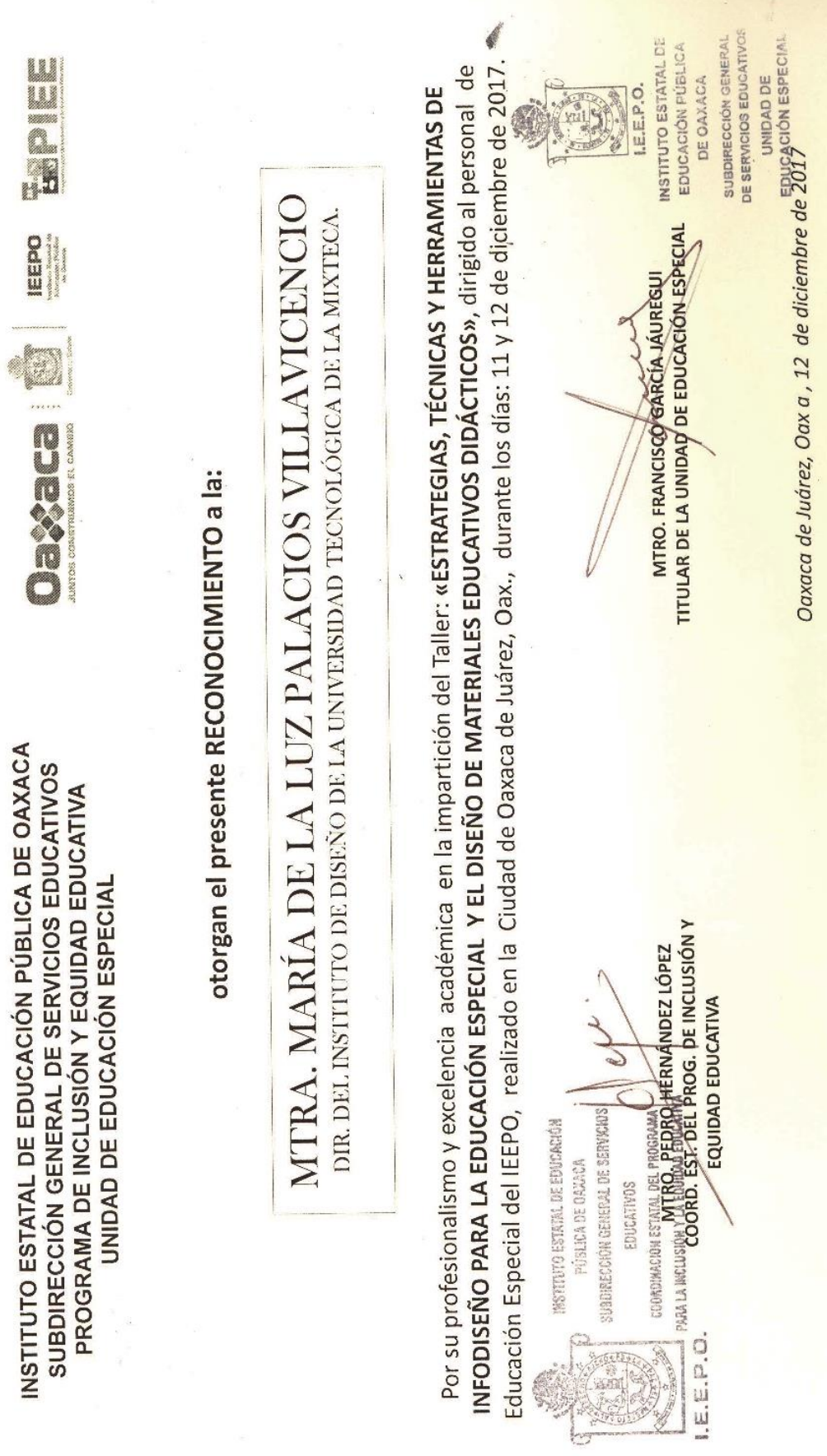

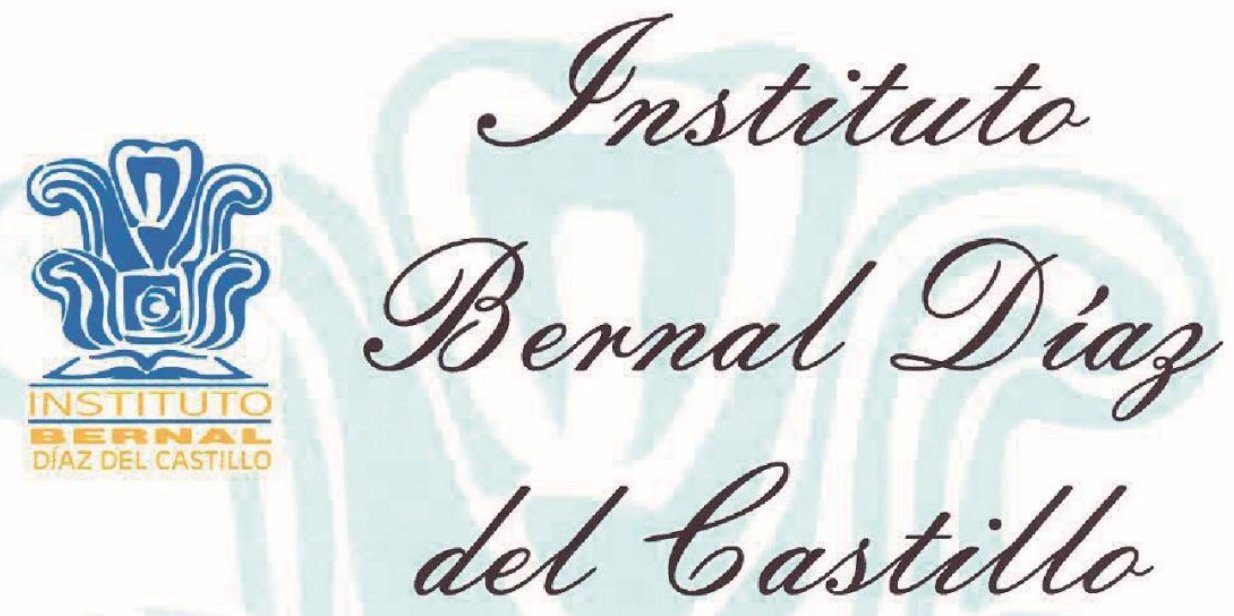

Otorga el presente:

\section{RECONOCIMIENTO A:}

\section{MTRA. MARÍA DE LA LUZ PALACIOS VILLAVICENCIO}

Pas bu pasticipación como panente en la conferencia "Qla OSicología de la inteligencia antifficial, un conocimiento aplicada" en la semana cultural del "Instituta OBenal ODiaz del Fastilla".

"Probidad, saber y talento al servicio de la comunidad".

Heraica Ciudad Huajuapan de Leán, Oax; a 13 de Junia de 2018.

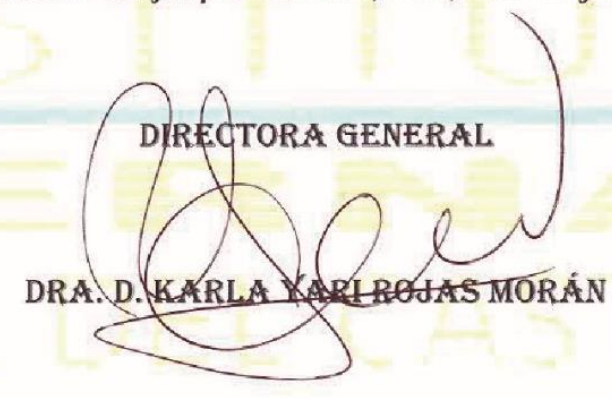




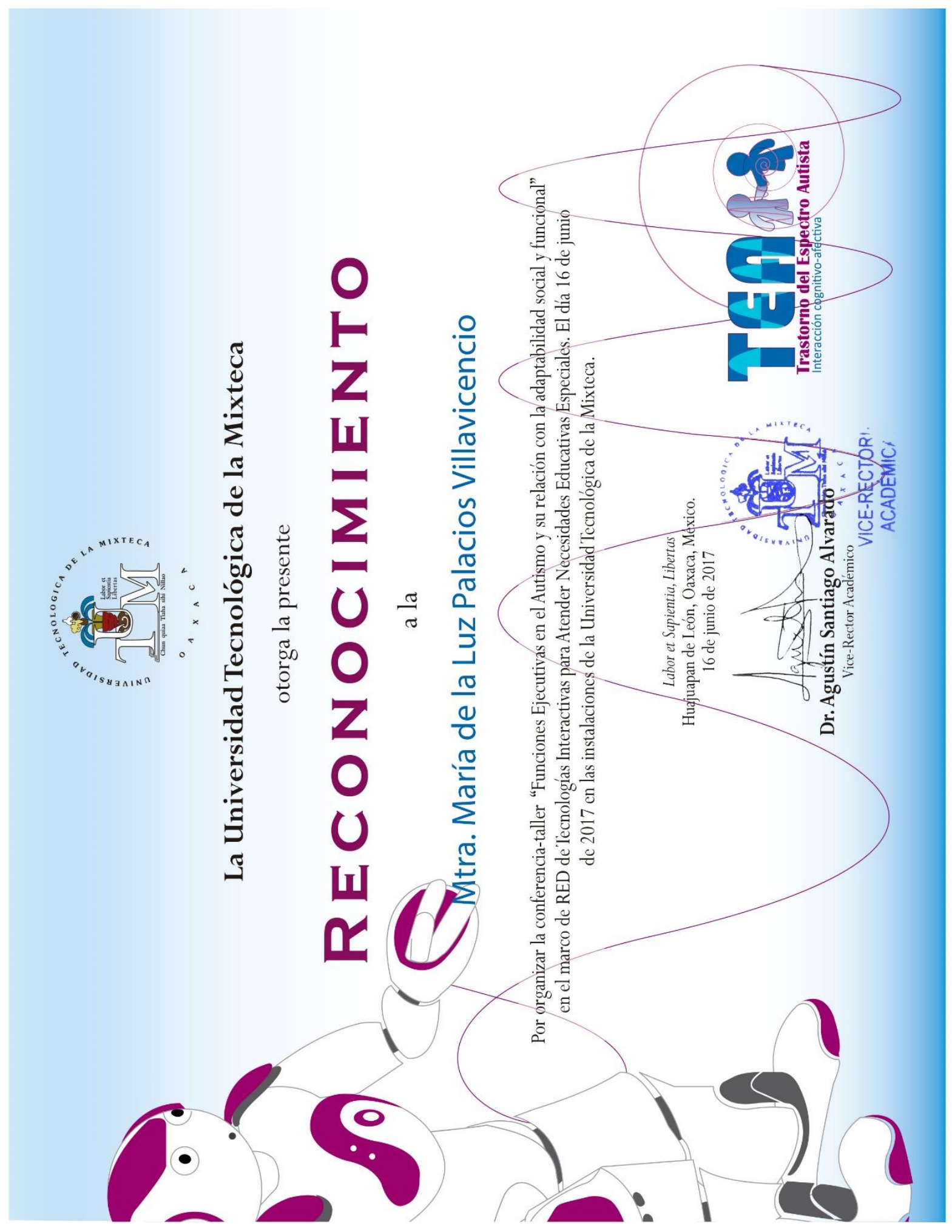




\section{Currículum vitae de la autora: María de la Luz Palacios Villavicencio}

Ocupación actual

Directora del Instituto de Diseño de la Universidad Tecnológica de la

Mixteca. Profesora-investigadora Titular A

Psicoterapeuta de niños y adolescentes (consulta privada)

Área de adscripción

Instituto de Diseño

Correo electrónico

luzpavi@gmail.com, luzpavi@mixteco.com.mx

\section{Semblanza curricular}

Estudie la maestría en Ciencias y Artes para el Diseño y la Lic. en Diseño de la Comunicación gráfica en la Universidad Autónoma Metropolitana-Xochimilco; y la Licenciatura en Psicología, en la Universidad Nacional Autónoma de México, en Cd. Universitaria. Actualmente soy directora del Instituto de Diseño en la Universidad Tecnológica de la Mixteca. Y representante del Cuerpo Académico UTMIX-CA-23 Integración Multidisciplinaria del Diseño en México desde 2016. He dirigido proyectos de investigación, aprobados y financiados por PRODEP, SEP, CONACYT..

\section{Publicaciones relacionadas con esta tesis}

1. Palacios-Villavicencio, M. L., Laureano-cruces, A. L., \& Arias-aguilar, J. A. (2020) Interaction between children of the autism spectrum and a humanoid robot modulated by levels of consciousness. International Journal of Innovative Science, Engineering \& Technology, 2020, 7(11), 121-133.

2. Soriano Herrera, A., Arias-Aguilar, J. A., Palacios-Villavicencio, M. L., \& Bretado Gallegos, R. F. 2019. Enseñanza del jarabe mixteco a niños de educación primaria con apoyo de tecnología robótica humanoide. Cuadernos del Sur. Instituto Nacional de Antropología e Historia (INAH), 24(46), 90-109.

3. Arias-Aguilar, J. A., Palacios-Villavicencio, M. L., Bretado-Gallegos, R., Medina-Nieto, M. A., Ruiz Benitez, A., Rodríguez-López, V., \& Estrada-Bautista, J. 2017. Analysis of children-humanoid robot interaction to support social skills development. XVIII International Conference on Human Computer Interaction, 17, Article 10, 1-4. celebrado en Cancún, México, September 25-27, 2017. ISBN: 978-1-4503-5229-1/17/09,

4. Cervantes Martínez, J. C., Hernández Ledesma, G., Ortiz Olivera, Á., Palacios- Villavicencio, M. L., \& Cruz Barbosa, R. (2017). Hacia un sistema de reconocimiento de posturas para personas con trastorno del espectro autista. En M. de L. Sánchez Guerrero, A. García Gaona, \& F. Álvarez Rodríguez (Eds.), Tecnologías emergentes para un mundo inteligente. El profesional de TIC y la transdisciplina (1a ed., pp. 37-42). ALFAOMEGA.

5. Palacios, Villavicencio, M.L., Espinoza Colón, J., y Estrada Bautista, J. 2016. El diseño en la mejora del bienestar social de niños con discapacidad. En Oguri Campos, L.E., Valdivia, B., López García, O. y Robles Aguilar O.A. (Ed.), Filosofía, Arte y Diseño. (pp. 970-987). Guanajuato, México: Universidad de Guanajuato y UAEM. ISBN: 978-607-441-401-1

\section{Dirección y participación en proyectos de investigación}

1. Hacia la mejora continua de la equidad del aprendizaje en atención e inclusión de la población estudiantil vulnerable. Programa de Inclusión y Equidad Educativa, financiado por la SEP (2019- 2021). Responsable.

2. Construcción del repositorio institucional para la UTM como herramienta de apoyo a la gestión documental, académica y científica. Repositorios Institucionales, financiado por CONACYT (2018-2019). Participante

3. Diseño de un sitio web y promoción turística de Bahías de Huatulco y alrededores. Clave CUP3CI19-09/03. Desarrollo de Sitio web Huatulco, UMAR-UTM-NOVA (2018-2021). Responsable de proyecto en UTM.

4. Fondo de Aportaciones Múltiples. Financiado por la SEP (2018). Responsable de proyecto.

5. Signos gráficos de comunicación para mejorar las funciones ejecutivas de niños con trastorno del Espectro Autista. UTM (2018-2020). Responsable de proyecto.

6. Fondo de Aportaciones Múltiples. Financiado por la SEP (2018). Responsable de proyecto.

7. Tecnologías interactivas para atender Necesidades Educativas Especiales (UTM-UPP-IMSS). Proyecto de Red de Cuerpos Académicos financiado por la SEP (2016- 2018). Responsable de proyecto.

8. Diseño de material didáctico lúdico multisensorial enfocado a satisfacer las necesidades de niños de primaria con capacidades diferentes. Proyecto de Fortalecimiento de Cuerpos Académicos financiado por la SEP (2011-2012). Responsable de proyecto.

9. Apoyando a niños con capacidades especiales para el CAM-04. Proyecto interno (2009). Responsable. 